\title{
DYNAMISCHE STRUKTUREN AM ZELLCORTEX: AKTIVIERBARKEIT UND AKKUMULATION VON EZRIN IN ABHÄNGIGKEIT VON PIP 2
}

\author{
Dissertation \\ zur Erlangung des \\ mathematisch-naturwissenschaftlichen Doktorgrades \\ „Doctor rerum naturalium“ \\ der Georg-August-Universität Göttingen
}

vorgelegt von

Sabine Bosk aus Nordhorn 
D7

Referentin: Prof. Dr. Claudia Steinem Korreferent: Prof. Dr. Bernd Abel

Tag der mündlichen Prüfung: 
meinen Eltern 

Abstract. Ezrin, a member of the ezrin/radixin/moesin (ERM) protein family, acts as a membrane-cytoskeleton linker, thereby participating in a variety of cellular events. The N-terminal region of ezrin specifically binds to the lipid L-aphosphatidylinositol-4,5-bisphosphate $\left(\mathrm{PIP}_{2}\right)$ while the $\mathrm{C}$-terminal region harbors a binding site for filamentous actin (F-actin). In monomeric ezrin, the respective terminal domains are tightly associated leaving ezrin in an inactive, so-called dormant state, in which the F-actin binding site is masked. Several means of regulation of ezrin's activation have been described including binding to $\mathrm{PIP}_{2}$ and phosphorylation of threonine 567 in the C-terminal domain of ezrin. To date, it is not known to what extent these two molecular factors contribute to a full activation of ezrin.

The aim of this study was to design an in vitro assay that permits a detailed investigation into the processes leading to ezrin activation. In this respect, we were especially interested in identifying the relative contributions and possible synergy of $\mathrm{PIP}_{2}$ binding and phosphorylation. For that purpose, the wild type of ezrin and two mutants mimicking the unphosphorylated and the phosphorylated state, respectively, were used. Solid-supported lipid bilayers (SLB) doped with either DOGS-NTA-Ni or PIP $_{2}$ allowed for specific immobilization of the proteins. Quartz crystal microbalance (QCM) experiments showed a high binding affinity in the range of $10 \mathrm{nM}$ of all three proteins and very high membrane coverage. From variations of the lipid composition of the lipid membranes we inferred that ezrin binds to several $\mathrm{PIP}_{2}$ molecules. Fluorescence microscopy experiments and a detailed analysis of ezrin binding on the membrane revealed that attractive protein-protein interactions lead to protein clustering on the membrane surface. Experiments employing a C-terminally truncated version of ezrin indicate that this attractive interaction involves C-terminal domains. Fluorescence microscopy on ezrin-decorated SLBs showed that, dependent on the mode of binding and phosphorylation state, ezrin is capable of binding F-actin. A clear synergism between phosphorylation and $\mathrm{PIP}_{2}$ as binding partner of ezrin was observed suggesting a conformational switch from dormant to active state. As this interaction was only observed on planar surfaces, but not in solution, we conclude that effective F-actin binding is accomplished by cooperative binding of ezrin clusters. Based on the experimental results, a detailed activation model of ezrin is presented that provides new insights into the regulation of the membranecytoskeleton connection. 



\section{INHALTSVERZEICHNIS}

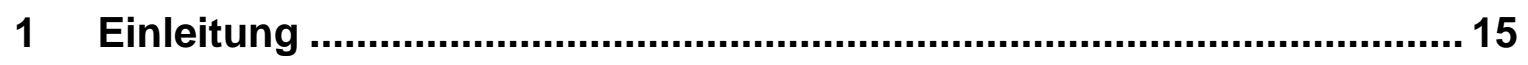

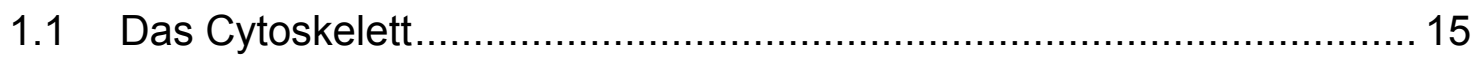

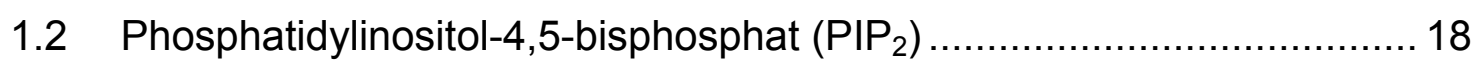

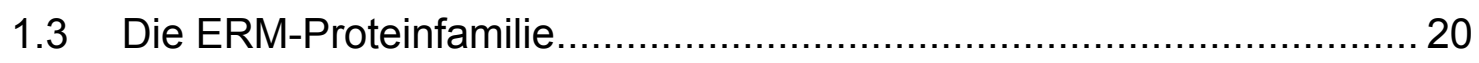

1.3.1 Die Struktur von Ezrin ............................................................ 22

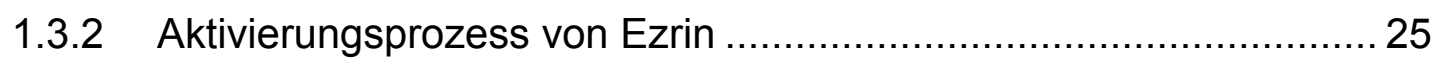

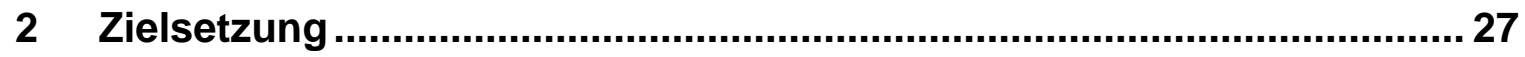

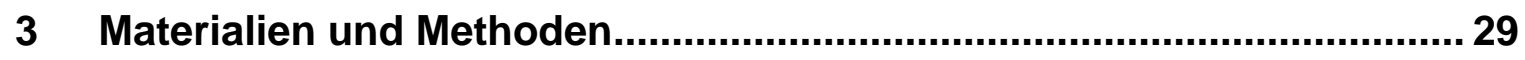

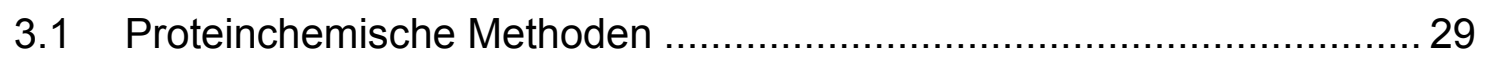

3.1.1 Kultivierung und Genexpression in Escherichia coli (E. coli) .......... 29

3.1.2 Aufreinigung der 6His-fusionierten Proteine ................................. 29

3.1.3 SDS-Polyacrylamid-Gelelektrophorese (SDS-PAGE) …................ 30

3.1.4 Umpuffern von Proteinlösungen .................................................. 32

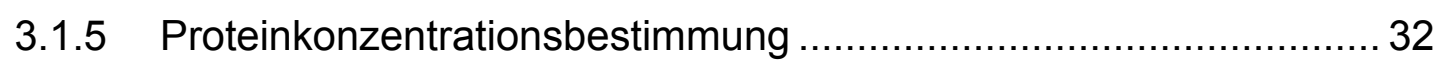

3.1.6 Fluoreszenzmarkierung der Proteine ……………...................... 33

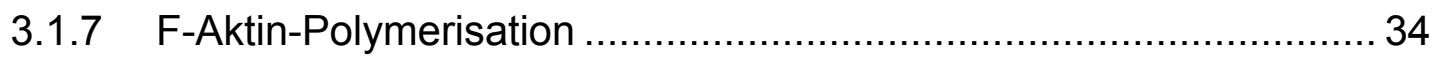

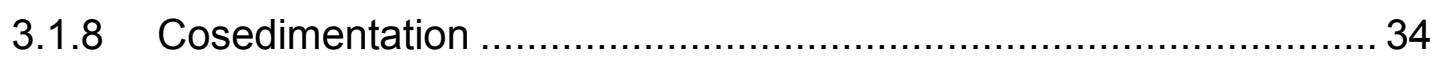

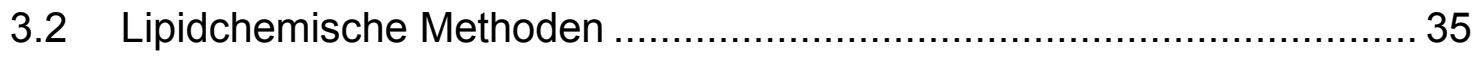

3.2.1 Herstellung und Reinigung goldbedampfter Quarzscheiben ........... 35

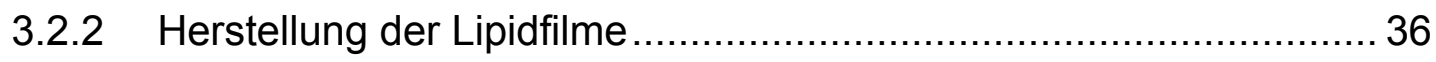

3.2.3 Präparation von festkörperunterstützten Lipiddoppelschichten auf

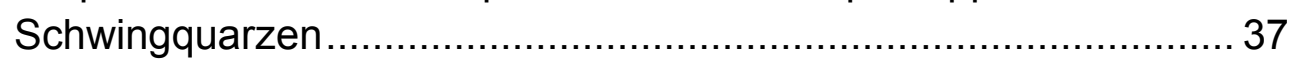

3.2.4 Präparation von festkörperunterstützten Lipiddoppelschichten auf

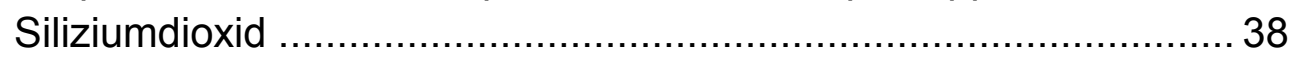

3.2.5 Präparation von festkörperunterstützten Lipidmonoschichten auf silanisiertem Glas 


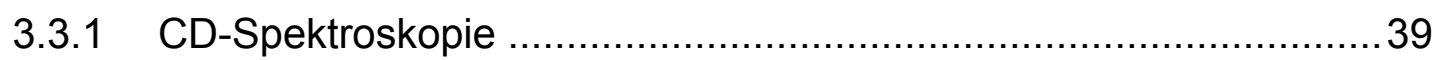

3.3.2 Impedanzspektroskopie........................................................ 42

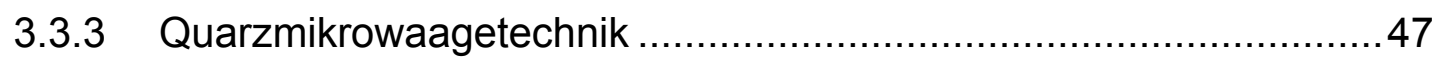

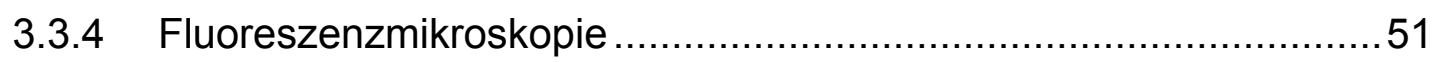

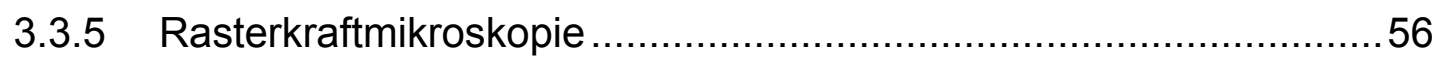

4 Proteinisolierung, Charakterisierung per CD-Spektroskopie, Fluoreszenzmarkierung ........................................................................59

4.1 Expression und Aufreinigung der Proteine N-ERMAD, Ezrin wt, Ezrin

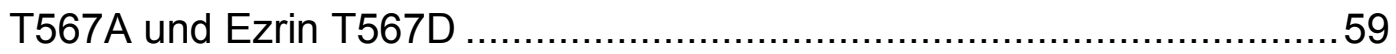

4.2 CD-spektroskopische Charakterisierung der Proteine N-ERMAD, Ezrin wt,

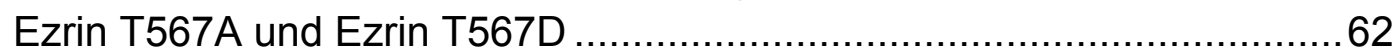

4.3 Markierung der Proteine Ezrin wt und Ezrin T567D .............................67

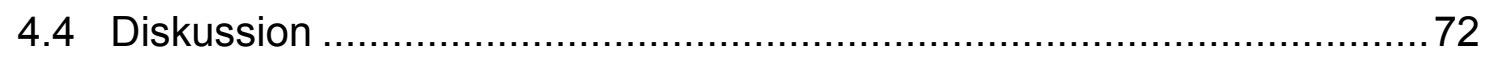

4.4.1 Proteinisolierung und -charakterisierung mittels CD-Spektroskopie72

4.4.2 Fluoreszenzmarkierung von Ezrin wt und Ezrin T567D mittels AlexaFluor633-maleimid .......................................................... 75

5 Quarzmikrowaagestudien zur Adsorption von Ezrin an festkörperunterstützten Membranen ......................................................77

5.1 Impedanzspektroskopie an festkörperunterstützten Membranen ............77

5.2 Quarzmikrowaagestudien zur Adsorption von Proteinen an festkörperunterstützten Membranen ...................................................... 79

5.2.1 Grundlagen der Langmuir-Adsorptionsisotherme .........................79

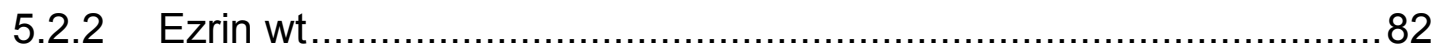

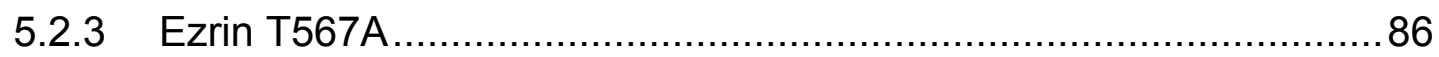

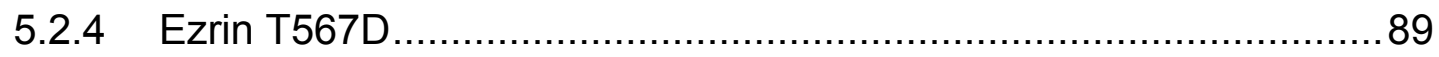

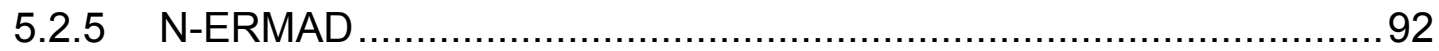

5.3 Bindungsverhalten von fluoreszenzmarkiertem Ezrin wt auf $\mathrm{PIP}_{2}$-haltigen

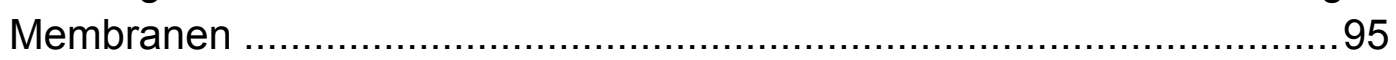

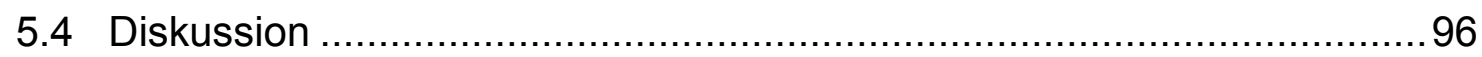


6 Untersuchungen zum clustering von Ezrin sowie Akkumulation von $\mathrm{PIP}_{2}$

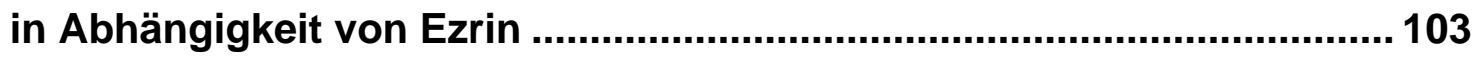

6.1 Quarzmikrowaagemessungen unter Variation des $\mathrm{PIP}_{2}$-Gehalts in der festkörperunterstützten Membran................................................... 103

6.1.1 Adsorption von Ezrin wt an festkörperunterstützte Membranen mit unterschiedlichem PIP $_{2}$-Gehalt................................................ 103

6.1.2 Adsorption von N-ERMAD an festkörperunterstützte Membranen mit unterschiedlichem PIP ${ }_{2}$-Gehalt................................................ 105

6.1.3 Adsorption von Ezrin wt an cholesterinhaltige Membranen .......... 106

6.2 Visualisierung der Bindung von Ezrin wt an $\mathrm{PIP}_{2}$-haltige Membranen mittels Rasterkraftmikroskopie ...................................................... 110

6.3 Selbst-Assoziationseigenschaften von Ezrin wt und Ezrin T567D......... 111

6.4 Auswertung der Adsorptionsisothermen unter Berücksichtigung kooperativen Bindungsverhaltens ............................................... 113

6.4.1 Scaled particle theory (SPT) ……............................................... 114

6.4.2 Modellierung der Adsorptionsisothermen von Ezrin T567A, Ezrin wt und Ezrin T567D an PIP 2 -haltige Membranen nach dem SPT-Modell

6.5 Laterale Mobilität von $\mathrm{PIP}_{2}$ in festkörperunterstützten Lipidmembranen 117

6.5.1 FRAP-Messungen an cholesterinfreien Membranen ..................... 118

6.5.2 FRAP-Messungen an cholesterinhaltigen Membranen ................ 122

6.6 Inhomogenität der cholesterinhaltigen Lipidmischung ……................... 123

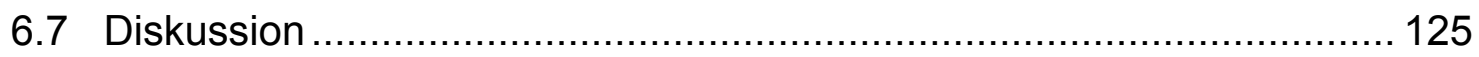

7 Aktivierbarkeit von Ezrin in Abhängigkeit von $\mathrm{PIP}_{2}$ und Phosphorylierung

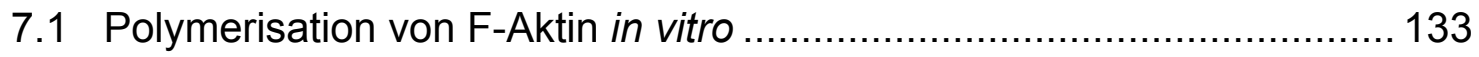

7.2 Spezifität der F-Aktin-Adsorption auf Ezrin-belegten

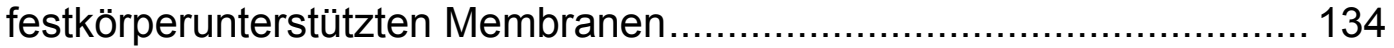

7.3 Vergleich der Affinität von Ezrin zu F-Aktin in Abhängigkeit von $\mathrm{PIP}_{2^{-}}$ Bindung und Phosphorylierungsgrad ............................................. 136

7.4 Cosedimentationsexperimente mit F-Aktin und Ezrin .......................... 142 
7.5 Diskussion 146

8 Bindungs- und Aktivierungsmodell von Ezrin......................................157

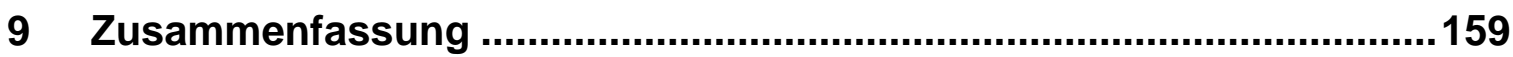

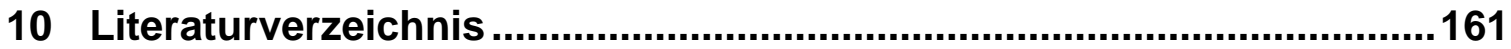

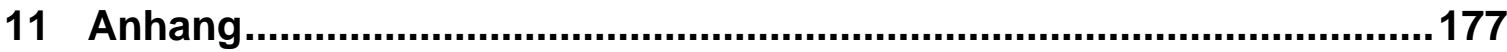

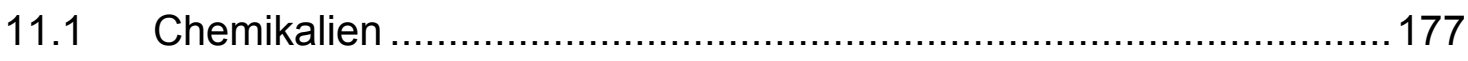

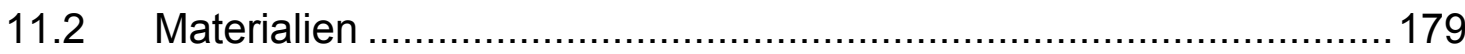

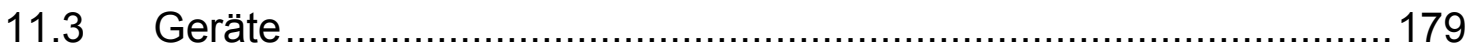

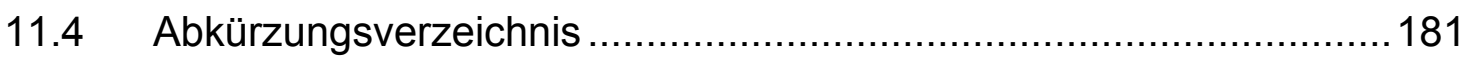

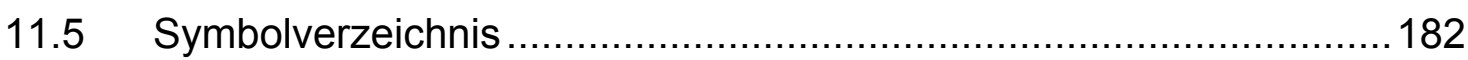

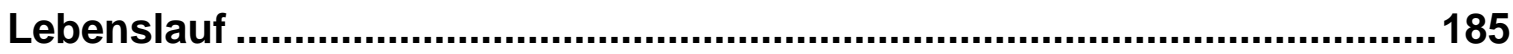

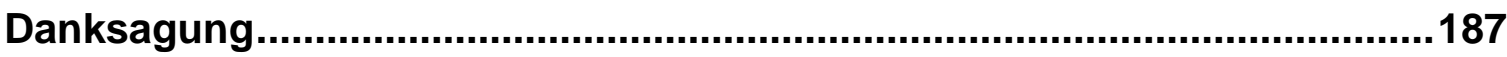




\section{EINLEITUNG}

\subsection{Das Cytoskelett}

Das Cytoskelett einer eukaryotischen Zelle ist ein dynamisches Geflecht aus Proteinen, das der Zelle mechanische Stabilität verleiht, ihre Beweglichkeit steuert und Transporte innerhalb der Zelle ermöglicht. Dieses Geflecht wird in drei verschiedene Filamentarten unterteilt, in Mikrotubuli, Intermediärfilamente und Aktinfilamente (F-Aktin) (1). Sie bestehen aus unterschiedlichen Proteinen und erfüllen verschiedene Aufgaben. In Abbildung 1.1 sind die verschiedenen Cytoskelettbestandteile von Epithelzellen durch Fluoreszenzfarbstoffe sichtbar gemacht.

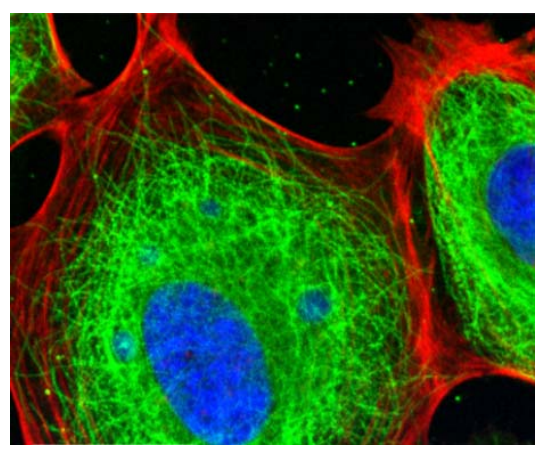

Abbildung 1.1: Fluoreszenzgefärbte Bestandteile von Epithelzellen (2). Rot: Aktinfilamente, Grün: Mikrotubuli, Blau: DNA im Zellkern.

Intermediärfilamente verleihen der Zelle mechanische Stabilität. Die Intermediärfilamente bildenden Proteine umfassen eine heterogene Proteingruppe. Je nach Gewebsart bilden unterschiedliche Proteine diese Strukturen aus. So werden in den polaren Epithelzellen, die die äußerste Zellschicht jedes Organs bilden, hauptsächlich verschiedene Formen von Keratin gefunden (3). Mikrotubuli, aufgebaut aus dem 55 kDa großen Protein Tubulin, bestimmen die Positionen der Zellorganellen in der Zelle und dirigieren den intrazellulären Transport. Sie bilden darüber hinaus während der Mitose und Meiose den Spindelapparat zur korrekten Aufteilung des Erbguts. Aktinfilamente 
bilden den sogenannten Zellcortex und befinden sich direkt unter der Plasmamembran, wodurch sie der Zelloberfläche ihre Form verleihen. Sie sind außerdem für die Beweglichkeit der gesamten Zelle verantwortlich.

Die Aktinfilamente entstehen in einem Polymerisationsprozess, der im Folgenden erläutert wird, aus dem monomeren Protein Aktin, welches auch globuläres (G-)Aktin genannt wird. Es bildet eines der häufigsten Proteine in Eukaryoten (4). Aktin besitzt eine Größe von $43 \mathrm{kDa}$ und weist zwei Bindungsstellen für ATP und zweiwertige Kationen auf. Die Besetzung der Bindungsstelle durch divalente Kationen, z.B. Calcium-lonen, reduziert die negative Nettoladung der Aktinmoleküle, so dass die Polymerisation durch Verringerung der elektrostatischen Abstoßung begünstigt wird (5). In Abbildung 1.2 ist ein AktinMonomer mit einem gebundenen ATP-Molekül dargestellt. Daneben befindet sich ein Modell des polymerisierten, filamentösen Aktins.
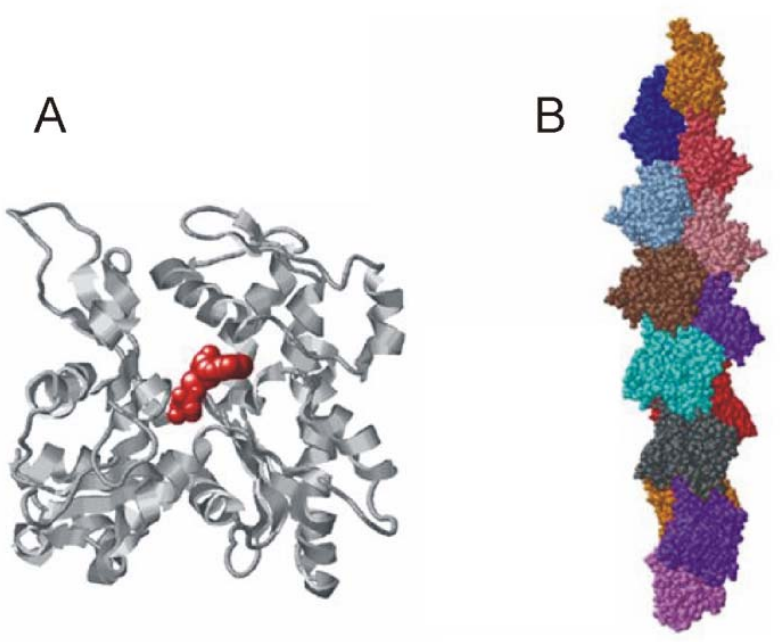

Abbildung 1.2 A: Aktin-Monomer mit gebundenem ATP. B: Aktin-Filament.

Die Untereinheiten des Filaments sind um $167^{\circ}$ gegeneinander gedreht und formen eine helikale Schraubenachse mit 2,7 nm Hub (6). Der maximale Durchmesser eines solchen Filaments beträgt ca. $9 \mathrm{~nm}$. Es existieren sechs verschiedene Isoformen von Aktin, welche sich in nur wenigen Aminosäuren unterscheiden und je nach Gewebetyp unterschiedlich exprimiert werden. NichtMuskelzellen verfügen ausschließlich über die Isoformen $\beta$ und $y(7)$. 
Der Polymerisationsvorgang zu Aktinfilamenten beginnt immer mit der Bildung eines Trimers, welches der geschwindigkeitsbestimmende Schritt ist. An dieses lagern sich in der Folge weitere Aktinmonomere an. Dieser Prozess vollzieht sich bei einer Konzentration oberhalb der kritischen Monomerkonzentration, die in vitro eine Funktion der Temperatur ist, und in Gegenwart von ATP und zweiwertigen Kationen abläuft. Das wachsende Aktinfilament besitzt zwei verschiedene Enden, es ist polarisiert. Die Addition von Monomeren findet bevorzugt am sogenannten Plus-Ende oder barbed end statt, der Filamentabbau am Minus-Ende, dem pointed end. So wächst das Filament bis zu einer gewissen Länge und geht dann in ein Fließgleichgewicht über, in dem Polymerisation und Depolymerisation gleich schnell vonstatten gehen. Dieser Prozess wird auch als Tretmühle (treadmilling) bezeichnet (6). Eine besondere Rolle kommt dem im wachsenden Filament eingeschlossenen Adenosintriphosphat zu: Dessen langsame Hydrolyse zu ADP destabilisiert das Polymer und die Dissoziation des Monomers wird begünstigt (8).

Um das Wachstum der Filamente im Hinblick auf Richtung und Geschwindigkeit zu kontrollieren, werden diese Vorgänge in vivo durch eine Vielzahl von verschiedenen Proteinen moduliert, von denen im Folgenden einige genannt werden sollen. Aktin-Depolymerisationsfaktoren (ADF), auch Cofilin genannt, beschleunigen den Abbau des Filaments am Minus-Ende und erhöhen dadurch die Monomerkonzentration und die Polymerisationsrate am Plus-Ende (6, 9). Gelsolin schneidet Aktinfilamente und bindet an deren Plus-Ende, es übt also eine sogenannte capping-Funktion aus, die das Aktinnetzwerk zerlegt. Diese Funktion wird durch $\mathrm{Ca}^{2+}$ und $\mathrm{PIP}_{2}$ negativ reguliert (10). Das erste bekannte GAktin-bindende Protein war Profilin, ein 16 kDa großes ubiquitäres Protein, welches durch den Austausch von ADP gegen ATP die Polymerisationsneigung des Monomers erhöht (11).

Um die Kräfte, die aus dem Wachstum und dem Abbau der Aktinfilamente resultieren, auf die Plasmamembran zu übertragen und so eine kontrollierte, gerichtete Formung der Zelloberfläche zu bewirken, ist eine dynamische Verknüpfung des Zellcortex mit der Plasmamembran nötig. Dies wird durch spezielle Proteine ermöglicht, die Bindungsstellen sowohl für Aktin als auch für Lipide oder Transmembranproteine der Plasmamembran bereithalten, und deren 
Aktivität über verschiedene zelluläre Signale kontrolliert wird. Eines der Lipide, die über solche Linkerproteine als Anheftungspunkt für das Cytoskelett dienen, ist $\mathrm{PIP}_{2}$, welches im folgenden Kapitel vorgestellt wird.

\subsection{Phosphatidylinositol-4,5-bisphosphat $\left(\mathrm{PIP}_{2}\right)$}

Phosphatidylinositol-4,5-bisphosphat bildet einen Gesamtanteil von 1\% aller Lipide der Plasmamembran und ist gleichzeitig das häufigste Phosphoinositol in der Zelle (12). Die Struktur des Lipids ist in Abbildung 1.3 wiedergegeben.

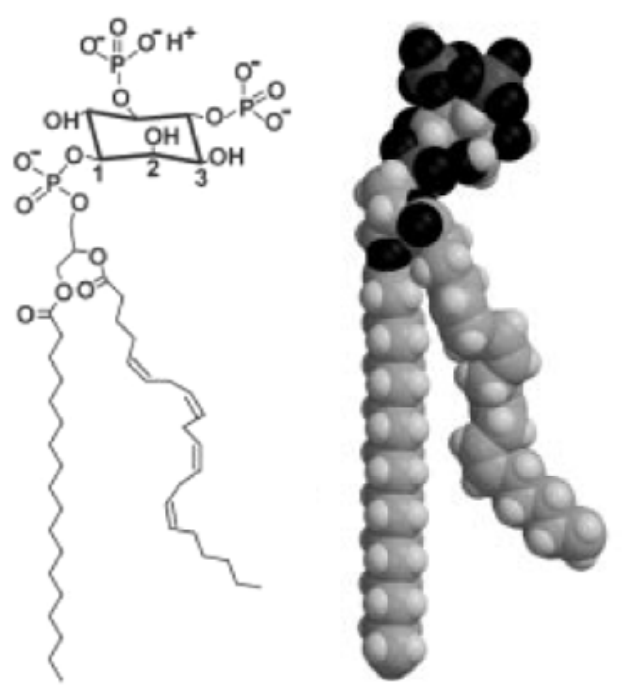

Abbildung 1.3: Chemische Struktur und Kalottenmodell des Membranlipids $\mathrm{PIP}_{2}$.

$\mathrm{PIP}_{2}$ weist unter physiologischen Bedingungen eine Gesamtladung von -3 bis -5 auf. Eine strukturelle Besonderheit dieses Lipids bildet das relativ große Inositol als Kopfgruppe, dadurch ragt diese etwas über die Membranebene hinaus (12). Die zellulären Aufgaben dieses Lipids sind erstaunlich vielfältig. Neben der seit langem etablierten Funktion als Quelle der beiden second messenger-Moleküle DAG (Diacylglycerol), welches die Proteinkinase $\mathrm{C}$ aktiviert, und $\mathrm{IP}_{3}$ (Inositol1,4,5-trisphosphat) zur Freisetzung von $\mathrm{Ca}^{2+}$ aus intrazellulären Speichern im Endoplasmatischen Retikulum (13) konnte für $\mathrm{PIP}_{2}$ im Zusammenhang mit Endound Exocytoseprozessen, mit Enzymaktivierung (14) sowie mit der Verknüpfung von Cytoskelett und Plasmamembran eine entscheidende Rolle identifiziert 
werden. Letztere Funktion wurde in einem eleganten Versuchsansatz von Raucher et al. (15) erstmals explizit nachgewiesen, indem die Adhäsionsenergie zwischen Cytoskelett und Plasmamembran mit Hilfe einer optischen Falle (laser tweezers) direkt gemessen wurde. Sie fanden, dass nach Senkung der $\mathrm{PIP}_{2^{-}}$ Konzentration in der Plasmamembran durch Zusatz einer Phosphatase die Adhäsionsenergie signifikant sank und folgerten daraus, dass $\mathrm{PIP}_{2}$ eine Schlüsselrolle in der Regulation der Plasmamembran-Zellcortex-Verbindung einnimmt.

Diese Regulation wird jedoch nicht direkt, sondern über die Wechselwirkung von $\mathrm{PIP}_{2}$ mit zahlreichen aktinbindenden Proteinen, die am Cytoskelettaufbau, abbau, der Quervernetzung der Cytoskelettfilamente und deren Anheftung an die Plasmamembran beteiligt sind, erreicht. Beispiele hierfür sind die Bindung von Profilin (siehe Kapitel 1.1), welches die Polymerisationsneigung von Aktin erhöht, oder die Bindung zu alpha-Actinin, welches ein F-Aktin-crosslinking bewirkt und über $\mathrm{PIP}_{2}$-Bindung positiv reguliert wird (16). Auch capping-Proteine (CapZ, Cap 32/34, Cap 100 (17-19)), die das Wachstum von Aktinfilamenten über eine Blockierung des Plus-Endes unterbinden, werden über das Lipid $\mathrm{PIP}_{2}$ reguliert. Das Protein Ezrin, welches im Zentrum dieser Arbeit steht, ist als wichtiger Bindungspartner von $\mathrm{PIP}_{2}$ bekannt und fungiert als Verbindung zwischen Plasmamembran und Zellcortex (20). Auf diese Interaktion wird in Kapitel 1.3 noch genauer eingegangen.

Die Verteilung des Lipids $\mathrm{PIP}_{2}$ innerhalb der Plasmamembran ist nicht homogen. Zum einen besteht eine deutliche Präferenz für die dem Cytoplasma zugewandte Seite (ca. 80\%) (21), zum anderen werden lokal erhöhte Konzentrationen von $\mathrm{PIP}_{2}$ in bestimmten Membranbereichen gefunden, und zwar vor allem dort, wo ein besonders hoher F-Aktin-Umsatz stattfindet (22). Bisher ist jedoch unzureichend geklärt, welche Mechanismen im Einzelnen dieser lokalen Konzentrationserhöhung zugrunde liegen. Diskutiert wird einerseits eine lokal erhöhte Synthese über die Aktivierung von PIP-5-Kinasen durch G-Proteine (23) in Kombination mit einer verringerten Diffusionsgeschwindigkeit der Lipide in solchen Membranbereichen, womöglich durch die Bildung von cholesterinreichen Domänen. Zum anderen weisen einige Studien darauf hin, dass durch die 
Assoziation mit bestimmten membranbindenden Proteinen eine solche $\mathrm{PIP}_{2^{-}}$ Anreicherung ermöglicht und gesteuert wird (24-25).

Es sind mehrere Möglichkeiten denkbar, die zu dieser Situation führen: Zunächst kann ein Protein mehrere Bindungsstellen für ein bestimmtes Lipid bereithalten und hierdurch eine Akkumulation bewirken. Beispielsweise findet man bei der Bindung von Annexin A2t an eine Membran eine Anreicherung von negativ geladenen Phosphatidylserinmolekülen unter dem Protein (26). Sowohl bei dem Protein MARCKS (myristoylated alanine-rich C kinase substrate), einem F-AktinLinkerprotein, als auch NAP-22 wurde eine spezifische Anreicherung von $\mathrm{PIP}_{2}$ in bestimmten Membranregionen gefunden (27-28). Beide Proteine erreichen dies über nichtspezifische elektrostatische Wechselwirkungen mit dem Lipid einerseits und bewirken andererseits, vermutlich durch eine „Membran-Verankerung“ über einen Myristinsäurerest, eine Lokalisation des Protein-Lipidkomplexes in cholesterinreichen Membranregionen. Schließlich kann auch die Oligomerisierung eines Proteins über laterale intermolekulare Anziehung an der Membranoberfläche eine lokal erhöhte Konzentration eines bestimmten Lipids herbeiführen.

\subsection{Die ERM-Proteinfamilie}

Die dynamische und regulierbare Verknüpfung der Plasmamembran mit dem Zellcortex ist die Voraussetzung für so grundlegende zelluläre Prozesse wie Endo- und Exocytose, Zellmigration oder die Zellformgebung. Es wurden bis dato eine Vielzahl von Proteinen identifiziert, die an der Regulation dieser Prozesse beteiligt sind, darunter befinden sich jedoch nur wenige, die eine direkte Verbindung der Plasmamembran mit dem Cytoskelett bilden. Die am besten untersuchte Klasse bildet die Ezrin-Radixin-Moesin-(ERM)Familie, eine Gruppe von Proteinen, welche eine hohe Homologie in ihrer Aminosäuresequenz aufweisen, deren Expressionsrate in verschiedenen Gewebetypen jedoch unterschiedlich ist. Ezrin wurde erstmals im Zellcortex der Mikrovilli und Membranknäule von Dünndarmepithelzellen gefunden (29). Radixin wurde zuerst aus Leberzellen isoliert (30) und Moesin wurde als Bindungspartner von Heparin 
identifiziert (31). Die schematischen Strukturen der ERM-Proteine sowie die Strukturhomologien sind in Abbildung 1.4 wiedergegeben.

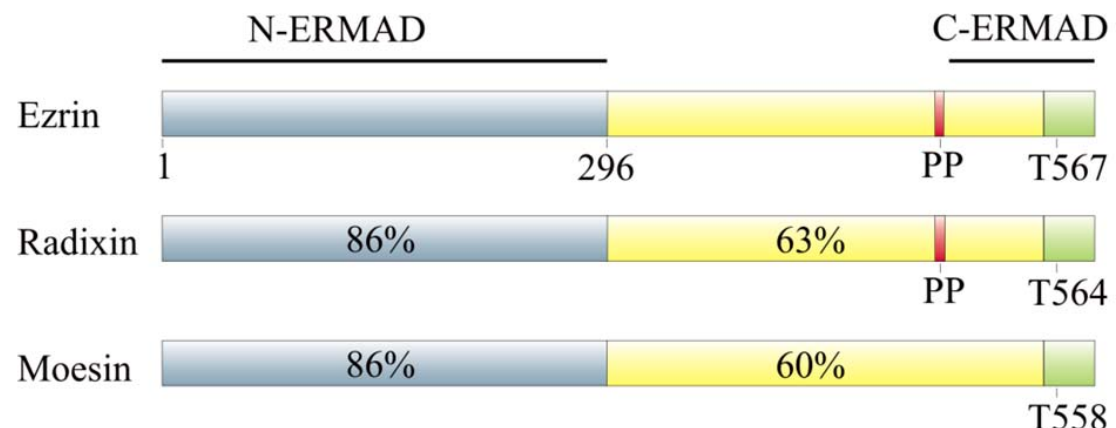

Abbildung 1.4: Schematische Darstellung der Proteine der ERM-Proteinfamilie (Ezrin, Radixin, Moesin). Die sequentielle Homologie von Radixin und Moesin beträgt im Vergleich zu Ezrin 86\% in der N-ERMAD und noch ca. $60 \%$ für die restlichen Aminosäuren. Ezrin und Radixin verfügen über eine Polyprolinsequenz (PP). Die Threoninreste T567 (Ezrin), T564 (Radixin) und T558 (Moesin) können durch Kinasen phosphoryliert werden und tragen so zur Aktivierung der Proteine bei.

Der N-terminale Bereich, der 296 Aminosäuren umfasst, weist unter den Vertebraten eine sehr hohe Sequenzhomologie von $86 \%$ auf. Er wird auch als FERM-Domäne (four-point-one, ezrin, radixin, moesin) bezeichnet. Dieser Name bezieht sich auf das Protein 4.1, welches den Prototypen dieser Proteinfamilie bildet (32). Auch im C-terminalen Bereich findet sich eine hohe Übereinstimmung von ca. $60 \%$ innerhalb der Proteinfamilie, insbesondere unter den letzten 34 Aminosäuren, wo die Bindung an das Cytoskelett erfolgt (33).

Entsprechend ihrer hohen sequentiellen Übereinstimmung wurden ähnliche, teilweise überlappende zelluläre Funktionen der Proteine der ERM-Familie dokumentiert. Der Phänotyp von Mäusen, deren Moesin-codierende Gensequenz deaktiviert wurde („Gen-Knockout“), zeigte keinerlei Veränderung gegenüber dem Wildtyp (34). Auch zeigten die Zellen der verschiedenen Gewebetypen keinen kompensatorischen Anstieg der Expressionsrate von Ezrin oder Radixin. Wenn allerdings die Expressionsrate eines einzelnen ERM-Proteins in bestimmten Gewebetypen gegenüber den anderen stark überwiegt, wie dies für Ezrin im Epithel des Dünndarms und des Magens der Fall ist, so zeigten sich in entsprechenden Knockout-Experimenten in vivo schwerwiegende Entwicklungsstörungen: In Ezrin-Knockout-Mäusen wurde beispielsweise eine 
abnorme Morphogenese des Dünndarmepithels festgestellt (35). In einer anderen Studie wiesen diese Mäuse keinerlei Sekretion von Magensäure auf (Achlorhydrie), was nach kurzer Zeit zum Tod führte (36). Eine Inaktivierung von Radixin in Mäusen führte zu Leberdefekten (37) und Taubheit (38).

\subsubsection{Die Struktur von Ezrin}

Das Protein Ezrin besitzt 586 Aminosäuren und eine Masse von ca. 70 kDa. Die Struktur des Proteins ist schematisch in Abbildung 1.5 wiedergegeben.

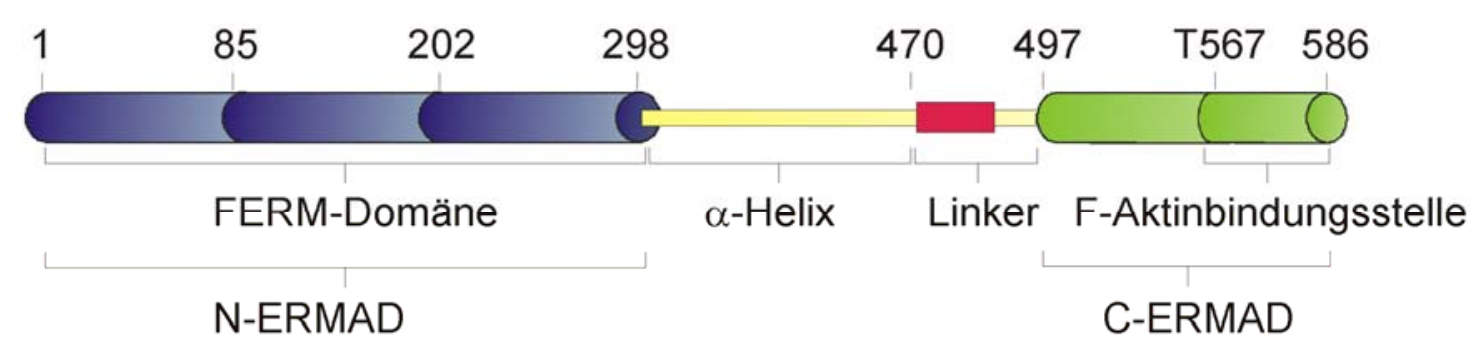

Abbildung 1.5: Schematische Struktur des Proteins Ezrin.

Über den N-terminalen Bereich des Proteins, auch N-ERMAD (N-Ezrin-RadixinMoesin-association domain) genannt, erfolgt die Membranbindung. Hier befinden sich Bindungsstellen für $\mathrm{PIP}_{2}$ sowie für integrale Membranproteine wie CD-43, CD-44 oder ICAM-1, -2 und -3 (39-45). Es gelang Smith und Mitarbeitern im Jahr 2003, die Röntgenkristallstruktur des N-terminalen Bereichs von Ezrin aufzuklären (46). So wurde festgestellt, dass der N-terminale Bereich N-ERMAD in drei Subdomänen F1, F2 und F3 unterteilt werden kann, die zusammen eine kleeblattartige Struktur bilden. Ein Modell dieser Struktur ist in Abbildung 6 dargestellt. Durch Mutationsstudien (site-directed mutagenesis), die von Barret et al. im N-ERMAD durchgeführt wurden, konnte die Bindungsstelle für $\mathrm{PIP}_{2}$ auf die Aminosäuren 12-115 in Subdomäne $F 1$ und 233-310 in Subdomäne $F 3$ eingegrenzt werden (47). Hier befindet sich eine Abfolge von basischen Aminosäuren, die in der ERM-Familie hoch konserviert ist und vornehmlich aus Lysinresten besteht $\left(\mathrm{KK}(\mathrm{X})_{\mathrm{n}} \mathrm{K} / \mathrm{RK}\right)$. Der Austausch dieser Reste gegen Asparagin führte zur weitgehenden Aufhebung der Bindung von Ezrin an $\mathrm{PIP}_{2}$. 


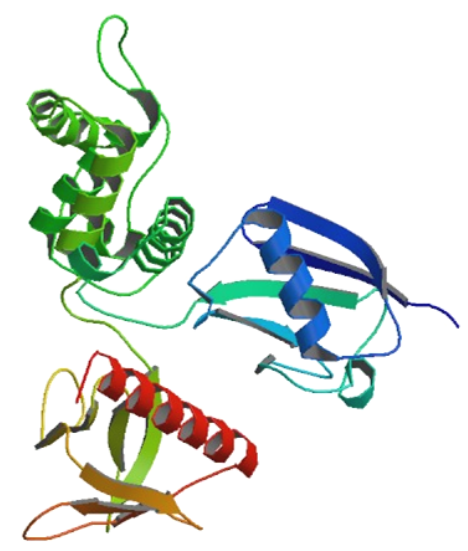

Abbildung 1.6: Strukturmodell der N-terminalen Domäne von Ezrin (N-ERMAD) (46).

Der C-terminale Bereich umfasst ca. 100 Aminosäuren und wird auch als CERMAD bezeichnet (C-Ezrin-Radixin-Moesin-association domain). Hier erfolgt die Bindung an F-Aktin, genauer über den Bereich der letzten 34 Aminosäuren, welcher ein KYKXL-Motiv aufweist und stark positiv geladen ist (39). Die N- und C-terminalen Domänen werden über eine a-helikale Sequenz verbunden, die etwa 200 Aminosäuren umfasst und eine Polyprolinsequenz beinhaltet.

Eine Sonderstellung besitzt der Threoninrest 567 im C-ERMAD (siehe Abbildung 1.5). An diesem erfolgt über Proteinkinasen eine Phosphorylierung, die in der Aktivierung des Proteins eine entscheidende Rolle spielt. Eine Besonderheit der ERM-Proteine ist, dass sie in verschiedenen Zuständen vorliegen können, dem inaktiven (dormant) Zustand und dem aktiven (active) Zustand (48). Der dormant state ist dadurch charakterisiert, dass die beiden terminalen Domänen über eine Selbstassoziation die Bindungsstellen für F-Aktin und für die meisten Membranproteine maskieren (39). Der Aktivierungsprozess, dessen genauer Ablauf Gegenstand aktueller Forschung ist, resultiert in einer geöffneten Konformation und der Freilegung der genannten Bindungsstellen. Kapitel 1.3.2 wird eine ausführliche Einordnung der derzeit bekannten Aktivierungsparameter bieten. 


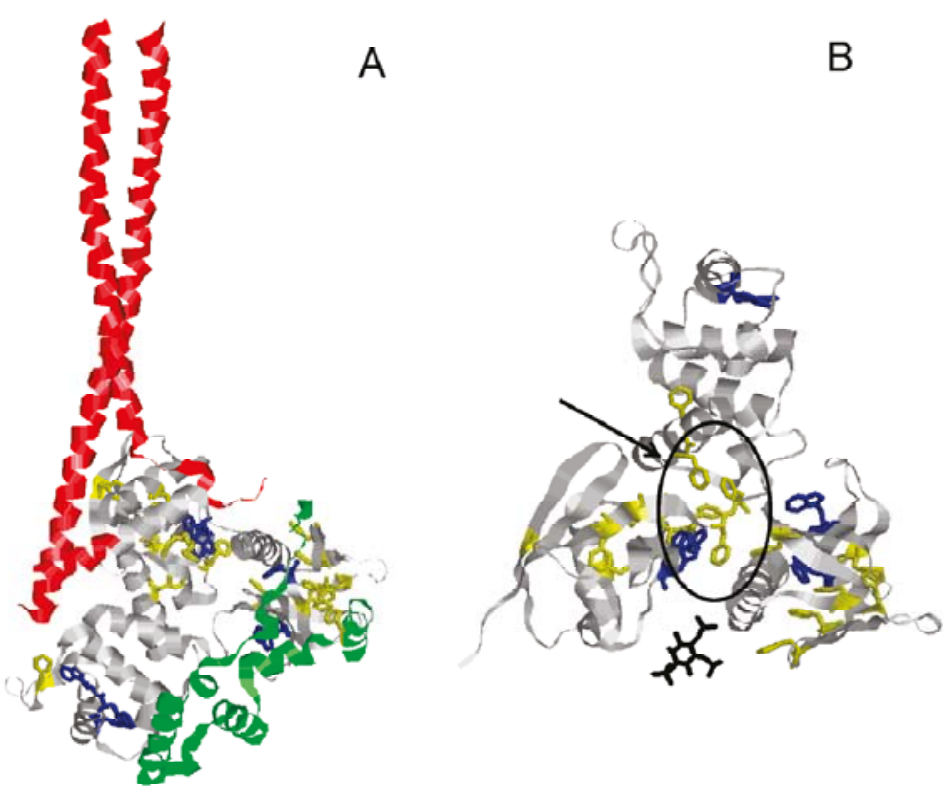

Abbildung 1.7: Dreidimensionale Struktur von (A) Ezrin und (B) der FERM-Domäne komplexiert mit $\mathrm{IP}_{3}$, abgeleitet aus röngenkristallographischen Strukturbestimmungen von Moesin $(A,(49))$ und Radixin (B, (50)).

Bisher konnte lediglich für das inaktive Moesin eine hochauflösende röntgenkristallographische Strukturaufklärung durchgeführt werden (49). Es kann jedoch aufgrund der hohen Sequenzhomologie von Ezrin und Moesin davon ausgegangen werden, dass diese Ergebnisse auf die Struktur von Ezrin weitgehend übertragbar sind. Daneben führte die Kristallisation und anschließende Röntenstrukturanalyse der FERM-Domäne von Radixin, komplexiert mit Inositol-1,4,5-trisphosphat $\left(\mathrm{IP}_{3}\right)$, zu neuen Einblicken in die Struktur des aktivierten Proteins (50). Das Ergebnis einer Strukturberechnung von Ezrin basierend auf diesen Erkenntnissen ist in Abbildung 1.7 gezeigt. Anhand der dreidimensionalen Darstellung wird deutlich, dass die a-helikale Linker-Region zwischen C- und N-Terminus aus der ansonsten recht kompakten Struktur des inaktiven Proteins herausragt und sich wieder zurückfaltet. So ist es möglich, dass in dieser inaktiven Form der C-Terminus über spezifische Wechselwirkungen eine starke Bindung zur FERM-Domäne ausbildet und so einen großen Teil seiner Oberfläche bedeckt. Die Wechselwirkungen, die zu dieser stabilen Selbst-Assoziation führen, beruhen einerseits auf der Vermittlung der Bindung über Wassermoleküle, andererseits wird über hydrophobe Wechselwirkungen ein sehr enger Kontakt zwischen einzelnen Regionen hergestellt. Auch elektrostatische Anziehungskräfte zwischen gegensinnig 
geladenen Aminosäuren der $\mathrm{N}$ - und $\mathrm{C}$-terminalen Domäne tragen zur Bindung bei. Zur Aktivierung des Proteins müssen diese intermolekularen Assoziationen aufgehoben werden, ein Prozess, der im folgenden Kapitel genauer erläutert werden soll.

\subsubsection{Aktivierungsprozess von Ezrin}

Um das Protein Ezrin vom inaktiven in den aktiven Zustand zu überführen und die F-Aktin-Bindungsdomäne freizulegen, muss eine Dissoziation der beiden terminalen Domänen erfolgen. Bis dato konnten zwei unabhängige Aktivierungswege identifiziert werden, die diesen Prozess initiieren. Koltzscher und Mitarbeiter konnten im Jahr 2003 mit Hilfe von Cosedimentationsexperimenten nachweisen, dass die F-Aktin-Bindefähigkeit von Ezrin in Anwesenheit des Proteins S100 und $\mathrm{Ca}^{2+}$ gesteigert ist (51). S100P als Vertreter der Superfamilie der calciumbindenden EF-Hand-Proteinfamilie wurde in diesem Experiment als Bindungspartner des N-Terminus von Ezrin identifiziert. Koltzscher et al. schlossen daraus, dass Ezrin im Rahmen von intrazellulären $\mathrm{Ca}^{2+}-$ Kaskaden in den aktivierten Zustand überführt werden kann. Dieser Aktivierungsweg stellt eine relativ neue Alternative zu einem bereits länger im wissenschaftlichen Diskurs befindlichen, nach heutigen Erkenntnissen vermutlich zweischrittigen Mechanismus dar.

Einen wesentlichen Faktor dieser in zwei Schritten ablaufenden Aktivierung bildet die Phosphorylierung des Threoninrests 567 im C-Terminus des Proteins (52-53). Hierbei wird über verschiedene Kinasen, die teilweise zellspezifisch vorkommen (52-56), ein Phosphatrest auf die Threoninseitenkette übertragen, was im gleichen Zuge eine negative Ladung an dieser Stelle einführt. Anhand des Proteins Moesin konnte gezeigt werden, dass die entsprechende Phosphorylierung von T558 durch sterische und elektrostatische Effekte eine konformative Aktivierung bewirkt (57). Allerdings erfordert dieser Aktivierungsweg als vorausgehenden Schritt die Bindung des Proteins Ezrin an die Plasmamembran, genauer an $\mathrm{PIP}_{2}$, wie Fievet et al. (58) im Jahr 2004 beweisen konnten. Durch die Einführung von Mutationen im N-Terminus des Proteins konnten sie die Assoziation mit $\mathrm{PIP}_{2}$ unterbinden. Dieser Ansatz wurde kombiniert mit einer Mutation von Threonin $567 \mathrm{zu}$ Aspartat, wodurch eine 
Phosphorylierung an dieser Position nachgestellt werden sollte. Ihre experimentellen Ergebnisse bewiesen, dass für eine stabile Assoziation mit Cytoskelettelementen die vorhergehende Bindung von Ezrin an $\mathrm{PIP}_{2}$ essentiell ist. Die zurzeit angenommene Erklärung für diese Voraussetzung ist, dass $\mathrm{PIP}_{2}$ eine strukturelle Veränderung im Ezrinmolekül bewirkt, die den Threoninrest für entsprechende Proteinkinasen besser zugänglich macht (59). Diese Theorie liefert allerdings keine Erklärung dafür, dass eine konformativ aktive Mutante, wie sie Fievet et al. in vivo verwendeten, keine Bindung an das Cytoskelett zeigte. Es ist bisher nicht eingehend erforscht worden, ob die Assoziation an $\mathrm{PIP}_{2}$ allein einen signifikanten Beitrag zur Aktinbindefähigkeit von Ezrin leistet, und welchen Einzelbeitrag die anschließende Phosphorylierung von T567 zur Gesamtaktivierung bewirkt. Ein indirekter Hinweis darauf, dass die $\mathrm{PIP}_{2}$-Bindung allein auch ohne anschließende Phosphorylierung die Verknüpfung von Plasmamembran und Cytoskelett über Ezrin ermöglicht, findet sich in einer Publikation von Roch et al. aus dem Jahr 2010 (60): Dort konnte unter Verwendung von transgenen Taufliegen (Drosophila melanogaster), die eine Cterminal GFP-markierte konstitutiv inaktive Mutante von Moesin (Moesin T558AGFP) exprimierten, eine unveränderte Entwicklung bestimmter Zelltypen beobachtet werden. 


\section{ZiELSETZUNG}

Das Protein Ezrin, ein Mitglied der ERM (Ezrin, Radixin, Moesin)-Proteinfamilie, dient der dynamischen Verknüpfung von Plasmamembran und Cytoskelett. Es ist damit an so vielfältigen und grundlegenden zellulären Prozessen wie Endo- und Exocytose, Zellmigration und Zelladhäsion beteiligt. Das Protein kann im inaktiven, cytosolischen Zustand vorliegen sowie im membrangebundenen, aktivierten Zustand, in dem es befähigt ist, an filamentöses Aktin (F-Aktin) des Cytoskeletts zu binden. Die molekularen Faktoren, die die Überführung des Proteins in diesen aktivierten Zustand ermöglichen, sind bisher nur unzureichend verstanden. Insbesondere konnte bislang keine Abgrenzung der individuellen Einflüsse einzelner bereits identifizierter Aktivierungsparameter, die Bindung an das Lipid Phosphatidylinositol-4,5-bisphosphat $\left(\mathrm{PIP}_{2}\right)$ sowie eine anschließende Phosphorylierung am Threoninrest 567 des Proteins, erfolgen.

Ziel der vorliegenden Arbeit ist die Realisierung eines Modellsystems auf Basis von festkörperunterstützten Membranen, anhand dessen die Bindung von Ezrin an F-Aktin in Analogie zur zellulären Situation untersucht werden kann. Hierbei sollen die Einflüsse der einzelnen Aktivierungsparameter individuell adressiert und die Beiträge zur Gesamtaktivierung identifiziert werden. Dabei dienen der Wildtyp des Proteins sowie zwei Mutanten - die unphosphorylierbare sowie die pseudophosphorylierte Form des Proteins - der Untersuchung des Einflusses der Phosphorylierung, während die Bindung an eine mit PIP $\mathrm{P}_{2}$ oder Ni-1,2-dioleoyl-snglycero-3-([N(5-amino-1 carboxypentyl)iminodiessigsäure]succinyl) (DOGS-NTA$\mathrm{Ni})$ dotierte Membran das gezielte Studium des Einflusses des Bindungspartners $\mathrm{PIP}_{2}$ erlaubt. Die Interaktionsstudien an Oberflächen sollen durch Untersuchungen in Lösung ergänzt werden. Darüber hinaus sollen über eine gezielte Variation der Membranzusammensetzung Informationen über die Stöchiometrie der Bindung von Ezrin an $\mathrm{PIP}_{2}$ sowie das Bindungsverhalten von Ezrin auf der Oberfläche gewonnen werden. 



\section{Materialien Und Methoden}

\subsection{Proteinchemische Methoden}

\subsubsection{Kultivierung und Genexpression in Escherichia coli (E. coli)}

Im Rahmen dieser Arbeit wurden Escherichia coli-Bakterien des Stamms BL21(DE3) pLysS verwendet. Die transfizierten Stämme wurden in einer glycerinhaltigen Lösung bei $-80^{\circ} \mathrm{C}$ gelagert. Ausgehend von dieser Lösung wurden Vereinzelungsausstriche auf sterilen LB-Agarplatten (engl. lysogeny broth) ausgeführt und bei $37^{\circ} \mathrm{C}$ über Nacht inkubiert. Zur Selektion von plasmidtragenden E.coli-Stämmen wurde allen flüssigen Medien und Selektionsnährböden nach dem Autoklavieren (20 min, $121^{\circ} \mathrm{C}$ ) und Abkühlen auf ca. $50{ }^{\circ} \mathrm{C}$ das Antibiotikum Kanamycin zugesetzt. Für die Anzucht einer Bakterienkolonie wurde anschließend mittels einer sterilen Pipettenspitze eine Einzelkolonie gepickt und in $10 \mathrm{~mL}$ LB-Medium über Nacht bei $37^{\circ} \mathrm{C}$ kultiviert. $5 \mathrm{~mL}$ dieser Vorkultur wurden am nächsten Tag zur Inokulation der Hauptkultur (250 mL) verwendet. Die Hauptkultur wurde bei $37^{\circ} \mathrm{C}$ unter Schütteln bis zu einer optischen Dichte von $\mathrm{OD}_{600}=0,6$ herangezogen. Zur Induktion der Genexpression wurde $1 \mathrm{mM}$ Isopropyl- $\beta$-D-thiogalactopyranosid (IPTG) zugesetzt und weitere vier Stunden bei $37^{\circ} \mathrm{C}$ geschüttelt. Anschließend wurde die Kultur für 10 min auf Eis gestellt. Um die Zellen zu ernten, wurde 10 min bei $4000 \times \mathrm{g}$ zentrifugiert.

LB-Medium: $1 \%$ Trypton, 0,5\% Hefeextrakt, $1 \% \mathrm{NaCl}, 60 \mu \mathrm{g} / \mathrm{mL}$ Kanamycin LB-Agar: $\quad 1 \%$ Trypton, $0,5 \%$ Hefeextrakt, $1 \% \mathrm{NaCl}, 1,5 \%$ Agar, $60 \mu \mathrm{g} / \mathrm{mL}$ Kanamycin

\subsubsection{Aufreinigung der 6His-fusionierten Proteine}

Das aus der Zentrifugation erhaltene Zellpellet wurde in Lysispuffer $(25 \mathrm{~mL})$ resuspendiert. Der Zellaufschluss erfolgte unter Ultrasonifizierung (Sonopuls, 
Bandelin, cycle $50 \%, 5 \times 30$ s) und das Lysat wurde von unlöslichen Bestandteilen durch Ultrazentrifugation getrennt $\left(94000 \times \mathrm{g}, 1 \mathrm{~h}, 4^{\circ} \mathrm{C}\right)$. Anschließend wurde der resultierende Überstand dreimal über eine mit Äquilibrierungspuffer eingestellte Ni-NTA-Agarosesäule (Bettvolumen ca. 2,5 mL) gegeben. Das Säulenmaterial wurde dreimal mit je $20 \mathrm{~mL}$ Waschpuffer I sowie zweimal mit je $10 \mathrm{~mL}$ Waschpuffer II gespült. Die Ablösung des Proteins von der Säule erfolgte mittels Elutionspuffer. Die erhaltene Proteinlösung wurde bei $4{ }^{\circ} \mathrm{C}$ gelagert. Alle Wasch- und Elutionsschritte wurden per SDS-PAGE analysiert.

Lysispuffer:

40 mM HEPES, 20 mm Imidazol, 300 mM NaCl, 1 mm EDTA, $10 \mathrm{~mm}$ Mercaptoethanol, Roche complete mini ETDA-free (Proteaseinhibitor-Mischung, 1 Tablette/ $10 \mathrm{~mL}), \mathrm{pH} 7,4(\mathrm{NaOH})$

Äquilibrierungspuffer: $\quad 40$ mM HEPES, 25 mM Imidazol, 300 mM NaCl, pH 7,4 $(\mathrm{NaOH})$

Waschpuffer I: $\quad 40 \mathrm{~mm}$ HEPES, $20 \mathrm{~mm}$ Imidazol, $150 \mathrm{~mm} \mathrm{NaCl}, 1 \mathrm{~mm}$ $\mathrm{MgCl}_{2}, 10 \mathrm{~mm}$ Mercaptoethanol, $\mathrm{pH}$ 7,4 (NaOH)

Waschpuffer II: $40 \mathrm{~mm}$ HEPES, 35 mm Imidazol, $150 \mathrm{~mm} \mathrm{NaCl}, 1 \mathrm{~mm}$ $\mathrm{MgCl}_{2}, 10 \mathrm{~mm}$ Mercaptoethanol, $\mathrm{pH} 7,4(\mathrm{NaOH})$

Elutionspuffer: 250 mM Imidazol, $\mathrm{pH} 7,4(\mathrm{HCl})$

\subsubsection{SDS-Polyacrylamid-Gelelektrophorese (SDS-PAGE)}

Die SDS-PAGE ist ein Verfahren zur Trennung von Proteingemischen nach ihrer Größe (61). Sie wurde zur Analyse der Elutionsfraktionen sowie der Waschschritte durchgeführt. Hierbei werden Polyacrylamid-Gele eingesetzt, die durch radikalische Polymerisation von Acrylamid und Quervernetzung durch $N, N$ '-Methylenbisacrylamid entstehen. Als Initiator wird APS (Ammoniumperoxidsulfat) eingesetzt, TEMED ( $, N, N^{\prime}, N^{\prime}$ Tetramethylethylendiamin) dient als Katalysator der Reaktion.

Die Proteinfaltung wird durch Zusatz des anionischen Detergenz SDS (Natriumdodecylsulfat) zerstört, wobei sich diese langkettigen aliphatischen Moleküle an die gestreckte Aminosäurekette anheften, deren Eigenladung maskieren und gleichzeitig eine der Länge der Aminosäurekette in etwa 
proportionale negative Gesamtladung erzeugen. Das Reduktionsmittel DTT (Dithiothreitol) wird hinzugegeben, um eventuell vorhandene Disulfidbrücken zu reduzieren. Zusätzlich werden die Proben für fünf Minuten auf ca. $95^{\circ} \mathrm{C}$ erhitzt, um den Denaturierungsprozess zu unterstützen.

Die Proben werden im elektrischen Feld zunächst in einem großporigen Sammelgel aufkonzentriert, damit anschließend in einem feinporigeren Trenngel die Auftrennung der Probe nach den darin enthaltenen Proteinmassen aufgrund unterschiedlich großer Wanderungsgeschwindigkeiten durch das Gel erfolgen kann. Zur Identifizierung dieser Massen läuft ein sogenannter Marker, ein Gemisch von Proteinen bekannter Molmassen, mit.

Für die vorliegende Arbeit wurden 17\%ige Polyacrylamidgele $(10 \times 10 \mathrm{~cm})$ nach einer Vorschrift von Laemmli (61) verwendet. Die Elektrophorese wurde bei einer Stromstärke von $15 \mathrm{~mA}$ durchgeführt. Nach dem Ende des Trennvorgangs wurden die Gele 15 min in Färbelösung inkubiert und anschließend über Nacht in Entfärbelösung geschwenkt. Sobald sich die Proteinbanden farblich deutlich gegenüber dem Hintergrund abhoben, konnte das Gel mit Trocknungslösung versetzt werden und zwischen zwei Cellophanfolien im Spannrahmen getrocknet werden.

Sammelgel (5\%): $\quad 1,4 \mathrm{~mL} \mathrm{H} \mathrm{H}_{2} \mathrm{O}, 0,25 \mathrm{~mL} 1 \mathrm{M}$ Tris/ $\mathrm{HCl}, 0,33 \mathrm{~mL}$ AcrylamidBisacrylamid (29:1, 30\%), $20 \mu \mathrm{L}$ 10\% (w/v) APS, $2 \mu \mathrm{L}$ TEMED, pH 6,8

Trenngel (12,5\%): $\quad 1,6 \mathrm{~mL} \mathrm{H} \mathrm{H}_{2} \mathrm{O}, 1,3 \mathrm{~mL} 1.5 \mathrm{M} \mathrm{Tris} / \mathrm{HCl}, 2,1 \mathrm{~mL}$ AcrylamidBisacrylamid (29:1, 30\%), $50 \mu \mathrm{L} 10 \%(w / v)$ SDS, 50 $\mu \mathrm{L} 10 \%(w / v)$ APS, $2 \mu \mathrm{L}$ TEMED, pH 8,8

Probenpuffer (6×): $\quad 175 \mathrm{mM}$ Tris/HCl, 5\% (w/v) SDS, 15\% (v/v) Glycerin, 0,06 g/L Bromphenolblau, 0,3 M DTT, pH 6.8

Laufpuffer: $25 \mathrm{~mm}$ Tris, $192 \mathrm{~mm}$ Glycin, 0,1\% (w/v) SDS

Färbelösung: 0,5\% (w/v) Coomassie Brilliant Blue R-250, 45\% (v/v) Methanol, 18,5\% (v/v) Eisessig

Entfärbelösung: $\quad 5 \%(v / v)$ Methanol, $7,5 \%(v / v)$ Eisessig

Trocknungslösung: $\quad 20 \%(v / v)$ Ethanol, $10 \%(v / v)$ Glycerin 


\subsubsection{Umpuffern von Proteinlösungen}

Die Proteinlösungen mussten nach der affinitätschromatographischen Reinigung aus dem Elutionspuffer in die jeweiligen Messpuffer überführt werden. Dazu wurden Dialyseschläuche mit einer Massenausschlussgrenze von 5000 Da verwendet. Diese Schläuche wurden vor ihrer Verwendung in 5-10 cm lange Stücke geschnitten und in Reinstwasser eingeweicht. Zur anschließenden Reinigung wurden die Schläuche für $30 \mathrm{~min}$ in einer $10 \mathrm{mM} \mathrm{NaHCO}$-Lösung sowie weitere zweimal für $30 \mathrm{~min}$ in einer $10 \mathrm{mM}$ EGTA-Lösung auf $80{ }^{\circ} \mathrm{C}$ erhitzt. Die abschließende Spülung erfolgte für $30 \mathrm{~min}$ bei $80^{\circ} \mathrm{C}$ in Reinstwasser. Zur Aufbewahrung wurden die Schlauchstücke abgekühlt und in einer $10 \mathrm{mM} \mathrm{NaN}_{3}$ Lösung bei $4{ }^{\circ} \mathrm{C}$ aufbewahrt. Eine Dialyse wurde stets über Nacht bei $4{ }^{\circ} \mathrm{C}$ gegen ein mindestens 300fach größeres Volumen durchgeführt. Am nächsten Morgen wurde die Dialyseflüssigkeit einmal ausgetauscht und weitere 2-3 Stunden dialysiert.

\subsubsection{Proteinkonzentrationsbestimmung}

Die Konzentration der Proteinlösungen wurde über UV/Vis-Spektroskopie bestimmt. Dabei wird die Absorption der aromatischen Aminosäuren bei einer Wellenlänge von bei $\lambda=280 \mathrm{~nm}$ gemessen. Nach dem Lambert-Beer'schen Gesetz gilt:

$$
E=\varepsilon \cdot d \cdot c
$$

Hierbei ist $E$ die gemessene Extinktion bei $\lambda=280 \mathrm{~nm}, d$ die optische Weglänge, $c$ die gesuchte Konzentration und $\varepsilon$ der Extinktionskoeffizient des Proteins, über dessen Größe vor allem der Anteil der aromatischen Aminosäuren Tyrosin und Tryptophan entscheidet. Zur Berechnung der Konzentrationen von Ezrin wt und Mutanten wurde ein Extinktionskoeffizient von $66900 \mathrm{~cm}^{-1} \mathrm{M}^{-1}$ ermittelt, für $\mathrm{N}$ ERMAD ein Extinktionskoeffizient von $52400 \mathrm{~cm}^{-1} \mathrm{M}^{-1}(62)$. 


\subsubsection{Fluoreszenzmarkierung der Proteine}

Zur fluoreszenzmikroskopischen Detektion von Ezrin wurde das Protein mit einem Maleimid-gekoppelten Fluorophor gelabelt. Dabei wird die Markierungssubstanz über die Cystein-Seitenketten des Proteins, Cys117 und/oder Cys284, unter Ausbildung eines Thioethers kovalent mit dem Protein verknüpft. Der gewählte Farbstoff AlexaFluor633-Maleimid (Invitrogen, Eugene, USA) besitzt ein Absorptionsmaximum bei $\lambda=632 \mathrm{~nm}$, das Emissionsmaximum liegt bei $\lambda=647 \mathrm{~nm}$.

Ezrin wurde in einer Konzentration von ca. $20 \mu \mathrm{M}$ in E1-Puffer vorgelegt und mit einem zehnfachen Überschuss Dithiothreitol (DTT) versetzt, um mögliche Disulfidbindungen zu reduzieren. Die Lösung wurde anschließend über Nacht gegen DTT-freien, entgasten Puffer dialysiert. Das Reagenz AlexaFluor633Maleimid wurde in Dimethylsulfoxid (DMSO) gelöst und in einem Verhältnis von 20:1 (AlexaFluor633-Maleimid:Ezrin) tropfenweise in die gerührte Proteinlösung gegeben. Das Reaktionsgemisch wurde anschließend über Nacht gerührt. Durch Zugabe von Mercaptoethanol (2 $\mathrm{mm}$ ) wurde die Reaktion gequencht, und überschüssiger Farbstoff wurde anschließend über Größenausschlusschromatographie entfernt (Sephadex-NAP 25, GE Life Sciences). Alle Reaktionsschritte wurden bei $4{ }^{\circ} \mathrm{C}$ durchgeführt.

Die Bestimmung der Labelingrate erfolgte über UV/Vis-Spektroskopie. Hierbei wurde für den Fluorophor ein Extinktionskoeffizient $\varepsilon_{632}=91300 \mathrm{~cm}^{-1} \mathrm{M}^{-1}$ verwendet (63). Die Proteinkonzentration wurde über die Absorption bei $\lambda=280$ $\mathrm{nm}$ bestimmt, wobei eine Korrektur aufgrund der Anwesenheit des Farbstoffes eingeführt werden musste, welcher selbst eine gewisse Absorption in diesem Spektralbereich beisteuert. Nach Herstellerangaben (Invitrogen, Produktinformation für Alexa Fluor 633 Protein labeling kit) berechnet sich die Proteinkonzentration nach folgender Formel:

$$
C=\frac{\left[A_{280}-\left(A_{632} \times 0,55\right)\right]}{66900},
$$

wobei $66900 \mathrm{~cm}^{-1} \mathrm{M}^{-1}$ den Extinktionskoeffizienten $\varepsilon_{280}$ des Proteins bezeichnet. E1-Puffer: $20 \mathrm{~mm}$ Tris, $50 \mathrm{~mm} \mathrm{KCl,} \mathrm{0,1} \mathrm{mM} \mathrm{EDTA,} \mathrm{pH} \mathrm{7,4.}$ 


\subsubsection{F-Aktin-Polymerisation}

Für die Studien zur Wechselwirkung von F-Aktin mit Ezrin wurde aus menschlichen Thrombozyten gewonnenes, zu >95\% reines Aktin (Cytoskeleton, Denver, USA) verwendet. Hierbei lagen die beiden Isoformen $\beta$ - und $\gamma$-Aktin in einem Verhältnis von 85:15 vor. Das lyophilisierte Protein wurde zunächst in GPuffer zu einer Konzentration von $10 \mathrm{mg} / \mathrm{mL}$ gelöst, aliquotiert $(100 \mu \mathrm{L})$ und mit Hilfe von flüssigem Stickstoff eingefroren und bei $-80^{\circ} \mathrm{C}$ gelagert. Vor Benutzung wurde die benötigte Menge G-Aktin bei $4{ }^{\circ} \mathrm{C}$ mit G-Puffer auf $0,4 \mathrm{mg} / \mathrm{mL}$ verdünnt, möglichst vollständig gelöst und eine Stunde auf Eis gestellt, um gebildete Aggregate aufzulösen. Dabei wurde Dithiothreitol (DTT) in einer Konzentration von $0,2 \mathrm{~mm}$ zugesetzt, um eine Oxidation der Proteine zu vermeiden. Die Lösung wurde anschließend bei $17000 \times \mathrm{g}$ und $4{ }^{\circ} \mathrm{C}$ für $15 \mathrm{~min}$ zentrifugiert. Der Überstand wurde in ein neues Gefäß überführt und mit einer Salzlösung, deren Menge einem Zehntel des Gesamtvolumes entsprach, versetzt, um die Polymerisation zu F-Aktin zu initiieren. Zur Stabilisierung der Filamente und zur Unterdrückung der Depolymerisation wurde Phalloidin in äquimolarer Menge zur Aktinlösung hinzugegeben. Darüber hinaus wurde für die fluoreszenzmikroskopischen Untersuchungen 0,01 mol\% AlexaFluor488Phalloidin zugesetzt. Nachdem diese Komponenten gemischt waren, wurde die Lösung direkt verwendet, d.h. die Inkubation von ezrinbelegten Flächen vorgenommen, so dass sich die Polymerisation in situ vollzog.

G-Puffer: $\quad 5 \mathrm{~mm}$ Tris/ $\mathrm{HCl}, 0,2 \mathrm{~mm} \mathrm{CaCl} 2,0,2 \mathrm{~mm}$ ATP, $5 \%(w / v)$ Sucrose, $1 \%$ $(w / v)$ Dextran

Salzlösung: $500 \mathrm{~mm} \mathrm{KCl,} 20 \mathrm{~mm} \mathrm{MgCl} 2,20 \mathrm{~mm}$ ATP

\subsubsection{Cosedimentation}

Zur Untersuchung der Bindung von Ezrin wt und Mutanten an F-Aktin in Lösung wurden Cosedimentationsstudien durchgeführt. Hierzu wurden zunächst die Ezrinlösungen in F-Puffer, aber ohne ATP durch Ultrazentrifugation (30 min, $\left.100000 \times \mathrm{g}, 4{ }^{\circ} \mathrm{C}\right)$ geklärt und der Überstand vom Pellet getrennt. Die 
Proteinkonzentration wurde per UV-Absorptionsmessung bestimmt und anschließend ATP (0,5 mM) hinzugegeben. Das G-Aktin wurde gemäß der Beschreibung in Kapitel 3.1.7 behandelt, und die Polymerisation der Mischung zu F-Aktin wurde in den Zentrifugationsgefäßen vollzogen. Nach $30 \mathrm{~min}$ Polymerisationszeit wurde Ezrin in der gewünschten Konzentration (0,5 - 1,5 mM) hinzugegeben, die Mischung für weitere 30 min inkubiert und anschließend für 30 min zentrifugiert $\left(100000 \times \mathrm{g}, 4^{\circ} \mathrm{C}\right)$. Der Überstand wurde bis auf $20 \mu \mathrm{L}$ abgezogen, das Pellet mit F-Puffer gewaschen und anschließend wieder zentrifugiert. Anschließend wurde der gesamte flüssige Überstand abgezogen, das Pellet mit Hilfe von F-Puffer und Probenpuffer aufgeschlämmt, und äquivalente Mengen von Überstand und Pellet wurden per SDS-PAGE analysiert.

F-Puffer: $20 \mathrm{~mm}$ Tris/HCl, $50 \mathrm{~mm} \mathrm{KCl,} \mathrm{0,2} \mathrm{mM} \mathrm{MgCl} 2, \mathrm{pH}$ 7,4.

\subsection{Lipidchemische Methoden}

\subsubsection{Herstellung und Reinigung goldbedampfter Quarzscheiben}

Zur Durchführung von Impedanzspektroskopie- und Quarzmikrowaagemessungen wurden Quarzscheiben verwendet, die beidseitig mit einer Chromschicht als Haftvermittler sowie mit Gold, welches als Elektrode diente, bedampft waren. Hierzu wurden hochpolierte $5 \mathrm{MHz}$ AT-cut Quarzscheiben mit einem Durchmesser von $14 \mathrm{~mm}$ und einer Dicke von 0,33 mm verwendet (Abbildung 3.1). Um eine hochreine Oberfläche zu erzeugen, wurden die Quarze vor der Bedampfung in einer wässrigen Detergenzlösung (5\% ( $v / v)$ Mucasol) für $15 \mathrm{~min}$ bei $70^{\circ} \mathrm{C}$ im Ultraschallbad gereinigt, anschließend mit Reinstwasser (MilliQ-Qualität) gespült und erneut für $15 \mathrm{~min}$ bei $70^{\circ} \mathrm{C}$ in Reinstwasser beschallt. Die Quarze wurden dann einzeln mit Reinstwasser gespült und im Stickstoffstrom getrocknet. Die sauberen Quarzscheiben wurden anschließend in einer Aufdampfanlage vom Typ BAE 250 der Firma Balzers bedampft. Hierzu wurden 16 Quarzscheiben in eine Kupferschablone gelegt, mit zwei mit den Aufdampfmetallen bestückten Wolframschiffchen in die Apparatur eingespannt und unter Hochvakuum $\left(10^{-9}\right.$ bar) durch thermische Verdampfung erst mit einer $10 \mathrm{~nm}$-Chromschicht und dann mit einer $100 \mathrm{~nm}$-Goldschicht versehen. Der 
Schichtdickenzuwachs während der einzelnen Bedampfungsschritte wurde über einen Referenzschwingquarz verfolgt. Die Rückseite der Quarze wurde in gleicher Weise behandelt, wobei das Bedampfungsmuster hierbei um $180^{\circ}$ gedreht aufgebracht wurde (siehe Abbildung 3.1). Die Fläche der resultierenden Goldelektrode betrug $0,255 \mathrm{~cm}^{2}$ auf jeder Seite.

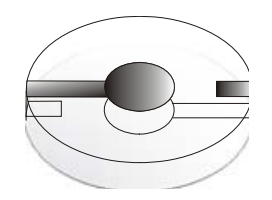

Abbildung 3.1: Schematische Darstellung eines Schwingquarzes mit aufgedampften Goldelektroden.

Zur Wiederverwendung der goldbedampften Quarzscheiben musste die chemisorbierte Oktanthiolschicht oxidativ entfernt werden. Die Quarzscheiben wurden hierzu für zwei Minuten in $80^{\circ} \mathrm{C}$ heiße „Piranha“-Lösung (75\% ( $\left./ \mathrm{V}\right)$ $\mathrm{H}_{2} \mathrm{SO}_{4}$ konz., $25 \%(\mathrm{v} / \mathrm{v}) \mathrm{H}_{2} \mathrm{O}_{2}(30 \%$ ig) ) getaucht, anschließend mit Reinstwasser einzeln gespült und im Stickstoffstrom getrocknet. Die Quarze konnten so bis zu fünf Mal verwendet werden.

Ab einer gewissen Zahl von Recyclingvorgängen erhöhte sich die Rauigkeit der aufgedampften Goldschicht und der Quarz musste eine neue Bedampfung erhalten. Das vollständige Ablösen der Goldschicht erfolgte durch Eintauchen in eine 0,25 $\mathrm{M} \mathrm{I}_{2} /$ 0,5 M KI-Lösung. Dabei geht Gold unter Bildung des stabilen Gold(I)-Komplexes $\left[\mathrm{Aul}_{2}\right]^{-}$in Lösung. Die Chromschicht wurde in einer basischen Kaliumhexacyanoferrat(III)-Lösung $\left(5 \mathrm{M} \mathrm{KOH}, \quad 1 \mathrm{M} \mathrm{K}_{3}\left[\mathrm{Fe}(\mathrm{CN})_{6}\right]\right)$ zu Chromit $\left[\mathrm{Cr}(\mathrm{OH})_{6}\right]^{3-}$ oxidiert. Nach gründlicher Reinigung (siehe oben) konnten die Quarze neu bedampft werden.

\subsubsection{Herstellung der Lipidfilme}

Zur Herstellung der Lipidfilme wurden zunächst Stammlösungen der benötigten Lipide in Chloroform hergestellt. Im Fall von $\mathrm{PIP}_{2}$ wurde ein Lösungsmittelgemisch aus Chloroform, Methanol und $\mathrm{H}_{2} \mathrm{O}$ (8:2:1) gewählt, um das Lipid vollständig in Lösung zu bringen. Um eine Gesamtlipidmasse von 0,2 mg pro Lipidfilm zu erhalten, wurden anschließend entsprechende Volumina 
der Stammlösungen in den gewünschten molaren Verhältnissen in Reagenzgläser pipettiert. Das Lösungsmittel wurde bei $38^{\circ} \mathrm{C}$ unter einem Stickstoffstrom verblasen, wodurch sich ein dünner Lipidfilm auf dem Boden des Reagenzglases bildete. Zur vollständigen Entfernung von Lösungsmittelresten wurden die Filme für drei Stunden bei $40^{\circ} \mathrm{C}$ im Vakuum getrocknet, die Reagenzgläser mit Parafilm verschlossen und bis zur ihrer Verwendung bei $4{ }^{\circ} \mathrm{C}$ gelagert.

Zur Herstellung von unilamellaren Vesikeln (large unilamellar vesicles, LUV) wurde der Lipidfilm für 20 min in Puffer suspendiert, quellen gelassen und dreimal in fünfminütigen Abständen auf einem Vortex-Mixer für $30 \mathrm{~s}$ aufgeschüttelt. Dabei kam es zur Ablösung des Lipidfilms von der Reagenzglaswand, und multilamellare Vesikel (MLV) wurden gebildet. Die Überführung in unilamellare Vesikel erfolgte über Extrusion durch eine Polycarbonatmembran mit mittlerer Porengröße von $100 \mathrm{~nm}$ in einem Miniextruder (Liposofast, Avestin, Kanada). Dazu wurde die Suspension 31-mal durch die Membran gedrückt.

\subsubsection{Präparation von festkörperunterstützten Lipiddoppelschichten auf Schwingquarzen}

Zunächst wurde die obere Goldelektrode des Schwingquarzes mit dem auf der Unterseite des Quarzes befindlichen Kontaktelektrodenstück über Silberleitlack leitend verbunden, so dass beide Goldelektroden von der Unterseite des Quarzes aus kontaktiert werden konnten. Der Quarz wurde anschließend fünf Minuten im Argonplasma (Harrick, New York, USA) gereinigt, dann sofort in die Messzelle eingesetzt und mit $200 \mu \mathrm{L}$ einer 60 mM ethanolischen Oktanthiollösung für mindestens zwei Stunden bei Raumtemperatur oder über Nacht bei $4{ }^{\circ} \mathrm{C}$ inkubiert. Die überstehende ethanolische Lösung wurde anschließend fast komplett abgezogen und anschließend fünfmal mit je $1 \mathrm{~mL}$ Ethanol p.a. und fünfmal mit je $1 \mathrm{~mL}$ Puffer gespült. Anschließend wurde die vollständige Ausbildung der Oktanthiolmonoschicht per Impedanzspektroskopie überprüft. Spezifische Kapazitäten im Bereich von 1,9 bis $2,3 \mu \mathrm{F} / \mathrm{cm}^{2}$ zeigten eine ausreichende Bedeckung der Oberfläche an. Die Präparation der Lipiddoppelschicht erfolgte durch Spreiten von unilamellaren Vesikel auf der 
hydrophoben Oberfläche der Alkanketten des chemisorbierten Thiols. Die Monoschicht wurde für ca. eine Stunde mit einer Vesikelsuspension einer Konzentration von $\mathrm{c}=0,5 \mathrm{mg} / \mathrm{mL}$ überschichtet. Dann wurde diese durch zehnmaliges Spülen mit reinem Puffer ausgetauscht, um überschüssige Vesikel auf der gebildeten Membran zu entfernen. Es wurde erneut ein Impedanzspektrum aufgenommen, um die Qualität der gebildeten Lipiddoppelschicht zu überprüfen. Die Membran konnte für die mikrogravimetrische Untersuchung verwendet werden, wenn die Kapazität der Doppelschicht zwischen $1,0-1,3 \mu \mathrm{F} / \mathrm{cm}^{2}$ lag.

E1-Puffer: $20 \mathrm{~mm}$ Tris, $50 \mathrm{~mm} \mathrm{KCl,} \mathrm{0,1} \mathrm{mm} \mathrm{EDTA,} \mathrm{pH} \mathrm{7,4.}$

\subsubsection{Präparation von festkörperunterstützten Lipiddoppelschichten auf Siliziumdioxid}

Zur Präparation von artifiziellen Membransystemen auf Siliziumdioxid wurden zunächst polierte Siliziumträger, deren Oberfläche eine $100 \mathrm{~nm}$ dicke Oxidschicht aufwies, mit Hilfe eines faseroptischen Ritzgriffels in ca. $(2,0 \times 0,8) \mathrm{cm}^{2}$ große Rechtecke geschnitten, mit Isopropanol und Reinstwasser gründlich abgespült und in einem Teflonhalter platziert. Anschließend wurden die Siliziumträger mit einer $70{ }^{\circ} \mathrm{C}$ heißen ammoniakalischen Wasserstoffperoxidlösung $\left(\mathrm{NH}_{3}\right.$ (25\%): $\mathrm{H}_{2} \mathrm{O}_{2}(30 \%): \mathrm{H}_{2} \mathrm{O}$ 1:1:5 (v/v)) inkubiert, um eine hydrophile Hydroxidschicht auf der Oberfläche zu erzeugen. Die Siliziumplättchen wurden mit Reinstwasser gründlich gespült, unter einem Stickstoffstrom getrocknet und sofort in einem Probenhalter mit einer Vesikellösung $(c=0,5 \mathrm{mg} / \mathrm{mL})$ überschichtet. Nach einer Inkubationszeit von 1-2 Stunden wurde die Probe intensiv mit reinem Puffer gespült, um überschüssige Vesikel zu entfernen. Die Qualität der festkörperunterstützten Membran wurde mittels Fluoreszenzmikroskopie untersucht. 


\subsubsection{Präparation von festkörperunterstützten Lipidmonoschichten auf silanisiertem Glas}

Zur Präparation einer festkörperunterstützten Monoschicht auf silanisiertem Glas wurde zunächst ein Mikroskopie-Deckglas (Plano, Wetzlar) zunächst einmal in fünfprozentiger Hellmanex-Lösung und zweimal in Reinstwasser im Ultraschallbad für jeweils 15 Minuten gereinigt, anschließend im Stickstoffstrom getrocknet sowie unter Vakuum bei $90^{\circ} \mathrm{C}$ für weitere zwei Stunden getrocknet. Nach dem Abkühlen wurde das Glas in einem Probenhalter platziert und die Oberfläche möglichst gleichmäßig mit ca. $20 \mu \mathrm{L}$ Hexamethyldisilazan überschichtet. Die Probe wurde in einer Petrischale im Abzug zum Trocknen über Nacht aufbewahrt. Die hydrophobe Oberfläche der Probe wurde am nächsten Tag mit einer Vesikellösung ( $c=0,5 \mathrm{mg} / \mathrm{mL}$ ) überschichtet, für eine Stunde inkubiert und anschließend gründlich mit Puffer gespült. Die Qualität der festkörperunterstützten Lipidmonoschicht wurde mittels Fluoreszenz-mikroskopie untersucht.

\subsection{Biophysikalische Methoden}

\subsubsection{CD-Spektroskopie}

Das Phänomen des Circulardichroismus (griechisch „dichroos“ für „Zweifarbig“) beruht auf der unterschiedlichen Wechselwirkung von rechts- und linkszirkular polarisiertem Licht mit optisch aktiver Materie. Die daraus ableitbare spektroskopische Methode wird als CD-Spektroskopie bezeichnet. Mit Hilfe dieser Methode wurden im Rahmen dieser Arbeit Informationen über die Sekundärstrukturanteile der verwendeten Proteine Ezrin wt, T567A, T567D und N-ERMAD ermittelt.

Um zirkular polarisiertes Licht zu erzeugen, nutzt man optisch anisotrope Materialien, die unterschiedliche Phasengeschwindigkeiten für Licht in Abhängigkeit seiner Polarisationsrichtung zeigen. So wird ein Lichtstrahl beim Auftreffen auf ein doppeltbrechendes Material in einen ordentlichen und einen außerordentlichen Strahl zerlegt, deren elektrische Feldvektoren senkrecht zueinander stehen. Eine Phasendifferenz ergibt sich aus den unterschiedlichen 
Ausbreitungsgeschwindigkeiten der beiden linear polarisierten Wellen im optisch anisotropen Material, welches typischerweise aus einem Kristall wie Kalzit besteht. Die Überlagerung der in dieser Weise phasenverschobenen Wellen resultiert in einer je nach Drehsinn links- oder rechtszirkular polarisierten Welle, wie sie in Abbildung 3.2 gezeigt ist.

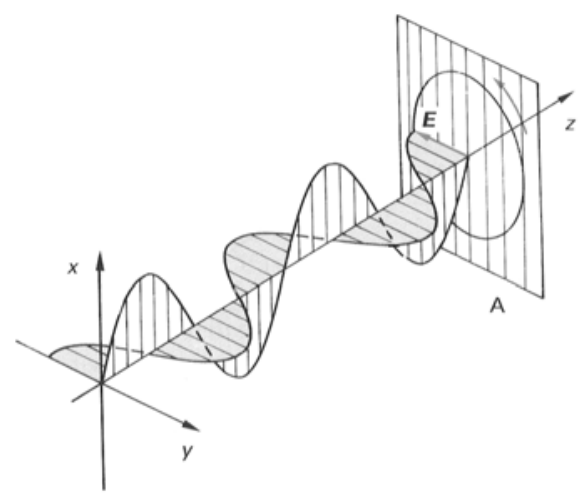

Abbildung 3.2: Graphische Darstellung von zirkular polarisiertem Licht, das durch Phasenverschiebung zweier linear polarisierter Wellen um $\pi / 2$ entsteht.

Wenn nun eine Proteinlösung mit sowohl rechts- als auch linkszirkular polarisiertem Licht bestrahlt wird, treten die elektromagnetischen Wellen mit der Proteinstruktur in Wechselwirkung. Dabei sind unter Verwendung von fernem UV-Licht vor allem elektronische Übergänge innerhalb der Amidgruppen $\left(n \rightarrow \pi^{*}\right.$ sowie $\pi \rightarrow \pi^{*}$ ) für eine Absorption verantwortlich. Da die energetische Lage dieser Übergänge sehr stark durch die räumliche Struktur des Polypeptid-Rückgrats beeinflusst werden, ergibt sich hier eine besondere Sensitivität für die verschiedenen Sekundärstrukturelemente eines Proteins (64). Besonders sorgfältig muss die Wahl des Puffers getroffen werden, da bestimmte lonen und Puffersubstanzen eine hohe Absorption im Messbereich aufweisen (65). Für die in dieser Arbeit gezeigten Messungen wurden die Proteine per Dialyse in einen Phosphatpuffer überführt.

Die eigentliche Messgröße in der CD-Spektroskopie ist die Differenz der Extinktionskoeffizienten für die verschieden zirkular polarisierten Wellen, wie Gleichung [3.3] zeigt (66): 
[3.3]

$$
\Delta \varepsilon=\varepsilon_{\mathrm{L}}-\varepsilon_{\mathrm{R}}
$$

Aus historischen Gründen wird in der Praxis die Elliptizität $\theta_{(\lambda)}$ angegeben:

$$
\theta_{(\lambda)}=\text { const } \cdot\left(\varepsilon_{\mathrm{L}}^{\prime}-\varepsilon_{\mathrm{R}}^{\prime}\right) \cdot c \cdot d(\mathrm{Grad})
$$

hierbei ist $d$ die Schichtdicke in $\mathrm{cm}, c$ die Konzentration in $\mathrm{gcm}^{-3}$ und $\varepsilon^{\prime}$ der Extinktionskoeffizient in $\mathrm{cm}^{2} \mathrm{~g}^{-1}$. Der Vorfaktor beträgt nach folgender Gleichung etwa 33:

$$
\text { const }=\ln 10 \cdot 180 / 2 \pi \approx 33 \text {. }
$$

Typische CD-Spektren verschiedener einzelner Sekundärstrukturelemente sind in Abbildung 3.3 wiedergegeben.

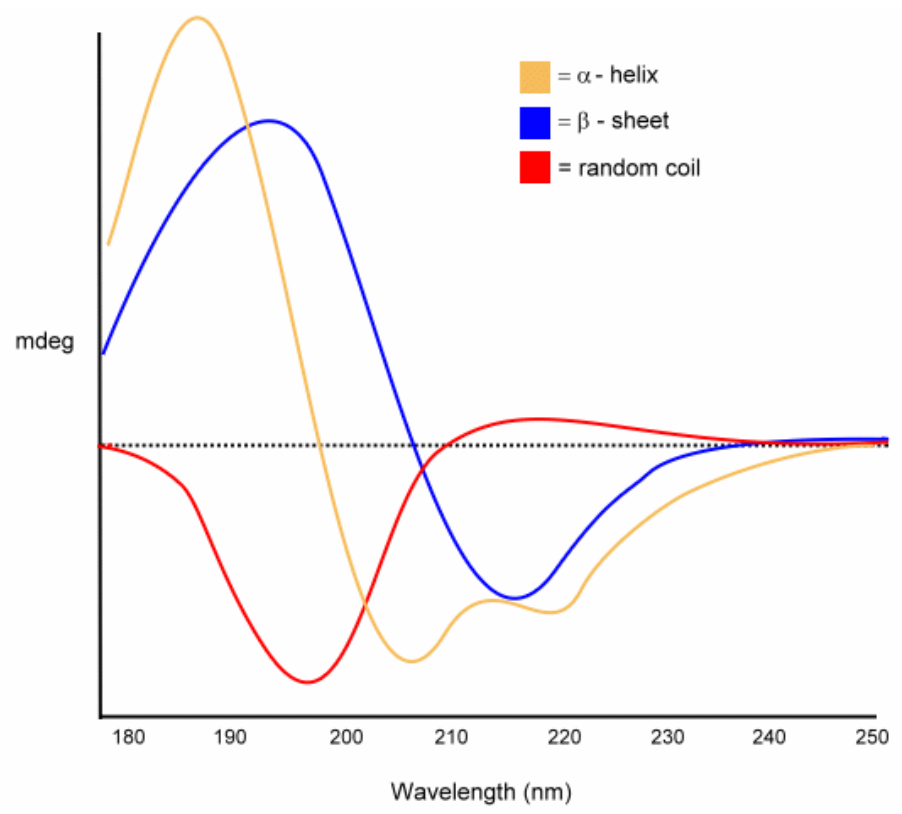

Abbildung 3.3: Berechnete CD-Spektren einzelner möglicher Sekundärstrukturelemente eines Proteins (67).

Um aus einem aufgenommenen CD-Spektrum eines Proteins, das verschiedene Strukturelemente enthält, Informationen über die prozentualen Anteile dieser an der Gesamtstruktur zu extrahieren, müssen die Daten dekonvuliert werden. Im Rahmen der vorliegenden Arbeit wurde hierzu das online verfügbare Programm DichroWeb genutzt $(64,68)$. Der verwendete Algorithmus war CDSSTR mit 
Referenzdatensatz 7, welcher die CD-Spektren von 49 verschiedenen löslichen Proteinen mit bekannter Röntgenstruktur nutzt.

Phosphatpuffer: $20 \mathrm{~mm} \mathrm{KH}_{2} \mathrm{PO}_{4} / \mathrm{K}_{2} \mathrm{HPO}_{4}, 0,1 \mathrm{~mm}$ EDTA, pH 8.

\subsubsection{Impedanzspektroskopie}

Die Impedanzspektroskopie (auch dielektrische Spektroskopie) ist ein elektrochemisches Messverfahren, das zur Charakterisierung der dielektrischen Eigenschaften eines Mediums in Abhängigkeit der Frequenz eines von außen angelegten elektrischen Feldes eingesetzt wird (69). Im Rahmen dieser Arbeit wurde die Messmethode zur Kontrolle der Qualität von festkörperunterstützten Doppelschichten auf goldbedampften Schwingquarzen genutzt.

In der Impedanzspektroskopie wird an ein zu untersuchendes System eine sinusförmige Wechselspannung kleiner Amplitude angelegt, deren Frequenz in einem weiten Bereich (hier: $10^{-1}-10^{6} \mathrm{~Hz}$ ) variiert wird. Das resultierende Stromsignal wird aufgezeichnet und die frequenzabhängige Impedanz (Wechselstromwiderstand) des Systems wird ermittelt. Analog zum Ohm'schen Gesetz lässt sich die Impedanz Z durch Gleichung [3.6] beschreiben:

$$
Z(\omega)=\frac{U(\omega, t)}{I(\omega, t)}=\frac{U_{0} \cdot \exp (i \omega t)}{I_{0}(\omega) \cdot \exp (i(\omega t-\Theta(\omega t)))}=|Z|(\omega) \cdot \exp (i \Theta(\omega))
$$

mit $U$ als Stromspannung und $I$ als Stromstärke. Demnach ist die komplexe Impedanz $Z$ bei einer gegebenen Frequenz $\omega$ durch ihren Betrag $|Z|$ und die Phasenverschiebung $\Theta$ charakterisiert. Die komplexe Impedanz lässt sich nach Gleichung [3.7] in ihren Real- und Imaginärteil aufteilen:

$$
Z(\omega)=Z^{r e}(\omega)+i Z^{i m}(\omega)
$$

wobei $Z^{\text {re }}$ auch als Wirkwiderstand und $Z^{\text {im }}$ als Blindwiderstand bezeichnet werden. 
Der Betrag der Impedanz $|Z|$ wird durch geometrische Addition von Real- und Imaginärteil der Impedanz erhalten (Gleichung [3.8]):

$$
|Z|=\sqrt{\left(Z^{r e}\right)^{2}+\left(Z^{i m}\right)^{2}} .
$$

Für die Phasenverschiebung $\Theta$ zwischen Spannung und Strom gilt folgende Gleichung:

$$
\Theta=\arctan \left(\frac{Z^{i m}}{Z^{r e}}\right) .
$$

Zur Darstellung der frequenzabhängigen Impedanz bieten sich verschiedene Möglichkeiten an. Eine Auftragung des Betrags der Impedanz $|Z|$ bzw. der Phasenverschiebung $\Theta$ gegen die Frequenz liefert das als Bode-Diagramm bezeichnete Impedanzspektrum (Abbildung 3.6). Diese Darstellungsweise wurde in der vorliegenden Arbeit ausschließlich verwendet. Um die gemessenen Daten intrinsischen elektrischen Eigenschaften des Systems zuzuordnen, wird aus verschiedenen elektrischen Bauteilen ein so genanntes Ersatzschaltbild konstruiert, dessen Impedanzverhalten dieselbe Frequenzabhängigkeit wie das zu untersuchende elektrochemische System zeigt.

Nach der Chemisorption von Oktanthiol an der Goldoberfläche und anschließender Fusionierung unilamellarer Vesikel auf der hydrophoben Grenzfläche erhält man eine festkörperunterstützte Membran (siehe Kapitel 3.2.3). Die Kapazität $C_{m}$ dieser Schicht kann in erster Näherung in Analogie zu einem Plattenkondensator nach Gleichung [3.10] beschrieben werden:

$$
C_{\mathrm{m}}=\frac{\varepsilon_{0} \varepsilon_{\mathrm{r}} A}{d}
$$


wobei $\varepsilon_{0}$ die elektrische Feldkonstante ist und $A$ die Fläche der Membran bezeichnet. Sowohl die Dicke der Membran $d$ als auch die relative Dielektrizitätskonstante $\varepsilon_{\mathrm{r}}$ entscheiden damit über die Gesamtkapazität der Membran bei gegebener Fläche, wobei hier grundsätzlich die Länge der hydrophoben Alkylketten den größten Einfluss ausübt. Der Grund hierfür ist deren niedrige Dielektrizitätskonstante $\left(\varepsilon_{r}=2-4\right.$ verglichen mit $\varepsilon_{r}=10-80$ der polaren Kopfgruppen) und die vergleichsweise große Ausdehnung dieses hydrophoben Bereiches. Natürliche Membranlipide tragen typischerweise jeweils ca. $2 \mathrm{~nm}$ lange hydrophobe Alkylketten, wohingegen die polaren Kopfgruppen lediglich 0,6-1 nm zur Gesamtlänge beitragen (70).

Neben der Membrankapazität $C_{\mathrm{m}}$ müssen der Membranwiderstand $R_{\mathrm{m}}$, der Ohm'sche Widerstand $R_{\Omega}$ der Elektrolytlösung und die Kapazität $C_{\text {el }}$ der elektrochemischen Doppelschicht an der Grenzfläche berücksichtigt werden. Die Anordnung dieser Bauteile zu einem elektrischen Schaltkreis ergibt das in Abbildung 3.6 dargestellte Ersatzschaltbild.

Die Membrankapazität $C_{\mathrm{m}}$ und der Membranwiderstand $R_{\mathrm{m}}$ befinden sich parallel zueinander. Sie sind in Reihe mit $R_{\Omega}$ und $C_{\text {el }}$ angeordnet. Im Fall hoher spezifischer Membranwiderstände von mehr als $1 \mathrm{M} \Omega \cdot \mathrm{cm}^{-2}$ lassen sich die beiden Kapazitäten $C_{\text {el }}$ und $C_{\mathrm{m}}$ im für diese Arbeit genutzten Frequenzfenster von $\left(10^{-1}-10^{6}\right) \mathrm{Hz}$ nicht unterscheiden. Daher vereinfacht sich das in Abbildung Abbildung 3.4 B dargestellte Ersatzschaltbild zu einer Reihenschaltung (siehe Abbildung $3.4 \mathrm{C}$ ) aus einer Kapazität $C_{\text {el+m }}$, die sich aus der Kapazität der elektrochemischen Doppelschicht und der Membran zusammensetzt, und dem Elektrolytwiderstand $R_{\Omega}$ (71). Dieses vereinfachte Schaltbild wurde in der vorliegenden Arbeit zur Auswertung der gemessenen Impedanzspektren herangezogen. 


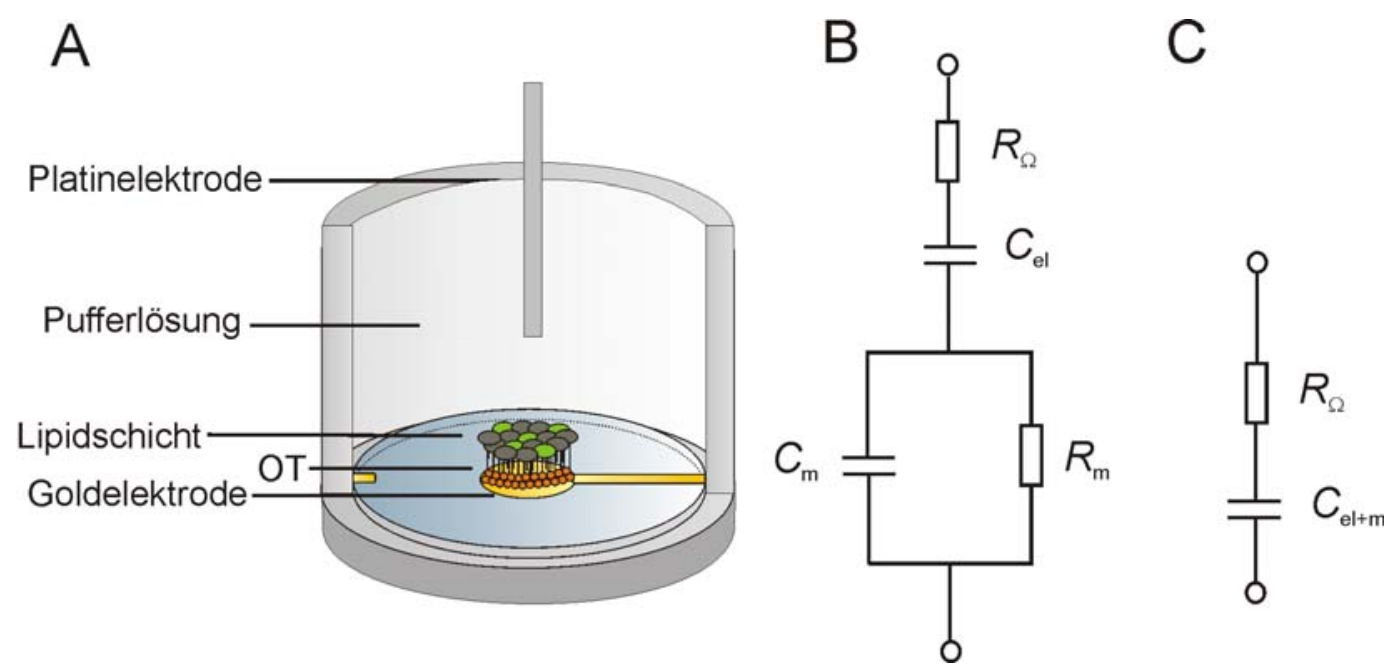

Abbildung 3.4: A Schematische Darstellung des Messaufbaus für die impedanzspektroskopische Untersuchung einer festkörperunterstützten Doppelschicht aus einer Oktanthiol- (OT) und einer Phospholipidschicht, überschichtet mit einer Pufferlösung. Die frequenzabhängige Impedanz wurde mittels eines Impedanzanalysators aufgenommen. Als Arbeitselektrode diente die beschichtete Goldelektrode, auf der die Membran immobilisiert war, die Gegenelektrode bildete eine in die Pufferlösung eingetauchte platinierte Platinelektrode. B Ersatzschaltbild für das elektrochemische System. $C_{\mathrm{m}}$ und $R_{\mathrm{m}}$ beschreiben die Kapazität und den Widerstand der Membran, $R_{\Omega}$ bezeichnet den Elektrolytwiderstand. Die Kapazität der elektrochemischen Doppelschicht an der Grenzfläche wird durch $C_{\text {el }}$ ausgedrückt. C Vereinfachtes Ersatzschaltbild für hohe Membranwiderstande im verwendeten Frequenzbereich von $0,1 \mathrm{~Hz}-1 \mathrm{MHz}$.

Abbildung 3.5 zeigt ein simuliertes Bode-Diagramm mit den Parametern $C_{\mathrm{el}+\mathrm{m}}=0,3 \mu \mathrm{F}$ und $R_{\Omega}=200 \Omega$.

Im Spektrum sind zwei charakteristische Bereiche zu erwähnen. Zunächst wird bei hohen Frequenzen $\left(f=10^{4}-10^{6} \mathrm{~Hz}\right)$ der Gesamtbetrag der Impedanz $|Z|$ durch den frequenzunabhängigen Widerstand $R_{\Omega}$ bestimmt und ist in diesem Frequenzbereich konstant. Die Phasenverschiebung $\varphi$ zwischen Spannung und Strom beträgt $0^{\circ}$. Im Frequenzbereich von $10^{-1}-10^{4} \mathrm{~Hz}$ ist ein frequenzabhängiges Verhalten zu beobachten, welches auf die kapazitiven Eigenschaften der Membran zurückzuführen ist. Die Phasenverschiebung steigt auf $-90^{\circ}$, und auch ein Anstieg der Gesamtimpedanz wird detektiert. 


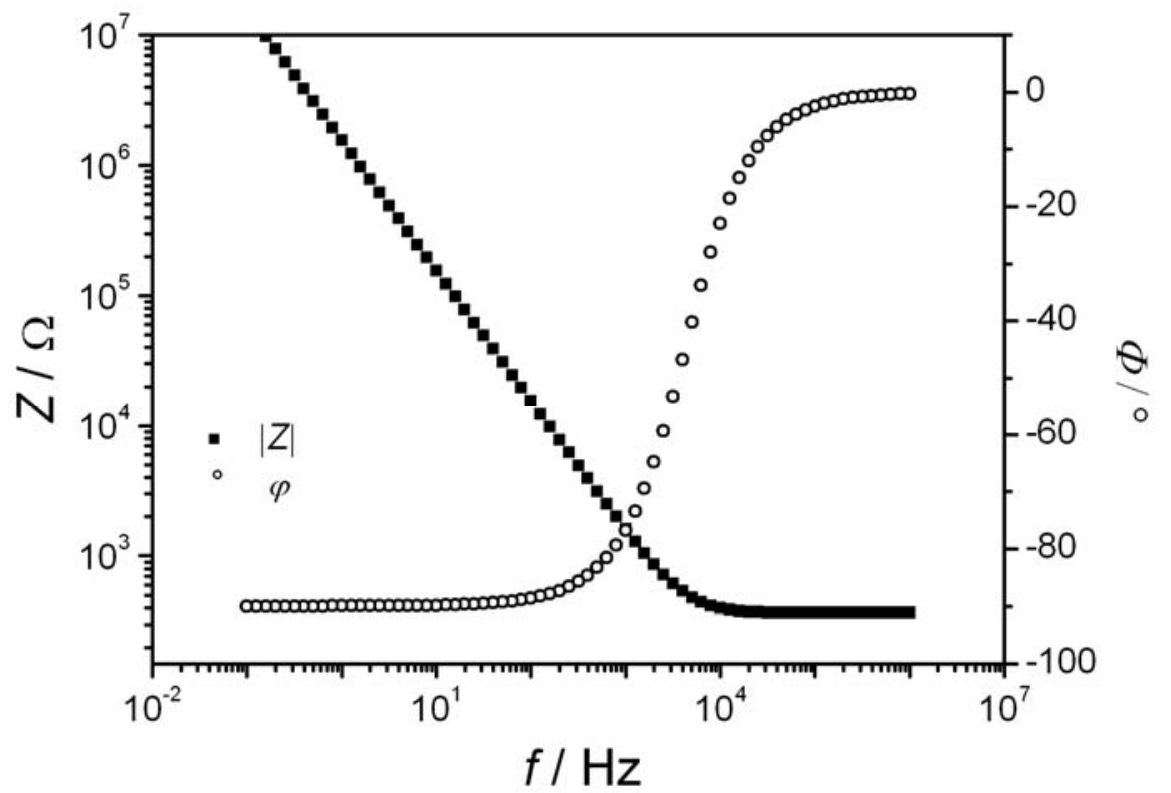

Abbildung 3.5: Simuliertes Bode-Diagramm für das in Abb. 3.4 C dargestellte Ersatzschaltbild mit $C_{\mathrm{el}+\mathrm{m}}=0,3 \mu \mathrm{F}$ und $R_{\Omega}=200 \Omega$.

Um das aufgenommene Impedanzspektrum auswerten zu können, müssen die Parameter des gewählten Ersatzschaltbildes an die experimentellen Daten mittels einer nicht-linearen Kurvenanpassung angepasst werden (nonlinear-leastsquare-fit-Verfahren). Für den Fall des dargestellten Schaltbildes ist die Übertragungsfunktion gegeben durch die Gleichungen [3.11] und [3.12]:

$$
|Z|(\omega)=\sqrt{R_{\Omega}^{2}+\left(\frac{1}{\omega C_{\mathrm{el}+\mathrm{m}}}\right)^{2}},
$$

$$
\varphi(\omega)=\arctan \left(\frac{1}{\omega R_{\Omega} C_{\mathrm{el+m}}}\right)
$$

Die impedanzspektroskopische Untersuchung der präparierten festkörperunterstützen Mono- bzw. Doppelschichten wurde mit einem Impedanzanalysator SI 1260 (Solartron Instruments, Farnborough, Großbritannien) durchgeführt. Dabei diente die Goldelektrode der Quarzscheibe mit einer Fläche von $0,255 \mathrm{~cm}^{2}$ als Arbeitselektrode. Als Gegenelektrode 
fungierte ein in die Pufferlösung eingetauchter platinierter Platindraht. Mit Hilfe eines Computers wurde über das Programm ZPlot 2.8 eine Wechselspannung mit einer Amplitude von $30 \mathrm{mV}$ angelegt, die Frequenz im Bereich von $10^{-1}$ $10^{6} \mathrm{~Hz}$ variiert und die Stromantwort des Systems aufgezeichnet. So konnten der frequenzabhängige Betrag der Impedanz sowie die Phasenverschiebung ermittelt werden. Insgesamt wurden 61 Messpunkte aufgenommen, die in doppelt- bzw. halblogarithmischer Form gegen die Frequenz aufgetragen wurden.

\subsubsection{Quarzmikrowaagetechnik}

Die Quarzmikrowaage (quartz crystal microbalance $=\mathrm{QCM}$ ) ist ein Instrument, das sich zur sondenfreien und zeitaufgelösten Untersuchung von Adsorptionsprozessen an Oberflächen eignet (72). Das zentrale Bauteil einer Quarzmikrowaage ist ein Schwingquarz, der aufgrund seiner piezoelektrischen Eigenschaften durch Anlegen einer Spannung zu einer resonanten Schwingung angeregt werden kann. Aufgrund der hohen Güte und der damit verbundenen Frequenzstabilität solcher Schwingquarze finden diese in zahlreichen elektronischen Geräten seit langem ihre Anwendung (Armbanduhren, Computer) (73). Einzug in das Gebiet der Analytik hielt die Quarzmikrowaage durch die von Sauerbrey 1959 abgeleitete Proportionalität zwischen Frequenzänderung $\Delta f$ und Massenbeladung $\Delta m(74)$ :

$$
\Delta f=-\frac{2 f_{0}^{2}}{\sqrt{\rho_{\mathrm{q}} \mu_{\mathrm{q}}}} \frac{\Delta m}{A} .
$$

Dabei ist $f_{0}$ die Resonanzfrequenz des Quarzes, $\rho_{\mathrm{q}}$ und $\mu_{\mathrm{q}}$ bezeichnen die Dichte und den Schermodul des Quarzes, $A$ ist die Fläche des im Bereich der Goldelektrode schwingenden Plättchens und $\Delta m$ die Masse des auf dem Quarz abgeschiedenen Materials. Der lineare Zusammenhang ist nur gültig unter der Annahme, dass die abgeschiedene Fremdmasse dieselbe Dichte wie das Quarzmaterial hat, Rigidität gegenüber der Quarzschwingung aufweist, homogen verteilt ist und nicht mehr als $0,5 \%$ der Gesamtmasse beträgt. Aufgrund dieser 
Erkenntnis wurde die Quarzmikrowaagetechnik in den 1960er und 1970er Jahren verstärkt für analytische Massebestimmungen im Vakuum und an Luft verwendet (73). Die Etablierung dieser Technik in der Bioanalytik konnte jedoch erst mit einiger Verspätung erfolgen, da geeignete Oszillatorschaltkreise fehlten, welche die durch Flüssigkeiten gedämpfte Quarzschwingung treiben. Auch mussten neue theoretische Modelle zur Quarzoszillation unter Flüssigkeit entwickelt werden. Erste Ansätze zur Lösung dieses Problems stammen von Nomura und Okuhara aus den 1980er Jahren (75). Mittlerweile findet die Quarzmikrowaage ihr Einsatzgebiet auch als Biosensor zur Untersuchung von z.B. AntigenAntikörper-Interaktionen (76), Protein-Lipid-Wechselwirkungen (77), DNAHybridisierungen (78) oder sogar der Detektion der Bindung von ganzen Viren an Grenzflächen (79).

Um die Temperaturabhängigkeit der Resonanzfrequenz des Resonators zu minimieren und um die Überlagerung von verschiedenen Schwingungen im Quarz zu unterbinden, wurden für die Experimente so genannte TSMResonatoren (thickness shear mode = Dickenscherschwingung) verwendet. Diese Quarzscheiben werden, wie in Abbildung 3.6 C zu sehen ist, in einem Winkel von $35^{\circ} 10^{\prime}$ (AT-cut) oder $-49^{\circ}$ (BT-cut) zur optischen Achse $z$ des Kristalls geschnitten und zeigen im Bereich von $0{ }^{\circ} \mathrm{C}$ bis $50{ }^{\circ} \mathrm{C}$ einen Temperaturkoeffizienten von nahezu Null, das bedeutet, dass in diesem Temperaturbereich das Schwingungsverhalten des Quarzes konstant ist. Im Material breitet sich die akustische Welle als Dickenscherschwingung aus, wie es in Abbildung 3.6 B gezeigt ist.

Durch Anlegen eines äußeren elektrischen Feldes an den Quarz wird eine Schwingung erzeugt, deren Eigenfrequenz ausschließlich durch die Dicke des Materials bestimmt wird, wie aus Gleichung [3.14] ersichtlich wird:

$$
f_{0}=\frac{v_{\mathrm{q}}}{\lambda_{\mathrm{q}}}=\frac{v_{\mathrm{q}}}{2 d_{\mathrm{q}}}=\frac{1}{2 d_{\mathrm{q}}} \cdot \frac{\sqrt{\mu_{\mathrm{q}}}}{\sqrt{\rho_{\mathrm{q}}}} .
$$

Hierbei entspricht $v_{\mathrm{q}}$ der Ausbreitungsgeschwindigkeit der akustischen Welle, die eine Materialkonstante darstellt, $d_{\mathrm{q}}$ der Dicke des Quarzes und $\lambda_{\mathrm{q}}$ der 
Wellenlänge (80). Für diese Arbeit wurden $330 \mu \mathrm{m}$ dicke $5 \mathrm{MHz}$ AT-cut Quarze eingesetzt.

A

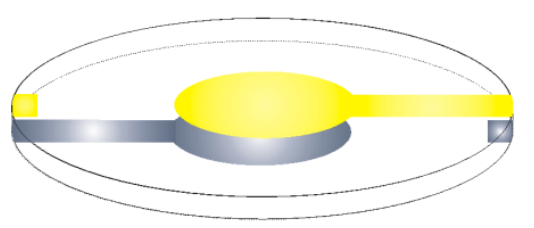

B

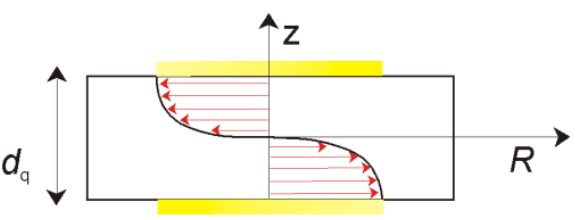

C

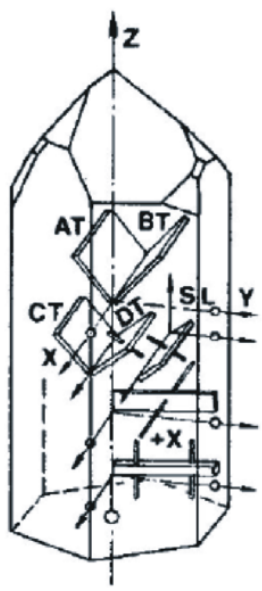

Abbildung 3.6: A Schwingquarz mit aufgedampften Elektroden. B Ausbreitung einer Dickenscherschwingung durch das Quarzmaterial. C Verschiedene Schnitte durch einen Quarzkristall.

Die von Sauerbrey abgeleitete Linearität zwischen der Massenabscheidung und der Frequenzänderung der Quarzschwingung ist streng genommen nur gültig für homogene, rigide Massenabscheidungen. Während der Abscheidung viskoelastischer Schichten auf der Quarzoberfläche kann Energie der Quarzschwingung in das System dissipieren und so die Frequenz des Quarzes durch Dämpfung beeinflussen. Um Frequenzänderungen der Quarzoszillation als reine Massenabscheidungen interpretieren zu können, müssen daher solche viskoelastischen Effekte ausgeschlossen werden.

Zur Detektion viskoelastischer Effekte während der Adsorption von Proteinen wurde eine amplitudenkontrollierte QCM (QCM 200, Stanford Research Systems, Kalifornien, USA) verwendet. Die Resonanzfrequenz des schwingenden Quarzes wird hierbei über eine spezielle Verstärkungsregelung stabilisiert, so dass eine Dämpfung durch viskoelastische Effekte ausgeglichen werden kann und Serienresonanz vorliegt. Aus der resultierenden Stromantwort erhält man das Impedanzverhalten des Quarzes. Mit Hilfe des Butterworth-van Dyke-Modells (BVD), welches zur Beschreibung von TSM-Resonatoren in der Nähe ihrer Resonanzfrequenz verwendet wird und für die verwendete amplitudenkontrollierte QCM gültig ist, können aus dem Parameter $R$ 
Informationen über viskoelastische Effekte erhalten werden. Abbildung 3.7 zeigt das gültige Ersatzschaltbild.

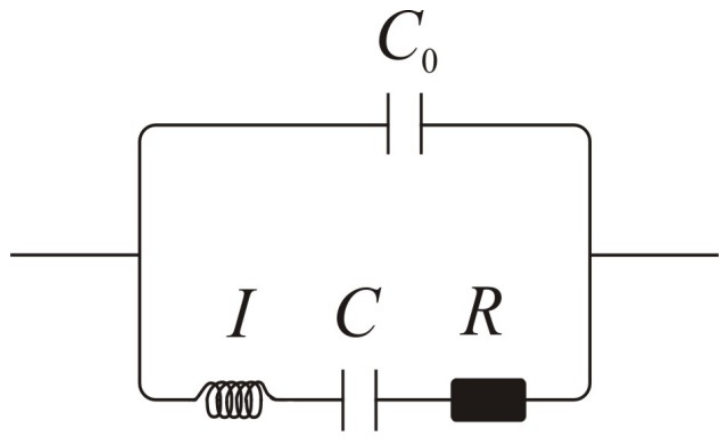

Abbildung 3.7: BVD-Ersatzschaltbild. Die gekennzeichneten Bauteile spiegeln im Einzelnen folgende Eigenschaften des Quarzes wider: $C_{0}$ : statische Kapazität für die Admittanz entfernt von der Resonanz; $L$ : schwingende Masse; $C$ : mechanische Elastizität des Quarzes; $R$ : Energieverluste aufgrund von Dämpfung.

Aus dem Impedanzverhalten des Quarzes wird der Parameter $R$ ausgelesen, welcher die Energiedissipation der Schwingung widerspiegelt. Die Korrelation der Dissipation $D$ mit der Güte der Quarzschwingung $Q$ kann wie folgt ausgedrückt werden:

$$
Q=\frac{\omega L}{R}=\frac{1}{D}
$$

Dabei gilt $\omega=2 \pi f$. $L$ ist die Induktivität des unbeladenen Quarzes, welche über eine Kalibriermessung des unbeladenen Quarzes ermittelt werden muss.

Zur Durchführung eines Quarzmikrowaage-Experiments wurde nach der gründlichen Reinigung der Goldflächen im Argonplasma der Schwingquarz zwischen zwei Kalrez ${ }^{\circledR}$-Dichtringen (DuPont Performance Elastomers, Wilmington, USA) in die Messkammer eingespannt. Diese Dichtringe bestehen aus einem Perfluoroelastomer, welches eine besonders hohe Lösemittelbeständigkeit besitzt. Anschließend wurde die festkörperunterstützte Doppelschicht wie in Kapitel 3.2.3 beschrieben auf dem Quarz präpariert und mittels Impedanzspektroskopie die Qualität der gebildeten Membran sichergestellt. Dann wurde die Messzelle mit einem Deckel luftdicht verschlossen. Der Deckel fungierte zugleich als Zu- und Ablass für die Puffer- 
und Proteinlösung. Für die Messung wurde die Kammer in einen auf $20^{\circ} \mathrm{C}$ temperierten Faraday-Käfig gestellt und der Quarz über zwei Federkontakte mit dem Oszillatorschaltkreis der QCM 200 verbunden. Die Lösungen konnten mit Hilfe einer Peristaltikpumpe (Ismatec, Wertheim-Mondfeld) bei einer konstanten Durchflussrate von ca. 0,36 $\mathrm{mL} / \mathrm{min}$ durch die Zelle geleitet werden. Der Aufbau eines solchen Experiments ist schematisch in Abbildung 3.8 wiedergegeben.

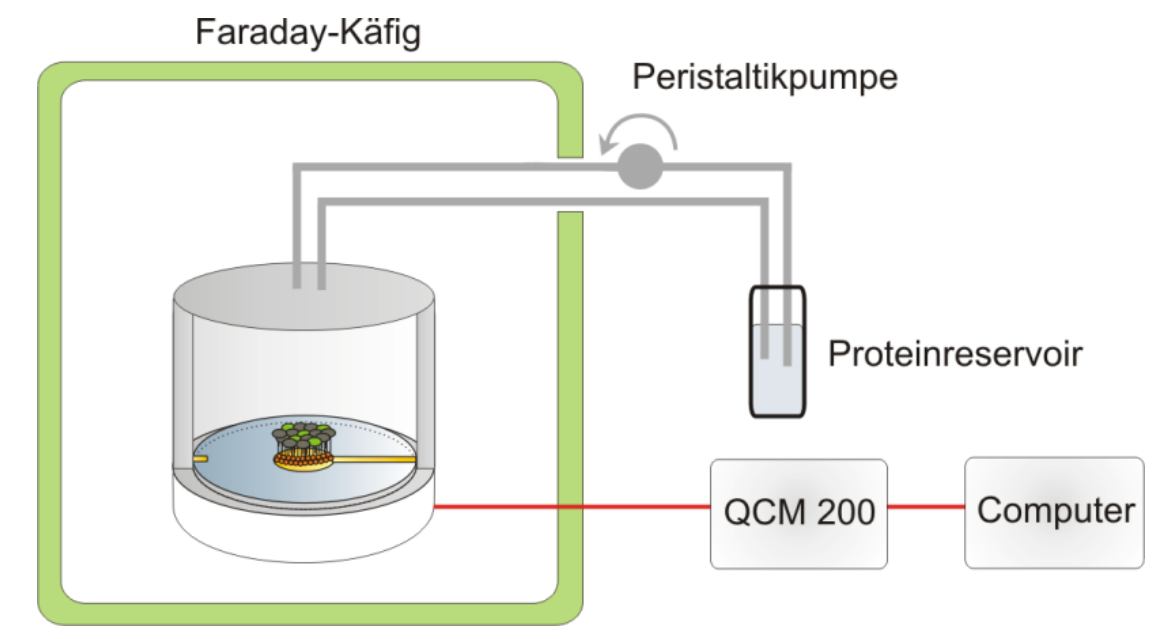

Abbildung $\quad 3.8$ : Schematischer Aufbau eines Quarzmikrowaageexperiments.

Die Zuleitung der Lösungen erfolgte über die Mitte des Deckels, der Austritt hingegen über die Seiten. Die Lösungen wurden in einem außerhalb des Faraday-Käfigs befindlichen Reservoir vorgelegt und über die Peristaltikpumpe in den Kreislauf gebracht. Änderungen der Resonanzfrequenz des Quarzes aufgrund von Massenabscheidungen auf der Quarzoberfläche wurden detektiert und durch einen Computer als Frequenz-Zeit-Diagramm aufgezeichnet.

\subsubsection{Fluoreszenzmikroskopie}

In den Biowissenschaften findet die Fluoreszenzmikroskopie auf vielfältigen Gebieten ihren Einsatz, zum Beispiel zur Beobachtung von zellulären Vorgängen auf molekularer Ebene. Hierbei wird der Marker, ein Fluorophor, entweder von außen in die Zelle eingebracht und bindet dann als Ligand spezifisch an 
bestimmte Zielverbindungen, oder es wird durch rekombinante Genexpression eine autofluoreszierende Spezies, z.B. das green fluorescent protein (GFP), gebildet, die mit dem zu markierenden nativen Protein fusioniert ist. Durch diesbezügliche Arbeiten von Shimomura, Chalfie und Tsien wurde die zellbiologische Forschung entscheidend vorangetrieben (81-83).

Zur Markierung einzelner biologischer Makromoleküle und Strukturen wurden in dieser Arbeit unterschiedliche Fluorophore als Sonden verwendet. Diese Fluorophore zeichnen sich durch die Eigenschaft aus, nach Absorption elektromagnetischer Strahlung in einen angeregten elektronischen Zustand überzugehen, um dann spontan Fluoreszenzlicht zu emittieren und so in den Grundzustand zurückkehren. Das Prinzip der Fluoreszenz lässt sich anhand eines Jablonski-Diagramms veranschaulichen (Abbildung 3.9).

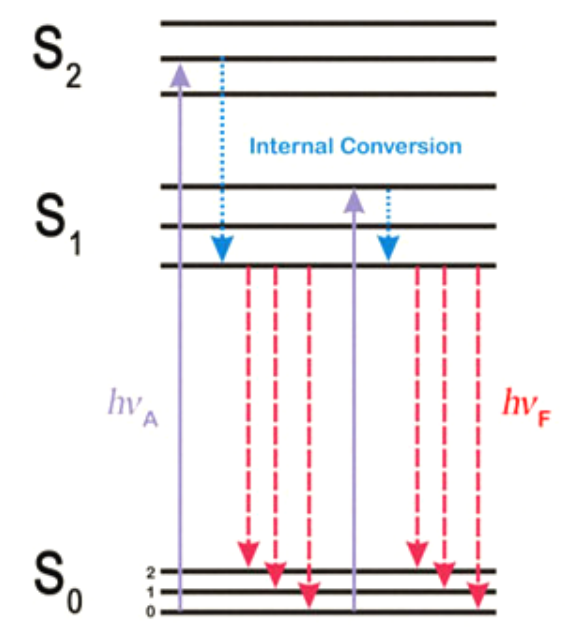

Abbildung 3.9: Jablonski-Diagramm.

Im Grundzustand $\mathrm{S}_{0}$ liegen die Elektronen spingepaart vor. Trifft nun Anregungslicht einer geeigneten Wellenlänge $h v_{\mathrm{A}}$ auf das Molekül, absorbiert ein Elektron dessen Energie und wird so in einen der angeregten Zustände, $\mathrm{S}_{1}$ oder $\mathrm{S}_{2}$, angehoben. Dieser Übergang erfolgt nach dem Franck-Condon-Prinzip vertikal und mit der höchsten Wahrscheinlichkeit in den Zustand mit maximalem Übergangsdipolmoment. Im angeregten Zustand (hier $\mathrm{S}_{1}$ bzw. $\mathrm{S}_{2}$ ) liegen die Elektronen weiterhin in antiparallelen Spins vor - d.h. dieser Übergang ist spinerlaubt - allerdings nun in verschiedenen Orbitalen. Über strahlungslose Desaktivierung (Internal Conversion) fällt das Molekül zunächst in den Schwingungsgrundzustand des ersten angeregten Zustandes $\mathrm{S}_{1}$ zurück. Von dort 
erfolgt die Rückkehr in den elektronischen Grundzustand, indem eine spontane Emission von Fluoreszenzlicht auftritt. Die Wellenlänge des Fluoreszenzlichtes ist normalerweise größer als die des Anregungslichtes (84), und die Lebensdauer des angeregten Zustands beträgt nur ca. $10^{-6} \mathrm{~s}$. Daher werden in einem Fluoreszenzmikroskop spezielle Filter und Spiegel zur gleichzeitigen Anregung und Detektion der Fluoreszenz genutzt. In Abbildung 3.10 ist der Aufbau eines Epifluoreszenzmikroskops schematisch dargestellt.

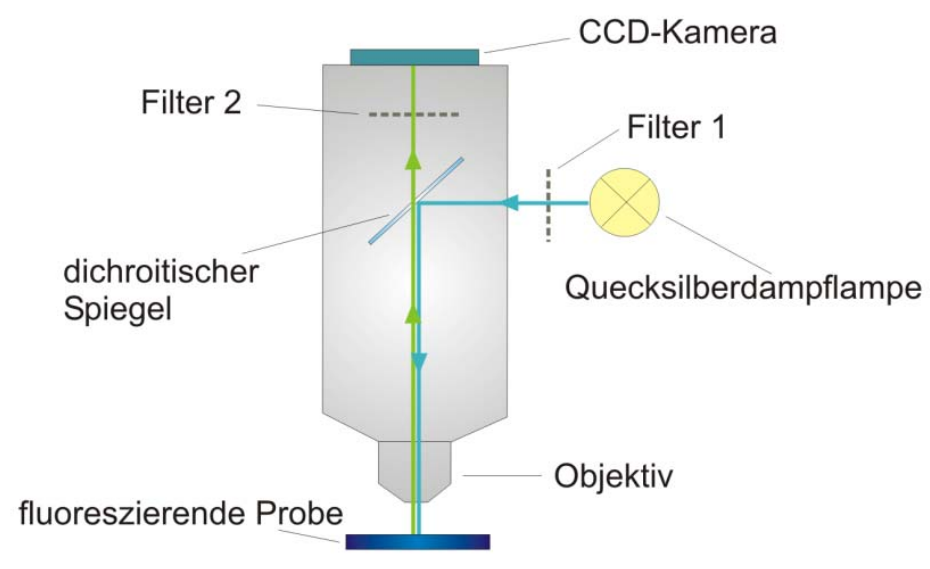

Abbildung 3.10: Schematischer Aufbau eines Epifluoreszenzmikroskops.

Die Quecksilberdampflampe dient als Lichtquelle und emittiert ein Spektrum von ca. $270 \mathrm{~nm}$ bis $700 \mathrm{~nm}$. Um das Anregungswellenlicht der gewünschten Wellenlänge zu selektieren, ist ein erster Bandpassfilter (Filter 1) im Strahlengang platziert. Das Licht trifft anschließend auf einen dichroitischen Spiegel und wird auf die Probe gelenkt. Die angeregten Fluorophore der Probe senden nun Fluoreszenzlicht einer höheren Wellenlänge als der des Anregungslichtes aus, dieses wird im Objektiv gesammelt und kann den dichroitischen Spiegel unabgelenkt passieren. Ein zweiter Bandpassfilter unterdrückt ungewünschte Streustrahlung, und das Signal wird per CCD-Kamera oder am Okular registriert.

Das Auflösungsvermögen eines Epifluoreszenzmikroskops wird dadurch negativ beeinflusst, dass durch die Beleuchtung von Fluorophoren, die vor oder hinter der Fokusebene liegen, ein erhebliches Hintergrundsignal entsteht. Vor allem für 
Studien an dreidimensionalen Objekten wie Zellen oder GUVs (giant unilamellar vesicles) wird daher häufig auf eine Weiterentwicklung des klassischen Epifluoreszenzmikroskops, das sogenannte konfokale Laserrastermikroskop, zurückgegriffen.

Mit Hilfe der konfokalen Laserrastermikroskopie (CLSM, confocal laser scanning microscopy) kann vor allem eine deutlich bessere Tiefenschärfe der Abbildung erzielt werden. Hierfür werden zwei mit der zu untersuchenden Probenebene konfokale Lochblenden (pinholes) in den Strahlengang eingebracht. Die erste Lochblende sorgt dafür, dass nur ein scheibenförmiger Bereich der Probe bestrahlt wird und so die Beleuchtungsintensität in benachbarten Ebenen verringert ist. Eine zweite Lochblende vor dem Detektor absorbiert den Anteil an Fluoreszenzlicht, das aus Ebenen außerhalb des Fokus stammt und daher nicht in der Apertur konvergiert. In Abbildung 3.11 ist der Aufbau eines konfokalen Laserrastermikroskops schematisch wiedergegeben.

Um eine derartig präzise Fokussierung des Anregungslichtes und eine hohe Fluoreszenzintensität zu erhalten, werden anstelle einer Lampe meist Laser eingesetzt. Über diese Kombination von konfokalen Lochblenden und Illumination durch Laser wird in biologischen Proben typischerweise eine Auflösung in der $\mathrm{x}, \mathrm{y}$-Ebene von $0,3 \mathrm{~nm}$ und in z-Richtung von ca. 0,7 nm erreicht (85). Dreidimensionale Objekte lassen sich anhand sogenannter z-stacks (Stapel) nach Scannen der einzelnen Ebenen am Computer rekonstruieren. 


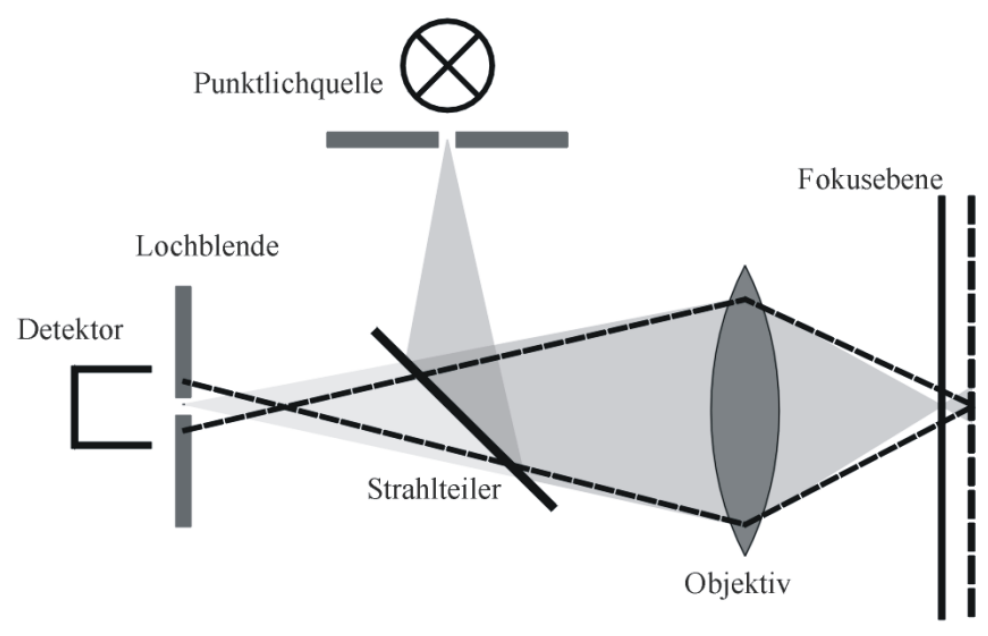

Abbildung 3.11: Strahlengang in einem konfokalen Laserrastermikroskop.

In dieser Arbeit wurden drei verschiedene Fluoreszenzfarbstoffe verwendet, deren Anregung und Detektion mit Hilfe des konfokalen Laserrastermikroskops unter folgenden Bedingungen vorgenommen wurden: Zur Anregung von AlexaFluor488-Phalloidin wurde ein Argon-Laser mit der Wellenlänge $\lambda=488 \mathrm{~nm}$ verwendet. Die Emission wurde im Bereich von $\lambda=515-552 \mathrm{~nm}$ detektiert. Die Anregung der Perylenfluoreszenz wurde über einen Diodenlaser bei $\lambda=405 \mathrm{~nm}$ erreicht, während das emittierte Fluoreszenzlicht in einem Wellenlängenbereich von $\lambda=426-485 \mathrm{~nm}$ aufgenommen wurde. Die AlexaFluor633-MaleimidFluoreszenz konnte mit Hilfe des Argonlasers bei $\lambda=633 \mathrm{~nm}$ angeregt werden, während die Emission des Fluoreszenzlichts in einem Wellenlängenbereich von $\lambda=640-660 \mathrm{~nm}$ detektiert wurde. Für alle Aufnahmen wurde ein WasserImmersionsobjektiv mit 63-facher Vergrößerung verwendet (W Plan Apochromat, $\mathrm{NA}=1.0$, Zeiss). Des Weiteren wurden verschiedene fluoreszierende $\mathrm{PIP}_{2}$ Derivate verwendet. Diese besaßen an einer der hydrophoben Ketten in kovalenter Bindung einen von Bodipy abgeleiteten Farbstoff. Die chemischen Strukturen dieser fluoreszierenden Lipide mit den zugehörigen Anregungs- und Detektionswellenlängenbereichen sind in Abbildung 3.12 aufgeführt. 
$\mathrm{PIP}_{2}$-BodipyTMR

$\lambda=514 \mathrm{~nm} /$

$\lambda=550-600 \mathrm{~nm}$

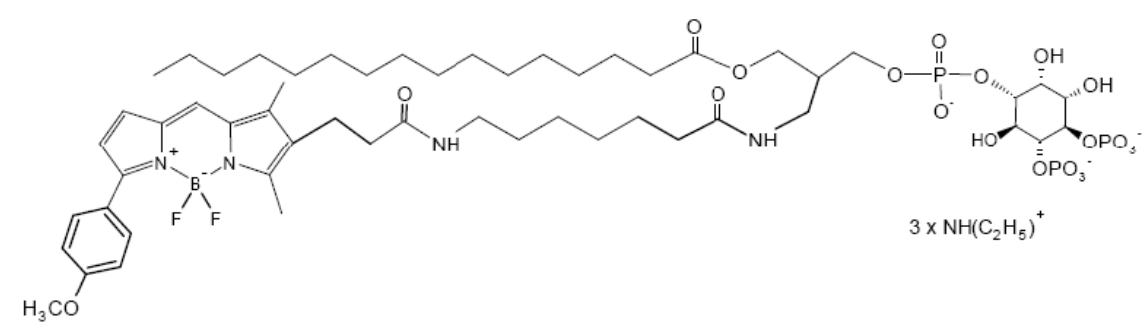

PIP $_{2}$-BodipyFL

$\lambda=488 \mathrm{~nm} /$

$\lambda=515-550 \mathrm{~nm}$

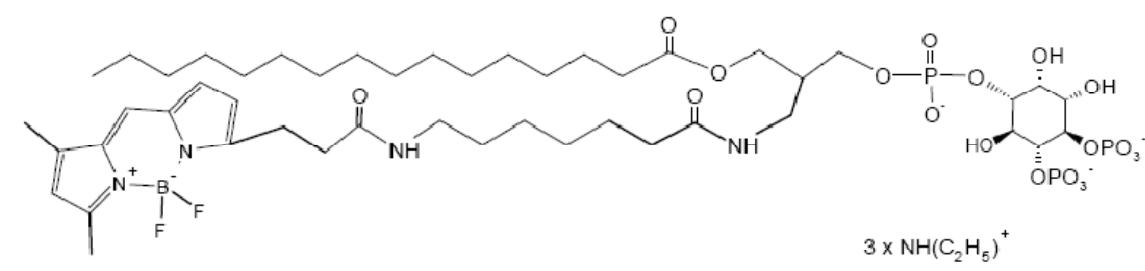

PIP $_{2}$-BodipyTopFluor

$\lambda=488 \mathrm{~nm} /$

$\lambda=515-550 \mathrm{~nm}$

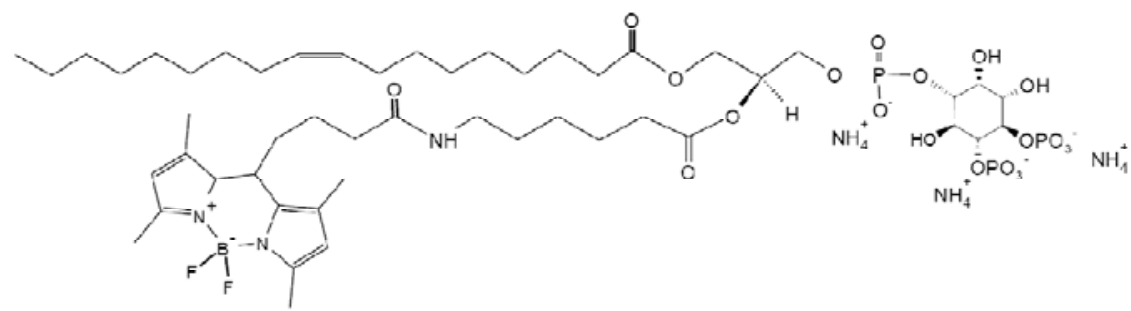

Abbildung 3.12: Auflistung der Anregungs- und Detektionswellenlängenbereiche sowie chemischen Strukturen der verwendeten fluoreszierenden $\mathrm{PIP}_{2}$-Derivate.

\subsubsection{Rasterkraftmikroskopie}

Die herkömmliche optische Mikroskopie ist ihrer Auflösung auf Objekte $\geq 200 \mathrm{~nm}$ beschränkt. Zur Untersuchung von kleineren Strukturen eignet sich zum Beispiel das Rasterkraftmikroskop (atomic force microscope, AFM), das 1986 von Binning und Quate als Weiterentwicklung des Rastertunnelmikroskops erstmals vorgestellt wurde (86). Hiermit können nicht-leitende Oberflächen sowohl an Luft als auch in wässriger Umgebung mit hoher lateraler und vertikaler Auflösung $(\sim 0,1 \mathrm{~nm})$ abgebildet werden. Auch Materialeigenschaften können durch diese Technik charakterisiert werden. 


\section{Messprinzip}

Anhand von Abbildung 3.13 kann das Messprinzip der Rasterkraftmikroskopie veranschaulicht werden. Zum Abrastern der Probenoberfläche wird ein Federbalken (cantilever), an dem sich eine feine Messspitze befindet, Linie für Linie über die Fläche geführt. Dabei wirken je nach Abstand zwischen Spitze und Probe und abhängig vom Material attraktive oder repulsive Kräfte. Während der cantilever in $\mathrm{x}$ - und $\mathrm{y}$-Richtung die Probenoberfläche abfährt, bedingt die Oberflächenstruktur eine Verbiegung des cantilevers, was mit Hilfe der Reflektion eines Laserstrahls auf einer 4-Quadranten-Diode registriert wird.

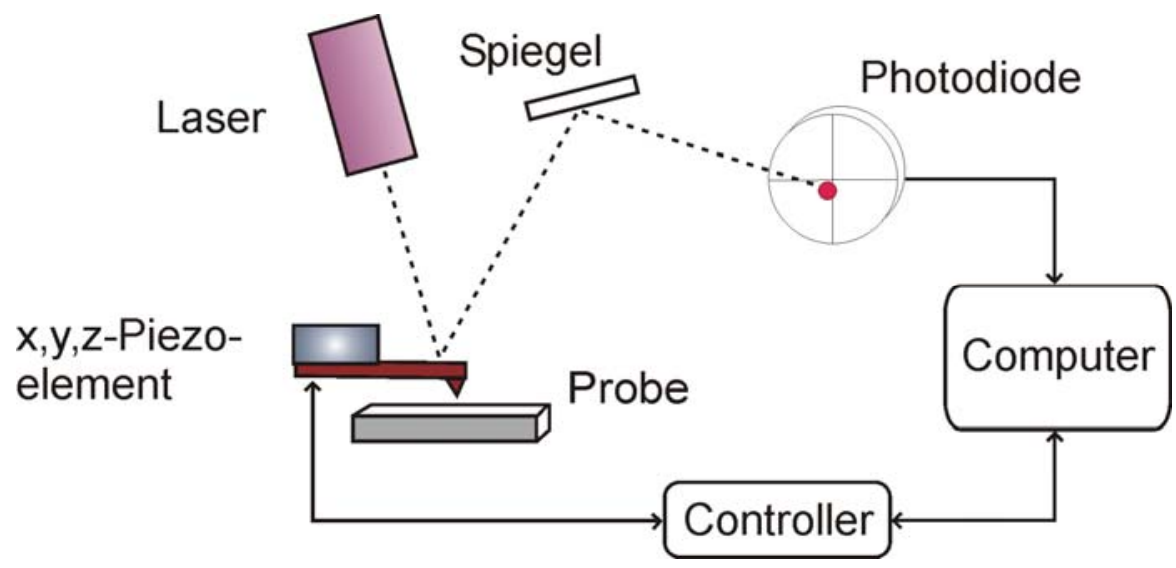

Abbildung 3.13: Schematische Darstellung des Messprinzips der Rasterkraftmikroskopie.

Über einen Computer wird das Signal der Auslenkung an den Controller weitergegeben, welcher wiederum eine Neuausrichtung des Piezoelements steuert. Die Regelgröße, welche abhängig vom Messmodus ist, wird so dem Sollwert angepasst.

In der Rasterkraftmikroskopie werden verschiedene Betriebsmodi unterschieden. $\mathrm{Zu}$ den statischen Messmodi gehört der contact mode, bei dem ein ständiger repulsiver Kontakt zwischen Messspitze und Probe besteht. Die Regelgröße, welche hier konstant gehalten wird, ist die Verbiegung des cantilevers, was einer konstanten Krafteinwirkung auf die Probenoberfläche gleichkommt (constant force mode). Jedoch können hier recht hohe laterale Kräfte wirken, welche 
Objekte zur Seite schieben oder bei weichen Proben die Auflösung verschlechtern. Um die laterale Kraft zu minimieren, wurde der intermittent contact mode entwickelt, welcher für die Untersuchung von biologischen Proben dem contact mode häufig vorgezogen wird. Dabei wird der cantilever mit Hilfe eines zusätzlichen Piezoelements in eine sinusförmige Schwingung nahe seiner Resonanzfrequenz versetzt. Während der cantilever in in $x$ - und $y$-Richtung die Probe abfährt, berührt er die Probenoberfläche periodisch. Die Regelgröße in diesem Messmodus ist die Amplitude der Schwingung, welche durch einen zu geringen Abstand zwischen Probe und Messspitze gedämpft wird. Sowohl im contact mode als auch im intermittent contact mode wird aus der Regelung des Piezoelements in z-Richtung die topographische Information über die Probenoberfläche gewonnen. Diese werden am Computer zu einem hochauflösenden mikroskopischen Bild konstruiert.

\section{Durchführung}

Die AFM-Messungen wurden am NanoWizard II-Gerät der Firma JPK Instruments (Berlin, Deutschland) durchgeführt. Dabei wurde stets in Puffer (E1) gearbeitet. Alle gezeigten Aufnahmen wurden im contact mode erstellt. Die verwendeten cantilever waren aus Silizium (CSC 38, Micromash, Tallinn, Estland). Die nominale Federkonstante lag bei 0,03 N/m, die Resonanzfrequenz bei $10 \mathrm{kHz}$. Die gezeigten Bilder wurden mit einer Scangeschwindigkeit von 1-2 $\mathrm{Hz}$ aufgenommen. 


\section{Proteinisolierung, Charakterisierung Per CD- SPEKTROSKOPIE, FLUORESZENZMARKIERUNG}

\subsection{Expression und Aufreinigung der Proteine N-ERMAD, Ezrin wt, Ezrin T567A und Ezrin T567D}

Die im Rahmen dieser Arbeit verwendeten Proteine wurden mittels rekombinanter Genexpression aus Escherichia coli-Bakterien gewonnen. Es wurden der Wildtyp von humanem Ezrin sowie die N-terminale Domäne des Proteins, N-ERMAD, isoliert. Außerdem wurden zwei Mutanten des Proteins Ezrin isoliert, welche die dauerhaft phosphorylierte Form (T567D) beziehungsweise die dauerhaft unphosphorylierte Form (T567A) darstellen. Alle Proteine waren mit einem $\mathrm{N}$-terminalen His-tag versehen, welcher die affinitätschromatographische Reinigung erleichterte sowie teilweise als spezifische Bindungsstelle zur Immobilisierung der Proteine genutzt wurde. Nach jedem der in Kapitel 3.1 erläuterten Arbeitsschritte wurden Proben genommen, um diese mit Hilfe von SDS-PAGE zu analysieren und den Verlauf der Isolierung zu dokumentieren.

Zunächst soll der Verlauf der Isolierung von N-ERMAD besprochen werden. In Abbildung 4.1 sind die Ergebnisse der gelelektrophoretischen Auftrennung der einzelnen Proben nach Färbung mit Coomassie Brilliant Blau zu sehen. 


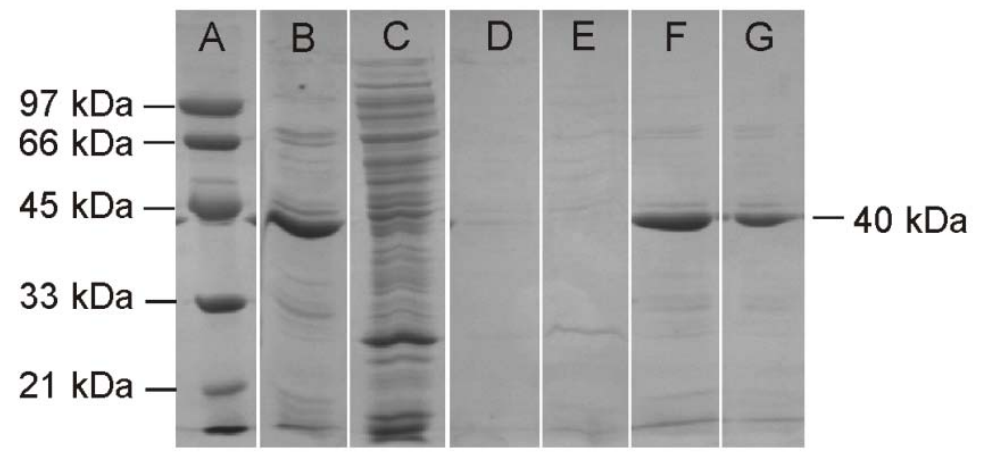

Abbildung 4.1: SDS-PAGE von Proben, die während der Isolierung und Aufreinigung von NERMAD genommen wurden. A: Marker, B: Zelllysat nach $3 \mathrm{~h}$ IPTG-Induktion und UltraschallZellaufschluss, C: Durchlauf, D: Waschschritt 1, E: Waschschritt 2, F und G: typische Elutionsfraktionen.

Die theoretische Masse des Proteins N-ERMAD entspricht 34,9 kDa (87). Die Spur B im SDS-Gel zeigt, dass nach der Induktion der Genexpression durch IPTG-Zugabe eine Proteinbande bei ca. $40 \mathrm{kDa}$ gegenüber den anderen nachgewiesenen Proteinen deutlich hervortritt und damit im verwendeten Expressionssystem überexprimiert wurde. Dass dieses Molgewicht nicht der theoretischen Masse des Proteins N-ERMAD entspricht, kann durch den His-tag erklärt werden, der über eine Linkerstruktur von 24 Aminosäuren fusioniert am NTerminus des Proteins vorliegt. Dieses Konstrukt erhöht die Molmasse um ca. 3,5 kDa.

Nach Zelllyse und Zentrifugation wurde die Lösung über eine Ni-NTAAgarosesäule aufgereinigt, wobei N-ERMAD über einen N-terminalen 6His-Tag spezifisch komplexiert werden sollte. Spur C zeigt, dass sich viele Proteine unterschiedlicher Massen im Durchlauf befanden und nicht an der Säule haften blieben. Hier sieht man ebenfalls, dass nahezu das gesamte 6His-fusionierte Protein an der Säule gebunden wurde und daher nur in sehr geringer Intensität in Spur C vorhanden ist. Die Spuren D und E zeigen Proben aus zwei Waschschritten, während derer unspezifisch adsorbierte Proteine von der Säule eluiert wurden. Durch einen Imidazolsprung $(250 \mathrm{~mm}$ ) konnten anschließend die Proteine eluiert werden, die über den N-terminalen 6His-Tag an die Säule gebunden waren. Die Spuren F und G zeigen die gelelektrophoretische Analyse dieser Fraktionen. Die dominierende Proteinbande ist hier bei einer Masse von 
ca. $40 \mathrm{kDa}$ zu finden. Wie weiter oben dargelegt, handelt es sich hierbei um N-ERMAD. Darüber hinaus sind weitere nieder- und hochmolekulare Banden im Gel zu erkennen, die jedoch aufgrund ihrer deutlich schwächeren Intensität vernachlässigbar sind. Insgesamt konnte das Protein N-ERMAD in einem sehr guten Reinheitsgrad von ca. $95 \%$ und einer Ausbeute von ca. $2,4 \mathrm{mg} / 250 \mathrm{~mL}$ Kulturmedium isoliert werden.

Die Prozeduren zur Isolierung von Ezrin T567A, Ezrin wt und Ezrin T567D entsprachen exakt der Vorgehensweise bei der Isolierung von N-ERMAD. In Abbildung 4.2 werden daher lediglich die Analysen der Elutionsfraktionen der einzelnen Mutanten dargestellt.
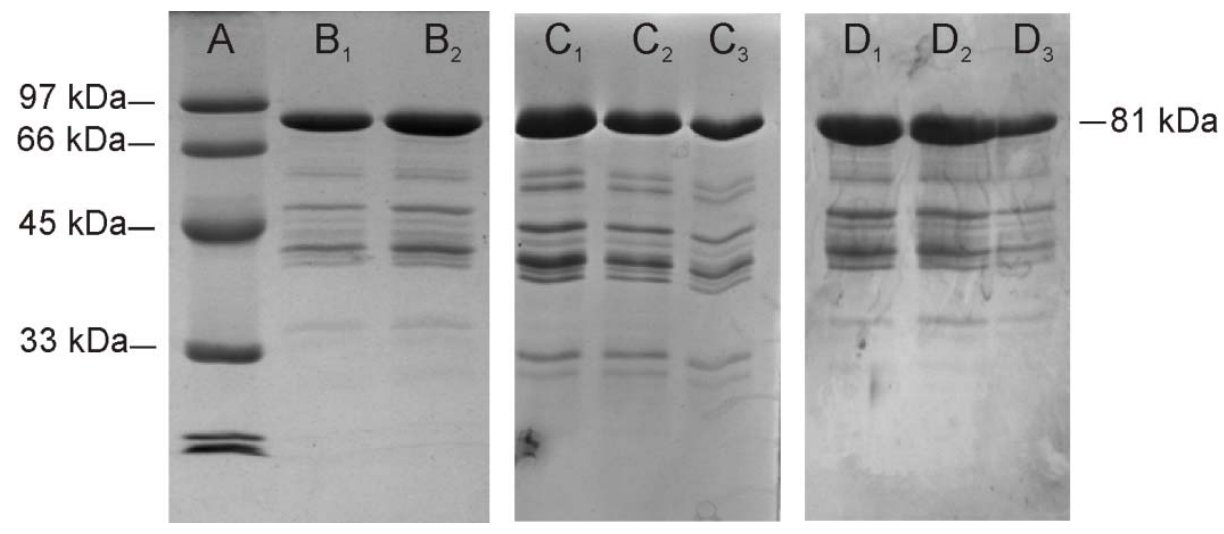

Abbildung 4.2: SDS-PAGE zur Analyse der Elutionsfraktionen der Isolierung von $\mathbf{B}_{1-2}$ Ezrin T567A, $\mathbf{C}_{1-3}$ Ezrin wt, $\mathbf{D}_{1-3}$ Ezrin T567D. Zur Zuordnung der Proteinbanden gemäß der in innen enthaltenen Proteingrößen ist ein Marker $(\mathbf{A})$ aufgetragen.

In allen drei Fällen konnte eine gute Ausbeute von ca. 3,8 mg Protein pro $250 \mathrm{~mL}$ Kulturmedium erzielt werden. In Abbildung 4.2 B sind neben der Marker-Spur zwei Proben aus Elutionsfraktionen der Isolierung von Ezrin T567A dargestellt. Die klar dominierende Bande stell die obere Bande der Masse von ca. $81 \mathrm{kDa}$ dar. Die theoretische Masse von Ezrin T567A sowie auch für Ezrin wt und Ezrin T567D beträgt $70 \mathrm{kDa}$. Das Erscheinen der Proteinbande bei einer um $11 \mathrm{kDa}$ erhöhten Masse ist zum einen durch den 3,5 kDa schweren N-terminalen His-tag zu erklären. Hauptsächlich jedoch wird die scheinbar hohe Molmasse von Ezrin und den verwendeten Mutanten deshalb beobachtet, weil die Wanderungsgeschwindigkeit dieser Proteine im Polyacrylamidgel überproportional niedrig ist. Dieser Artefakt wurde bereits mehrfach beschrieben 
und wird durch die recht hohe Eigenladung der Proteine sowie das Vorhandensein der Heptaprolinsequenz im a-helicalen Teil erklärt (88-89).

Diese Masse wird für Ezrin in einer gelelektrophoretischen Auftrennung erwartet. Unter der Hauptbande finden sich einige weitere niedermolekulare Proteinbanden. Auch in den Elutionsfraktionen von Ezrin wt (Abbildung 4.2 C) und Ezrin T567D (Abbildung 4.2 D) finden sich diese Banden, die sich untereinander sowohl im Intensitätsverhältnis als auch in der Masse sehr ähneln. Es wurde bereits in einer vorhergehenden Doktorarbeit gezeigt (90), dass diese niedermolekularen Proteinfragmente einen His-Tag tragen und spezifisch an die Affinitätssäule binden. Zusätzliche Aufreinigungsschritte per Ionenaustauschchromatographie führten in der Vergangenheit nicht zu einer signifikanten Verbesserung der Reinheit (90-91). Jedoch beträgt die Reinheit der erhaltenen Ezrinlösungen insgesamt ca. 90\%. Insofern konnten die Proteinlösungen in der vorliegenden Form für die folgenden Studien verwendet werden.

\subsection{CD-spektroskopische Charakterisierung der Proteine N- ERMAD, Ezrin wt, Ezrin T567A und Ezrin T567D}

Die Proteine N-ERMAD sowie Ezrin wt und Mutanten wurden CDspektroskopisch charakterisiert, um Informationen über deren Sekundärstrukturanteile zu gewinnen. Insbesondere sollte hierbei der Einfluss der eingeführten Punktmutationen auf die Gesamtsekundärstruktur der Proteine Ezrin T567A und Ezrin T567D untersucht werden.

Zur Messung wurden die Proteine aus dem Elutionspuffer in $20 \mathrm{~mm}$ Phosphatpuffer überführt. CD-Spektren konnten in einem Messbereich von $\lambda=240 \mathrm{~nm}$ bis $\lambda=190 \mathrm{~nm}$ aufgenommen werden. Es stellte sich heraus, dass ein sehr gutes Signal-zu-Rauschen-Verhältnis in einem Konzentrationsbereich von 0,5-0,8 $\mu \mathrm{M}$ erzielt werden konnte. Die jeweils eingesetzten Konzentrationen wurden im Anschluss an die CD-spektroskopischen Messungen mit Hilfe von UV/Vis-Absorptionsmessungen genau bestimmt (siehe Kapitel 3.1.5).

Zunächst wurde ein Spektrum des Proteins N-ERMAD aufgenommen, welches in Abbildung 4.3 gezeigt ist. 


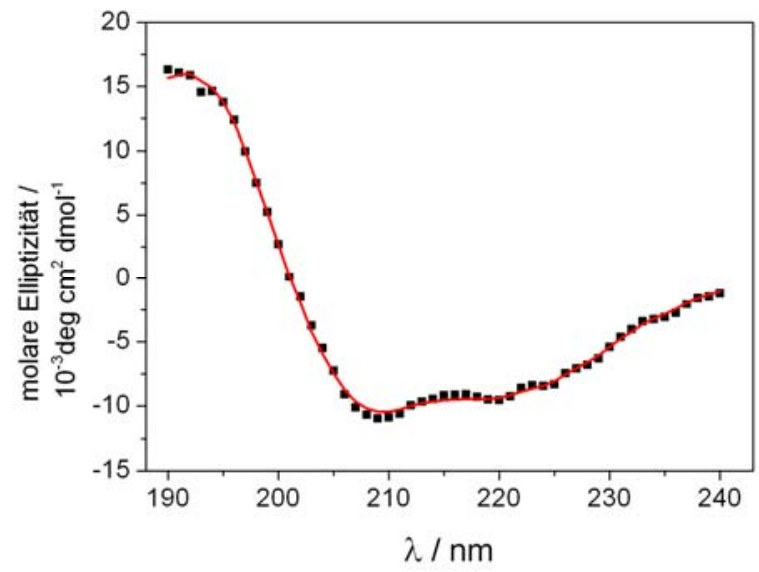

Abbildung 4.3: Gemessenes CD-Spektrum (schwarz) von N-ERMAD in Puffer (20 mM $\mathrm{KH}_{2} \mathrm{PO}_{4} / \mathrm{K}_{2} \mathrm{HPO}_{4}, 0,1 \mathrm{~mm}$ EDTA, pH 8). Rekonstruktion der Daten (rot) mit Hilfe des Programms DichroWeb, Algorithmus CDSSTR, Referenzdatensatz 7 (Erläuterungen siehe Text).

Das aufgenommene Spektrum ist in Abbildung 4.3 als schwarze Punkte dargestellt. In rot ist die Anpassung an die Daten dargestellt, die mit Hilfe des Programms DichroWeb unter Verwendung des Algorithmus CDSSTR mit Referenzdatensatz 7 vorgenommen wurde. Daneben wurde ein weiterer Algorithmus und die Kombination mit verschiedenen Referenzdatensätzen genutzt, um die Sekundärstrukturanteile des Proteins zu berechnen. Die Ergebnisse dieser Rechnungen sind graphisch nicht dargestellt. Da die Röntgenstruktur des Proteins N-ERMAD bereits literaturbekannt ist (46), konnten die erhaltenen Resultate mit diesen Daten verglichen werden. Auf dieser Basis wurde entschieden, welche Kombination die beste Übereinstimmung mit der Röntgenstruktur zeigt und aufgrund dessen für die Strukturberechnung von Ezrin wt, T567A und T567D geeignet scheint. Die Ergebnisse dieser Berechnungen sind in Tabelle 4.1 dargestellt.

Tabelle 4.1: Ergebnisse der Dekonvolution des CD-Spektrums von N-ERMAD unter Verwendung verschiedener Algorithmen und Referenzdatensätze.

\begin{tabular}{l|c|c|c|c|c} 
Algorithmus & CONTIN & CONTIN & CDSSTR & CDSSTR & $\begin{array}{l}\text { Röntgen- } \\
\text { struktur (46) }\end{array}$ \\
\cline { 1 - 5 } Referenzsatz & 4 & 7 & 4 & 7 & 35 \\
\hline a-Helix / \% & 29,4 & 29,1 & 28 & 31 & 24
\end{tabular}


Es zeigte sich, dass alle genutzten Strukturberechnungen einen ähnlichen $\alpha-$ helikalen Anteil von 28-31\% ergeben. Eine etwas größere Variation ergab sich bei der Berechnung des $\beta$-Faltblatt-Anteils. Hier bewegten sich die Berechnungen im Bereich von 20,5-23\%. Die beste Übereinstimmung mit den Literaturdaten ergab die Berechnung nach Algorithmus CDSSTR mit Referenzdatensatz 7. Dieser wurde zur Dekonvolution der CD-Spektren von Ezrin T567A, Ezrin wt und Ezrin T567D herangezogen. Die entsprechenden Spektren sind in Abbildung 4.4 gezeigt.

Die gemessenen CD-Spektren der Proteine sind in schwarz dargestellt. Die Daten wurden mit Hilfe des Programms DichroWeb rekonstruiert (rot). Alle Spektren weisen im Bereich von $\lambda=208-224 \mathrm{~nm}$ zwei Minima auf, die auf große $\alpha-$ helicale Anteile in der Proteinsekundärstruktur hinweisen. Es wurde eine Dekonvolution der Datensätze durchgeführt, um die Einzelbeiträge der Sekundärstrukturelemente zum Spektrum der Gesamtstruktur zu ermitteln. 

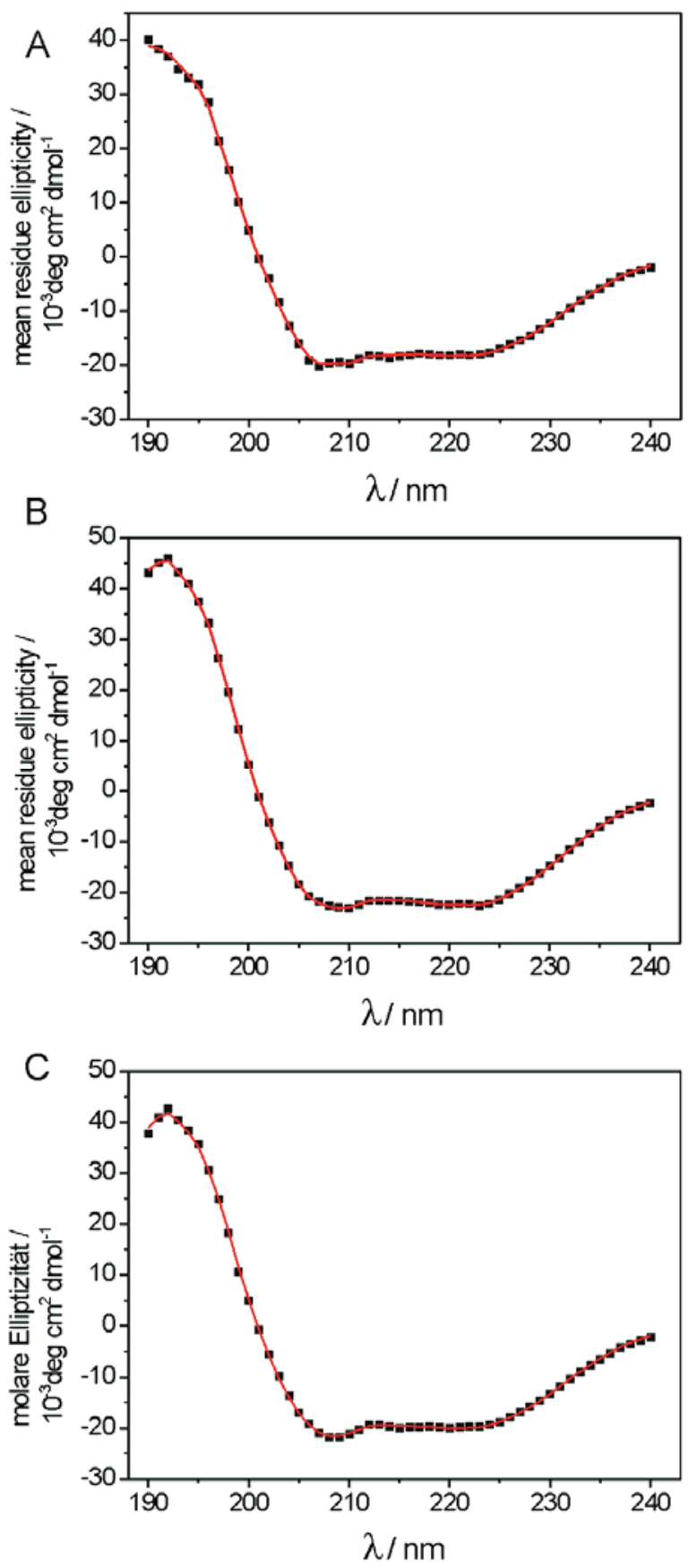

Abbildung 4.4: Gemessene CD-Spektren (schwarz) von A) Ezrin T567A, B) Ezrin wt und C) Ezrin T567D in $20 \mathrm{~mm} \mathrm{KH} \mathrm{PO}_{4} / \mathrm{K}_{2} \mathrm{HPO}_{4}, 0,1 \mathrm{~mm}$ EDTA, pH 8. Rekonstruktion der Daten (rot) mit Hilfe des Programms DichroWeb, Algorithmus CDSSTR, Referenzdatensatz 7.

In Tabelle 4.2 sind die Ergebnisse dieser Analysen aufgeführt. Neben den prozentualen Beiträgen der Strukturelemente zur Gesamtstruktur des Proteins findet sich in der Tabelle der Ausdruck normalized root mean squared deviation (NRMSD), welcher die Abweichung der berechneten von der gemessenen 
Struktur bezeichnet und damit ein Maß für die Qualität der Ergebnisse darstellt. Für ein gutes Ergebnis sollte dieser Wert <0,1 betragen (92), was in allen der vorgestellten vier Anpassungen gewährleistet ist.

Tabelle 4.2: Ergebnisse der Dekonvolution der CD-Spektren von N-ERMAD, Ezrin T567A, Ezrin wt und Ezrin T567D mit Hilfe des Programms DichroWeb unter Verwendung des Algorithmus CDSSTR und Referenzdatensatz 7. Angegeben sind die prozentualen Beiträge zur Gesamtstruktur sowie die normalized root mean squared deviation (NRMSD) als Maß für die Abweichung der berechneten von der gemessenen Struktur.

\begin{tabular}{l|l|l|l|l} 
& N-ERMAD & Ezrin T567A & Ezrin wt & Ezrin T567D \\
\hline a-Helix / \% & 31 & 60 & 71 & 65 \\
\hline$\beta$-Faltblatt / \% & 22 & 7 & 4 & 4 \\
\hline Schleifen / \% & 18 & 8 & 7 & 9 \\
\hline ungeordnet / \% & 30 & 25 & 18 & 22 \\
\hline NRMSD & 0,033 & 0,019 & 0,007 & 0,016
\end{tabular}

Die Proteine Ezrin T567A, Ezrin wt und Ezrin T567D zeigen im Vergleich mit NERMAD einen deutlich höheren $\alpha$-helicalen Anteil von 60-71\%. Der Anteil an $\beta$ Faltblattstrukturen ist hingegen stark verringert. Diese Unterschiede waren zu erwarten, da N-ERMAD im Vergleich zu den vollständigen Proteinen nicht über die a-helicale Linkerstruktur verfügt und auch der C-Terminus fehlt. Untereinander zeigen die Proteine Ezrin wt, Ezrin T567A und Ezrin T567D relativ geringe strukturelle Unterschiede bezüglich der $\beta$-Faltblattstrukturen und Schleifen. Größere Variation weisen hingegen der $\alpha$-helicale Anteil (60-71\%) sowie die ungeordneten Strukturanteile (18-25\%) auf. Interessant ist vor allem, dass die deutlichsten Strukturunterschiede zwischen Ezrin T567A und Ezrin wt auftreten. Sowohl der a-helicale (60\% bzw. 71\%) als auch der ungeordnete Strukturanteil (25\% bzw. 18\%) ist bei beiden Proteinen signifikant verschieden. Dies deutet darauf hin, dass die Punktmutation der Aminosäure 567 einen Einfluss auf die Gesamtstruktur des Proteins ausübt. Dies kann auch anhand der Mutante T567D beobachtet werden. Der Vergleich der Ergebnisse von Ezrin wt und Ezrin T567D zeigt, dass durch den Austausch von Threonin gegen das negativ geladene Aspartat die Sekundärstruktur sowohl hinsichtlich der $\alpha$ - 
helicalen (71\% bzw. $65 \%)$ als auch der ungeordneten Strukturanteile (18\% bzw. $22 \%)$ verändert werden.

\subsection{Markierung der Proteine Ezrin wt und Ezrin T567D}

Zur fluoreszenzmikroskopischen Detektion der Proteine Ezrin wt und Ezrin T567D auf festkörperunterstützten Membranen wurden diese mit dem Fluoreszenzfarbstoff AlexaFluor633-Maleimid markiert. Dabei reagierten die Cysteinseitengruppen, genauer die Thiolfunktionen, mit dem Maleimid. Die entsprechende Reaktion, die die Komponenten kovalent miteinander verknüpft, läuft spontan nach folgendem Schema $4.1 \mathrm{ab}$ :<smiles>O=C1C=CC(=O)N1O</smiles><smiles>[R]NC(=O)C(CS)NC([R])=O</smiles><smiles>[R]NC(=O)C(CSC1CC(=O)N(OO)C1=O)NC([R])=O</smiles>

Schema 4.1: Reaktion zur Markierung des Proteins über dessen Cystein-Seitenketten mit einem Maleimid-verknüpften Fluoreszenzfarbstoff.

Nachdem die Reaktion beendet war, wurde überschüssiger Farbstoff mit Mercaptoethanol umgesetzt. Das fluoreszenzmarkierte Protein wurde anschließend mit Hilfe einer Größenausschlusschromatographie über eine Säule von freiem Farbstoff getrennt. Der Durchlauf wurde in $200 \mu \mathrm{L}-$ Fraktionen aufgefangen und per SDS-PAGE sowie UV/Vis-spektroskopisch untersucht. Um zunächst zweifelsfrei nachzuweisen, in welchen Proben das Protein vorhanden war, wurde eine SDS-PAGE-Analyse der einzelnen Fraktionen durchgeführt. Das Ergebnis dieser Analyse ist in Abbildung 4.5 dargestellt. 


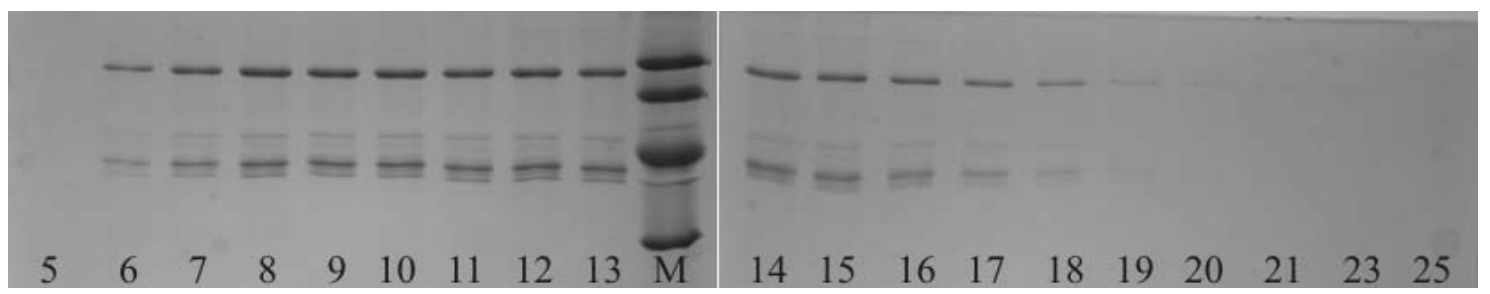

Abbildung 4.5: SDS-PAGE zur Analyse verschiedener Fraktionen des fluoreszenzmarkierten Proteins Ezrin wt.

Es ist anhand der SDS-PAGE nach Coomassie-Färbung der Proteinbanden zu erkennen, dass in den Fraktionen 6 bis einschließlich 19 das Protein Ezrin wt enthalten ist. Hier wird auch deutlich, dass die ursprüngliche Masse des Proteins von ca. $81 \mathrm{kDa}$ erhalten geblieben ist und das Protein nicht unter den Reaktionsbedingungen der Markierungs-Prozedur hydrolysiert wurde. Anschließend wurden UV/Vis-Absorptionsmessungen durchgeführt und die Proteinkonzentration sowie die Labelingrate für jede Fraktion gemäß der in Kapitel 3.1.7 beschriebenen Vorgehensweise berechnet. Das Spektrum der Proteinfraktion 6 von fluoreszenzmarkiertem Ezrin wt sowie das Spektrum einer Probe, in der nach dem Ergebnis der SDS-PAGE kein Protein vorhanden war, sind in Abbildung 4.6 gezeigt.

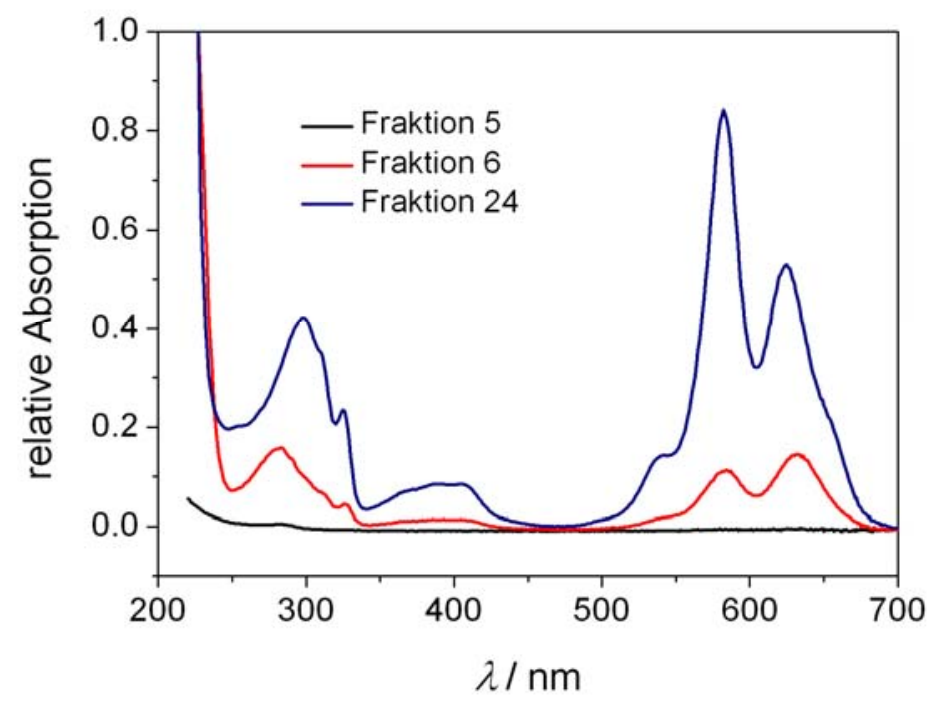

Abbildung 4.6: UV/Vis-Absorptionsspektren verschiedener Fraktionen des fluoreszenzmarkierten Proteins Ezrin wt. Puffer: 20 mm Tris, 50 mM KCl, 0,1 mm EDTA, pH 7,4. 
Das Spektrum der Fraktion 5 zeigt keine nennenswerten absorptiven Eigenschaften. In Fraktion 6 tritt zuerst eine signifikante Absorption in den Bereichen $\lambda=280 \mathrm{~nm}$, dem Absorptionsbereich des Proteins, und $\lambda=632 \mathrm{~nm}$ auf, der Bereich, in dem der verwendete Farbstoff eine starke Absorption aufweist. Hier befanden sich demnach sowohl Protein als auch Fluoreszenzfarbstoff in der Lösung. Die Proteinkonzentration sowie die Labelingrate für die gezeigten Fraktionen, die aus den Absorptionsmaxima gemäß Gleichung 3.5 ermittelt wurden, sind in Tabelle 4.3 aufgeführt.

Tabelle 4.3: Auflistung der auf Basis der UV/Vis-Absorptionsmessungen ermittelten Protein- und Farbstoffkonzentrationen sowie daraus berechnete Labelingraten (Farbstoff : Protein) für Ezrin wt.

\begin{tabular}{l|l|l|l} 
Fraktion & $\mathrm{C}_{(\text {Ezrin wt }} / \mu \mathrm{M}$ & $\mathrm{C}_{(\text {AlexaFluor632) }} / \mu \mathrm{M}$ & Labelingrate \\
\hline 6 & 1,14 & 1,60 & 1,4 \\
\hline 7 & 2,43 & 3,82 & 1,6 \\
\hline 8 & 3,85 & 6,48 & 1,7 \\
\hline 9 & 5,85 & 9,92 & 1,7 \\
\hline 10 & 5,31 & 10,9 & 2,1
\end{tabular}

Die erste Fraktion, die aus der Säule austrat, enthielt 1,14 $\mu \mathrm{m}$ Ezrin wt sowie 1,60 $\mu \mathrm{m}$ AlexaFluor633-Maleimid. Dies ergibt eine Labelingrate von 1:1,4. Dieses Ergebnis erscheint plausibel, da Ezrin wt über zwei Cysteinreste verfügt und daher mit maximal zwei Farbstoffmolekülen markiert sein kann. Anhand der Tabelle fällt auf, dass diese Labelingrate mit steigender Fraktionszahl zunimmt. Dies ist vermutlich auf einen gewissen Anteil an freiem Farbstoff zurückzuführen, welcher nicht vollständig durch die Säulenchromatographie abgetrennt werden konnte. Das Absorptionsspektrum dieser Fraktion zeigt auch deutlich eine Verschiebung des Extinktionsmaximums von anfänglich $\lambda=280 \mathrm{~nm}$ (Fraktion 6) zu $\lambda=300 \mathrm{~nm}$ (Fraktion 24). In Fraktion 24 ist laut dem Ergebnis der SDS-PAGE kein Protein vorhanden. Damit zeigt das dargestellte Spektrum das Absorptionsverhalten des reinen Farbstoffs.

Für die anschließenden Bindungsstudien an festkörperunterstützten Membranen wurde zunächst das fluoreszenzmarkierte Protein spezifisch immobilisiert und 
anschließend freier Farbstoff durch Spülen mit Puffer entfernt. Damit stellte die Anwesenheit von einem Rest freien Farbstoffs keine Einschränkung für die folgenden Experimente dar.

Eine analoge Untersuchung wurde nach der Fluoreszenzmarkierung der aktiven Mutante Ezrin T567D durchgeführt. Die UV/Vis-Absorptionsspektren einzelner Fraktionen nach Größenausschlusschromatographie sind in Abbildung $4.7 \mathrm{zu}$ finden.

In den UV/Vis-Spektren der einzelnen Fraktionen sind ab Fraktion 7 deutliche Absorptionsbanden in den interessierenden Bereichen $\lambda=280 \mathrm{~nm}$ und $\lambda=632 \mathrm{~nm}$ vorhanden. Das bedeutet, dass ab der Fraktion 7 markiertes Protein aus der Säule ausgetreten ist. Es wurden 16 Fraktionen à ca. $200 \mu \mathrm{L}$ aufgefangen. Die Proteinkonzentrationen sowie die Labelingrate dieser einzelnen Fraktionen sind in Tabelle 4.4 aufgeführt. Verglichen mit den Spektren, die vom fluoreszenzmarkierten Ezrin wt erhalten wurden, findet beim markierten Ezrin T567D mit steigender Fraktionsnummer keine deutliche Verschiebung des Absorptionsmaximums bei $\lambda=280 \mathrm{~nm}$ hin zu größeren Wellenlängen statt. 


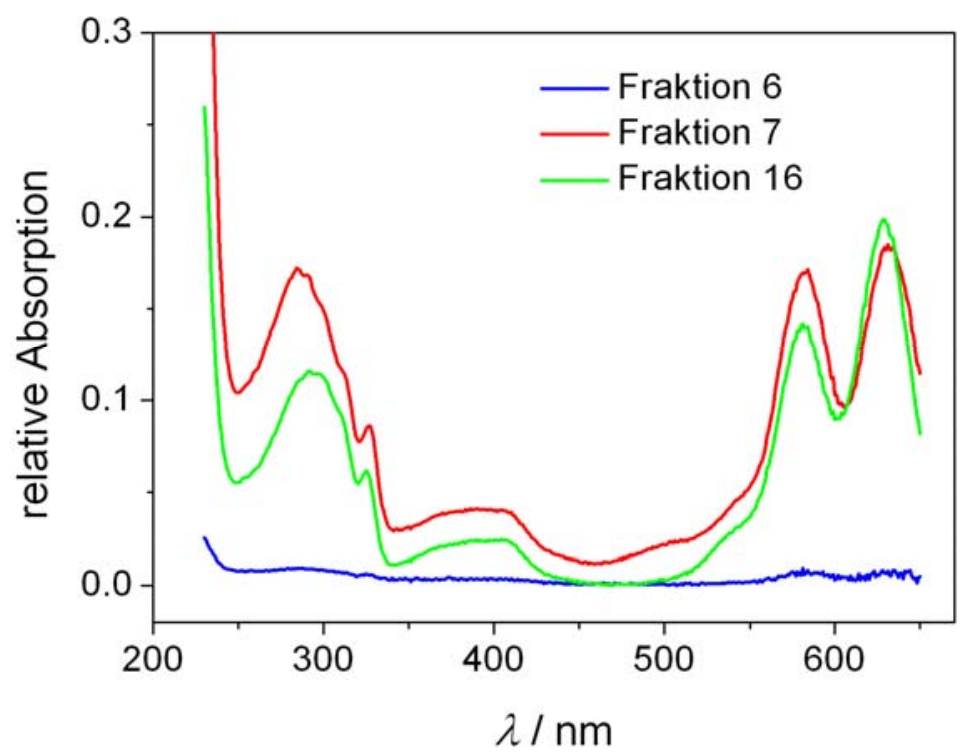

Abbildung 4.7: UV/Vis-Absorptionsspektren verschiedener Fraktionen des fluoreszenzmarkierten Proteins Ezrin T567D. Puffer: 20 mM Tris, 50 mM KCl, 0,1 mM EDTA, pH 7,4.

Auch steigt das errechnete Label:Protein-Verhältnis nicht in der Weise an wie im Fall des Ezrin wt. Insgesamt scheint daher der freie Farbstoff besser vom fluoreszenzmarkierten Protein abgetrennt worden zu sein. Im Rahmen der Messgenauigkeit ist als Gesamtergebnis eine Labelingrate von 2 ermittelt worden.

Tabelle 4.4: Auflistung der auf Basis der UV/Vis-Absorptionsmessungen ermittelten Protein- und Farbstoffkonzentrationen sowie daraus berechnete Labelingraten (Farbstoff : Protein) für Ezrin T567D.

\begin{tabular}{l|l|l|l} 
Fraktion & $\mathrm{C}_{(\text {Ezrin wt) }} / \mu \mathrm{M}$ & $\mathrm{C}_{(\text {AlexaFluor632) }} / \mu \mathrm{M}$ & Labelingrate \\
\hline 7 & 1,05 & 2,03 & 1,9 \\
\hline 8 & 3,95 & 8,54 & 2,2 \\
\hline 9 & 6,50 & 14,46 & 2,2 \\
\hline 10 & 7,71 & 19,82 & 2,5 \\
\hline 12 & 9,93 & 21,18 & 2,1 \\
\hline 14 & 7,15 & 19,58 & 2,7 \\
\hline 16 & 0,0 & 20,80 & -
\end{tabular}




\subsection{Diskussion}

\subsubsection{Proteinisolierung und -charakterisierung mittels CD-Spektroskopie}

Die Isolierung der verwendeten Proteine N-ERMAD, Ezrin wt sowie der beiden Ezrinmutanten Ezrin T567A und Ezrin T567D wurde nach einer Vorschrift von Koltzscher et al. durchgeführt (51). Die Proteinaufreinigung erfolgte über Affinitätschromatographie mittels einer Nickel-Agarose-Säule, an die alle gewünschten Proteine über ihren N-terminalen His-tag spezifisch gebunden wurden. Im Fall von N-ERMAD konnte über diese Reinigung eine nahezu 100\%ige Reinheit erhalten werden, was über SDS-PAGE durch den Erhalt einer einzelnen gefärbten Proteinbande bei ca. 40 kDa nachgewiesen werden konnte. Die Proteine Ezrin wt, Ezrin T567A und Ezrin T567D zeigten in den jeweiligen Elutionsfraktionen dagegen einen gewissen Anteil an Verunreinigungen. Bei allen drei Proteinen konnten neben der Hauptbande bei ca. 81 kDa einige niedermolekulare Proteinbanden identifiziert werden. Dieser Befund ist literaturbekannt (90), und es wurden bereits einige letztlich erfolglose Anstrengungen unternommen, die Reinheit der Proteinlösung zu verbessern. Insgesamt kann aus dem Vergleich der Intensitäten dieser Banden mit der Hauptbande bei $81 \mathrm{kDa}$ jedoch abgeschätzt werden, dass ca. $90 \%$ der in der Probe enthaltenen Moleküle den gesuchten Proteinen entsprachen.

Die CD-spektroskopische Analyse sollte Erkenntnisse darüber liefern, inwieweit die native Struktur des Wildtyps von Ezrin durch die Punktmutationen am Threoninrest 567 beeinflusst wird. Generell wurde die CD-Spektroskopie zur Bestimmung der Sekundärstrukturanteile eines Proteins in der Vergangenheit als weniger akkurat betrachtet als eine vollständige Strukturaufklärung mittels NMR oder Röntgenstreuung. Die ständige Weiterentwicklung von empirischen Algorithmen und Erweiterung von Referenzdatensätzen auf Grundlage von hochauflösenden Synchrotron-Röntgenstreuungsexperimenten hat jedoch zu einer deutlichen Verbesserung der Anwendbarkeit dieser Methode geführt (64). Insbesondere für schlecht kristallisierbare Proteine bietet die CD-Spektroskopie eine schnell anwendbare Alternative zur Strukturbestimmung. In der Tat wurde bisher keine erfolgreiche Kristallisation von Ezrin dokumentiert, sondern lediglich der N-terminale Teil des Proteins, N-ERMAD (46). Es ist denkbar, dass die ca. 
170 Aminosäuren umfassende zentrale $\alpha$-helicale Linkerstruktur des Proteins durch die gestreckte Konformation und eine damit einhergehende gewisse Flexibilität die Bildung eines Einkristalls erschwert.

Zunächst wurde ein Vergleich der Ergebnisse aus der CD-Spektroskopie an $\mathrm{N}$-ERMAD mit denen einer Röngtenstrukturanalyse des bereits kristallisierten N-ERMAD vorgenommen, um die Übereinstimmung des verwendeten Dekonvolutionsalgorithmus mit den kristallographischen Daten zu überprüfen. Hierfür wurden zwei Standard-Algorithmen zur Dekonvolution von CD-Spektren mit Hilfe des online verfügbaren Programms DichroWeb (68) angewendet und die Resultate gegenübergestellt. Der Algorithmus CONTIN/LL, eine Variante von CONTIN nach Provencher und Glöckner (93), sowie der Algorithmus CDSSTR nach Johnsson (94) werden im allgemeinen als gleich leistungsstark betrachtet, wobei für den Ansatz nach CONTIN/LL ein vergleichsweise geringerer Wellenlängenmessbereich ausreicht und die Methode nach CDSSTR einen weniger umfangreichen Referenzdatensatz benötigt (95). Zur Berechnung der Sekundärstrukturanteile wurden des weiteren Referenzdatensätze aus 43 (Referenzdatensatz 4) beziehungsweise 48 (Referenzdatensatz 7) löslichen Proteinen, deren Sekundärstrukturanteile aus Röntgenstreuexperimenten bekannt sind, mit den Dekonvolutionsalgorithmen kombiniert. Die Übereinstimmung der Dekonvolution der CD-spektroskopischen Ergebnisse von N-ERMAD mit den aus Röntgenstrukturanalysen bekannten Daten war für alle vier Kombinationen recht hoch und wich bezüglich des $\alpha$-helicalen Anteils um bis zu $7 \%$ und bezüglich des $\beta$-Faltblattanteils um bis zu 3,5\% nach unten ab. Die beste Übereinstimmung mit der Literatur (35\% $\alpha$-Helix-, $24 \% \quad \beta$-Faltblattanteil) zeigte die Kombination aus Algorithmus CDSSTR und Referenzdatensatz 7 mit $31 \%$ a-helicalem und 21\% $\beta$-Faltblattanteil. Daher wurde diese Methode als die für das zu untersuchende System geeignetste befunden und für die Sekundärstrukturbestimmung von Ezrin wt und Mutanten herangezogen.

Die Ergebnisse der CD-spektroskopischen Untersuchungen von Ezrin wt stimmen wie in Kapitel 4.2 dargestellt mit den Mutanten Ezrin T567A und Ezrin T567D bezüglich ihrer $\beta$-Faltblatt- und Schleifenanteile recht gut überein. Die Abweichungen der $\alpha$-helicalen und ungeordneten Strukturanteile sind hingegen signifikant unterschiedlich. Dies belegt, dass die Mutation des Threoninrestes 
T567 in beiden Fällen eine Strukturbeeinflussung nach sich zieht. Im Falle der Mutation zu Aspartat (T567D) wird diskutiert, dass eine Konformationsänderung des Proteins in Folge der Phosphorylierung an diesem regulatorischen Threoninrest auf sterische sowie elektrostatische Effekte zurückzuführen ist (57). Diese werden in vitro durch die Einführung der negativ geladenen Seitenkette von Aspartat nachgeahmt. Die Mutation von Threonin zu Alanin hingegen, wie sie bei Ezrin T567A vorliegt, bedeutet einen Austausch einer hydrophilen gegen eine hydrophobe Aminosäure. Gegenwärtig sind keine experimentellen Resultate literaturbekannt, welche einen direkten Hinweis darauf liefern, dass diese Mutation die Sekundärstruktur von Ezrin beeinflusst.

Ein interessantes Ergebnis wurde von Ishikawa et al. unter Verwendung der Radixinmutanten T564E und T564A gefunden (96). Die Mutante T564E wies anstelle des Threonins eine Glutamatseitenkette auf und ist vergleichbar mit der in dieser Arbeit verwendeten Threonin-Aspartat-Mutante. Ishikawa et al. konnten mit Hilfe von elektronenmikroskopischen Aufnahmen zeigen, dass die pseudophosphorylierte Form Radixin T564E einen Länge von 28-42 nm aufwies und gestreckt vorlag, während die dauerhaft inaktive Form Radixin T564A und der Wildtyp globuläre Formen annahmen und Durchmesser von 8-14 nm besaßen. Die vergleichsweise harschen experimentellen Bedingungen, unter denen diese Ergebnisse erzielt wurden (Aufsprühen einer proteinhaltigen Glycerinlösung auf Glimmer und anschließendes Trocknen unter Hochvakuum), müssen allerdings kritisch betrachtet werden. Liu et al. publizierten ein ähnliches Resultat auf Basis von rasterkraftmikroskopischen Messungen an getrocknetem Ezrin wt, T567A und T567D (97). Die strukturellen Unterschiede zwischen Ezrin wt und Ezrin T567D, die in der vorliegenden Arbeit mittels CD-spektroskopischer Untersuchungen gefunden wurden, können im Kontext der zitierten Studien als Konformationsänderung der pseudophosphorylierten Variante hin zu einer geöffneten Form interpretiert werden. Die per CD-Spektroskopie gefundenen Unterschiede in den Sekundärstrukturen von Ezrin wt und Ezrin T567A hingegen können nicht auf eine solch deutliche Streckung der Proteinstruktur zurückgeführt werden. Vielmehr scheint die T567A-Mutation subtile Strukturveränderungen innerhalb der globulären Konformation zu verursachen, die nur mit Hilfe von hochauflösenden Strukturanalysen genauer definiert werden könnten. 


\subsubsection{Fluoreszenzmarkierung von Ezrin wt und Ezrin T567D mittels AlexaFluor633-maleimid}

Die Proteine Ezrin wt und Ezrin T567D wurden für fluoreszenzmikroskopische Untersuchungen mit einem Fluoreszenzfarbstoff markiert. Die Wahl des Fluoreszenzfarbstoffes wurde auf Basis von folgenden Überlegungen getroffen: Zunächst sollten die Möglichkeiten der Verknüpfung dieses Farbstoffes an die Proteinstruktur nicht zu zahlreich sein, um eine Überladung des Proteins mit Farbstoff zu vermeiden. Des Weiteren sollte der Farbstoff klein sein, um eine möglichst geringe Beeinflussung der nativen Konformation des Proteins zu gewährleisten. Zuletzt sollte der Farbstoff eine hohe Photostabilität aufweisen.

Da beide Ezrin-Versionen über lediglich zwei Cysteinreste (C117, C284) verfügen, wurde ein Maleimid-basierter Farbstoff ausgewählt, welcher kovalent über eine stabile Kohlenstoff-Schwefel-Bindung an das Protein gebunden wird. Da diese Reaktion spontan abläuft, konnte sie unter milden Bedingungen in gepufferter wässriger Lösung (E1-Puffer) durchgeführt werden. Sowohl durch SDS-PAGE (siehe Kapitel 4.3) als auch durch QCM-Messungen (siehe Kapitel 0) konnte bewiesen werden, dass die strukturelle Integrität des Proteins nach der Markierungs-Reaktion erhalten bleibt und die Bindefähigkeit des Proteins für $\mathrm{PIP}_{2}$ unverändert ist.

Die exakte chemische Struktur des Farbstoffs ist patentrechtlich geschützt und geheim. Jedoch wird vom Hersteller eine ungefähre Masse von 1,3 kDa angegeben, welche verglichen mit den etwa $28 \mathrm{kDa}$ aufweisenden GFPabgeleiteten Farbstoffen, wie sie für in vivo-Experimente häufig verwendet werden, sehr gering ist.

Die erzielte Labelingrate war für beide Proteine sehr gut. Für Ezrin wt wurde ein Farbstoff-zu-Protein-Verhältnis von 1,4 erhalten. Für die aktive Mutante Ezrin T567D konnte eine etwas höhere Labelingrate von ca. 2 erzielt werden. Möglicherweise ist hierbei einer der beiden Cysteinreste durch die gestreckte Konformation des Proteins besser zugänglich als im Wildtyp des Proteins. In beiden Ansätzen konnte durch Größenausschlusschromatographie keine vollständige Abtrennung des abreagierten, freien Farbstoffs erreicht werden, was sich in einem Anstieg der Fluorophorkonzentration mit steigenden Fraktionszahlen äußerte. Da mit einem 20-fachen Überschuss des 
fluoreszierenden Reagenz gearbeitet wurde, ist es wahrscheinlich, dass eine Überladung der Säule stattgefunden hat und nach Auffangen der ersten Proteinfraktionen auch freier Farbstoff aus der Säule ausgetreten ist. Daher könnte eine Verbesserung der Reinheit des fluoreszenzmarkierten Proteins vermutlich durch ein größeres Säulenvolumen erreicht werden. Allerdings stellte dieser geringe Anteil an freiem Farbstoff für die folgenden Studien keine Einschränkung dar. Da hierbei das fluoreszenzmarkierte Protein spezifisch an Membranoberflächen immobilisiert wurde und anschließendes Spülen mit Puffer ungebundene Moleküle entfernte, wurde gewissermaßen dort ein weiterer Reinigungsschritt vorgenommen. Dadurch wird sichergestellt, dass das in den fluoreszenzmikroskopischen Experimenten beobachtete Fluoreszenzlicht ausschließlich auf membrangebundenes Protein zurückzuführen ist. 


\section{QUARZMIKROWAAGESTUDIEN ZUR ADSORPTION VON EZRIN AN FESTKÖRPERUNTERSTÜTZTEN MEMBRANEN}

Zur Untersuchung der spezifischen Wechselwirkung von Ezrin und $\mathrm{PIP}_{2}$ wurde die Quarzmikrowaagetechnik eingesetzt. Diese Technik erlaubt eine labelfreie und zeitaufgelöste Detektion von Adsorptionsprozessen an einer Grenzfläche, zum Beispiel die Adsorption von Proteinen an einer auf dem Schwingquarz der Quarzmikrowaage präparierten Lipidmembran. Dabei können sowohl kinetische als auch thermodynamische Parameter der Wechselwirkung quantifiziert werden. Im Rahmen dieser Arbeit wurde die Quarzmikrowaage verwendet, um die Wechselwirkung von $\mathrm{PIP}_{2}$ sowie DOGS-NTA-Ni mit Ezrin wt und seinen Mutanten zu charakterisieren und zu vergleichen. Diese Ergebnisse wurden dazu genutzt, eine vollständig proteinbelegte Oberfläche zu generieren, die zur Messung der F-Aktin-Affinität als Funktion der beiden Aktivierungsparameter, Bindung an $\mathrm{PIP}_{2}$ sowie Phosphorylierung, dienen sollte.

Hierzu wurden festkörperunterstützte Lipidmembranen bestehend aus POPC/PIP 2 im Verhältnis 9:1 hergestellt. Neben Membranen mit dem spezifischen Interaktionspartner $\mathrm{PIP}_{2}$ wurden in einer weiteren Versuchsreihe Membranen aus dem Lipidgemisch DOPC/DOGS-NTA-Ni eingesetzt. Als alternative Methode zur Immobilisierung von Ezrin wurde hierbei der $\mathrm{N}$-terminale His-Tag des Proteins über das NTA-Ni-fusionierte Lipid komplexiert und so das Protein in einer definierten, einheitlichen Orientierung an der Lipidmembran gebunden.

\subsection{Impedanzspektroskopie an festkörperunterstützten Membranen}

Zur Messung der Adsorption von Ezrin an einer festkörperunterstützen Membran war es notwendig, zunächst die Qualität der Membranen zu überprüfen und sicherzustellen, dass diese vollständig ausgebildet waren und keine Defekte 
aufwiesen. Hierzu eignete sich die Impedanzspektroskopie als schnelle und nicht-invasive Methode zur Charakterisierung der elektrischen Eigenschaften der Grenzschicht.

Die Präparation erfolgte gemäß der in Kapitel 3.4.2 aufgeführten Beschreibung. Zunächst wurde auf der Goldelektrode des Schwingquarzes eine Oktanthiolmonoschicht und anschließend mittels Spreiten von unilamellaren Vesikeln eine Doppelschicht erzeugt. Nach jedem Präparationsschritt wurde ein Impedanzspektrum der entstandenen Schicht gemessen. Die Daten wurden in einem Bode-Diagramm dargestellt, wie es exemplarisch in Abbildung $5.1 \mathrm{zu}$ sehen ist.

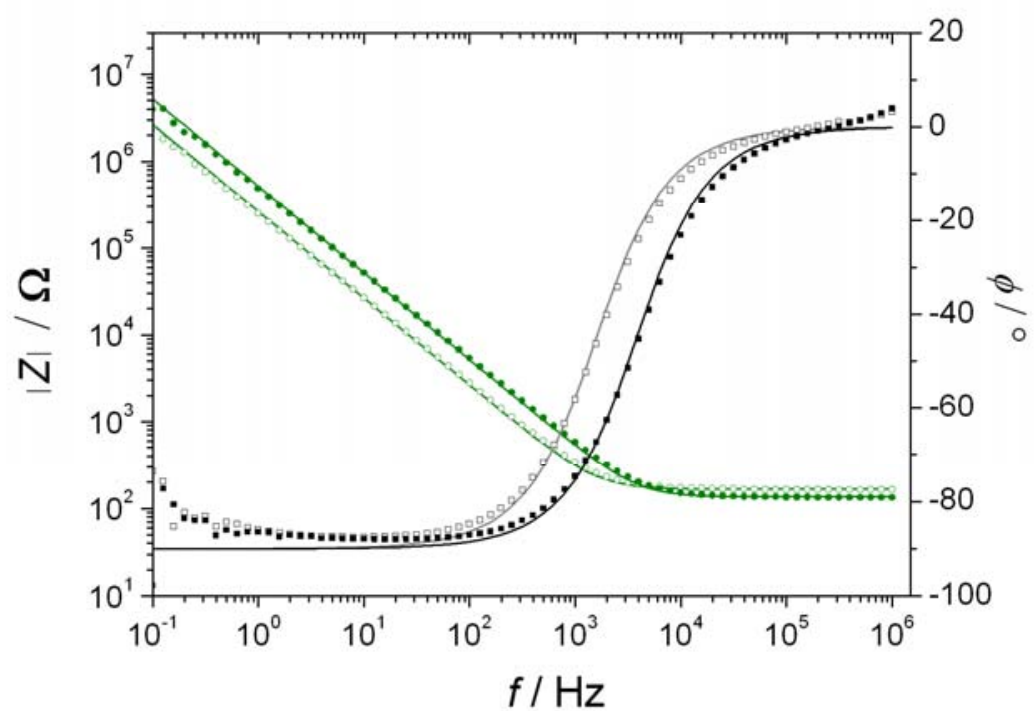

Abbildung 5.1: Impedanzspektrum einer Oktanthiol (OT)-Monoschicht $(0,0)$ und der OTPOPC/PIP 2 (98:2)-Doppelschicht $(\square, \boldsymbol{\square})$ auf der Goldelektrode eines Schwingquarzes. Aufgetragen sind der Betrag der Impedanz $|Z| / \Omega$ sowie der Phasenwinkel $\Phi /^{\circ}$ als Funktion der Frequenz der angelegten Wechselspannung. Die durchgezogenen Linien repräsentieren die Anpassung der Parameter des Ersatzschaltbildes (siehe Abbildung $3.5 \mathrm{C}$ ) an die gemessenen Werte. Für die OT-Monoschicht ergibt sich daraus eine spezifische Kapazität von $2,02 \mu \mathrm{F} / \mathrm{cm}^{2}$ und für die OT$\mathrm{POPC} / \mathrm{PIP}_{2}$ (98:2)-Doppelschicht eine spezifische Kapazität von $1,00 \mu \mathrm{F} / \mathrm{cm}^{2}$.

Durch Anpassung der Parameter des in Abbildung $3.5 \mathrm{C}$ gezeigten Ersatzschaltbildes konnten die spezifischen Kapazitäten der gebildeten Schichten ermittelt werden. Die Kapazität der Oktanthiol-Monoschicht konnte im Mittel zu $(2,2 \pm 0,2) \mu \mathrm{F} / \mathrm{cm}^{2} \quad(n=139)$ bestimmt werden. Die Kapazität der Lipidmonoschicht $C_{\text {Lipid }}$ kann gemäß Gleichung [5.1] aus der Gesamtkapazität der Doppelschicht $C_{\text {OT+Lipid }}$ berechnet werden: 


$$
C_{\text {Lipid }}=\frac{1}{1 / C_{\text {OT+Lipid }}-1 / C_{\text {OT }}}
$$

So ergab sich für die Lipidmischung DOPC/DOGS-NTA-Ni (9:1) eine mittlere spezifische Kapazität von $(2,6 \pm 0,2) \mu \mathrm{F} / \mathrm{cm}^{2} \quad(n=27)$. Für die $\mathrm{PIP}_{2}$-haltigen Lipidmembranen konnte eine spezifische Kapazität der Lipidmonoschicht von $(3,3 \pm 0,3) \mu \mathrm{F} / \mathrm{cm}^{2} \quad(n=30)$ gefunden werden. Es konnte keine systematische Abhängigkeit des $\mathrm{PIP}_{2}$-Gehalts, welcher für einige Messungen zwischen 0-10 mol\% variiert wurde, gefunden werden. Auch der Zusatz von $30 \mathrm{~mol} \%$ Cholesterin bewirkte keine signifikante Veränderung der spezifischen Kapazität der erhaltenen Lipidmonoschicht.

\subsection{Quarzmikrowaagestudien zur Adsorption von Proteinen an festkörperunterstützten Membranen}

Mit Hilfe des in Kapitel 3.2.7 beschriebenen Messaufbaus wurden die Bindungseigenschaften der Proteine N-ERMAD, Ezrin wt, Ezrin T567A und Ezrin T567D an festkörperunterstützte Membranen untersucht. Die verwendeten Membranen bestanden aus DOPC/DOGS-NTA-Ni (9:1) oder POPC/PIP 2 (9:1). Es konnte in vorhergehenden Experimenten an festkörperunterstützten Membranen bewiesen werden, dass bei einem Anteil von $10 \mathrm{~mol} \%$ Rezeptorlipid eine maximale Oberflächenbedeckung gewährleistet ist (98). Darüber hinaus konnte im Rahmen der vorliegenden Arbeit anhand von Fluoreszenzbildern (siehe Kapitel 6.5) gezeigt werden, dass $\mathrm{PIP}_{2}$ homogen in der Membran verteilt ist und keine Domänenbildung zu beobachten war.

Zur Auswertung dieser Adsorptionsstudien wurde zunächst das Adsorptionsmodell nach Langmuir angewendet. Die zugrunde liegende Theorie zur Beschreibung der Thermodynamik von Adsorptionen sollen im Folgenden vorgestellt werden. Daran anschließend werden die aufgenommenen Daten und deren Auswertung präsentiert.

\subsubsection{Grundlagen der Langmuir-Adsorptionsisotherme}

Die Adsorption von Proteinen an festkörperunterstützen Membranen ist eine Grenzflächenreaktion, zu deren Beschreibung in vielen Fällen die Langmuir- 
Adsorptionsisotherme herangezogen werden kann. Dabei ist das dynamische Gleichgewicht von Adsorption und Desorption eines Stoffes an einer Grenzfläche von der Temperatur und der Konzentration des Adsorbats abhängig. Der Ansatz zur Beschreibung der Adsorption nach Langmuir ist gültig unter folgenden Annahmen:

1. Die Adsorption von Molekülen an der Grenzfläche führt höchstens zu einer Monolage an adsorbiertem Material.

2. Die Oberflächenbeschaffenheit ist einheitlich und alle Bindungsstellen sind gleichwertig.

3. Die Besetzung der Bindungsstellen erfolgt unabhängig voneinander.

Zur Beschreibung der Thermodynamik der Bindung eines gelösten Liganden L an einen Bindungsplatz $B$ ist es nötig, neben dem Bindungsprozess auch Transportprozesse an die Grenzfläche zu berücksichtigen. Durch die Adsorption des Liganden an einen Bindungsplatz nimmt die Konzentration des freien Liganden $c_{\mathrm{L}}$ in der Wechselwirkungsschicht $\mathrm{ab}$, was durch Massentransport an die Oberfläche ausgeglichen wird. Für den Fall, dass dieser Massentransport mindestens zehnmal schneller als die Kinetik der Adsorption $k^{+}$ist, ist der geschwindigkeitsbestimmende Schritt die Bindung des Liganden, es handelt sich dann um eine ratenkontrollierte Reaktion.

Das dynamische Gleichgewicht von freiem Ligand $L$ und gebundenem Ligand $L$ $B$ ist:

$$
\mathrm{L}+\mathrm{B} \underset{k}{\stackrel{k^{+}}{\rightleftharpoons}} \mathrm{L}-\mathrm{B}
$$

mit den Geschwindigkeitskonstanten $k^{+}$für die Adsorption und $k$ für die Desorption. Damit ergibt sich für die Adsorptionsgeschwindigkeit des Liganden die Differentialgleichung:

$$
\frac{\mathrm{d} \Gamma_{\mathrm{L}-\mathrm{B}}(t)}{\mathrm{d} t}=k^{+} \Gamma_{\mathrm{B}}(t) c_{\mathrm{L}}(t)-k^{-} \Gamma_{\mathrm{L}-\mathrm{B}}(t) .
$$


Dabei ist $c_{\mathrm{L}}(t)$ die Konzentration des freien Liganden in Lösung und $\Gamma_{\mathrm{B}}(t)$ bzw $\Gamma_{\mathrm{L}-\mathrm{B}}(t)$ die Flächenkonzentration der freien Bindungsplätze bzw. des gebundenen Liganden an der Oberfläche zum Zeitpunkt $t$. Über die Substitution der freien Bindungsplätze $\Gamma_{\mathrm{B}}(t)$ durch $\Gamma_{\mathrm{B}, 0}-\Gamma_{\mathrm{L}-\mathrm{B}}(t)$, wobei $\Gamma_{\mathrm{B}, 0}$ die Konzentration der freien Bindungsplätze zum Zeitpunkt $t=0$ ist, und die Annahme, dass der Ligand $\mathrm{L}$ im Überschuss vorliegt und $c_{\mathrm{L}}(t)$ daher mit der Anfangskonzentration $c_{\mathrm{L}, 0}$ gleichgesetzt werden kann, gelangt man zu folgendem Ausdruck:

$$
\frac{\mathrm{d} \Gamma_{\mathrm{L}-\mathrm{B}}(t)}{\mathrm{d} t}+\left(k^{+} c_{\mathrm{L}, 0}+k^{-}\right) \Gamma_{\mathrm{L}-\mathrm{B}}(t)=k^{+} c_{\mathrm{L}, 0} \Gamma_{\mathrm{B}, 0} .
$$

Im Gleichgewichtsfall sind die Geschwindigkeiten der Adsorption und der Desorption gleich und $\mathrm{d} \Gamma_{\mathrm{L}-\mathrm{B}}(t) / \mathrm{d} t=0$; damit ergibt sich:

$$
k^{+} c_{\mathrm{L}, 0}\left(\Gamma_{\mathrm{B}, 0}-\Gamma_{\mathrm{L}-\mathrm{B}}\right)=k^{-} \Gamma_{\mathrm{L}-\mathrm{B}},
$$

wobei $\Gamma_{\mathrm{L}-\mathrm{B}}$ die Konzentration des gebundenen Liganden im Gleichgewicht bezeichnet. Wenn man des Weiteren berücksichtigt, dass gilt:

$$
K_{\mathrm{D}}=\frac{k^{-}}{k^{+}}
$$

und

$$
\Theta=\frac{\Gamma_{\mathrm{L}-\mathrm{B}}}{\Gamma_{\mathrm{B}, 0}}
$$

mit $K_{\mathrm{D}}$ als Dissoziationskonstante und $\Theta$ als Belegungsgrad mit $0 \leq \Theta \leq 1$, folgt: 


$$
\Theta=\frac{C_{\mathrm{L}, 0}}{K_{\mathrm{D}}+C_{\mathrm{L}, 0}} .
$$

Eine Auftragung des Belegungsgrades in Abhängigkeit der Konzentration bei konstanter Temperatur liefert eine Adsorptionsisotherme, aus der sich über Anpassung des Parameters $K_{D}$ die Dissoziationskonstante der beschriebenen Gleichgewichtsreaktion quantitativ bestimmen lässt.

Die Oberflächenkonzentration des gebundenen Liganden wurde in dieser Arbeit experimentell mit Hilfe der Quarzmikrowaage bestimmt. Die im Experiment detektierte Änderung der Resonanzfrequenz $\Delta f$ ist nach Sauerbrey direkt proportional zur abgeschiedenen Masse. Für den Belegungsgrad ergibt sich:

$$
\Theta=\frac{\Delta f_{e}}{\Delta f_{\max }},
$$

wobei $\Delta f_{\mathrm{e}}$ die maximale Frequenzänderung nach Zugabe einer definierten Ligand-konzentration $c_{\llcorner, 0}$ und $\Delta f_{\max }$ bei maximaler Sättigung der zur Verfügung stehenden Bindungsstellen durch den Liganden bezeichnet. Die Kombination von Gleichung [5.7] mit [5.8] liefert einen Ausdruck für die Abhängigkeit der Frequenzänderung $\Delta f_{\mathrm{e}}$ von der Ligandkonzentration $c_{\llcorner, 0}$, die sogenannte Langmuir-Isotherme:

$$
\Delta f_{\mathrm{e}}=\Delta f_{\text {max }} \frac{\mathrm{C}_{\mathrm{L}, 0}}{K_{\mathrm{D}}+\mathrm{C}_{\mathrm{L}, 0}} .
$$

\subsubsection{Ezrin wt}

Zunächst wurde die Adsorption von Ezrin wt an $\mathrm{PIP}_{2}$ - sowie DOGS-NTA-Nihaltigen festkörperunterstützten Membranen mittels der Quarzmikrowaagetechnik untersucht. Hierbei sollten die Bindungsaffinität sowie die maximale Frequenzänderung bei vollständiger Sättigung des Systems quantifiziert werden. In Abbildung 5.2 sind repräsentative QCM-Messkurven der Bindung von Ezrin wt an eine DOGS-NTA-Ni-haltige Membran (A) sowie an eine PIP $_{2}$-haltige Membran (B) gezeigt. 

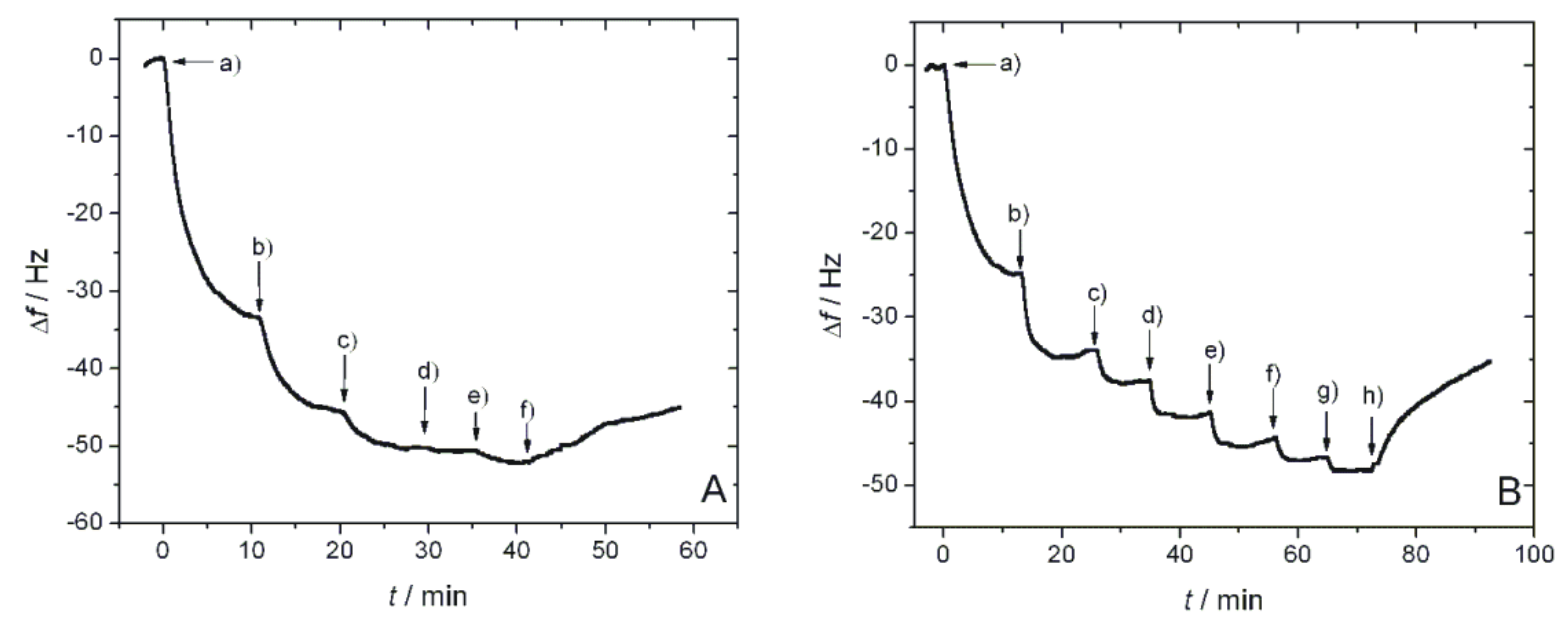

Abbildung 5.2: A Zeitaufgelöste Änderung der Resonanzfrequenz eines $5 \mathrm{MHz}$ AT-cut-Quarzes, funktionalisiert mit einer OT-DOPC/DOGS-NTA-Ni (9:1)-Doppelschicht nach schrittweiser Erhöhung der Konzentration von Ezrin wt und anschließendem Spülen mit Puffer. Konzentrationen: a) $13 \mathrm{~nm}$ b) $39 \mathrm{~nm}$ c) $90 \mathrm{nM}$ d) $161 \mathrm{~nm}$ e) $249 \mathrm{~nm}$ f) $280 \mathrm{~nm}$ g) spülen mit Puffer (E1: $20 \mathrm{~mm}$ Tris/ $\mathrm{HCl}, 50 \mathrm{~mm} \mathrm{KCl,} \mathrm{0,1} \mathrm{mM} \mathrm{EDTA,} \mathrm{0,1} \mathrm{mm} \mathrm{NaN}_{3}$, pH 7,4).

B Zeitaufgelöste Änderung der Resonanzfrequenz eines $5 \mathrm{MHz}$ AT-cut-Quarzes, funktionalisiert mit einer OT-POPC/PIP 2 (9:1)-Doppelschicht nach schrittweiser Erhöhung der Konzentration von Ezrin wt und anschließendem Spülen mit Puffer. Konzentrationen: a) $19 \mathrm{nM}$ b) $44 \mathrm{nM}$ c) $91 \mathrm{nM}$ d) $148 \mathrm{~nm}$ e) $233 \mathrm{~nm}$ f) $282 \mathrm{~nm} \mathrm{~g}$ ) spülen mit Puffer (E1: $20 \mathrm{~mm}$ Tris/HCl, $50 \mathrm{~mm} \mathrm{KCl,} \mathrm{0,1} \mathrm{mm} \mathrm{EDTA,}$ $\left.0,1 \mathrm{mM} \mathrm{NaN}_{3}, \mathrm{pH} 7,4\right)$.

Aufgetragen sind exemplarisch jeweils die Änderungen der Resonanzfrequenz $\Delta f_{(t)}=f_{(t)}-f_{(t=0)}$ nach Zugabe verschiedener Konzentrationen von Ezrin wt zur festkörperunterstützten Membran im Durchfluss. Dabei bezeichnet $f_{(\mathrm{t})}$ die Frequenz zum Zeitpunkt $t$ und $f_{(t=0)}$ die Frequenz zu Beginn der Messung. Alle Messungen wurden bei $20^{\circ} \mathrm{C}$ durchgeführt. Es ist zu erkennen, dass die Resonanzfrequenz des Quarzes bei schrittweiser Erhöhung der Ezrinkonzentration abnimmt, bis schließlich die maximale Resonanzfrequenzänderung im Fall der OT-DOPC/DOGS-NTA-Ni (9:1)Doppelschicht bei ca. $53 \mathrm{~Hz}$, im Fall der OT-POPC/PIP 2 (9:1)-Doppelschicht bei ca. $58 \mathrm{~Hz}$ erreicht war. Eine weitere Erhöhung der Proteinkonzentration führte zu keiner weiteren Änderung der Resonanzfrequenz, was darauf schließen lässt, dass die Resonatoroberfläche mit Protein abgesättigt war. Das anschließende Spülen mit Puffer bewirkte eine Erhöhung der Resonanzfrequenz um $9 \mathrm{~Hz}$ bzw. $16 \mathrm{~Hz}$, hierbei wurde also ein Teil des gebundenen Proteins wieder von der Resonatoroberfläche abgelöst. Dies kann einerseits auf unspezifisch gebundene Anteile, andererseits auf eine partielle Reversibilität der Bindung hindeuten. 
Die Auftragung der Resonanzfrequenzänderung $\Delta f_{\mathrm{e}}$ im Gleichgewicht gegen die eingesetzte Proteinkonzentration liefert die entsprechenden Adsorptionsisothermen. So kann zunächst die maximale Resonanzfrequenzänderung $\Delta f_{\max }$ aus der Auftragung ermittelt werden. Darüber hinaus kann die minimal nötige Konzentration an Protein, um diese maximale Frequenzänderung hervorzurufen, aus dem Sättigungsbereich der Isotherme abgelesen werden. Diese Konzentration wird als Sättigungskonzentration bezeichnet. In Abbildung 5.3 sind jeweils zwei einzelne Messungen als Adsorptionsisothermen der Bindung von Ezrin wt an DOGS-NTA-Ni-haltige (A) bzw. PIP $_{2}$-haltige (B) Membranen dargestellt. In beiden untersuchten Messsystemen trat eine gewisse Streuung der Daten bezüglich der maximalen Frequenzänderung auf. Die dargestellten Kurven repräsentieren die jeweils maximalen und minimalen Gesamtfrequenzänderungen und damit die Streubreite der Datenpunkte, die sich für die Adsorption an DOGS-NTA-Ni-haltige Membranen auf ca. $30 \mathrm{~Hz}$ belief. Für die Adsorption an $\mathrm{PIP}_{2}$-haltige Membranen wurde eine Streuung der maximalen Frequenzänderung über einen Bereich von ca. $20 \mathrm{~Hz}$ gefunden.
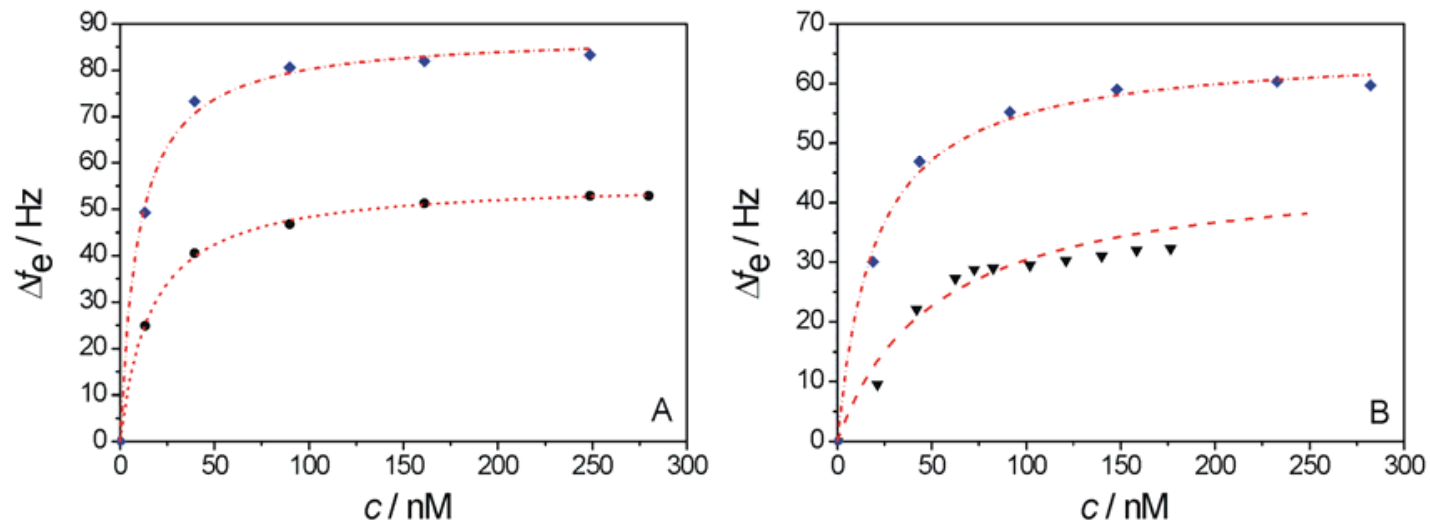

Abbildung 5.3: Adsorptionsisothermen der Bindung von A Ezrin wt an DOGS-NTA-Ni-haltige festkörperunterstützte Membranen. B Adsorptionsisothermen der Bindung von Ezrin wt an $\mathrm{PIP}_{2^{-}}$ haltige festkörperunterstützte Membranen Die verschiedenen Farben repräsentieren unterschiedliche Messungen. Die dargestellten Linien repräsentieren eine Anpassung der Langmuir-Isotherme an die Datenpunkte. 
Die maximale Resonanzfrequenzänderung wurde für jede Einzelmessung individuell bestimmt. Im statistischen Mittel betrug die maximale Resonanzfrequenzänderung für die Bindung an DOGS-NTA-Ni-haltige Membranen $(67 \pm 19) \mathrm{Hz}(n=3)$. Die Adsorption von Ezrin wt an $\mathrm{PIP}_{2}$-haltige Membranen bewirkte im Mittel einen maximalen Frequenzabfall von $(52 \pm 13) \mathrm{Hz}$ $(n=3)$. Für weiterführende Auswertungen wurde eine Normierung der Daten vorgenommen, um eine bessere Übersichtlichkeit der Daten zu gewähren sowie alle aufgenommenen Kurven in die Ermittlung der Dissoziationskonstante des gebildeten Komplexes einzubeziehen. In erster Näherung kann die Adsorption des Proteins anhand des Langmuir-Adsorptionsmodells beschrieben werden (siehe Kapitel 5.2). Die Anpassung der Langmuir-Adsorptionsisotherme an die normierten Daten ist in Abbildung 5.4 gezeigt.
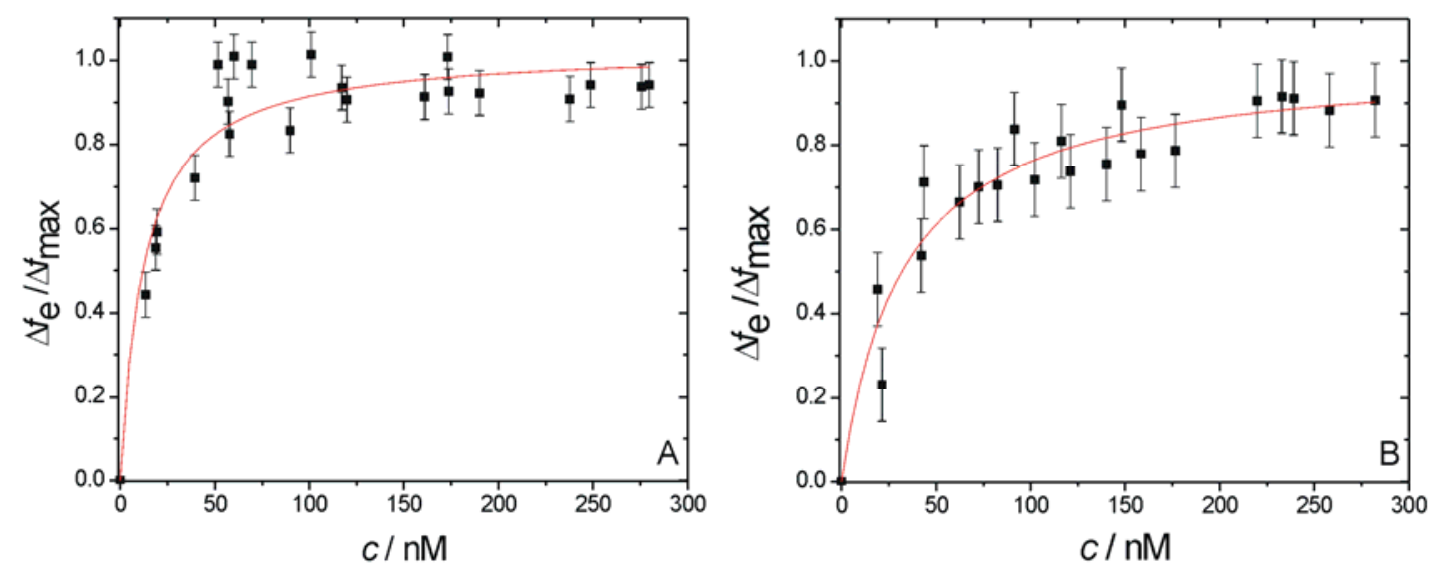

Abbildung 5.4 Auftragung der normierten Resonanzfrequenzänderung $\Delta f_{\mathrm{e}} / \Delta f_{\max }$ als Funktion der eingesetzten Proteinkonzentration $c$. Die durchgezogene Linie repräsentiert eine Anpassung an die Daten nach dem Langmuir-Adsorptionsmodell (nach Gleichung [5.9]).

A: Normierte Adsorptionsisotherme der Bindung von Ezrin wt an eine OT-DOPC/DOGS-NTA-Ni (9:1)-Doppelschicht. Die Anpassung der Langmuir-Isotherme an die Datenpunkte ergab eine Dissoziationskonstante von $K_{\mathrm{D}}=(12 \pm 2) \mathrm{nM}$.

B: Normierte Adsorptionsisotherme der Bindung von Ezrin wt an eine OT-POPC/PIP 2 (9:1)Doppelschicht. Die Anpassung der Langmuir-Isotherme an die Datenpunkte ergab eine Dissoziationskonstante von $K_{\mathrm{D}}=(32 \pm 6) \mathrm{nM}$.

Die Fehlerbalken in der in Abbildung 5.4 gezeigten Auftragung wurden durch die Mittelwertbildung der aus verschiedenen Messungen ermittelten Werte von $\Delta f_{\max }$ bei gleicher eingesetzter Proteinkonzentration und darauffolgender Berechnung 
der Standardabweichung berechnet. Es ergaben sich aus der Anpassung der Langmuir-Isotherme an die Datenpunkte eine Dissoziationskonstante von $K_{\mathrm{D}}=(12 \pm 2) \mathrm{nM}$ für die Bindung von Ezrin wt an DOGS-NTA-Ni-haltige Membranen. Die Bindung von Ezrin wt an $\mathrm{PIP}_{2}$-haltige Membranen wies eine Dissoziationskonstante von $K_{\mathrm{D}}=(32 \pm 6) \mathrm{nM}$ auf. Die Sättigung der DOGS-NTANi-haltigen Membran war ab einer Ezrin wt-Konzentration von ca. $100 \mathrm{nM}$ gegeben, die der $\mathrm{PIP}_{2}$-haltigen Membran lag etwas höher mit ca. $125 \mathrm{nM}$.

\subsubsection{Ezrin T567A}

In analoger Weise wurden Experimente zur Adsorption von Ezrin T567A an festkörperunterstützen Membranen durchgeführt, um das Bindungsverhalten des Proteins an beiden gewählten Membransystemen zu charakterisieren. In Abbildung 5.5 sind repräsentative Messungen an DOGS-NTA-Ni-haltigen (A) sowie $\mathrm{PIP}_{2}$-haltigen (B) Doppelschichten unter Verwendung verschiedener Konzentrationen von Ezrin T567A gezeigt. 

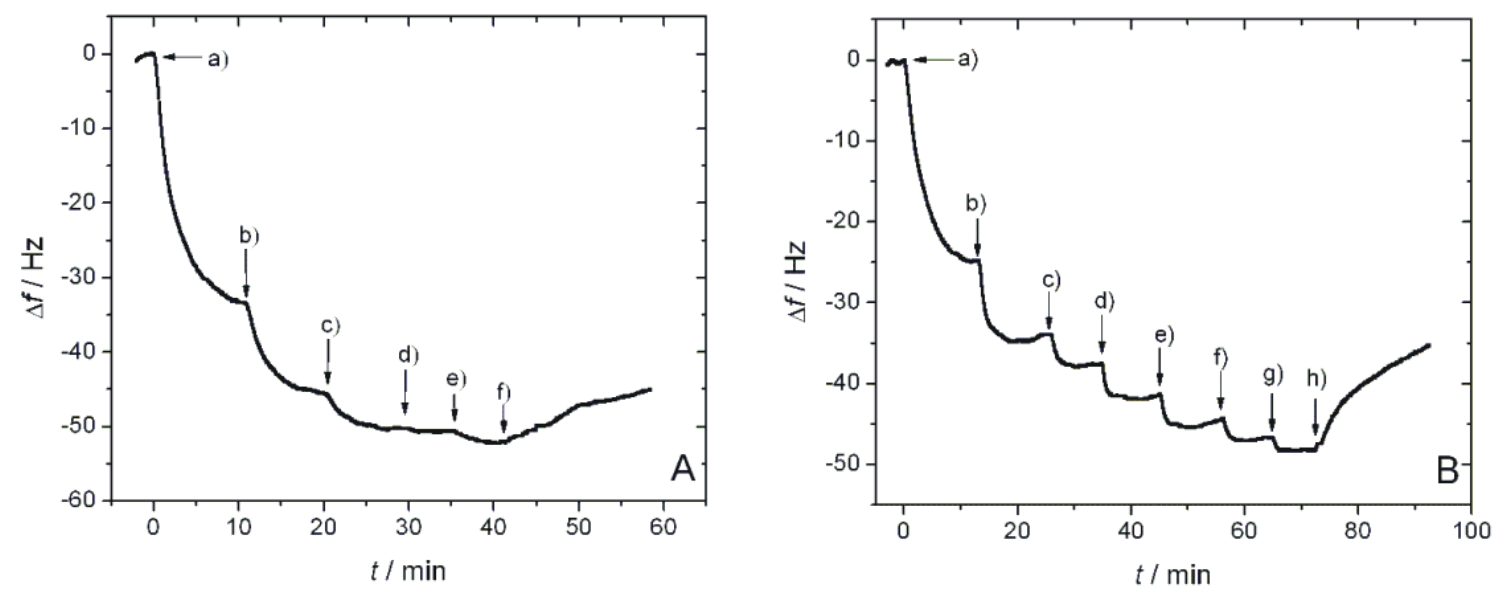

Abbildung 5.5 A Zeitaufgelöste Änderung der Resonanzfrequenz eines $5 \mathrm{MHz}$ AT-cut-Quarzes, funktionalisiert mit einer OT-DOPC/DOGS-NTA-Ni (9:1)-Doppelschicht nach schrittweiser Erhöhung der Konzentration von Ezrin T567A und anschließendem Spülen mit Puffer. Konzentrationen: a) $35 \mathrm{~nm}$ b) $104 \mathrm{nM}$ c) $231 \mathrm{nM}$ d) $348 \mathrm{nM}$ e) $488 \mathrm{nM}$ f) spülen mit Puffer (E1: 20 $\mathrm{mM}$ Tris/ $\mathrm{HCl}, 50 \mathrm{~mm} \mathrm{KCl}, 0,1 \mathrm{~mm}$ EDTA, 0,1 $\mathrm{mM} \mathrm{NaN}_{3}, \mathrm{pH}$ 7,4).

B Zeitaufgelöste Änderung der Resonanzfrequenz eines $5 \mathrm{MHz}$ AT-cut-Quarzes, funktionalisiert mit einer OT-POPC/PIP 2 (9:1)-Doppelschicht nach schrittweiser Erhöhung der Konzentration von Ezrin T567A und anschließendem Spülen mit Puffer. Konzentrationen: a) $36 \mathrm{nM} \mathrm{b)} 70 \mathrm{nM} \mathrm{c)} 104$ nM d) $201 \mathrm{~nm} \mathrm{e)} 291 \mathrm{~nm}$ f) $376 \mathrm{~nm} \mathrm{~g}) 455 \mathrm{~nm} \mathrm{~h}$ ) spülen mit Puffer (E1: $20 \mathrm{~mm} \mathrm{Tris/HCl,} 50 \mathrm{~mm} \mathrm{KCl}$, $0,1 \mathrm{~mm}$ EDTA, $\left.0,1 \mathrm{~mm} \mathrm{NaN}_{3}, \mathrm{pH} 7,4\right)$.

Die schrittweise Erhöhung der Konzentration von Ezrin T567A führte im Fall der DOGS-NTA-Ni-haltigen Membran zu einer maximalen Verringerung der Resonanzfrequenz um $52 \mathrm{~Hz}(\mathrm{~A})$, im Fall der $\mathrm{PIP}_{2}$-haltigen Membran von $48 \mathrm{~Hz}$ (B). Der anschließend eingeleitete Spülvorgang führte zu einer Frequenzerhöhung von $7 \mathrm{~Hz}(\mathrm{~A})$ beziehungsweise $12 \mathrm{~Hz}(\mathrm{~B})$. Auch hier wurde demnach, wie schon zuvor bei Ezrin wt gezeigt wurde, durch das Spülen mit reinem Puffer eine partielle Ablösung des Proteins von der Sensoroberfläche induziert.

Die Auftragung der resultierenden Resonanzfrequenzänderungen gegen die eingesetzte Proteinkonzentration führte zu den in Abbildung 5.6 aufgeführten Adsorptionsisothermen der Bindung von Ezrin T567A an DOGS-NTA-Ni-haltige (A) bzw. PIP ${ }_{2}$-haltige Membranen (B). Es sind jeweils zwei Messungen dargestellt, die die Grenzwerte der maximalen und minimalen Frequenzänderung markieren. Weitere aufgenommene Messkurven befanden sich zwischen den dargestellten Kurven. Die Streubreite der maximalen Frequenzänderung betrug für beide Membransysteme ca. $33 \mathrm{~Hz}$. Aus den einzelnen Messungen wurden die 
mittleren maximalen Resonanzfrequenzänderungen $\Delta f_{\max } \quad \mathrm{zu} \quad(58 \pm 13) \mathrm{Hz}$ (DOGS-NTA-Ni, $n=5)$ beziehungsweise $(71 \pm 19) \mathrm{Hz}\left(\mathrm{PIP}_{2}, n=6\right)$ bestimmt.
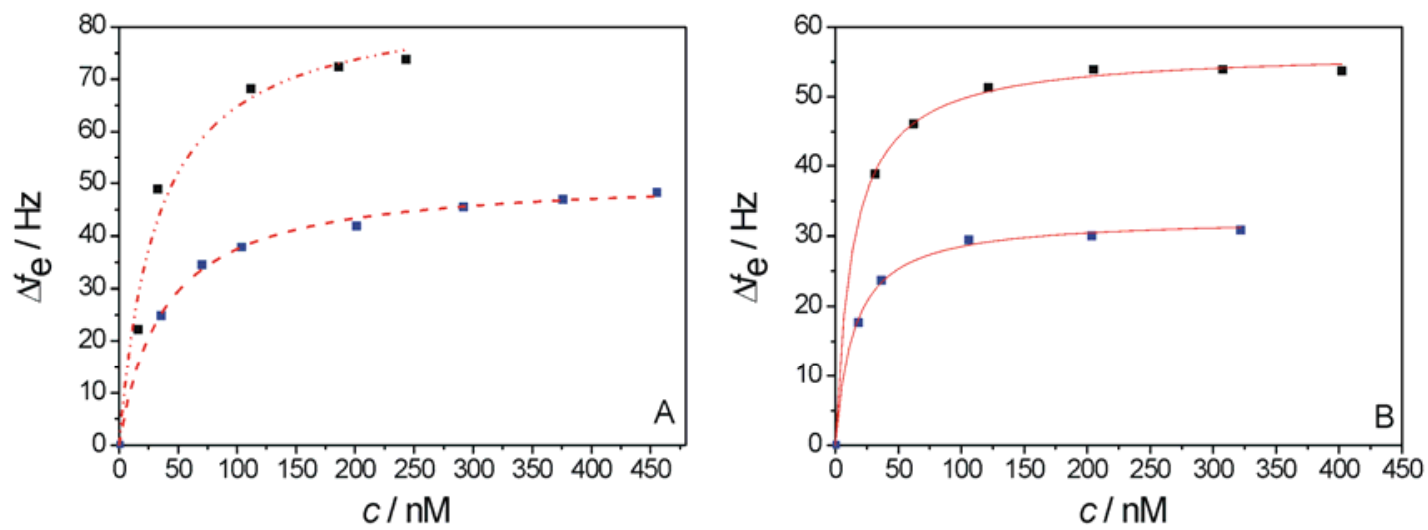

Abbildung 5.6 A Adsorptionsisotherme der Bindung von Ezrin T567A an DOGS-NTA-Ni-haltige festkörperunterstützte Membranen. Die verschiedenen Farben repräsentieren unterschiedliche Messungen. B Adsorptionsisotherme der Bindung von Ezrin T567A an $\mathrm{PIP}_{2}$-haltige festkörperunterstützte Membranen. Die dargestellten Kurven repräsentieren eine Anpassung der Langmuir-Isotherme an die Datenpunkte.

Eine Dissoziationskonstante der Bindung wurde aus einer Anpassung der Langmuir-Isotherme an die normierten ermittelten Daten bestimmt. Dabei ergab sich für die Bindung von Ezrin T567A an DOGS-NTA-Ni ein Wert von $K_{\mathrm{D}}=(31 \pm 4) \mathrm{nM}$ und für die Bindung an $\mathrm{PIP}_{2}$ ebenfalls ein Wert von $K_{\mathrm{D}}=(31 \pm 3) \mathrm{nM}$. Die entsprechenden Auftragungen sind in Abbildung 5.7 aufgeführt. Hieraus lässt sich auch die Sättigungskonzentration der Systeme ablesen: Für DOGS-NTA-Ni-haltige Membranen konnte ab einer Proteinkonzentration von ca. $115 \mathrm{~nm}$ keine weitere signifikante Frequenzänderung des Quarzes detektiert werden. Für $\mathrm{PIP}_{2}$-haltige Membranen wurde dies bei einem Wert von ca. $125 \mathrm{~nm}$ erreicht. 

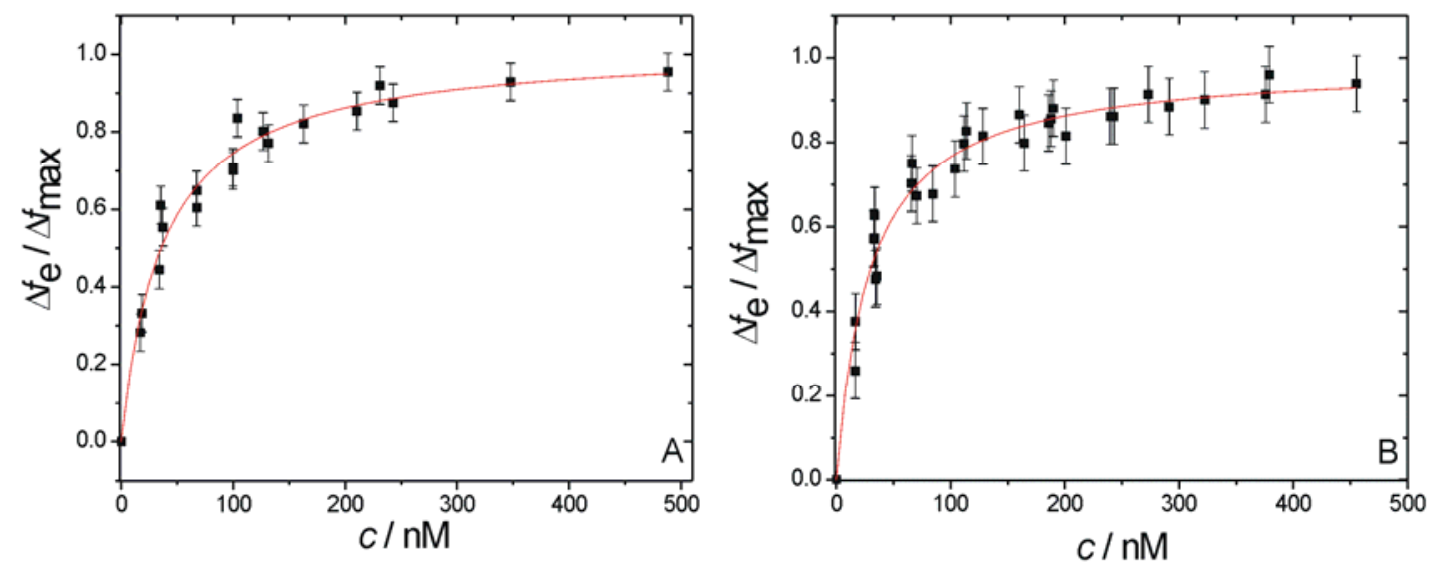

Abbildung 5.7: Auftragung der normierten Resonanzfrequenzänderung $\Delta f_{\mathrm{e}} / \Delta f_{\max }$ als Funktion der eingesetzten Proteinkonzentration $c$. Die durchgezogene Linie repräsentiert eine Anpassung an die Daten nach dem Langmuir-Adsorptionsmodell (nach Gleichung [5.9]).

A: Normierte Adsorptionsisotherme der Bindung von Ezrin T567A an eine OT-DOPC/DOGSNTA-Ni (9:1)-Doppelschicht. Die Anpassung der Langmuir-Isotherme an die Datenpunkte ergab eine Dissoziationskonstante von $K_{\mathrm{D}}=(31 \pm 4) \mathrm{nM}$.

B: Normierte Adsorptionsisotherme der Bindung von Ezrin T567A an eine OT-POPC/PIP 2 (9:1)Doppelschicht. Die Anpassung der Langmuir-Isotherme an die Datenpunkte ergab eine Dissoziationskonstante von $K_{\mathrm{D}}=(31 \pm 3) \mathrm{nM}$.

\subsubsection{Ezrin T567D}

Schließlich wurde ein Datensatz zur Charakterisierung der Interaktion von Ezrin T567D mit DOGS-NTA-Ni-haltigen sowie PIP $_{2}$-haltigen festkörperunterstützten Membranen aufgenommen mit dem Ziel, die Bindungsparameter des Proteins zu quantifizieren sowie die Konzentration zu bestimmen, ab der eine Absättigung der Oberfläche erhalten wurde. Repräsentative Messkurven aus entsprechenden Quarzmikrowaageexperimenten sind in Abbildung 5.8 gezeigt. 

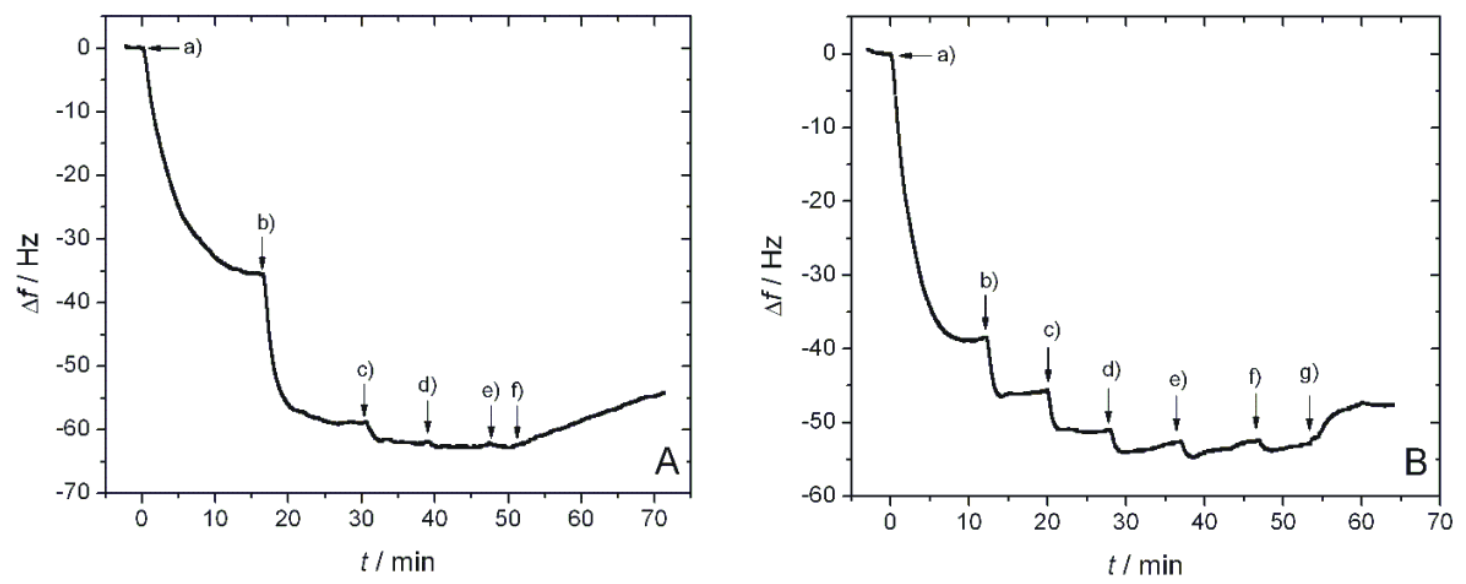

Abbildung 5.8 A Zeitaufgelöste Änderung der Resonanzfrequenz eines $5 \mathrm{MHz}$ AT-cut-Quarzes, funktionalisiert mit einer OT-DOPC/DOGS-NTA-Ni (9:1)-Doppelschicht nach schrittweiser Erhöhung der Konzentration von Ezrin T567D und anschließendem Spülen mit Puffer. Konzentrationen: a) $14 \mathrm{~nm} \mathrm{~b}) 43 \mathrm{nM}$ c) $98 \mathrm{nM}$ d) $178 \mathrm{nM}$ e) $274 \mathrm{nM}$ f) spülen mit Puffer (E1: $20 \mathrm{~mm}$ Tris/ $\mathrm{HCl}, 50 \mathrm{~mm} \mathrm{KCl,} \mathrm{0,1} \mathrm{mM} \mathrm{EDTA,} \mathrm{0,1} \mathrm{mM} \mathrm{NaN}_{3}$, $\mathrm{pH}$ 7,4).

B Zeitaufgelöste Änderung der Resonanzfrequenz eines $5 \mathrm{MHz}$ AT-cut-Quarzes, funktionalisiert mit einer OT-POPC/PIP 2 (9:1)-Doppelschicht nach schrittweiser Erhöhung der Konzentration von Ezrin T567D und anschließendem Spülen mit Puffer. Konzentrationen: a) $31 \mathrm{nM}$ b) $62 \mathrm{nM} \mathrm{c)} 121$ nM d) $205 \mathrm{~nm} \mathrm{e)} 308 \mathrm{~nm}$ f) $402 \mathrm{~nm} \mathrm{~g}$ ) Spülen mit Puffer (E1: $20 \mathrm{~mm}$ Tris/HCl, $50 \mathrm{~mm} \mathrm{KCl,} \mathrm{0,1} \mathrm{mM}$ EDTA, 0,1 $\mathrm{mm} \mathrm{NaN}_{3}$, pH 7,4).

Im abgebildeten Beispiel wurde unter Verwendung einer DOGS-NTA-Ni-haltigen Membran nach schrittweiser Erhöhung der Ezrin T567D-Konzentration eine maximale Resonanzfrequenzverringerung um $\Delta f_{\max }=63 \mathrm{~Hz}$ beobachtet. Das gleiche Vorgehen unter Verwendung einer $\mathrm{PIP}_{2}$-haltigen Membran führte zu einer maximalen Frequenzänderung von $\Delta f_{\max }=54 \mathrm{~Hz}$. Beide Experimente wurden durch einen Spülvorgang mit reinem Puffer abgeschlossen, wobei von der DOGS-NTA-Ni-haltigen Membran eine partielle Desorption des Proteins von der Oberfläche einsetzte, welche zu einer Frequenzerhöhung um $7 \mathrm{~Hz}$ führte. Bei der $\mathrm{PIP}_{2}$-haltigen Membran kam es nach Spülen mit reinem Puffer zu einer Frequenzerhöhung um $6 \mathrm{~Hz}$. 

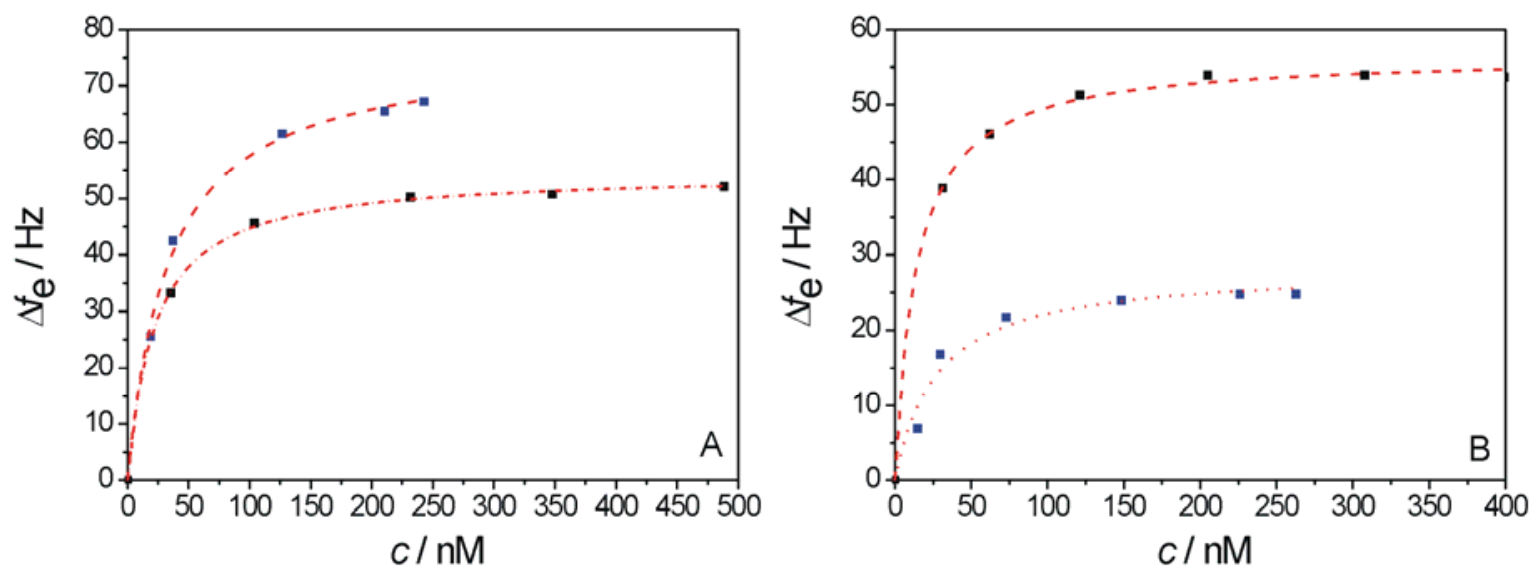

Abbildung 5.9: A Adsorptionsisotherme der Bindung von Ezrin T567D an DOGS-NTA-Ni-haltige festkörperunterstützte Membranen. Die verschiedenen Farben repräsentieren unterschiedliche Messungen. B Adsorptionsisotherme der Bindung von Ezrin T567D an $\mathrm{PIP}_{2}$-haltige festkörperunterstützte Membranen. Die dargestellten Kurven repräsentieren eine Anpassung der Langmuir-Isotherme an die Datenpunkte.

Aus verschiedenen Einzelmessungen wurden die in Abbildung 5.9 dargestellten Adsorptionsisothermen erstellt. Auch hier zeigte sich insbesondere für die $\mathrm{PIP}_{2}$ haltige Membran (Abbildung 5.9 B) eine breite Streuung der Datenpunkte. Die dargestellten Kurven bilden die Grenzwerte der bestimmten maximalen Frequenzänderungen und markieren damit einen Streubereich, der für das DOGS-NTA-Ni-haltige System zu ca. $20 \mathrm{~Hz}$ und für das $\mathrm{PIP}_{2}$-haltige System zu $28 \mathrm{~Hz}$ bestimmt wurde. Unter Einbeziehung aller aufgenommenen Messkurven ergab sich im statistischen Mittel maximale Frequenzänderungen von $(64 \pm 5) \mathrm{Hz}$ (DOGS-NTA-Ni, $n=5)$ und $(44 \pm 13) \mathrm{Hz}\left(\mathrm{PIP}_{2}, n=5\right)$ Die Normierung der Daten ist in Abbildung 5.10 gezeigt. Hier wurde eine Anpassung der LangmuirIsotherme an die normierten Daten vorgenommen und die Dissoziationskonstanten der Bindungen ermittelt, welche für die Interaktion von Ezrin T567D mit DOGS-NTA-Ni zu $K_{\mathrm{D}}=(17 \pm 4) \mathrm{nM}$ bestimmt werden konnte. Für die Interaktion von Ezrin T567D mit $\mathrm{PIP}_{2}$ wurde eine Dissoziationskonstante von $K_{\mathrm{D}}=(17 \pm 2) \mathrm{nM}$ bestimmt. Die DOGS-NTA-Ni-haltige Membran wies bei ca. $100 \mathrm{nM}$ eine Sättigung der Oberfläche mit gebundenem Protein auf, für $\mathrm{PIP}_{2}$ haltige Membranen lag dieser Wert ebenfalls bei ca. $100 \mathrm{nM}$. 

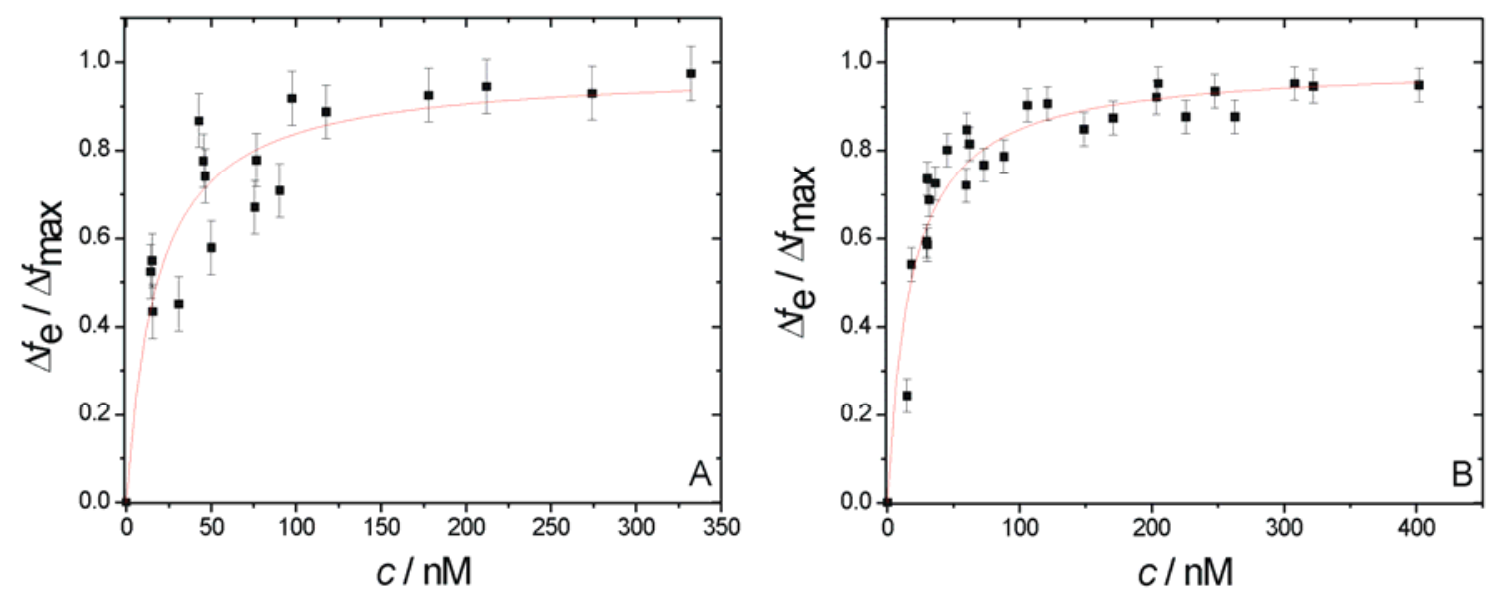

Abbildung 5.10 Auftragung der normierten Resonanzfrequenzänderung $\Delta f_{\mathrm{e}} / \Delta f_{\max }$ als Funktion der eingesetzten Proteinkonzentration $c$. Die durchgezogene Linie repräsentiert eine Anpassung an die Daten nach dem Langmuir-Adsorptionsmodell (nach Gleichung [5.9).

A: Normierte Adsorptionsisotherme der Bindung von Ezrin T567D an eine OT-DOPC/DOGSNTA-Ni (9:1)-Doppelschicht. Die Anpassung der Langmuir-Isotherme an die Datenpunkte ergab eine Dissoziationskonstante von $K_{\mathrm{D}}=(17 \pm 4) \mathrm{nM}$.

B: Normierte Adsorptionsisotherme der Bindung von Ezrin T567D an eine OT-POPC/PIP 2 (9:1)Doppelschicht. Die Anpassung der Langmuir-Isotherme an die Datenpunkte ergab eine Dissoziationskonstante von $K_{\mathrm{D}}=(17 \pm 2) \mathrm{nM}$.

\subsubsection{N-ERMAD}

Neben den vollständigen Proteinen Ezrin wt, Ezrin T567A und Ezrin T567D wurde auch das Bindungsverhalten von N-ERMAD an $\mathrm{PIP}_{2}$-haltigen festkörperunterstützte Membranen untersucht. Das Protein N-ERMAD umfasst 296 Aminosäuren und besteht damit lediglich aus der N-terminalen Membranbindungsstelle des nativen Proteins. Der Vergleich der Messungen mit dem Fragment N-ERMAD und dem vollständigen Protein Ezrin wt sollte eine Aussage zum Einfluss des C-Terminus auf das Bindungsverhalten des Proteins ermöglichen.

Zunächst wurden verschiedene QCM-Einzelmessungen an $10 \mathrm{~mol} \%-\mathrm{PIP}_{2^{-}}$ haltigen Membranen durchgeführt. In Abbildung 4.13 A ist beispielhaft eine Messung aufgeführt, bei der die Zugabe des Proteins N-ERMAD zu einer auf dem Schwingquarz präparierten Doppelschicht eine Verringerung der Resonanzfrequenz um ca. $32 \mathrm{~Hz}$ bewirkte. Das Spülen mit reinem Puffer führte zu einem Frequenzanstieg um ca. $8 \mathrm{~Hz}$. 


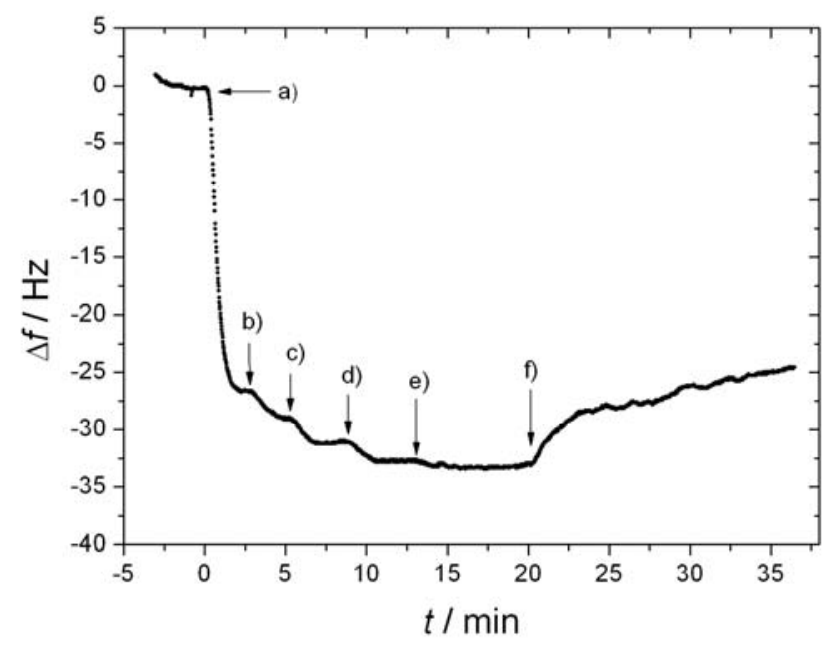

Abbildung 5.11: Zeitaufgelöste Änderung der Resonanzfrequenz eines $5 \mathrm{MHz}$ AT-cut-Quarzes, funktionalisiert mit einer OT-POPC/PIP 2 (9:1)-Doppelschicht nach schrittweiser Erhöhung der Konzentration von N-ERMAD und anschließendem Spülen mit Puffer. Konzentrationen: a) $512 \mathrm{~nm}$ b) $674 \mathrm{nM} \mathrm{c)} 969 \mathrm{nM}$ d) $1239 \mathrm{~nm}$ e) $1357 \mathrm{~nm}$ f) spülen mit Puffer (E1: $20 \mathrm{~mm}$ Tris/HCl, 50

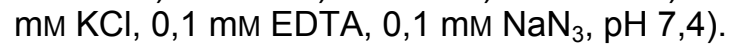

In Abbildung 5.11 ist die aus mehreren Einzelmessungen konstruierte Adsorptionsisotherme aufgeführt, anhand derer mit Hilfe des Langmuir-Modells eine Dissoziationskonstante für das System von $K_{\mathrm{D}}=(160 \pm 20) \mathrm{nM}$ bestimmt wurde. In dieser Stelle muss festgestellt werden, dass die Einzelmessungen zur Erstellung der Adsorptionsisotherme von N-ERMAD im Gegensatz zu allen gezeigten Messungen von Ezrin wt, T567A und T567D eine extrem geringe Streuung aufwies. Alle aufgenommenen Datenpunkte sind in Abbildung 5.11 aufgetragen und resultieren in einer maximalen Frequenzänderung von $\Delta f_{\max }=34 \mathrm{~Hz}$ und einem sehr kleinen Fehler von $\pm 3 \mathrm{~Hz}$. 


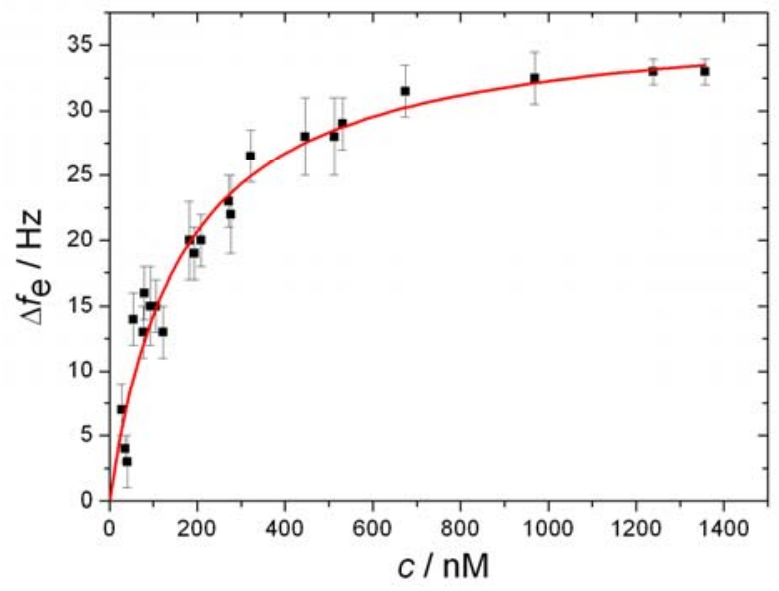

Abbildung 5.12: Adsorptionsisotherme der Bindung von N-ERMAD an eine $\mathrm{PIP}_{2}$-haltige festkörperunterstützte Membran. Die durchgezogene Linie repräsentiert eine Anpassung an die Daten nach dem Langmuir-Adsorptionsmodell. Dadurch ergab sich für die Dissoziationskonstante der Bindung von N-ERMAD an $\mathrm{PIP}_{2}$ ein Wert von $K_{\mathrm{D}}=(160 \pm 20) \mathrm{nM}$. Die maximale Frequenzänderung $\Delta f_{\max }$ wurde zu $(34 \pm 3) \mathrm{Hz}$ bestimmt.

Für das Interaktionspaar N-ERMAD-PIP 2 wurde ebenfalls anhand der Adsorptionsisotherme eine Sättigungskonzentration ausgelesen. Diese lag im Vergleich zu Ezrin wt und seinen Mutanten relativ hoch bei ca. 600 nM. In Tabelle 4.5 sind alle vorgestellten Ergebnisse zusammengefasst.

Tabelle 4.5: Zusammenfassung der anhand der Quarzmikrowaageexperimente ermittelten Daten zur Interaktion von Ezrin wt, Ezrin T567A, Ezrin T567D sowie N-ERMAD mit festkörperunterstützten Membranen. Anhand der Bestimmung der maximalen Frequenzänderung in jeder Einzelmessung wurde der Mittelwert $\Delta f_{\max }$ mit zugehöriger Standardabweichung gebildet. Die Dissoziationskonstante wurde aus einer Langmuir-Anpassung an die normierten Datenpunkte bestimmt. Der angegebene Fehler der Dissoziationskonstante $K_{D}$ ergibt sich aus dem Fehler der Anpassung.

\begin{tabular}{c|c|c|c|c|c|c|c} 
Membran & \multicolumn{2}{|l|}{ DOGS-NTA-Ni (10\%) } & $\mathrm{PIP}_{2}(10 \%)$ \\
\hline Protein & T567A & wt & T567D & T567A & wt & T567D & N-ERMAD \\
\hline$\Delta f_{\text {max }} / \mathrm{Hz}$ & $58 \pm 13$ & $67 \pm 19$ & $64 \pm 5$ & $71 \pm 19$ & $52 \pm 13$ & $44 \pm 13$ & $34 \pm 3$ \\
\hline Reversibiliät/\% & $9 \pm 7$ & $7 \pm 5$ & $8 \pm 2$ & $16 \pm 10$ & $19 \pm 11$ & $14 \pm 7$ & $33 \pm 24$ \\
\hline$K_{\mathrm{D}} / \mathrm{nM}$ & $31 \pm 4$ & $12 \pm 2$ & $17 \pm 4$ & $31 \pm 3$ & $32 \pm 6$ & $17 \pm 2$ & $160 \pm 20$ \\
\hline$C_{\text {sat }} / \mathrm{nM}$ & 115 & 100 & 100 & 150 & 125 & 100 & 600
\end{tabular}




\subsection{Bindungsverhalten von fluoreszenzmarkiertem Ezrin wt auf PIP $_{2}$-haltigen Membranen}

Um zu überprüfen, ob die Markierung des Proteins Ezrin wt mit dem

Fluoreszenzfarbstoff $\mathrm{zu}$ einer grundsätzlichen Beeinträchtigung seiner $\mathrm{PIP}_{2^{-}}$ Bindefähigkeit führt, wurde ein Quarzmikrowaageexperiment mit dem markierten Protein durchgeführt.

In Abbildung 5.13 ist die resultierende Messkurve des Experiments dargestellt. Es wird ersichtlich, dass sukzessive Zugaben des Proteins $\mathrm{zu}$ einer Resonanzfrequenzabnahme des Quarzes führen. Im Verlauf der Messung führt die Erhöhung der Proteinkonzentration auf einen finalen Wert von $129 \mathrm{~nm} \mathrm{zu}$ einer Gesamtresonanzfrequenzänderung von ca. $40 \mathrm{~Hz}$. Das Spülen mit reinem Puffer bewirkte einen Resonanzfrequenzanstieg um ca. $13 \mathrm{~Hz}$.

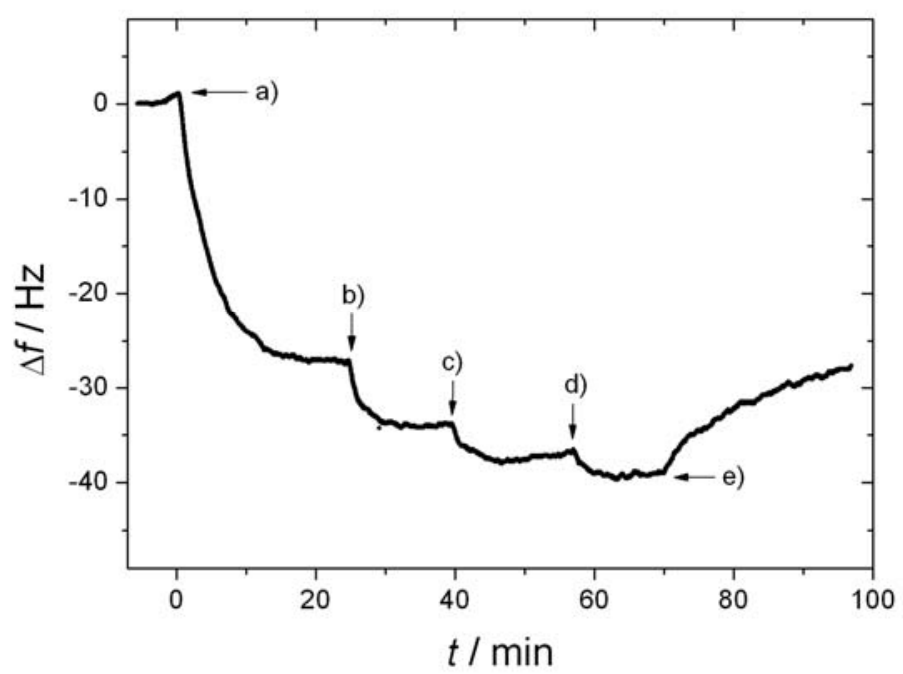

Abbildung 5.13: Zeitaufgelöste Änderung der Resonanzfrequenz eines $5 \mathrm{MHz}$ AT-cut-Quarzes, funktionalisiert mit einer OT-POPC/PIP 2 (9:1)-Doppelschicht nach schrittweiser Erhöhung der Konzentration von fluoreszenzmarkiertem Ezrin wt und anschließendem Spülen mit Puffer. Konzentrationen: a) $61 \mathrm{nM}$ b) $84 \mathrm{nM} \mathrm{c}) 107 \mathrm{nM}$ d) $129 \mathrm{nM}$ e) spülen mit Puffer (E1: $20 \mathrm{~mm}$ Tris/ $\mathrm{HCl}, 50 \mathrm{~mm} \mathrm{KCl}, 0,1 \mathrm{~mm}$ EDTA, 0,1 $\mathrm{mm} \mathrm{NaN}_{3}$, $\mathrm{pH}$ 7,4). 


\subsection{Diskussion}

Die Untersuchung und Charakterisierung der Wechselwirkung von Ezrin wt, Ezrin T567A, Ezrin T567D und N-ERMAD mit Modellmembranen erfolgte mit Hilfe der Quarzmikrowaagetechnik. Diese Methode eignete sich besonders für diese Studien, da der Adsorptionsprozess der Proteine an der Grenzfläche hochsensitiv und zeitaufgelöst beobachtet werden konnte. Ein weiterer Vorteil gegenüber anderen Strategien, Interaktionen zu untersuchen, ist die Tatsache, dass die Quarzmikrowaagetechnik keine Markierung der Bindungspartner erfordert (72, 99). Im Hinblick auf weitere Studien zur Aktivierbarkeit von membrangebundenem Ezrin war es darüber hinaus besonders interessant, die Interaktion an einer planaren Oberfläche zu verfolgen, welche der natürlichen Bindungssituation von Ezrin an der Plasmamembran möglichst gut nachempfunden ist.

Hierzu wurde zunächst eine Funktionalisierung des Quarzes vorgenommen, um eine spezifische und hochgeordnete Immobilisierung der Proteine auf der sensorischen Oberfläche zu gewährleisten. Die Chemisorption von Oktanthiol auf der Goldelektrode des Quarzes und das anschließende Spreiten von unilamellaren Vesikeln auf der hydrophoben Grenzfläche resultierte in der Ausbildung einer festkörperunterstützten Membran aus einer Oktanthiolschicht und einer Lipidschicht. Die vollständige Ausbildung der einzelnen Schichten wurde jeweils impedanzspektroskopisch sichergestellt, um eine gute Reproduzierbarkeit der Messungen zu gewährleisten. Dabei zeigte sich kein signifikanter Unterschied der erhaltenen Gesamtkapazitäten für die verschiedenen verwendeten Lipidmischungen. Der Belegungsgrad $\Theta$ der sensorischen Oberfläche lässt sich nach folgender Gleichung berechnen:

$$
\Theta=\frac{C_{\mathrm{el}+\mathrm{M}}-C_{\mathrm{el}}}{C_{\mathrm{M}}-C_{\mathrm{el}}}
$$

mit $C_{\text {el }}$ als Kapazität der Goldelektrode, $C_{\text {el+M }}$ als Kapazität der Goldelektrode mit darauf applizierter Mono-/Doppelschicht und $C_{\mathrm{M}}$ als Kapazität der Monoschicht bei $100 \%$ Bedeckung. Die theoretische Variable $C_{\mathrm{M}}$ wird über die klassische 
Kondensatorgleichung mit einer angenommenen Membrandicke von $d=4 \mathrm{~nm}$ und einer relativen Dielektrizitätskonstante $\varepsilon_{r}=2.4$ berechnet und ergibt sich zu $C_{\mathrm{M}}=0,53 \mu \mathrm{F} / \mathrm{cm}^{2}$. Die Kapazität $C_{\text {el }}$ der Goldelektrode betrug $33 \mu \mathrm{F} / \mathrm{cm}^{2}$ (100). Es wurden für weiterführende Quarzmikrowaagemessungen ausschließlich Membranen verwendet, deren spezifische Kapazitäten innerhalb der angegebenen Fehlergrenzen lagen und damit eine Oberflächenbelegung durch die festkörperunterstützte Membran von $\geq 98 \%$ gegeben war.

Auf der funktionalisierten Oberfläche des Schwingquarzes wurde anschließend die Immobilisierung der Proteine vorgenommen. Prinzipiell steht derzeit eine Fülle verschiedener Immobilisierungstechniken zum Studium von Interaktionen an Oberflächen zur Verfügung. Dabei beruht die schnellste und einfachste Methode auf unspezifischer Adsorption, bei der nach Inkubation der sensorischen Oberfläche mit Protein eine Immobilisierung des Proteins aufgrund von hydrophoben Wechselwirkungen erhalten wird. Die Nachteile bei diesem Vorgehen sind die Blockierung möglicher Interaktionsflächen des Proteins sowie die Tatsache, dass keine einheitliche Orientierung der Proteine auf der Oberfläche gewährleistet werden kann (101). Eine weitere Immobilisierungsmethode beruht auf der kovalenten Bindung des Proteins an eine aktivierte Sensoroberfläche. Dabei entsteht zum Beispiel über eine Kondensation von Hydroxylgruppen des Proteins mit einem oberflächenverknüpften Spacer eine neue chemische Bindung. Die Reaktionsbedingungen sowie die neue Bindung können jedoch zu Konformations- und in der Folge zu Aktivitätsveränderungen des Proteins führen (102-103).

Eine dritte Möglichkeit, welche auch in der vorliegenden Arbeit gewählt wurde, ist die Immobilisierung über die Komplexierung eines Affinitäts-Tags am Protein. Im Zusammenhang mit den geplanten Studien sollte dieses System eine hohe Bedeckung der Membranoberfläche mit Protein aufweisen, welches spezifisch und stabil gebunden ist. Dies kann durch die Bindung über den His-tag an DOGS-NTA-Ni gewährleistet werden (104). Die selektive Affinität des NTA-Nifusionierten Lipids, welches in der festkörperunterstützten Membran eingebettet war, garantiert eine spezifische Bindung des Hexahistidin (His)-Tags und einheitliche Orientierung der Proteine. Darüber hinaus bleibt in diesem System 
die laterale Beweglichkeit der Proteine weitestgehend gewahrt, da innerhalb der Membran eine laterale Diffusion der Lipide möglich ist. Die Stärke der Interaktion sowie die hohe Spezifität der Bindung zwischen His-tag und Ni-Komplex führen dazu, dass sich diese Methode zu einer gern gewählten Immobilisierungsstrategie entwickelt hat (105-106). Da der His-Tag am NTerminus der verwendeten Proteine angebracht war, konnte eine sehr gute Übereinstimmung mit der Orientierung des Proteins erreicht werden, die es bei der natürlichen Bindungssituation an der Plasmamembran einnimmt. Die geplanten anschließenden F-Aktin-Affinitätsstudien erforderten darüber hinaus eine ungehinderte Zugänglichkeit der C-terminalen Bindungsstelle, was ebenfalls durch diese Immobilisierungsstrategie gesichert werden konnte. Aus vorangegangenen Studien ist bekannt, dass durch Zusatz von $10 \mathrm{~mol} \%$ Rezeptorlipid eine maximale Oberflächenbedeckung durch Protein gegeben ist (98). Daher wurden Adsorptionsisothermen an 10\% Rezeptorlipid enthaltenden festkörperunterstützten Membranen aufgenommen.

Anhand dieser Studien sollte analysiert werden, mit welcher Affinität die verschiedenen Proteine an die Membranen binden, ob die Immobilisierungsmethoden in Bezug auf die Gesamtmenge an adsorbiertem Protein vergleichbar sind und welche Proteinkonzentration notwendig ist, um die maximale Belegung der Oberfläche zu erhalten. Die erhaltenen Parameter sollten im späteren Verlauf der Arbeit als Grundlage zur Etablierung eines F-AktinBindungsassays an Ezrin dienen (siehe Kapitel 7).

Zunächst lässt sich festhalten, dass die Proteine Ezrin wt, Ezrin T567A und Ezrin T567D mit hoher Spezifiät und Affinität an beiden Membransystemen immobilisiert werden konnten. Dies zeigte sich an Dissoziationskonstanten in der Größenordnung von $10^{-8} \mathrm{M}$, die aus den jeweiligen Adsorptionsisothermen mit Hilfe einer Langmuir-Anpassung gewonnen werden konnten. Damit zeigen sie eine gute Übereinstimmung mit vorherigen Ergebnissen, die für die Interaktion von Ezrin wt mit $\mathrm{PIP}_{2}$-haltigen festkörperunterstützten Membranen über kinetische Daten erhalten wurden (107). Im Gegensatz dazu wurden anhand von Cosedimentationsstudien mit $\mathrm{PIP}_{2}$-haltigen unilamellaren Vesikeln (large unilamellar vesicles, LUV) und Ezrin auch Dissoziationskonstanten berichtet, die bis zu zwei Größenordnungen höher lagen (108). Dieser Unterschied könnte auf 
die starke Krümmung des letztgenannten Membransystems zurückzuführen sein, welche eine geringere Stabilisierung des gebundenen Proteins durch benachbarte Proteine zulässt.

Der Anteil an reversibel gebundenem Protein stellte sich für beide Membransysteme als sehr gering dar. Im Falle von DOGS-NTA-Ni wurde durch Spülen mit reinem Puffer ein Resonanzfrequenzanstieg um ca. 10\% der Gesamtfrequenzänderung induziert. Dies impliziert, dass ca. $90 \%$ des gebundenen Proteins an der Oberfläche verblieben. Die vollständige Dissoziation des Komplexes und die Ablösung des Proteins von der funktionalisierten Oberfläche kann nur durch Spülen mit imidazolhaltigem Puffer induziert werden, was im Rahmen von Quarzmikrowaageexperimenten in der Arbeitsgruppe nachgewiesen wurde (Experimente nicht gezeigt).

Dem Adsorptionsmodell nach Langmuir liegt die Annahme zugrunde, dass die Bindung des Adsorbats an die Oberfläche vollständig reversibel ist. Da sich die Bindung der Proteine über ihren His-Tag an DOGS-NTA-Ni als größtenteils irreversibel darstellte, erscheint eine Auswertung der Daten nach Langmuir zunächst nicht korrekt. In der Tat ist jedoch die individuelle Bindung der HistidinSeitenkette reversibel mit einer Dissoziationskonstante im Bereich von $10^{-6} \mathrm{M}$ (109). Unter anderem von Lata et al. konnte bewiesen werden, dass der His-tag über mehr als eine Seitenkette komplexiert wird, und dass eine hohe Rezeptordichte zu einer multiplen Bindung des His-tags an mehrere Chelatormoleküle führt (110). Während die einzelne Bindung damit reversibel ist, führt ein schnelles re-binding zu einer effektiven irreversiblen Bindung und damit zu dem beobachteten Effekt.

Die Bindung von Ezrin an $\mathrm{PIP}_{2}$ stellte sich etwas anders dar. Hier konnte ein reversibel gebundener Anteil von Ezrin wt und den verwendeten Mutanten von ca. $20 \%$ gefunden werden. So muss davon ausgegangen werden, dass eine bis zu 10\% geringere Bedeckung der Membranoberfläche durch die Proteine nach Spülen vorliegt als unter Verwendung der Ni-funktionalisierten Membranen. Dennoch bleibt auch hier der Hauptanteil des Proteins an die Membranoberfläche gebunden. Dies konnte neben den genannten Quarzmikrowaageexperimenten in der Vergangenheit auch per Rasterkraftmikroskopie nachgewiesen werden: Das Spülen einer mit Ezrin wt 
belegten, $10 \% \mathrm{PIP}_{2}$-haltigen Membran konnte hier nur sehr kleine Bereiche der Membran freilegen (107).

Die Spezifität der Bindung von Ezrin an $\mathrm{PIP}_{2}$ wurde in der Vergangenheit vielfach untersucht. So konnte durch Niggli et al. anhand von Vesikelcopelletierungsstudien gezeigt werden, dass Ezrin zwischen den verschiedenen Phosphatidylinositiden und Phosphatidylserin diskriminiert und eine deutliche Präferenz für die Bindung an $\mathrm{PIP}_{2}$ beobachtet wird (111). Später konnte diese Spezifität von Blin et al. bestätigt werden. Sie bewiesen darüber hinaus, dass die Interaktion zwischen Ezrin und $\mathrm{PIP}_{2}$ nicht auf Oberflächenladungsdichte beruht, sondern eine molekulare Erkennung zugrunde liegt (108). Auch im Rahmen der vorliegenden Arbeit konnte diese spezifische Bindung erneut bestätigt werden, welche sich in einer direkten Abhängigkeit von adsorbiertem Ezrin und $\mathrm{PIP}_{2}$-Konzentration in der festkörperunterstützten Membran äußerte (siehe Kapitel 6.1.1).

Die Streubreite der maximalen Resonanzfrequenzänderung lag im Falle von Ezrin in allen untersuchten Systemen in einem Bereich von ca. $30 \mathrm{~Hz}$. Diese Streuung trat allerdings nicht unter Verwendung des N-terminalen Fragments von Ezrin, N-ERMAD, auf. Diese Streuung scheint daher spezifisch für die verwendeten Proteine Ezrin und Mutanten aufzutreten. Im Bezug auf N-ERMAD fällt des Weiteren auf, dass die Dissoziationskonstante der Bindung an $\mathrm{PIP}_{2}$ deutlich höher ausfiel sowie ein größerer Anteil an reversibel gebundenem Protein auftrat. Auch konnte eine verglichen mit Ezrin und Mutanten ca. fünffach höhere Sättigungskonzentration von 600 nM festgestellt werden.

Für die Bindung von Ezrin wt an $\mathrm{PIP}_{2}$ wurde in der Literatur ein kooperatives Bindungsverhalten beschrieben. Herrig et al. konnten mit Hilfe von rastekraftmikroskopischen Aufnahmen zeigen, dass die vollständige Belegung einer $3 \mathrm{~mol} \% \mathrm{PIP}_{2}$ enthaltenden festkörperunterstützten Membran aus einem „Keimwachstum“ resultiert. Dies bedeutet, dass die Besetzung der Adsorptionsplätze nicht unabhängig von der Belegung benachbarter Bindungsplätze ist. Es gelang Herrig et al., die Bindungskinetik von Ezrin wt mit Hilfe eines kooperativen Bindungsmodells zu beschreiben. Für N-ERMAD konnte jedoch keine Übereinstimmung mit dem Modell gefunden werden (107). In diesem Zusammenhang können die unterschiedlichen Ergebnisse bezüglich der 
Streubreite in den Isothermen sowie der vergrößerten Dissoziationskonstante für N-ERMAD und Ezrin wt beziehungsweise die Mutanten auf eine verringerte Protein-Protein-Interaktion im Fall von N-ERMAD erklärt werden. Wenn der stabilisierende Effekt der benachbarten gebundenen Proteine bei der Bindung von N-ERMAD an die Membranoberfläche wegfällt, würde dies in der Erhöhung der effektiven Dissoziationskonstante resultieren, was in den vorgestellten Studien auch tatsächlich der Fall war. Die Beobachtung, dass hier ein deutlich höherer Anteil an reversibel gebundenem Protein vorlag, stützt diese Hypothese. Vergleicht man die Strukturen von N-ERMAD und Ezrin, so unterscheiden sich diese um die a-helicale Linkerstruktur sowie die C-terminale F-AktinInteraktionsdomäne. Der Hypothese zufolge könnte die positive laterale Interaktion von Ezrin wt und Mutanten auf Bindungsstellen in diesen Domänen zurückzuführen sein. Im folgenden Abschnitt wird eine mögliche Kooperativität in Bezug auf die Bindung von Ezrin wt, Ezrin T567A und Ezrin T567D an PIP 2 genauer betrachtet.

Ein wichtiger Punkt, der in diesem Zusammenhang beachtet werden muss, ist die Tatsache, dass in der Quarzmikrowaagemessung neben dem abgeschiedenen Proteinmaterial auch dessen Hydrathülle detektiert wird (112). Wenn infolge einer Protein-Protein-Anziehung ein enger Kontakt zwischen den Ezrinmolekülen hergestellt wird, führt dies zum Ausschluss von Wassermolekülen in diesen Bereichen. Gleichzeitig können kleine Reservoirs von Wasser eingeschlossen werden, wenn die Hydrathülle, die die der PIP $_{2}$-Kopfgruppe umgibt (113), durch eine schnelle Bindung großer Mengen an Ezrin eingeschlossen wird. Diese Wassereinschlüsse würden von der Quarzmikrowaage als adsorbierte Masse detektiert werden. Die bereits erwähnte initale Keimbildung der Proteinbindung, die schließlich in einer gesamten Bedeckung der Membranoberfläche resultiert, ist schwer kontrollierbar. Sie hängt vermutlich stark von der Anfangskonzentration und dem Ausmaß der sukzessiven Konzetrationserhöhungen $a b$ und unterscheidet sich in jeder Messreihe geringfügig. Auch der Ausschluss von Wassermolekülen infolge der Zusammenlagerung von Proteinen kann nur schwierig abgeschätzt werden. Aus diesen Vorgängen könnte die beobachtete Streubreite der maximalen 
Resonanzfrequenzänderung, die bei Ezrin und Mutanten beobachtet wurde, entstehen.

Die Bindung des fluoreszenzmarkierten Proteins Ezrin wt an die festkörperunterstützte $\mathrm{PIP}_{2}$-haltige Membran beweist, dass die Bindungseigenschaften des Proteins nicht durch die Fluoreszenzmarkierung beeinflusst wurden. Der Abfall der Resonanzfrequenz des Quarzes um $40 \mathrm{~Hz}$ bei Zugabe von insgesamt 129 nM Protein ist im Bereich dessen, was für die Bindung des unmarkierten Proteins gefunden wurde (vergleiche Isothermen in Abbildung 5.3 B). Wie später gezeigt werden wird, konnte auch eine hochspezifische Bindung von F-Aktin an das fluoreszenzmarkierte Protein beobachtet werden (siehe Kapitel 7.2). Es konnte daher sichergestellt werden, dass die Fluoreszenzmarkierung keinen Einfluss auf die Aktivität des Proteins ausübt. Vermutlich trägt hierzu die Tatsache bei, dass die Fluoreszenzmarkierung unter milden Bedingungen stattfinden konnte und der Fluorophor relativ klein ist. Es wurde in verschiedenen Studien berichtet, dass sowohl C- als auch N-terminale große Markierungssubstanzen die Integrität des Proteins empfindlich beeinflussen (114). In einigen Publikationen wurde in der Vergangenheit darauf hingewiesen, dass Diskrepanzen bei experimentellen Ergebnissen bezüglich der Aktivierung von Ezrin auch auf unterschiedliche Markierungsstrategien zurückzuführen sein könnten (115). Die Besonderheit des untersuchten Proteins Ezrin liegt in der spezifischen Funktionalität beider terminaler Domänen. Die im Rahmen dieser Arbeit angewendete Markierungsstrategie hat sich damit als besonders geeignet erwiesen. Die Fluoreszenzmarkierung der Cysteinreste erfolgte entfernt von diesen terminalen Domänen an den Positionen 117 und 284 und hatte offensichtlich keine negativen Auswirkungen auf die Funktionalität von Ezrin zur Folge. 


\section{UNTERSUCHUNGEN ZUM CLUSTERING VON EZRIN SOWIE AKKUMULATION VON PIP 2 IN ABHÄNGIGKEIT VON EZRIN}

\subsection{Quarzmikrowaagemessungen unter Variation des $\mathrm{PIP}_{2^{-}}$ Gehalts in der festkörperunterstützten Membran}

Über die Bindungsverhältnisse von Ezrin wt und $\mathrm{PIP}_{2}$ ist gegenwärtig wenig bekannt. Einerseits wurde von Verena Niggli anhand von Modellrechnungen gezeigt, dass eine Bindung von Ezrin an $\mathrm{PIP}_{2}$ über lediglich eine Bindungsstelle unwahrscheinlich ist (116). Andererseits wurde anhand einer röntgenkristallographischen Studie der $\mathrm{N}$-terminalen Domäne von Radixin ein einzelnes $\mathrm{IP}_{3}$-Molekül, welches die Kopfgruppe von $\mathrm{PIP}_{2}$ bildet, in der basischen Bindungstasche vorgefunden (50). Um die natürliche Bindungssituation, wie sie der Assoziation von Ezrin an die Plasmamembran entspricht, möglichst gut nachzuahmen, wurde in der vorliegenden Arbeit ein neuer Ansatz verfolgt. Der Bindungsprozess von Ezrin an $\mathrm{PIP}_{2}$ wurde an festkörperunterstützten Modellmembranen mit Hilfe der Quarzmikrowaagetechnik untersucht, wobei durch die Variation des $\mathrm{PIP}_{2}$-Gehaltes in der Membran Rückschlüsse auf die Bindungsverhältnisse zwischen Ezrin und $\mathrm{PIP}_{2}$ ermöglicht wurden.

\subsubsection{Adsorption von Ezrin wt an festkörperunterstützte Membranen mit unterschiedlichem $\mathbf{P I P}_{\mathbf{2}}$-Gehalt}

Zunächst wurden festkörperunterstützte Membranen bestehend aus POPC und verschiedenen Anteilen an $\mathrm{PIP}_{2}$ präpariert. Anschließend wurde die maximale Frequenzänderung des Schwingquarzes unter Zugabe von Ezrin wt gemessen. Dabei wurde für das Protein eine Konzentration gewählt, die oberhalb der definierten Sättigungskonzentration lag. Die resultierenden maximalen Frequenzänderungen als Funktion der $\mathrm{PIP}_{2}$-Konzentration sind in Abbildung 6.1 A als Säulendiagramm gezeigt. Unter der Annahme, dass die Kopfgruppen der verwendeten Phopholipide in der Membran eine Fläche von ca. $70 \AA$ 
beanspruchen (117), ist der Stoffmengenanteil von $\mathrm{PIP}_{2}$ in der Mischung mit POPC dem Flächenanteil gleichzusetzen.

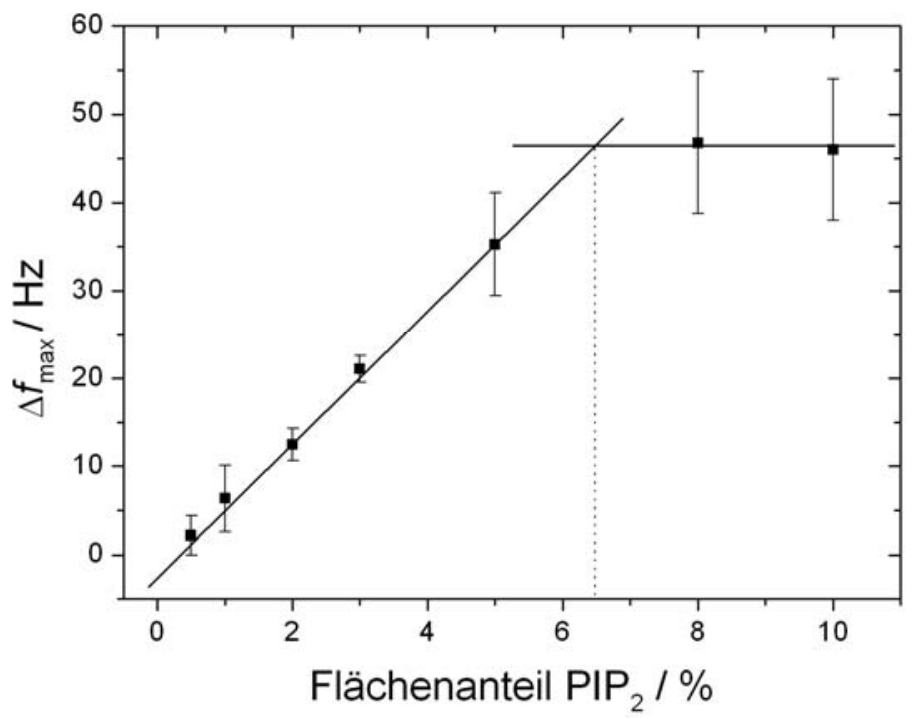

Abbildung 6.1: Mittelwerte der maximalen Resonanzfrequenzänderung nach Zugabe von Ezrin wt zu $\mathrm{PIP}_{2}$-dotierten festkörperunterstützten Membranen. Für alle Messungen wurden Ezrin wtKonzentrationen $\geq 500 \mathrm{nM}$ eingesetzt. Zur graphischen Bestimmung der Konzentration an $\mathrm{PIP}_{2}$, ab der eine verringerte Resonanzfrequenzänderung verzeichnet wurde, sind Geraden an die Messpunkte angelegt (Erläuterungen siehe Text).

Anhand der Auftragung wird deutlich, dass sich im Bereich von 0,5 - 5\% $\mathrm{PIP}_{2}$ ein nahezu linearer Anstieg der Resonanzfrequenzänderung mit steigendem $\mathrm{PIP}_{2^{-}}$ Gehalt ergibt. Auch die Erhöhung des $\mathrm{PIP}_{2}$-Anteils auf $8 \%$ führt zu einer weiteren Erhöhung der maximalen Resonanzfrequenzänderung, diese weicht aber vom linearen Verlauf leicht nach unten ab. Eine weitere Steigerung der $\mathrm{PIP}_{2^{-}}$ Konzentration bewirkte keine weitere Vergrößerung der Resonanzfrequenzänderung. Durch das Anlegen von zwei Geraden an die erhaltenen Datenpunkte wird ein Punkt definiert, ab dem die Verringerung des $\mathrm{PIP}_{2}$-Anteils in der Membran $\mathrm{zu}$ einer verringerten maximalen Resonanzfrequenzänderung führte. Dabei wird angenommen, dass die adsorbierte Menge Ezrin wt ab diesem Punkt linear mit dem PIP $_{2}$-Gehalt abnimmt. So kann aus dieser Messreihe bestimmt werden, dass ein Anteil von ca. 6,5\% $\mathrm{PIP}_{2}$ notwendig ist, um die maximale Belegung der Oberfläche durch das Protein Ezrin wt zu ermöglichen. Eine Verringerung des Anteils dieses Lipids wirkt sich direkt in einer geringeren Menge adsorbierten Materials aus. 


\subsubsection{Adsorption von N-ERMAD an festkörperunterstützte Membranen mit unterschiedlichem PIP $_{2}$-Gehalt}

Eine analoge Untersuchung wurde für die C-terminal verkürzte Version des Proteins, das Protein N-ERMAD, durchgeführt. Diese Messungen sollten mit den vorab vorgestellten Ergebnissen von Ezrin wt verglichen werden. So konnte der Einfluss, den der C-Terminus auf das Bindungsverhalten von Ezrin ausübt, untersucht werden.

In den dargestellten Experimenten wurde mit einer Konzentration $\mathrm{C}_{(\mathrm{N} \text {-ERMAD })} \geq 600 \mathrm{nM}$ gearbeitet, welche in den vorhergehenden Messungen als Sättigungskonzentration definiert worden war. Das Ergebnis der Messungen, die an Membranen mit unterschiedlichen $\mathrm{PIP}_{2}$-Gehalten durchgeführt wurden, ist in Abbildung 6.2 A als Säulendiagramm dargestellt.

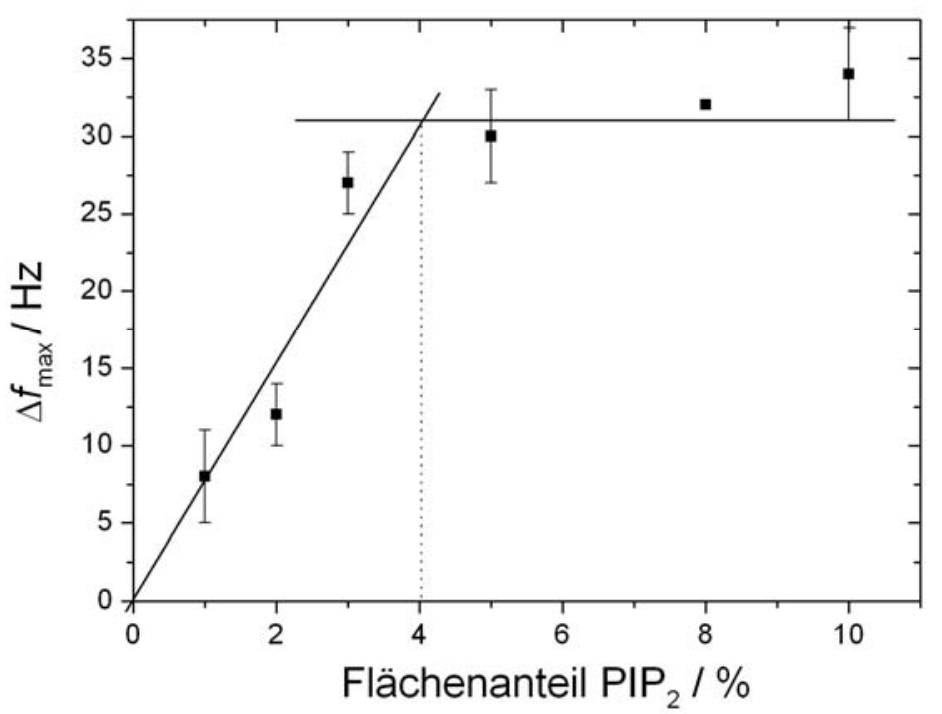

Abbildung 6.2 Mittelwerte der maximalen Resonanzfrequenzänderung nach Zugabe von NERMAD zu $\mathrm{PIP}_{2}$-dotierten festkörperunterstützten Membranen. Für alle Messungen wurden Proteinkonzentrationen $\geq 600 \mathrm{nM}$ eingesetzt. Zur graphischen Bestimmung der Konzentration an $\mathrm{PIP}_{2}$, ab der eine verringerte Resonanzfrequenzänderung verzeichnet wurde, sind Geraden an die Messpunkte angelegt (Erläuterungen siehe Text).

Es zeigte sich anhand einer graphischen Abschätzung mittels Anlegen von zwei Geraden, wie sie in Abbildung 6.2 B dargestellt ist, dass die Verringerung des $\mathrm{PIP}_{2}$-Gehalts der verwendeten festkörperunterstützten Membran erst ab einem Anteil von ca. 4\% zu einer verringerten Menge adsorbierten Proteins führte. Oberhalb dieses Wertes waren die jeweiligen maximalen Frequenzänderungen 
nahezu gleich. Unterhalb dieses Wertes wurden geringere Resonanzfrequenzänderungen registriert, was gleichbedeutend mit einer geringeren Menge an adsorbiertem Material ist.

\subsubsection{Adsorption von Ezrin wt an cholesterinhaltige Membranen}

In der Literatur finden sich kontroverse Resultate bezüglich eines möglichen Ezrin-induzierten clustering von $\mathrm{PIP}_{2}$. Anhand von Vesikelstudien mit fluoreszierendem $\mathrm{PIP}_{2}$ konnte gezeigt werden, dass die Bindung von Ezrin nicht $\mathrm{zu}$ einem $\mathrm{PIP}_{2}$-clustering führt, hingegen wurde an riesigen unilamellaren Vesikeln (giant unilamellar vesicles, GUVs) ein solches clustering gezeigt (108, 118). Der Unterschied zwischen den verwendeten Lipidmischungen der zitierten Studien war die Anwesenheit von Cholesterin in der Membran der GUVs. Es kann also vermutet werden, dass Cholesterin die Bildung oder Stabilisierung von $\mathrm{PIP}_{2}$-angereicherten Membranregionen ermöglicht. Daher wurde in Ergänzung zu den Daten der Adsorption von Ezrin wt auf $\mathrm{PIP}_{2}$-haltigen Membranen eine Studie angefertigt, bei der cholesterinhaltige Membranen verwendet wurden. Dabei orientiert sich der Anteil von 30 mol\% Cholesterin an der Zusammensetzung der natürlichen Plasmamembran (1).

Zunächst wurden mehrere Einzelmessungen mit steigenden Ezrin wtKonzentrationen an Membranen der Zusammensetzung POPC/Cholesterin/PIP 2 (6:3:1) durchgeführt, um die Bindung zu charakterisieren und eine Sättigungskonzentration für das Messsystem zu bestimmen. In Abbildung 6.3 ist eine solche Messung beispielhaft wiedergegeben. 


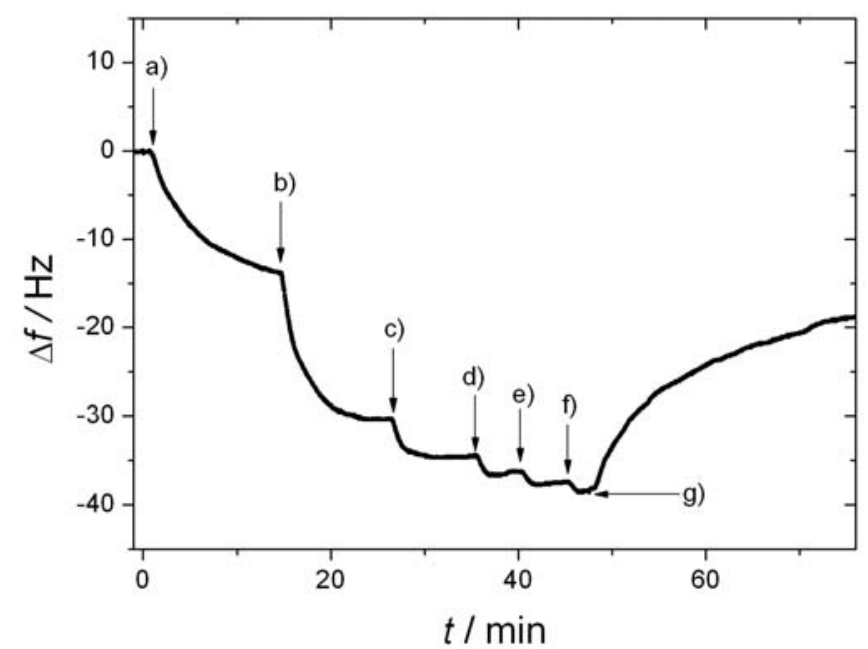

Abbildung 6.3: Zeitaufgelöste Änderung der Resonanzfrequenz eines $5 \mathrm{MHz}$ AT-cut-Quarzes, funktionalisiert mit einer OT-POPC/Cholesterin/PIP 2 (6:3:1)-Doppelschicht nach schrittweiser Erhöhung der Konzentration von Ezrin wt und anschließendem Spülen mit Puffer. Konzentrationen: a) $32 \mathrm{nM} \mathrm{b)} 65 \mathrm{nM} \mathrm{c)} 98 \mathrm{nM}$ d) $131 \mathrm{nM}$ e) $164 \mathrm{nM}$ f) $197 \mathrm{~nm}$ f) spülen mit Puffer (E1: $20 \mathrm{~mm}$ Tris/ $\mathrm{HCl}, 50 \mathrm{~mm} \mathrm{KCl,} \mathrm{0,1} \mathrm{mM} \mathrm{EDTA,} \mathrm{0,1} \mathrm{mm} \mathrm{NaN}_{3}$, $\mathrm{pH}$ 7,4).

Im abgebildeten Beispiel wurde nach sukzessiver Erhöhung der Ezrin wtKonzentration eine maximale Resonanzfrequenzverringerung von $\Delta f_{\max }=38 \mathrm{~Hz}$ beobachtet. Das Experiment wurde durch einen Spülvorgang mit reinem Puffer abgeschlossen, wobei eine Frequenzerhöhung bis auf ca. $23 \mathrm{~Hz}$ einsetzte.

Die Auftragung der Resonanzfrequenzänderung als Funktion der eingesetzten Proteinkonzentration führte $\mathrm{zu}$ den in Abbildung $6.4 \mathrm{~A}$ wiedergegebenen exemplarischen Adsorptionsisothermen. Die gezeigten Kurven repräsentieren jeweils die Grenzwerte, welche für die maximale Frequenzänderung gefunden wurden. Weitere Messkurven lagen zwischen diesen beiden Kurven. Aus dem Abstand dieser Kurven kann eine Streubreite von ca. $30 \mathrm{~Hz}$ abgelesen werden. Die Normierung der Messwerte aus allen durchgeführten Messungen ist in Abbildung 6.4 B gezeigt. 

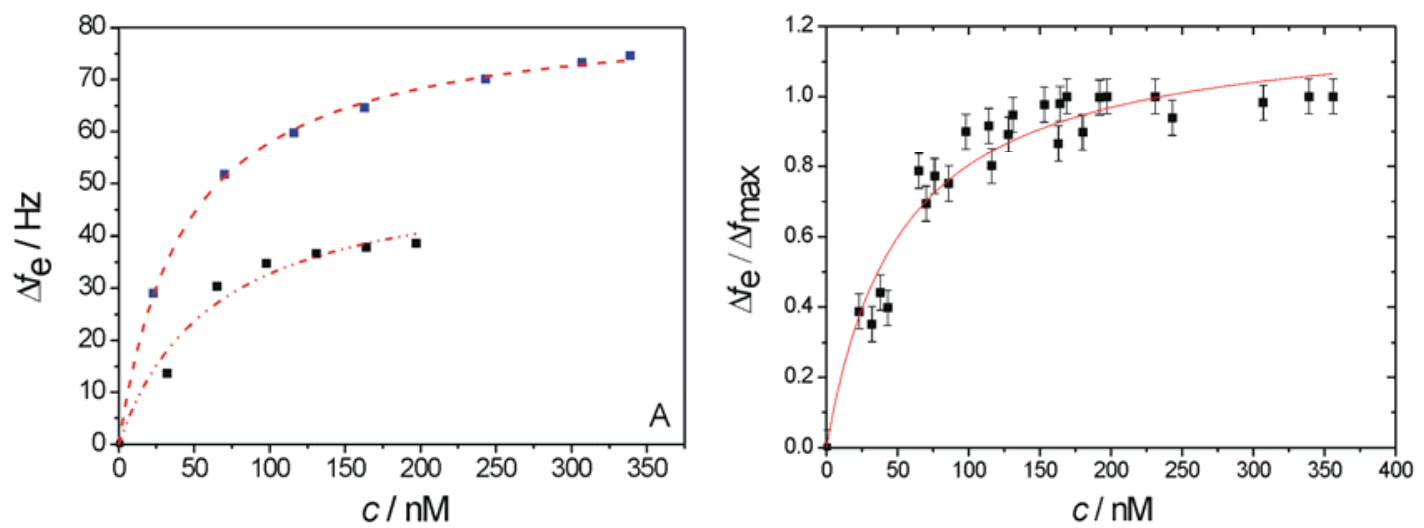

Abbildung 6.4 A Adsorptionsisotherme der Bindung von Ezrin wt an eine OT$\mathrm{POPC} /$ Cholesterin/PIP 2 (6:3:1)-Doppelschicht. Die verschiedenen Farben repräsentieren unterschiedliche Messungen. B Normierte Adsorptionsisotherme der Bindung von Ezrin wt an eine OT-POPC/Cholesterin/PIP (6:3:1)-Doppelschicht. Die Anpassung der Langmuir-Isotherme an die Datenpunkte ergab eine Dissoziationskonstante von $K_{\mathrm{D}}=(52 \pm 8) \mathrm{nM}$.

Die durchgezogene Linie in Abbildung 6.4 B repräsentiert eine Anpassung der Langmuir-Isotherme an die gemessenen Daten. Anhand dieser Anpassung wurde die Dissoziationskonstante des Systems zu $K_{\mathrm{D}}=(52 \pm 8) \mathrm{nM}$ bestimmt. Ebenfalls konnte hieraus die Sättigungskonzentration des Systems aus der Kurve bestimmt werden. Diese lag bei ca. 175 nM. Die durchschnittliche maximale Frequenzänderung wurde aus den Einzelmessungen bestimmt und betrug im Mittel $\Delta f_{\max }=(51 \pm 16) \mathrm{Hz}$. Die Reversibilität der Bindung stellte sich mit $(60 \pm$ 40)\% als besonders hoch und variabel dar.

Wie in den vorher gezeigten Experimenten wurde der prozentuale Anteil an $\mathrm{PIP}_{2}$ immer weiter verringert und die resultierende maximale Resonanzfrequenzänderung nach Zugabe von Ezrin wt registriert. Um diese Ergebnisse anschließend mit den Messungen ohne Cholesterin vergleichen zu können, muss hier berücksichtigt werden, dass ein Cholesterinmolekül einen geringeren Platzbedarf als ein Phospholipid besitzt. Infolgedessen befindet sich der Rezeptor $\mathrm{PIP}_{2}$ verglichen mit den vorangestellten Messungen in einer leicht erhöhten Anzahl pro Einheitsfläche in der festkörperunterstützten Membran. Einen Anhaltspunkt für das Ausmaß dieser Verdichtung liefern Filmwaagemessungen zur Bestimmung des Flächenbedarfs eines Lipids. Hierbei wird eine monomolekulare Lipidschicht an der Luft-Wasser-Grenzfläche gespreitet und durch Verringerung der verfügbaren Fläche die jeweiligen $A_{20^{-}}$ 
Werte der Lipide, welche den Platzbedarf des Moleküls bei einem Oberflächendruck von $20 \mathrm{mN} / \mathrm{m}$ kennzeichnen, bestimmt. Dieser Wert beträgt für die Phospholipide POPC und $\mathrm{PIP}_{2}$ ca. $70 \AA^{2}$, für Cholesterin ca. $40 \AA^{2}$. Demnach ergibt sich aus den verwendeten molaren Verhältnissen Phospholipid:Cholesterin (70:30) ein mittlerer Oberflächenbedarf pro Molekül von 60,3 $\AA^{2}$ und eine Erhöhung der Konzentration des Lipids $\mathrm{PIP}_{2}$ pro Einheitsfläche um den Faktor 1,14. Die Ergebnisse, korrigiert um die genannten Flächenverhältnisse, sind in Abbildung 6.5 aufgeführt.

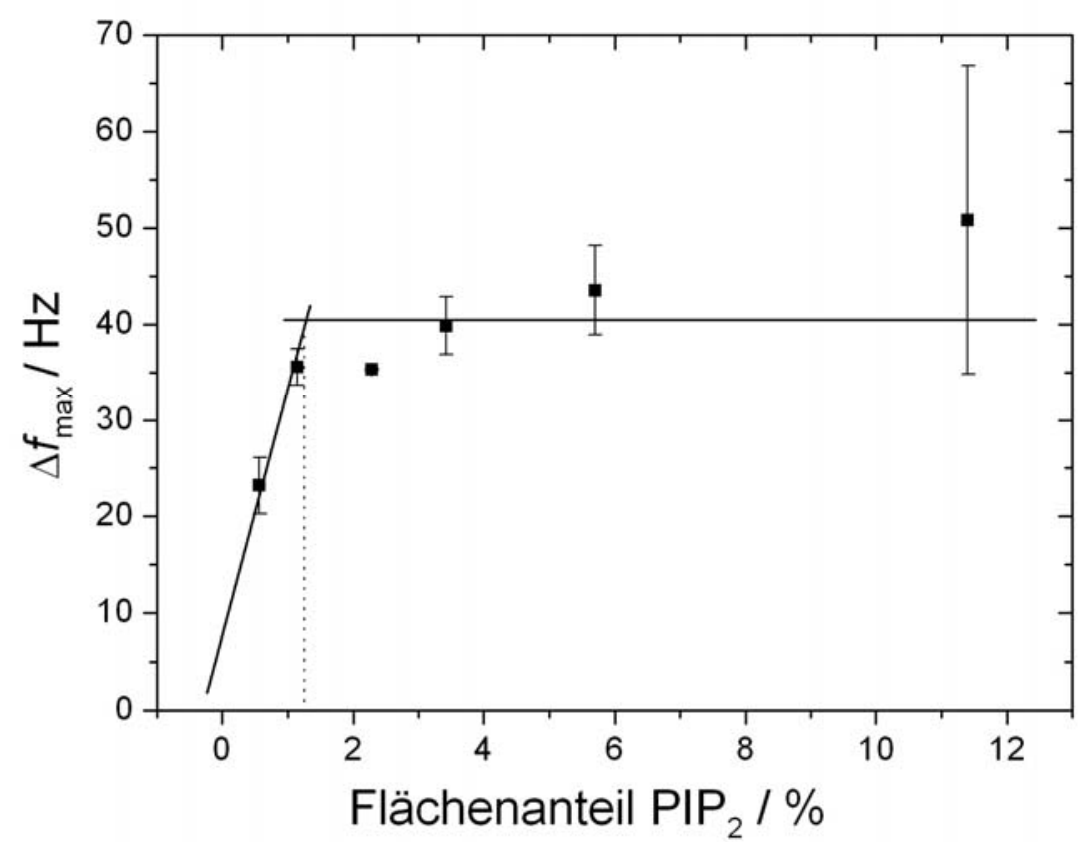

Abbildung 6.5 Mittelwerte der maximalen Resonanzfrequenzänderung nach Zugabe von Ezrin wt zu $\mathrm{PIP}_{2}$-dotierten festkörperunterstützten Membranen. Für alle Messungen wurden Proteinkonzentrationen $\geq 400 \mathrm{nM}$ eingesetzt. Die graphische Bestimmung der Konzentration an $\mathrm{PIP}_{2}$, ab der eine verringerte Resonanzfrequenzänderung verzeichnet wurde, erfolgte durch das Anlegen von Geraden an die gemessenen Punkte.

Eine graphische Bestimmung der Oberflächenkonzentration von $\mathrm{PIP}_{2}$, ab welcher eine signifikant geringere Frequenzänderung nach Zugabe von Ezrin wt zu verzeichnen war, ergab einen Wert von ca. $1,25 \% \mathrm{PIP}_{2}$. Niedrigere $\mathrm{PIP}_{2}$ Flächenanteile führten dazu, dass weniger Protein an die Oberfläche gebunden wurde; dies wiederum bewirkte eine starke Verringerung der Resonanzfrequenzänderung. 


\subsection{Visualisierung der Bindung von Ezrin wt an $\mathrm{PIP}_{2}$-haltige Membranen mittels Rasterkraftmikroskopie}

Nachdem die Parameter der Bindung von Ezrin wt an $\mathrm{PIP}_{2}$-haltige Membranen mittels Quarzmikrowaagemessungen definiert waren, wurden die Versuchsbedingungen für fluoreszenzmikroskopische Untersuchungen auf Siliziumdioxidoberflächen übertragen. Hierzu wurden festkörperunterstützte Membranen auf Siliziumdioxid präpariert (siehe Kapitel 3.2.4). Anschließend wurde ein Durchflusssystem verwendet, welches analog zum Aufbau der Quarzmikrowaage die Proteininkubation im konstanten Durchfluss ermöglichte. Es sollte zunächst über rasterkraftmikroskopische Aufnahmen ermittelt werden, ob die Membran unter diesen Bedingungen stabil ist und in welcher Art die Proteine unter Durchflussbedingungen an die Membran binden.

In Abbildung 6.6 $\mathrm{A}$ ist eine rasterkraftmikroskopische Aufnahme der durch Vesikelspreiten erhaltenen Membran aus POPC/PIP 2 (97:3) gezeigt. Die Fläche erscheint recht flach und ohne besondere strukturelle Auffälligkeiten, auch nach 30minütigem Durchfluss von Puffer konnte keine Zerstörung der Membranoberfläche oder ähnliches festgestellt werden. Die Bilder B, C und D zeigen jeweils eine festkörperunterstützte Membran aus POPC/PIP 2 (97:3) nach Inkubation der angegebenen Konzentrationen des Proteins Ezrin wt im Durchfluss. Auf der Membranoberfläche zeigte sich in Abhängigkeit der eingesetzten Proteinkonzentration eine steigende Bedeckung durch das Protein, welches auf der Membran eine Höhe von ca. 4-5 nm aufwies (siehe Profillinien B‘ und C'). Es zeigte sich besonders während der Abbildung der Probenoberfläche $B$, dass das gebundene Material sehr leicht verschiebbar war und zur Abbildung dieser Strukturen die Oberfläche mit einer hohen Geschwindigkeit abgerastert werden musste. In Abbildung 6.6 C konnte interessanterweise nachgewiesen werden, dass bereits eine sehr hohe Belegung der Membranoberfläche durch Protein erreicht war. In den rasterkraftmikroskopischen Aufnahmen dieser Probenoberflächen konnten lediglich kleinere Defektstellen mit einer Tiefe von ca. 0,5-1 $\mathrm{nm}$ nachgewiesen werden (Profillinien nicht gezeigt). 

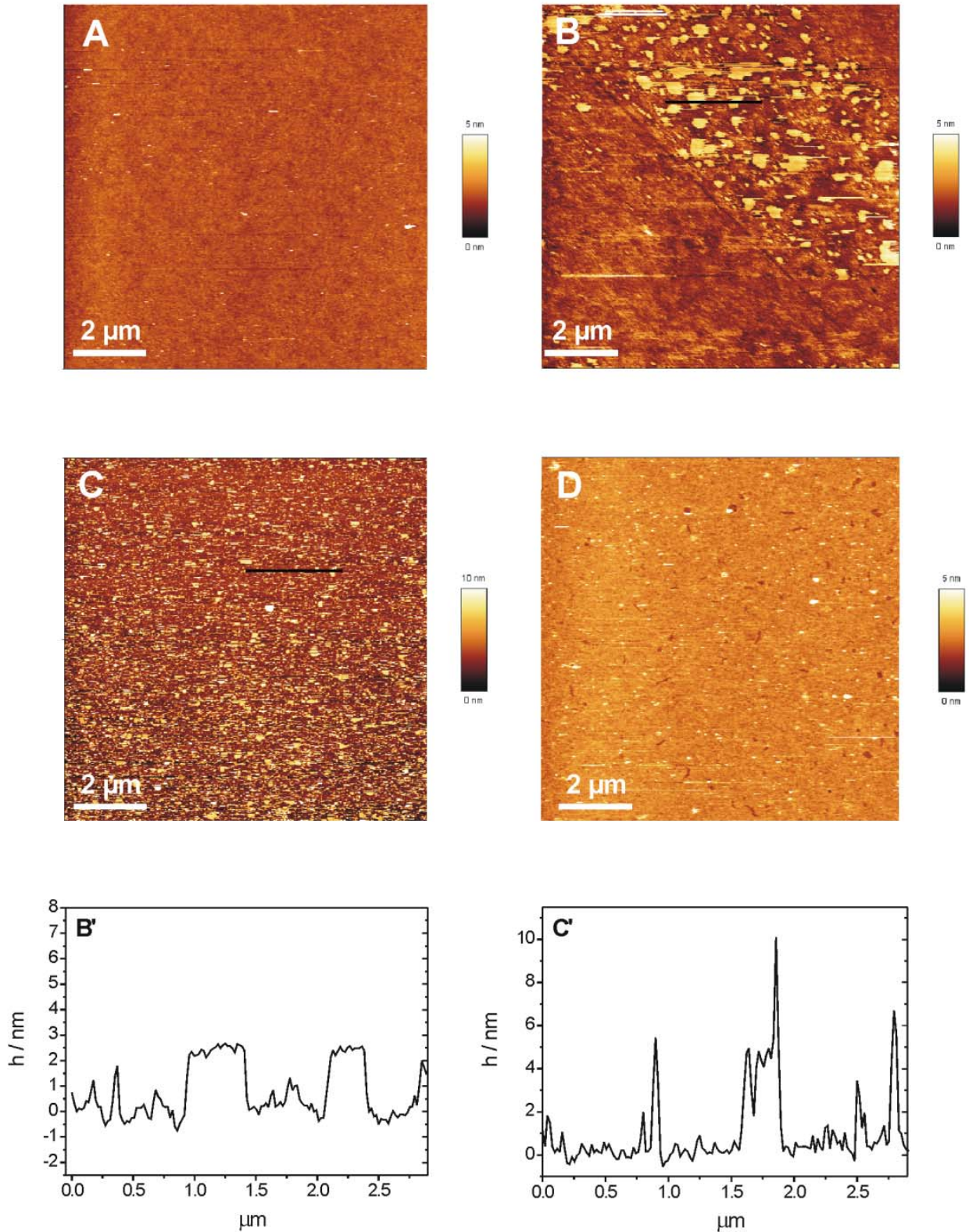

Abbildung 6.6: Rasterkraftmikroskopische Aufnahmen einer festkörperunterstützten Membran (POPC/PIP 2 97:3) auf Siliziumdioxid A) nach 30 min Durchfluss von reinem Puffer, B) nach Inkubation mit 0,02 $\mu \mathrm{M}$ Ezrin wt, C) nach Inkubation mit 0,05 $\mu \mathrm{M}$ Ezrin wt, D) nach Inkubation mit $1,00 \mu \mathrm{M}$ Ezrin wt im Durchfluss für 30 Minuten. In $\mathrm{B}^{\prime}$ und $\mathrm{C}^{\prime}$ sind die Höhenprofile der entsprechend markierten Linien gezeigt.

\subsection{Selbst-Assoziationseigenschaften von Ezrin wt und Ezrin T567D}

Es finden sich in der Literatur vielfach Hinweise darauf, dass Ezrin durch ein kooperatives Bindungsverhalten an der Membranoberfläche Cluster bildet (107, 
118). Diese Cluster bilden sich vermutlich aufgrund von intermolekularen attraktiven Wechselwirkungen zwischen den Proteinen. Es ist weiterhin beschrieben worden, dass in Lösung ein Gleichgewicht zwischen Monomeren und Dimeren des Wildtyps von ERM-Proteinen vorliegt. Im Gegensatz dazu können für die dauerhaft aktivierten Formen dieser Proteine in Lösung beinahe ausschließlich Monomere nachgewiesen werden (96). Daher wird vermutet, dass die Phosphorylierung von T567 im Ezrin eine intermolekulare Assoziation aufhebt. Bisher blieb jedoch ungeklärt, inwieweit die Phosphorylierung des Threoninrests 567 eine Clusterbildung während der Adsorption an Oberflächen beeinflusst. Um diese Fragestellung zu beantworten, wurden die Proteine Ezrin wt und Ezrin T567D wie in Kapitel 4.3 beschrieben mit einer Fluoreszenzsonde versehen und das Adsorptionsverhalten sowie die Anordnung der Proteine auf festkörperunterstützten Membranen fluoreszenzmikroskopisch untersucht. Beide vorgestellten Experimente wurden mindestens viermal mit jeweils sehr ähnlichen Resultaten durchgeführt.

Hierzu wurden festkörperunterstützte Lipidmembranen der Zusammensetzung POPC/PIP $2 /$ Perylen (98,5:0,5:1) durch Spreiten von Vesikeln auf hydrophilisierten Siliziumwafern hergestellt. Der stark verringerte Anteil an $\mathrm{PIP}_{2}$ von $0,5 \%$ sollte dazu führen, dass keine vollständige Bedeckung der Membranoberfläche durch Protein auftrat, sondern proteinfreie von proteinbelegten Membranbereichen leicht unterschieden werden können. Anschließend wurde eine 30minütige Inkubation im Durchfluss mit den fluoreszenzmarkierten Proteinen durchgeführt, mit Puffer gespült und die Membranoberfläche mit Hilfe des konfokalen Fluoreszenzmikroskops untersucht. Die in Abbildung 6.7 gezeigten Fluoreszenzaufnahmen stellen repräsentative Aufnahmen der Ergebnisse dieser Experimente dar.

In Abbildung 6.7 A sind deutlich mehrere Mikrometer große, unregelmäßig geformte fluoreszierende Bereiche zu erkennen, die als fluoreszenzmarkiertes Protein Ezrin wt identifiziert werden können. Auf mehreren Bereichen der Membran wurde eine solche Anreicherung von fluoreszenzmarkiertem Ezrin wt gefunden. Daneben existierten große Flächen, auf denen keinerlei Fluoreszenzsignal detektiert werden konnte. Das fluoreszenzmarkierte Protein war lediglich an einigen Stellen in der in Abbildung 6.7 A gezeigten Weise 
gehäuft vorzufinden. In Abbildung $6.7 \mathrm{~B}$ ist eine repräsentative Aufnahme von membrangebundenem Ezrin T567D gezeigt. Hier wurden im Gegensatz zu Ezrin wt lediglich deutlich kleinere, im Durchmesser weniger als etwa 0,5 $\mu \mathrm{m}$ aufweisende rot fluoreszierende Bereiche gefunden. Diese konnten jedoch auf der gesamten Membranoberfläche verteilt beobachtet werden.
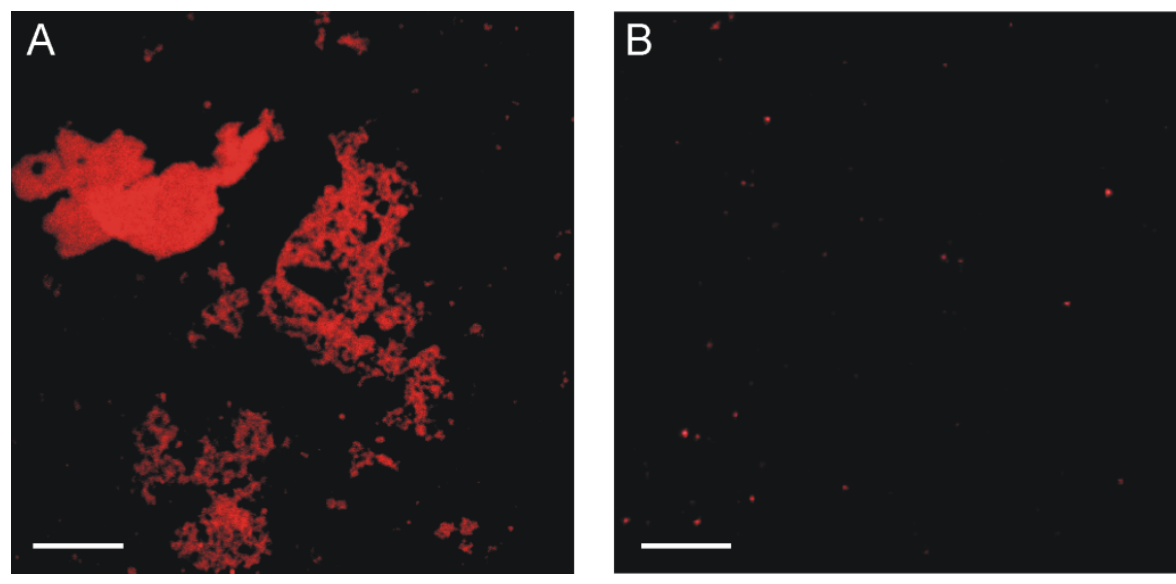

Abbildung 6.7 A: Mikroskopische Aufnahme der roten Fluoreszenz von AlexaFluor633markiertem Ezrin wt, adsorbiert auf einer festkörperunterstützten Membran aus POPC/PIP $/$ Perylen (98,5:0,5:1) auf Siliziumdioxid nach Inkubation von 0,05 $\mu$ M Ezrin für 30 min im Durchfluss. Maßstabsbalken: $10 \mu \mathrm{m}$.

B: Mikroskopische Aufnahme der roten Fluoreszenz von AlexaFluor633-markiertem Ezrin T567D, adsorbiert auf einer festkörperunterstützten Membran aus POPC/PIP $/$ Perylen (98,5:0,5:1) auf Siliziumdioxid nach Inkubation von 0,1 $\mu \mathrm{M}$ Ezrin für $30 \mathrm{~min}$ im Durchfluss. Maßstabsbalken: $10 \mu \mathrm{m}$.

Die sehr unterschiedlichen Clustergrößen deuten darauf hin, dass die ProteinProtein-Wechselwirkungen der verwendeten Proteine unterschiedlich sind und im Fall von Ezrin wt eine höhere Neigung zur Selbst-Assoziation als bei Ezrin T567D besteht.

\subsection{Auswertung der Adsorptionsisothermen unter Berücksichtigung kooperativen Bindungsverhaltens}

Das in Kapitel 6.2 dargestellte unterschiedliche Adsorptionsverhalten von Ezrin wt und Ezrin T567D an festkörperunterstützten, 0,5 mol\% $\mathrm{PIP}_{2}$ haltigen Membranen weist darauf hin, dass während des Adsorptionsprozesses der Proteine verschieden hohe laterale Interaktionskräfte zum Tragen kommen. 
Demnach scheint Ezrin wt eine höhere Neigung zur attraktiven Protein-ProteinInteraktion aufzuweisen als Ezrin T567D, was in der Ausbildung größerer Proteinaggregate auf der Membranoberfläche resultierte. Eine eingehendere Untersuchung dieser Hypothese wurde anhand der in Kapitel 5.2 vorgestellten Adsorptionsisothermen vorgenommen. Zu diesem Zweck wurde ein erweitertes Adsorptionsmodell eingesetzt, welches im Unterschied $\mathrm{zu}$ dem Adsorptionsmodell nach Langmuir die laterale Ausdehnung der adsorbierten Teilchen berücksichtigt. Durch Einführung eines zusätzlichen Parameters konnten des Weiteren Anziehungskräfte zwischen den adsorbierten Teilchen in die Anpassung einbezogen werden. Dieses Modell auf Basis der scaled particle theory (SPT) soll im Folgenden kurz vorgestellt werden. Im Anschluss werden die Ergebnisse der Anwendung dieses Modells auf die Messdaten gezeigt.

\subsubsection{Scaled particle theory (SPT)}

Die scaled particle theory wurde erstmals von Reiss, Frisch und Lebowitz im Jahr 1959 vorgestellt (119). Dieses Modell bezieht die Tatsache ein, dass fluide Körper eine räumliche Ausdehnung besitzen. Nach erfolgter Adsorption besetzt ein solcher Partikel aufgrund seiner Größe eine Fläche, welche für weitere Partikel nicht mehr als Adsorptionsfläche zur Verfügung steht. Die verfügbare Oberfläche ist damit eine Funktion ihres Belegungsgrades $\Theta$ :

$$
\Phi(\Theta)=(1-\Theta) \exp \left[-3 \frac{\Theta}{1-\Theta}-\left(\frac{\Theta}{1-\Theta}\right)^{2}\right]
$$

Hierbei wird berücksichtigt, dass das Adsorbat (hier: Protein) mehr als einen Gitterplatz besetzen kann. Die Funktion $\Phi(\Theta)$, welche die verfügbare Oberfläche beschreibt, kann in das bereits vorgestellte Modell nach Langmuir eingebunden werden und steht mit der Dissoziationskonstante $K_{D}$ wie folgt im Zusammenhang:

$$
K_{D}^{-1} c=\frac{\Theta}{\Phi(\Theta)}
$$


wobei $c$ die Proteinkonzentration in Lösung bezeichnet. Das Modell beschreibt einen nicht-kooperativen Adsorptionsvorgang an einer gleichförmigen Oberfläche, welcher zu einer Monolage des Adsorbats führt. Hierbei zeigen alle Bindungsplätze die gleiche Adsorptionsenergie.

Die Möglichkeit, dass das Adsorbat auf der Oberfläche auch untereinander Wechselwirkungen zeigt, kann durch eine Näherung nach Bragg und Williams einbezogen werden (120). Dadurch wird die Adsorptionsisotherme wie folgt erweitert:

$$
\frac{\Theta}{\Phi(\Theta)}=K_{D}^{-1} c \exp \left(\frac{\varepsilon \Theta}{k T}\right)
$$

Hierbei ist $\varepsilon$ die mittlere Protein-Protein-Wechselwirkungsenergie an der Oberfläche. Sie wird in Einheiten von $k T$ ausgedrückt. Dabei bedeutet ein negativer Wert von $\varepsilon$, dass benachbarte Partikel auf der Oberfläche einen stabilisierenden Effekt aufeinander ausüben, also positive Kooperativität auftritt und die Desorptionsrate durch diese Wechselwirkung verringert wird.

\subsubsection{Modellierung der Adsorptionsisothermen von Ezrin T567A, Ezrin wt und Ezrin T567D an PIP ${ }_{2}$-haltige Membranen nach dem SPT-Modell}

Die Adsorptionsisothermen, welche für die Interaktion von Ezrin T567A, Ezrin wt und Ezrin T567D an PIP $_{2}$-haltige Membranen mit Hilfe der Quarzmikrowaagetechnik aufgenommen wurden, wurden nach dem vorgestellten Adsorptionsmodell erneut ausgewertet. Es sollte untersucht werden, ob während der untersuchten Adsorptionsprozesse unterschiedliche intermolekulare ProteinProtein-Wechselwirkungen auftreten.

In Abbildung 6.8 sind die Adsorptionsisothermen der untersuchten Systeme aufgeführt. 

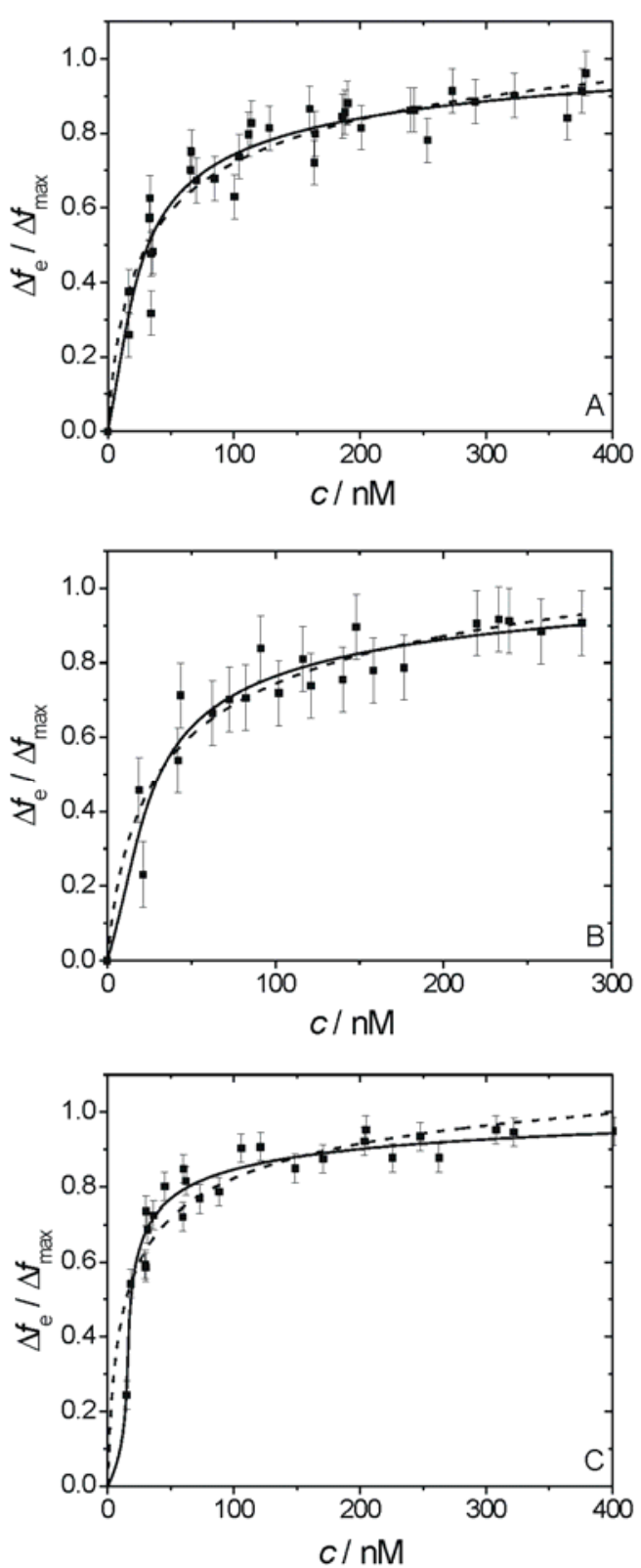

Abbildung 6.8: Adsorptionsisothermen von A Ezrin T567A, B Ezrin wt und C Ezrin T567D an 10\% $\mathrm{PIP}_{2}$-haltige Modellmembranen. Die gestrichelten Linien repräsentieren eine Anpassung von Gleichung [6.2] an die Datenpunkte. Die durchgezogenen Linien repräsentieren eine Anpassung von Gleichung [6.3] an die Datenpunkte.

Die Anpassungen der Gleichungen [6.2] und [6.3] an die Adsorptionsisothermen sind in der Darstellung als gestrichelte beziehungsweise durchgezogene Linien wiedergegeben. Interessanterweise ähneln sich die Kurvenverläufe im Fall von Ezrin T567A (Abbildung 6.8 A) und Ezrin wt (Abbildung 6.8 B) sehr stark. Eine etwas größere Abweichung der beiden Anpassungen zeigt sich dagegen im Fall von Ezrin T567D (Abbildung 6.8 C). Die jeweiligen Dissoziationskonstanten $K_{D}$ 
sowie die erhaltenen Interaktionsenergien in Einheiten von $k T$ sind in Tabelle Tabelle 6 aufgeführt.

Tabelle 6: Ergebnisse der Anpassung der Adsorptionsmodelle nach Gleichungen [6.2] und [6.3] an die aufgenommenen Isothermen der Interaktion von Ezrin T567A, Ezrin wt und Ezrin T567D mit $10 \% \mathrm{PIP}_{2}$-haltigen festkörperunterstützten Membranen.

\begin{tabular}{c|c|c|c} 
Protein & Ezrin T567A & Ezrin wt & Ezrin T567D \\
\hline$K_{\mathrm{D}} / \mathrm{nM}$ (nach GI. [6.2]) & $45 \pm 12$ & $52 \pm 32$ & $18 \pm 9$ \\
\hline$K_{\mathrm{D}} / \mathrm{nM}$ (nach Gl. [6.3]) & 104 & 121 & 235 \\
\hline$\varepsilon / k T$ & -5 & -6 & -10
\end{tabular}

Die Tabelle zeigt, dass für Ezrin T567A und Ezrin wt eine ähnliche Wechselwirkungsenergie $\varepsilon$ für die Adsorption an der Oberfläche ermittelt werden konnte. Die Stabilisierung der Proteinadsorption an der Oberfläche resultiert gleichzeitig in einer Vergrößerung der Dissoziationskonstante $K_{D}$ der ProteinLipid-Bindung. Dasselbe gilt für die Bindung von Ezrin T567D, allerdings scheint hier die positive Kooperativität der Proteinadsorption mit -10 kT deutlich stärker ausgeprägt als bei den beiden anderen Proteinen.

\subsection{Laterale Mobilität von $\mathrm{PIP}_{2}$ in festkörperunterstützten Lipidmembranen}

Die Verteilung und Beweglichkeit der Rezeptorlipide in der Doppelschicht können einen Einfluss auf das beobachtete kooperative Adsorptionsverhalten von Ezrin an diesen Flächen ausüben. Von besonderer Bedeutung für die Interpretation der Messergebnisse war daher die Untersuchung der Verteilung sowie der lateralen Mobilität von $\mathrm{PIP}_{2}$ in den verwendeten festkörperunterstützten Membranen. Um die Diffusion der Lipide in der Ebene beobachten und quantifizieren zu können, wurde die Methode des fluorescence recovery after photobleaching (FRAP) angewendet. Dazu wurden durch Spreiten von unilamellaren Lipidvesikeln 
festkörperunterstützte Membranen auf hydrophilisierten Siliziumwafern oder silanisierten Oberflächen präpariert. Die Membranen konnten durch einen kovalent an $\mathrm{PIP}_{2}$ gebundenen Farbstoff fluoreszenzmikroskopisch detektiert werden. Durch das laserinduzierte Bleichen eines diskreten, kreisrunden Bereichs (region of interest, $R O I$ ) der homogen fluoreszierenden Fläche wurde der Fluoreszenzfarbstoff in diesem $R O I$ irreversibel zerstört und erschien schwarz. Sofern eine Diffusion der umliegenden fluoreszierenden Lipide in diesen gebleichten Bereich vorlag, wurde ein Anstieg der Fluoreszenz im ROI über einen Zeitraum von wenigen Minuten beobachtet. Aus einer Auftragung der Fluoreszenzintensität gegen die Zeit kann mit Hilfe von geeigneten Algorithmen ein Diffusionskoeffizient ermittelt werden, wobei hierfür die Werte auf die Ausgangsintensität zum Zeitpunkt $t=0$ normiert werden.

\subsubsection{FRAP-Messungen an cholesterinfreien Membranen}

Für die FRAP-Messungen wurden verschiedene fluoreszierende $\mathrm{PIP}_{2}$-Varianten verwendet (siehe Kapitel 3.3.4). Diese Lipide zeigten ein unterschiedliches Diffusionsverhalten in der Membranebene. Zunächst sollen die Ergebnisse für das BodipyTMR-markierte $\mathrm{PIP}_{2}$ vorgestellt werden.

Das Spreiten von Vesikeln der Zusammensetzung POPC/PIP $/ \mathrm{PIP}_{2}$-BodipyTMR (97:1:2) führte zu einer homogen fluoreszierenden Membran, wie sie in Abbildung 6.8 A zum Zeitpunkt $t=-1 \mathrm{~s}$ dargestellt ist. Diese Homogenität deutet darauf hin, dass das Lipid $\mathrm{PIP}_{2}$ statistisch in der Membran verteilt vorliegt. Allerdings muss beachtet werden, dass das Auflösungsvermögen des Mikroskops eine mögliche Unterstrukturierung im Nanometerbereich nicht darstellen könnte. Es wurde ein Bleichfleck in der Membranebene durch einen kurzen, intensiven Laserpuls erzeugt und im Abstand von drei Sekunden fluoreszenzmikroskopische Aufnahmen der gebleichten Stelle gemacht. Es zeigte sich, dass der Bleichfleck über den Zeitraum der Messung nicht vollständig verschwand, sondern dass die Fluoreszenzintensität innerhalb von ca. $40 \mathrm{~s}$ auf $50 \%$ der Ausgangsintensität anstieg. Die entsprechende Auftragung ist in Abbildung $6.8 \mathrm{~B}$ gezeigt. Der insgesamt recht hohe immobile Anteil des fluoreszierenden Lipids, der auf $(60 \pm 7) \%$ bestimmt wurde, erlaubte keine exakte Berechnung des Diffusionskoeffizienten. Mit Hilfe eines Algorithmus, der von 
Jönsson et al. entwickelt wurde (121), wurde ein effektiver Diffusionskoeffizient von ca. $(4 \pm 2) \mu \mathrm{m}^{2} / \mathrm{s}$ abgeschätzt $(n=6)$, was im erwarteten Bereich für festkörperunterstützte Membranen liegt. Die Tatsache, dass der aufgebrachte Bleichfleck über die Gesamtdauer der Messung scharfe Ränder behält, sowie die Höhe des immobilen Anteils legen die Vermutung nah, dass die Diffusion ausschließlich auf die obere Monoschicht der Membran beschränkt ist.

A
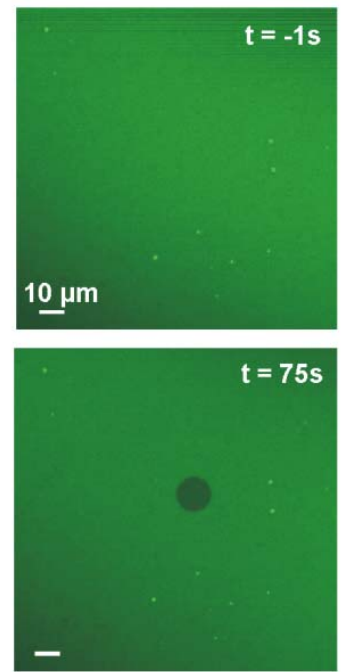

B

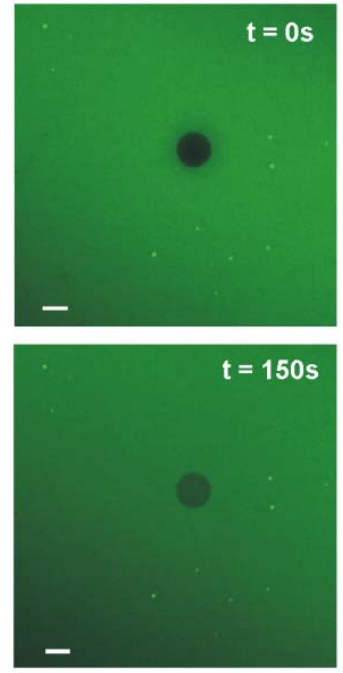

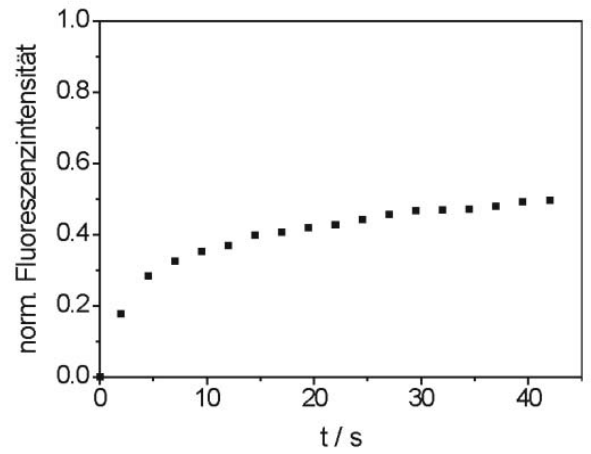

Abbildung 6.9 A: FRAP-Untersuchung zum Diffusionsverhalten von $\mathrm{PIP}_{2}$-BodipyTMR in einer festkörperunterstützten Membran, präpariert durch Spreiten von unilamellaren Vesikeln (POPC/PIP $/$ PIP $_{2}$-BodipyTMR (97:1:2)) auf hydophilisierten Siliziumwafern. Die fluoreszenzmikroskopischen Aufnahmen zeigen die Membran vor dem Bleichvorgang $(t=-1 \mathrm{~s})$ sowie nach dem Bleichvorgang zu den angegebenen Zeitpunkten ( $t=0 \mathrm{~s}, t=75 \mathrm{~s}, \mathrm{t}=150 \mathrm{~s})$. Der Bleichvorgang fand zum Zeitpunkt $0<t<1$ statt. B: Verlauf der Fluoreszenzintensität normiert auf die Intensität bei $t=0 \mathrm{~s}$. Diffusionskoeffizient: $D=2,5 \mu \mathrm{m}^{2} / \mathrm{s}$. Immobiler Anteil: $50 \%$. Puffer: E1 (20 mM TRIS/HCl, $50 \mathrm{mM} \mathrm{KCl,} \mathrm{0,1} \mathrm{mM} \mathrm{EDTA,} 1$ mM NaN 3 , pH 7,4.

Ein entsprechendes Experiment wurde unter Verwendung von Bodipy-TopFluormarkiertem $\mathrm{PIP}_{2}$ durchgeführt. Die Fluoreszenz der Membran in Abbildung 6.10 A weist keine Inhomogenität auf. Nach Setzen des Bleichflecks, welcher in der Abbildung zum Zeitpunkt $t=0 \mathrm{~s}$ dargestellt ist, wurde die Membran über einen gewissen Zeitraum fluoreszenzmikroskopisch aufgenommen. Dabei konnte festgestellt werden, dass kein Wiedergewinn der Fluoreszenzintensität über die Zeit eintrat und $\mathrm{PIP}_{2}$-Bodipy-TopFluor demnach keine Mobilität in der Membranebene besaß. Es fiel des Weiteren auf, dass ein relativ starkes Bleichen der Membranfluoreszenz infolge der wiederholten Beleuchtungen auftrat, 
welches in diesem Maß nicht unter Verwendung von PIP $_{2}$-BodipyTMR beobachtet wurde. Dies könnte zusätzlich die Quantifizierung einer (niedrigen) Diffusionskonstante erschwert haben.

A
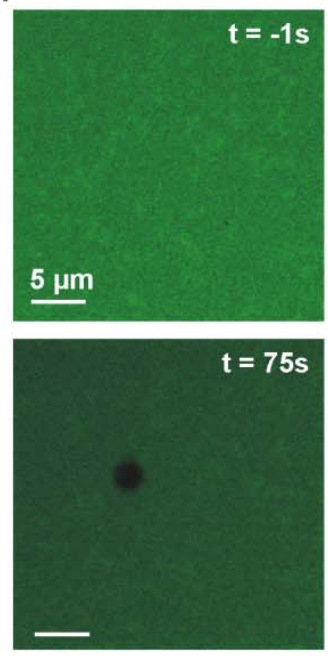

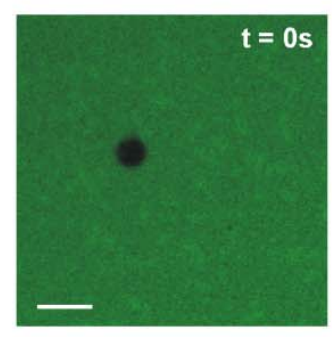

$t=150 s$
B

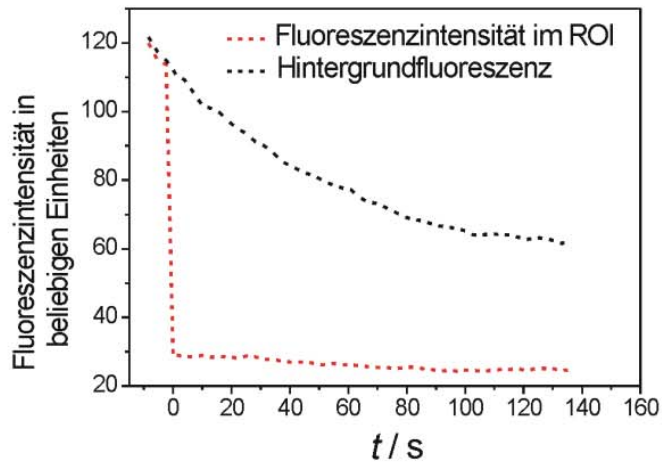

Abbildung 6.10 A: FRAP-Untersuchung zum Diffusionsverhalten von $\mathrm{PIP}_{2}$-Bodipy-TopFluor in einer festkörperunterstützten Membran, präpariert durch Spreiten von unilamellaren Vesikeln (POPC/PIP $/$ PIP $_{2}$-Bodipy-TopFluor (97:1:2)) auf hydophilisierten Siliziumwafern. Die fluoreszenzmikroskopischen Aufnahmen zeigen die Membran vor dem Bleichvorgang $(t=-1 \mathrm{~s})$ sowie nach dem Bleichvorgang zu den angegebenen Zeitpunkten ( $t=0 \mathrm{~s}, t=75 \mathrm{~s}, \mathrm{t}=150 \mathrm{~s}$ ). Der Bleichvorgang fand zum Zeitpunkt $0<t<1$ statt. B: Verlauf der Fluoreszenzintensität im gebleichten Bereich (ROI, rot) sowie der Fluoreszenzintensität des Hintergrundes (schwarz) in beliebigen Einheiten. Puffer: E1 (20 mM TRIS/HCl, $50 \mathrm{mM} \mathrm{KCl,} \mathrm{0,1} \mathrm{mM} \mathrm{EDTA,} 1 \mathrm{mM} \mathrm{NaN}$, pH 7,4 .

Für die Auftragung der Fluoreszenzintensitäten im gebleichten Bereich (ROI) sowie im Hintergrund (siehe Abbildung 6.10 B) wurde darauf verzichtet, eine Normierung der Daten vorzunehmen, um den starken Verlust der Fluoreszenzintensität des Hintergrundes darzustellen.

Anschließend wurde eine FRAP-Messung an einer PIP ${ }_{2}$-BodipyFL-haltigen Lipidmonoschicht durchgeführt. Diese wurde auf der hydrophoben Grenzschicht einer mit Hexamethyldisilazan (HMDS, siehe Kapitel 3.2.5) silanisierten Glasoberfläche durch das Spreiten von Vesikeln der Zusammensetzung $\mathrm{POPC} / \mathrm{PIP}_{2} / \mathrm{PIP}_{2}$-BodipyFL (97:1:2) präpariert. Das Resultat, eine Lipidmonoschicht auf hydrophoben Alkylketten des Silans gespreitet, entsprach damit sehr gut dem Membransystem, das in den Quarzmikrowaagemessungen 
zur Anwendung kam. Die FRAP-Messung an dieser Lipidmonoschicht ermöglichte eine Aussage zum Diffusionsverhalten von $\mathrm{PIP}_{2}$ in einer solchen Membran.

In Abbildung 6.11 A sind einige mikroskopische Aufnahmen der Membranfluoreszenz vor und nach Aufbringen des Bleichflecks gezeigt. Über die Dauer der Messung konnte beobachtet werden, dass die ehemals scharfen Ränder des Bleichflecks auseinander liefen und eine Wiederkehr der Fluoreszenzintensität in den gebleichten Membranbereich einsetzte. Eine Auftragung der normierten Fluoreszenzintensität gegen die Zeit (Abbildung Abbildung $6.11 \mathrm{~B}$ ) zeigt, dass die Fluoreszenzintensität zum Zeitpunkt $t=150 \mathrm{~s}$ wieder auf über 70\% der Ausgangsintensität angestiegen war. Eine Bestimmung des Diffusionskoeffizienten für diese Messung wurde anhand des Algorithmus von Jönsson et al. (121) durchgeführt. Hierbei konnten die Diffusionskonstante zu $0,26 \mu \mathrm{m}^{2} / \mathrm{s}$ und der immobile Anteil von $15 \%$ bestimmt werden.

A
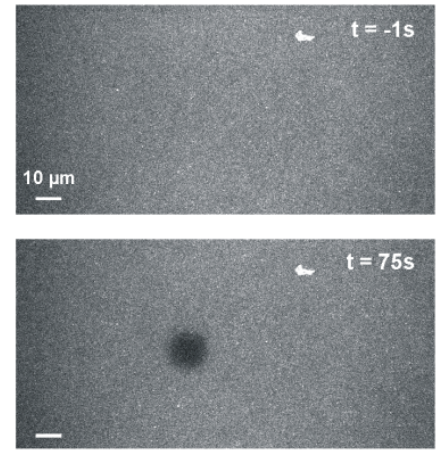
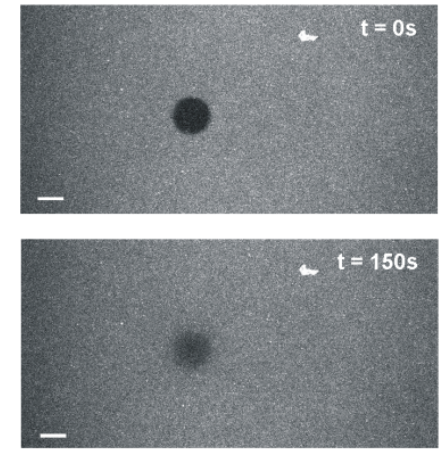

B

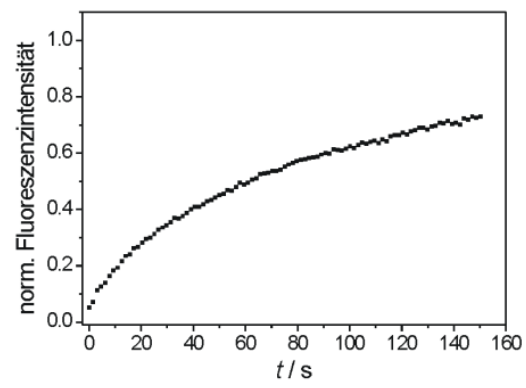

Abbildung 6.11 A: FRAP-Untersuchung zum Diffusionsverhalten von $\mathrm{PIP}_{2}$-BodipyFL in einer festkörperunterstützten Lipidmonoschicht, präpariert durch Spreiten von unilamellaren Vesikeln (POPC/PIP $/$ PIP $_{2}$-BodipyFL (97:1:2)) auf mittels HMDS silanisiertem Glas. Die fluoreszenzmikroskopischen Aufnahmen zeigen die Membran vor dem Bleichvorgang $(t=-1 \mathrm{~s})$ sowie nach dem Bleichvorgang zu den angegebenen Zeitpunkten ( $t=0 \mathrm{~s}, t=75 \mathrm{~s}, \mathrm{t}=150 \mathrm{~s})$. Der Bleichvorgang fand zum Zeitpunkt $0<t<1$ statt. B: Verlauf der Fluoreszenzintensität im gebleichten Bereich (ROI) normiert auf die Intensität bei $t=0 \mathrm{~s}$. Diffusionskoeffizient: $\mathrm{D}=0,26 \mu \mathrm{m}^{2} / \mathrm{s}$. Immobiler Anteil: 15\%. Puffer: E1 (20 mM TRIS/HCl, $50 \mathrm{mM} \mathrm{KCl,} \mathrm{0,1} \mathrm{mM} \mathrm{EDTA,}$ $1 \mathrm{mM} \mathrm{NaN}_{3}, \mathrm{pH} 7,4$. 


\subsubsection{FRAP-Messungen an cholesterinhaltigen Membranen}

Im Rahmen der vorliegenden Arbeit wurden unter anderem Messungen der Adsorption von Ezrin wt an cholesterinhaltige Membranen durchgeführt. Da nur für den Fluorophor PIP $_{2}$-BodipyTMR eine laterale Mobilität in der POPC-Matrix nachgewiesen werden konnte, wurde ausschließlich dieser für die weiterführenden Messungen verwendet. Der Einfluss von Cholesterin auf die Mobilität von $\mathrm{PIP}_{2}$-BodipyTMR wurde mittels FRAP-Experimenten untersucht. Hierzu wurden unilamellare Vesikel der Zusammensetzung POPC/Cholesterin/PIP $/ P_{2} / P_{2}$-BodipyTMR (67:30:1:2). Eine beispielhafte Messung ist in Abbildung 6.12 dargestellt.

A
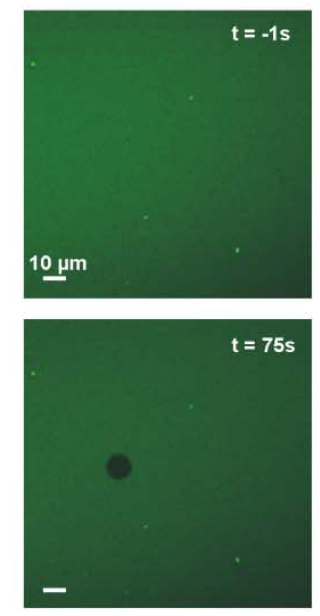
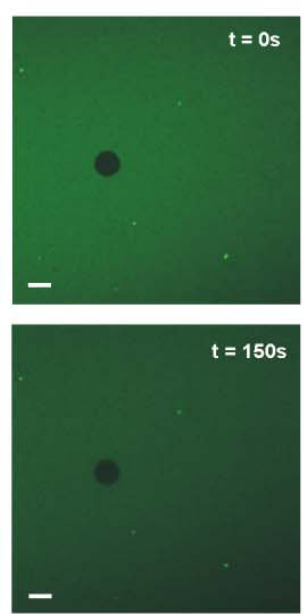

B

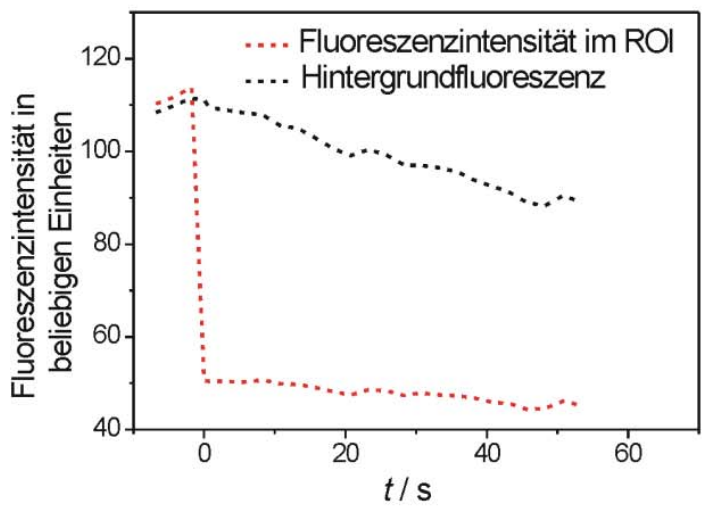

Abbildung 6.12 A: FRAP-Untersuchung zum Diffusionsverhalten der Lipide einer festkörperunterstützten Membran, präpariert durch Spreiten von unilamellaren Vesikeln (POPC/Cholesterin/PIP $2 / \mathrm{PIP}_{2}$-Bodipy-TMR (67:30:1:2)) auf hydophilisierten Siliziumwafern. Die fluoreszenzmikroskopischen Aufnahmen zeigen die Membran vor dem Bleichvorgang $(t=-1 \mathrm{~s})$ sowie nach dem Bleichvorgang zu den angegebenen Zeitpunkten ( $t=0 \mathrm{~s}, t=75 \mathrm{~s}, \mathrm{t}=150 \mathrm{~s})$. Der Bleichvorgang fand zum Zeitpunkt $0<t<1$ statt. B: Verlauf der Fluoreszenzintensität im gebleichten Bereich (ROI, rot) sowie der Fluoreszenzintensität des Hintergrundes (schwarz) in beliebigen Einheiten. Puffer: E1 (20 mM TRIS/HCl, $50 \mathrm{mM} \mathrm{KCl,} \mathrm{0,1} \mathrm{mM} \mathrm{EDTA,} 1 \mathrm{mM} \mathrm{NaN}, \mathrm{pH}$ $7,4)$.

Anhand der in Abbildung 6.12 A dargestellten Fluoreszenzaufnahmen wird deutlich, dass der aufgebrachte Bleichfleck über die Dauer der Messung keine Wiederherstellung der Fluoreszenzintensität aufweist. Auch die in Abbildung 6.12 $B$ dargestellte Auftragung der Fluoreszenzintensität gegen die Zeit weist keinen 
signifikanten Anstieg der Fluoreszenzintensität im gebleichten Bereich auf. Der Zusatz von Cholesterin zur Lipidmischung hat demnach zu einer drastischen Verringerung der lateralen Mobilität der BodipyTMR-markierten $\mathrm{PIP}_{2}$-Moleküle geführt.

\subsection{Inhomogenität der cholesterinhaltigen Lipidmischung}

Abschließend konnte mit Hilfe der FRAP-Technik die Frage adressiert werden, ob die cholesterinhaltige festkörperunterstützte Lipidmembran aus POPC/Cholesterin/PIP 2 eine homogene Verteilung der Lipide aufweist. Diese Untersuchung war im Hinblick auf die Quarzmikrowaagestudien interessant, bei denen unter Verwendung von cholesterinhaltigen Membranen der PIP $_{2}$-Gehalt immer weiter reduziert wurde und die Bindung von Ezrin wt an dieses Membransystem untersucht wurde (siehe Kapitel 6.1.3). Um eine Berechnung der Bindungsverhältnisse zu erlauben, mussten Informationen über die Verteilung der Lipide in dieser Membran gewonnen werden.
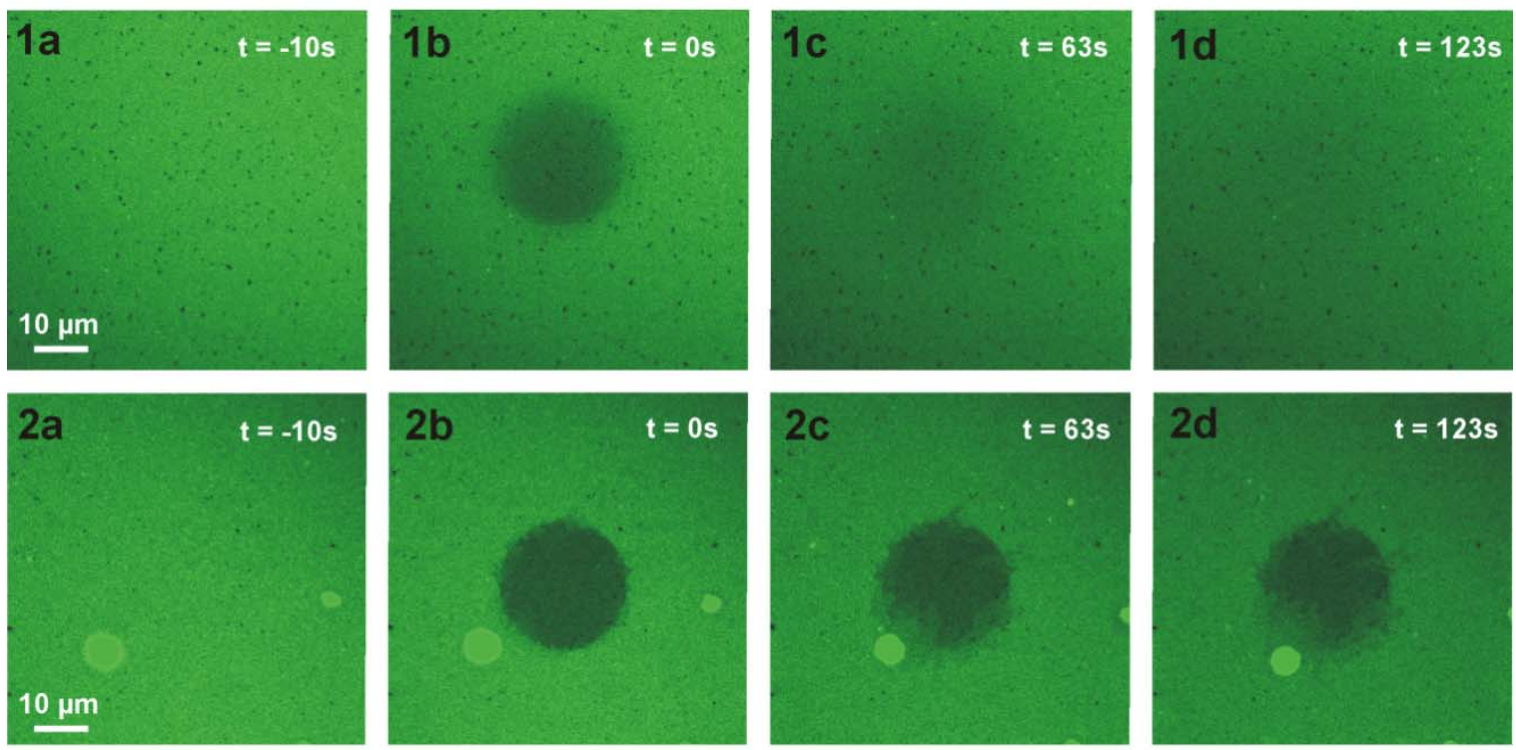

Abbildung 6.13: FRAP-Untersuchung zum Diffusionsverhalten der Lipide einer festkörperunterstützten Membran, präpariert durch Spreiten von unilamellaren Vesikeln bestehend aus 1 POPC/PIP $/$ /Bodipy-PC $(97,5: 3: 0,5)$ und 2 POPC/Cholesterin/PIP $/$ Podipy-PC $_{2}$ (67,5:30:3:0,5) auf hydophilisierten Siliziumwafern. Die fluoreszenzmikroskopischen Aufnahmen zeigen die Membran vor dem Bleichvorgang $(t=-10 \mathrm{~s})$ sowie nach dem Bleichvorgang zu den angegebenen Zeitpunkten ( $t=0 \mathrm{~s}, t=63 \mathrm{~s}, \mathrm{t}=123 \mathrm{~s})$. Der Bleichvorgang fand zum Zeitpunkt $-10 \mathrm{~s}<t<0 \mathrm{~s}$ statt. Puffer: E1 $(20 \mathrm{mM}$ TRIS $/ \mathrm{HCl}, 50 \mathrm{mM} \mathrm{KCl}, 0,1 \mathrm{mM}$ EDTA, $1 \mathrm{mM} \mathrm{NaN}$, $\mathrm{pH} 7,4)$. 
Hierzu wurden mit Hilfe des Lasers relativ große Bleichflecke auf zunächst homogen fluoreszierende Membranen aus POPC/PIP $/$ Bodipy-PC (97,5:2:0,5) beziehungsweise POPC/Cholesterin/PIP $2 /$ Bodipy-PC (67,5:39:2:0,5) aufgebracht. Die zeitabhängige Rückkehr der Fluoreszenzintensität stellte sich in den beiden beobachteten Systemen verschieden dar. In

Abbildung 6.13-1a ist eine festkörperunterstützte, mit dem fluoreszierenden Lipid Bodipy-PC dotierte Membran zu sehen, die abgesehen von mehreren kleinen Membrandefekten, die schwarz erscheinen, homogen fluoresziert. In

Abbildung 6.13-1b ist der Bleichfleck gezeigt, welcher zum Zeitpunkt $-10 \mathrm{~s}<t<0 \mathrm{~s}$ aufgebracht wurde. Die folgenden Bilder zeigen, wie die Fluoreszenzintensität in diesem gebleichten Bereich über die Zeit zurückkehrt. Für diese Aufnahmen wurde keine Diffusionskonstante ermittelt, da der Zeitraum, der zum Bleichen des recht großen Bereichs benötigt wurde, zu lang war, um die Rahmenbedingungen für die zugrunde liegende Auswertung einzuhalten. Es wurde anhand von weiteren Messungen an kleineren Bleichflecken eine vollständige Rückkehr der Fluoreszenzintensität beobachtet und ein Diffusionskoeffizient von $(1,2 \pm 0,5) \mu^{2} / \mathrm{s}(n=7)$ ermittelt. Eine exemplarische recovery-Kurve ist in Abbildung wiedergegeben. Die Mobilität des fluoreszierenden Lipids ist in diesem System gegeben.

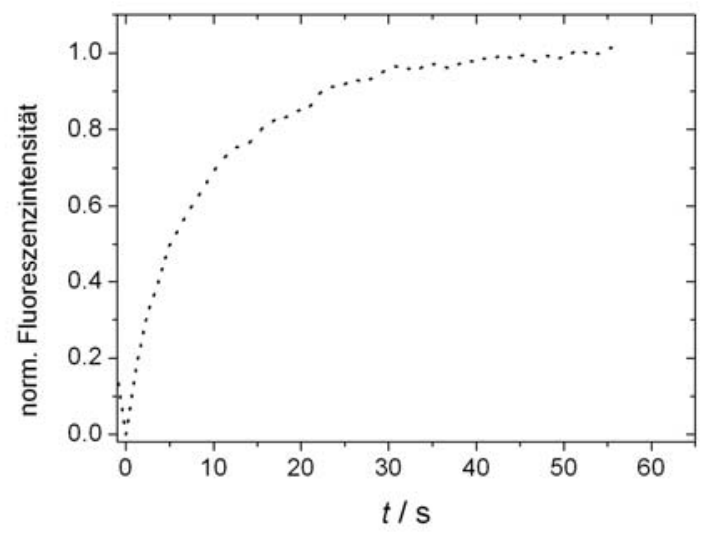

Abbildung 6.14: FRAP-Experiment zur Bestimmung der Mobilität von Bodipy-PC in einer festkörperunterstützten Membran aus POPC/PIP 2 /Bodipy-PC (97,5:3:0,5). Gezeigt ist der Verlauf der Fluoreszenzintensität im gebleichten Bereich (ROI) normiert auf die Intensität bei $t=0 \mathrm{~s}$. Diffusionskoeffizient: $D=(1,2 \pm 0,5) \mathrm{\mu m}^{2} / \mathrm{s}$. Immobiler Anteil: 0\%. Puffer: E1 (20 mM TRIS/ $\mathrm{HCl}$, $50 \mathrm{mM} \mathrm{KCl}, 0,1 \mathrm{mM}$ EDTA, $1 \mathrm{mM} \mathrm{NaN}_{3}, \mathrm{pH} \mathrm{7,4).}$ 
Die Messungen am cholesterinhaltigen Membransystem zeigten ein anderes Diffusionsverhalten des Bodipy-PC. In

Abbildung 6.13-2 ist das gleiche Experiment an dem cholesterinhaltigen Membransystem durchgeführt worden. Es zeigte sich auch hier eine gewisse Rückkehr von Fluoreszenzintensität in den gebleichten Bereich, allerdings schien die Diffusion der fluoreszierenden Lipide nicht gleichmäßig zu erfolgen, sondern es bildete sich über die Dauer der Messung ein unregelmäßig geformter dunkler Bereich. Dieser Effekt wurde regelmäßig beobachtet. Eine Quantifizierung der Diffusionsgeschwindigkeit von Bodipy-PC erscheint in diesem Fall nicht sinnvoll, da je nach Platzierung und Größe des Bleichflecks eine grundlegend unterschiedliche Fluoreszenzrückkehr in den ROI beobachtet wurde. Festzuhalten ist die Tatsache, dass die cholesterinhaltige Lipidmembran nicht in allen Regionen eine gleiche Mobilität der fluoreszierenden Lipide aufzuweisen schien.

\subsection{Diskussion}

In bestimmten Bereichen der natürlichen Plasmamembran, so zum Beispiel im Bürstensaum (Mikrovilli) des Darmepithels oder in Scheinfüßchen, sogenannten Filopodien und Lamellipodien, findet sich eine hohe Konzentration sowohl des Lipids $\mathrm{PIP}_{2}$ als auch von membrangebundenem Ezrin. In der aktuellen Literatur zur Interaktion von Ezrin und $\mathrm{PIP}_{2}$ wird kontrovers diskutiert, welche zellulären Mechanismen zu dieser Anhäufung führen könnten. Einerseits ist denkbar, dass das Protein Ezrin mehr als eine Bindungsstelle für $\mathrm{PIP}_{2}$ bereithält und zu einer Assoziation mit mehreren Lipiden führt. So könnte die basische Bindungsstelle von Ezrin die elektrostatische Abstoßung der negativ geladenen Lipidkopfgruppen kompensieren und eine Zusammenführung der Lipide in der Membran bewirken. Ein solches Verhalten konnte für das Protein MARCKS gefunden werden, welches selektiv an $\mathrm{PIP}_{2}$ bindet und so zu einer Aufkonzentrierung des Lipids führt. In Ezrin und MARCKS sind die Bindungsstellen für $\mathrm{PIP}_{2}$ ähnlich aufgebaut (27). Andererseits könnte auch eine attraktive Protein-Protein-Interaktion, welche die Bildung von membrangebundenen Proteinen zu einem Cluster initiiert, zu einer Aufkonzentration des gebunenen Lipids in den proteinbelegten 
Membranbereichen führen. Dabei schließen sich die genannten Möglichkeiten nicht gegenseitig aus.

In Experimenten, bei welchen die Bindung von Ezrin wt an festkörperunterstützte Membranen mit Hilfe der Quarzmikrowaage untersucht wurde, konnte durch Variation des Gehalts an $\mathrm{PIP}_{2}$ ein Punkt definiert werden, ab dem immer weniger Ezrin wt an die Membran gebunden wurde. Dieser war bei einem Prozentsatz von 6,5\% $\mathrm{PIP}_{2}$ erreicht. Für die Messungen unter Verwendung der N-terminalen Domäne des Proteins, N-ERMAD, wurde dieser bereits bei einem Prozentsatz von $4 \%$ erreicht. Die Lipidmischung mit 30\% Cholesterin zeigte hingegen, dass bereits ab 1,25\% $\mathrm{PIP}_{2}$ die Oberflächenkonzentration an Ezrin unverändert blieb. Erst unterhalb von 1,25\% konnte eine signifikante Verringerung der adsorbierten Proteinmenge beobachtet werden.

Aus den Größenverhältnissen der Interaktionspartner können die theoretischen Bindungsverhältnisse abgeschätzt werden: Die N-terminale FERMInteraktionsdomäne von Ezrin belegt eine Fläche von ca. $4900 \AA^{2}(46,50)$. Unter der Annahme, dass die Kopfgruppe von $\mathrm{PIP}_{2}$ eine Fläche von $70 \AA^{2}$ einnimmt und alle Phospholipide gleich groß sind, ergibt sich, dass bei ideal dichter Proteinpackung und einer maximal erreichbaren Oberflächenbedeckung von $60 \%$ schon bei einem Membrangehalt von 1,4\% $\mathrm{PIP}_{2}$ die Interaktionspartner im Verhältnis 1:1 vorliegen. Dieser Wert entspricht auch etwa der Grenzoberflächenkonzentration, die für die vollständige Belegung der cholesterinhaltigen Membran bestimmt wurde.

Demgegenüber konnte in der cholesterinfreien Membran eine vollständige Belegung durch Ezrin wt erst ab einem $\mathrm{PIP}_{2}$-Gehalt von 6,5\% gefunden werden. Dies bedeutet, dass in diesem Fall von jedem Protein mehr als ein Molekül PIP 2 gebunden werden muss. Der Unterschied zwischen den beiden genannten Membransystemen konnte durch FRAP-Messungen deutlich gemacht werden: Die Diffusion der $\mathrm{PIP}_{2}$-Moleküle in der Membranebene war in der cholesterinhaltigen Membran stark eingeschränkt. In einer cholesterinfreien Membran konnte hingegen in der oberen Lipidmonoschicht eine Diffusion von $\mathrm{PIP}_{2}$ beobachtet werden. Daher wird die stark verringerte Mobilität der $\mathrm{PIP}_{2}$ Moleküle auf den Einfluss von Cholesterin zurückgeführt. Dass Cholesterin die Diffusionsgeschwindigkeit von Lipiden in der Membranebene herabsetzt, ist 
bekannt. Dieser Effekt wird auf eine dichtere Packung der Fettsäureketten und/oder eine Hemmung der ungesättigten Fettsäureketten, bestimmte Konformationen einzunehmen, zurückgeführt (122-123).

Es ergibt sich also eine veränderte Stöchiometrie für die Bindung von Ezrin an $\mathrm{PIP}_{2}$ mit einem Verhältnis von 1:7-8. Dieser Befund kann folgendermaßen gedeutet werden: In der cholesterinfreien Membran können nach Membranassoziation von Ezrin und Bindung des ersten Moleküls $\mathrm{PIP}_{2}$ weitere $\mathrm{PIP}_{2}$-Moleküle unter das gebundene Protein rekrutiert werden, dort binden und die Membranassoziation von Ezrin weiter stabilisieren. Im cholesterinhaltigen Membransystem ist eine solche Diffusion nicht möglich, und Ezrin verbleibt an der Membran gebunden an lediglich ein Molekül $\mathrm{PIP}_{2}$. Entsprechend ergibt sich hier eine schwächere Bindung von Ezrin an die Membran. Dies wird durch die größere Dissoziationskonstante und den höheren Anteil an reversibel gebundenem Protein reflektiert, der am cholesterinhaltigen Membransystem für die Bindung von Ezrin an $\mathrm{PIP}_{2}$ gefunden wurde. Die Erklärung für die unterschiedliche Zahl an gebundenem $\mathrm{PIP}_{2}$ pro Molekül Ezrin in den verwendeten Membransystemen ist damit, dass Ezrin grundsätzlich mehrere Bindungsstellen für $\mathrm{PIP}_{2}$ bereithält, und dass resultierende multiple Bindung zu einer stabileren Assoziation von Ezrin an der Membran führt. Die Theorie, dass Ezrin mehr als eine $\mathrm{PIP}_{2}$-Bindungsstelle besitzt, wird seit längerem in der Literatur diskutiert, aber konnte bisher nicht abschließend geklärt werden. Es existieren sowohl Indizien für eine einzelne als auch für mehrere solcher $\mathrm{PIP}_{2}$ Bindungsstellen $(50,116)$.

Die Messungen zur Adsorption von N-ERMAD an Membranen mit variablen $\mathrm{PIP}_{2}$ Anteilen im Vergleich zu denen mit Ezrin wt zeigen wiederum eine veränderte Stöchiometrie der Bindung. Die maximale Oberflächenkonzentration an $\mathrm{N}$ ERMAD ist bereits bei $4 \% \mathrm{PIP}_{2}$-haltigen Membranen vorhanden und ergibt ein theoretisches Verhältnis der Bindung von N-ERMAD an $\mathrm{PIP}_{2}$ von 1:4-5. Weshalb die volle Flächenbelegung früher als bei Ezrin wt erreicht wird, kann auf Basis der aufgenommenen Daten nicht abschließend geklärt werden. Jedoch kann anhand einer Analyse des Bindungsverhaltens von Ezrin auf der Oberfläche ein Erklärungsansatz geliefert werden, der sich auf eine intermolekulare Protein- 
Protein-Anziehung der Ezrin wt-Moleküle beruft. Hierauf wird im Lauf der Diskussion zurückgekommen.

Die fluoreszenzmikroskopischen Aufnahmen, welche die Adsorption von fluoreszenzmarkiertem Ezrin wt an eine 0,5\% $\mathrm{PIP}_{2}$-haltige Membran zeigen, weisen Bereiche auf, in denen Cluster des Proteins mehrere Mikrometer im Durchmesser aufweisen, während andere Membranbereiche komplett unbelegt sind. Diese Beobachtung legt nah, dass eine intermolekulare Protein-ProteinAnziehung zwischen membrangebundenem Ezrin wt auftritt. Dadurch erfolgt die Besetzung von Bindungsplätzen bevorzugt in Nachbarschaft von bereits proteinbelegten Bereichen. Zusätzlich ist denkbar, dass die intermolekulare Anziehung zwischen den membrangebundenen Proteinen zu einer Verdichtung der adsorbierten Masse im Sinne einer 2-dimensionalen Kristallisation führt, die bewirkt, dass die proteinbelegte Fläche kleiner wird. Solche Vorgänge wurden bereits an anderen Proteininteraktionssystemen beobachtet (124-125). Gleichzeitig würde dies auch zu Wasserausschluss aus den Kontaktbereichen der Proteine führen, worauf an anderer Stelle in dieser Arbeit bereits eingegangen wurde (siehe Kapitel 5.4).

Aus diesem Kristallisationsvorgang ergibt sich auch der Ansatz, der das unterschiedliche Adsorptionsverhalten von N-ERMAD und Ezrin wt an festkörperunterstützten Membranen mit unterschiedlichem $\mathrm{PIP}_{2}$-Gehalt erläutern kann. Da die attraktive Protein-Protein-Wechselwirkung für Ezrin wt abermals beobachtet wurde, in der Vergangenheit jedoch dokumentiert wurde, dass das Protein N-ERMAD diese Selbst-Assoziationsneigung nicht zeigt (90), nimmt wahrscheinlich das Protein Ezrin wt eine geringere Fläche auf der festkörperunterstützten Membran ein als N-ERMAD. Die berechnete Bindung von sieben bis acht $\mathrm{PIP}_{2}$ durch ein Molekül Ezrin wt ergibt sich durch das Rearrangement der Lipide infolge der Kristallisation von Ezrin wt, die zu einer großen Anhäufung von $\mathrm{PIP}_{2}$ unter der proteinbelegten Fläche führt und umliegende Flächen an $\mathrm{PIP}_{2}$ verarmen lässt. Diese Umordnung tritt bei $\mathrm{N}$ ERMAD nicht oder nur in verringertem Maß auf.

Da N-ERMAD ausschließlich aus der N-terminalen Domäne des nativen Proteins besteht, muss die intermolekulare Anziehung auf Domänen im C-Terminus des Wildtyps beruhen. In der Literatur wurde schon vielfach die intermolekulare Kopf- 
zu-Schwanz-Assoziation von Ezrin beschrieben $(115,126)$. Daneben existiert seit längerem die Theorie, dass auch die a-helicale Region zu einer Dimerisierung von Ezrin wt führen kann, indem eine coiled coil-Struktur gebildet wird. Das resultierende Dimer würde dann eine spiegelsymmetrische anstelle einer Kopfzu-Schwanz-Assoziation aufweisen (127). In jedem Fall sind offenbar C-terminale Domänen in die Selbst-Assoziation des Proteins involviert, die im N-ERMAD fehlen. Eine schematische Darstellung der möglichen resultierenden Dimere zeigt Abbildung 6.15.

A

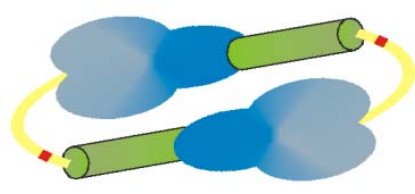

B

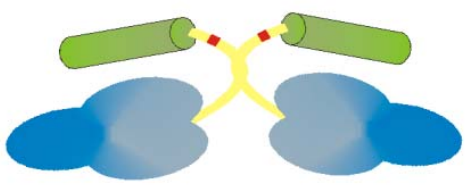

Abbildung 6.15: Möglichkeiten der Dimerisierung von Ezrin wt in Form einer Kopf-zu-SchwanzAssoziation (A) oder durch Bildung einer coiled coil-Struktur der zentralen a-helicalen Domänen (B).

In der Literatur wurde mehrfach dokumentiert, dass ERM-Proteine in Lösung als Dimere vorliegen, während eine deutliche Verschiebung hin zu gelösten Monomeren bei pseudophosphorylierten Mutanten auftritt $(96,115)$. Es wird daher vermutet, dass die intermolekulare Anziehung durch die Phosphorylierung von T567 verringert wird. Membrangebundenes Ezrin zeigt allerdings eine Verteilung von Monomeren bis zu höheren Oligomeren (128). Die Abhängigkeit der Selbstassoziation vom Phosphorylierungsgrad zeigen die Fluoreszenzexperimente zum Bindungsverhalten von Ezrin T567D an einer 0,5\% $\mathrm{PIP}_{2}$-haltigen Membran: Hier konnten im Gegensatz zum unphosphorylierten Protein Ezrin wt keine größeren proteinbelegten Bereiche gefunden werden. Die Bindung des fluoreszenzmarkierten Proteins T567D erfolgte in sehr viel kleineren Aggregaten über die gesamte Membranoberfläche verteilt. Damit scheint die eingangs aufgestellte Hypothese bestätigt, dass infolge der Phosphorylierung die attraktive Protein-Protein-Wechselwirkung auch an der Membran vermindert wird. In der zugehörigen Fachliteratur wurden nur wenige Studien publiziert, die sich dieser Thematik widmen. So konnten Zhu et al. nachweisen, dass in Magenbelegzellen an der apikalen Membran zunächst Ezrin-Oligomere vorliegen 
(129). Nach Stimulation der Säuresekretion durch IBMX (3-Isobutyl-1methylxanthin) und Histidin konnte eine Monomerisierung der Proteine gefunden werden. Diese Beobachtung wurde jedoch von Zhu et al. nicht hinsichtlich des Phosphorylierungsgrades der Proteine weitergehend analysiert. Gautreau et al. konnten in transgenen Epithelzelllinien nachweisen, dass die unphosphorylierbare Mutante Ezrin T567A als Oligomer an der Plasmamembran gebunden vorlag und keine Assoziation mit dem Cytoskelett aufwies. Die pseudophosphorylierte Mutante T567D hingegen konnte als Monomer vorgefunden werden und bildete eine stabile Verbindung zwischen Plasmamembran und Cytoskelettelementen (130). Dieses Ergebnis entspricht damit der aufgestellten Hypothese, dass infolge der Phosphorylierung eine intermolekulare Anziehung von Ezrin geschwächt wird.

Die unterschiedliche Selbst-Assoziationsneigung der Protein Ezrin wt und Ezrin T567D beeinflusst offensichtlich das Adsorptionsverhalten der Proteine an $\mathrm{PIP}_{2^{-}}$ haltigen Membranen. Daher wurden im Rahmen der vorliegenden Arbeit Versuche unternommen, die Stärke dieser Protein-Protein-Interaktionen anhand der in Kapitel 5.2 gezeigten Adsorptionsisothermen von Ezrin wt, Ezrin T567D und Ezrin T567A an 10\% PIP $_{2}$-haltigen Membranen zu belegen. Hierzu wurde ein Modell nach Bragg und Williams adaptiert, mit der scaled particle theory kombiniert und die Adsorptionsisothermen neu ausgewertet. Dabei konnte für die konstitutiv inaktive Mutante Ezrin T567A sowie Ezrin wt eine geringere ProteinProtein-Bindungsenergie als für das pseudophosphorylierte Ezrin T567D gefunden werden. Dies widerspricht dem Ergebnis der fluoreszenzmikroskopischen Untersuchungen, wonach Ezrin T567D eine geringere Energie der Protein-Protein-Bindung aufweisen sollte. Die Aussagekraft dieser Modellierung scheint allerdings für den verfügbaren Datensatz recht eingeschränkt. So ist in Abbildung $6.8 \mathrm{C}$ deutlich erkennbar, dass ein einzelner Datenpunkt den sigmoidalen Verlauf der Kurve stark beeinflusst. Es sollten für die Anwendung dieses Adsorptionsmodells in Zukunft weitere Datenpunkte in diesen niedrigen Konzentrationsbereichen gesammelt werden. Darüber hinaus sollten Messtechniken eingesetzt werden, die eine größere Sensitivität in diesem Konzentrationsbereich liefern. Eine interessante, ebenfalls markierungsfreie Alternative zur Quarzmikrowaagetechnik bietet zum 
Beispiel die reflektometrische Interferenzspektroskopie, welche anstelle der gravimetrischen eine zeitaufgelöste Schichtdickenbestimmung mit Auflösungen bis zu einigen pm erlaubt (131). 



\section{AKtivierbarkeit VON EZRIN IN ABHÄNGIGKeIt VON PIP 2 UND PHOSPHORYLIERUNG}

Die Aktivierung von Ezrin umfasst nach gegenwärtigem Kenntnisstand zwei Schritte. Zunächst erfolgt die Bindung an das Membranlipid $\mathrm{PIP}_{2}$ und anschließend eine Phosphorylierung am Threoninrest 567. Durch die Aktivierung wird das Protein in einen Zustand überführt, in dem es befähigt ist, an filamentöses Aktin zu binden und so eine Verbindung zwischen Plasmamembran und Zellcortex herzustellen. Im Rahmen dieser Arbeit wurde ein in vitro-Assay entworfen, welcher die separate Untersuchung beider Aktivierungsparameter erlaubt und die Bindung von F-Aktin als Funktion des Aktivierungszustands von Ezrin quantifizierbar macht.

\subsection{Polymerisation von F-Aktin in vitro}

Der geplante experimentelle Assay erforderte die Polymerisierung von filamentösem Aktin in vitro. Hierzu wurden Versuchsbedingungen etabliert, die mit einer sehr guten Reproduzierbarkeit F-Aktinfilamente einer Länge von ca. 1 $7 \mu \mathrm{m}$ lieferten (siehe Kapitel 3.1.7). In Abbildung 7.1 ist das Ergebnis einer Polymerisation gezeigt.

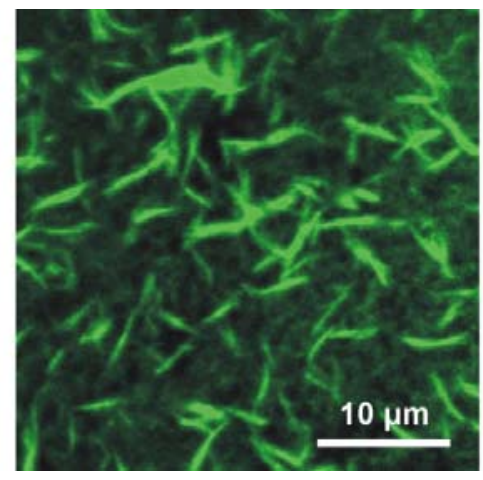

Abbildung 7.1: Konfokalmikroskopische Aufnahme von AlexaFluor488-Phalloidin-markiertem FAktin, gebunden über Ezrin wt an eine festkörperunterstützte Membran der Zusammensetzung POPC/PIP $/$ Perylen (89:10:1) in F-Puffer $(20 \mathrm{mM}$ TRIS/HCl, $50 \mathrm{mM} \mathrm{KCl}, 1 \mathrm{mM} \mathrm{MgCl}$, 2 mM ATP, $\mathrm{pH} 7,4)$. 
Selten wurden auch längere Filamente von bis zu $10 \mu \mathrm{m}$ beobachtet. In der Natur werden Filamentlängen von 0,22 - $13 \mu \mathrm{m}$ gefunden, damit liegen die erhaltenen Filamente in dieser Größenordnung (132). Zur Visualisierung der entstandenen Filamente wurde AlexaFluor488-markiertes Phalloidin genutzt, welches mit hoher Affinität in einem stöchiometrischen Verhältnis von 1:1-2 an F-Aktin bindet und dabei die Depolymerisationsrate drastisch herabsetzt (133-134).

\subsection{Spezifität der F-Aktin-Adsorption auf Ezrin-belegten festkörperunterstützten Membranen}

Wie in Kapitel 5.2 ausführlich beschrieben, wurden mit Hilfe der Quarzmikrowaage Bedingungen etabliert, bei denen auf festkörperunterstützten Membransystemen aus DOPC/DOGS-NTA-Ni (9:1) bzw. POPC/PIP 2 (9:1) sehr gut reproduzierbar ein hoher Bedeckungsgrad von Ezrin wt und Mutanten erreicht werden konnte. In weiterführenden Experimenten sollte nun die Affinität von Ezrin wt und Mutanten zu F-Aktin in Abhängigkeit des verwendeten Bindungsmodus untersucht werden. Da sich die Quarzmikrowaagetechnik in der Vergangenheit jedoch als ungeeignet erwiesen hatte, die Interaktion von Ezrin und F-Aktin zu verfolgen (90), wurde ein alternativer Ansatz zur Untersuchung dieser Interaktion gewählt. Zur Erweiterung dieser Versuchsanordnung hin zu Affinitätstest von Ezrin und F-Aktin wurden die Membranpräparation und anschließende Proteininkubation auf Siliziumwafer übertragen. Um die Ausbildung einer homogenen Membran fluoreszenzmikroskopisch verfolgen und verifizieren zu können, wurden dem Lipidgemisch 1 mol\% Perylen zugesetzt. Um die Spezifität der F-Aktinadsorption zu untersuchen, wurde zunächst der $\mathrm{PIP}_{2^{-}}$ Gehalt der Modellmembran auf $0,5 \mathrm{~mol} \%$ reduziert. Die Inkubation von Ezrin sollte so nicht zu einer geschlossenen Proteinschicht, sondern zu einzelnen Proteinclustern auf der Oberfläche führen, wie bereits in Abbildung 6.7 A gezeigt werden konnte. Um diese proteinbelegten Flächen von unbelegten mikroskopisch unterscheiden zu können, wurde mit dem Fluoreszenzfarbstoff AlexaFluor633Maleimid markiertes Ezrin wt eingesetzt. Die Inkubation einer auf hydrophilem Siliziumdioxid präparierten Membran mit 0,1 $\mu \mathrm{M}$ Ezrin wt im Durchfluss führte zu der in Abbildung 7.2 abgebildeten Situation. In Abbildung 7.2 A ist die blaue 
Fluoreszenz der Perylen-markierten Membran zu erkennen. In Abbildung 7.2 B ist ein rot fluoreszierender Cluster von membrangebundenen Ezrinmolekülen zu erkennen.
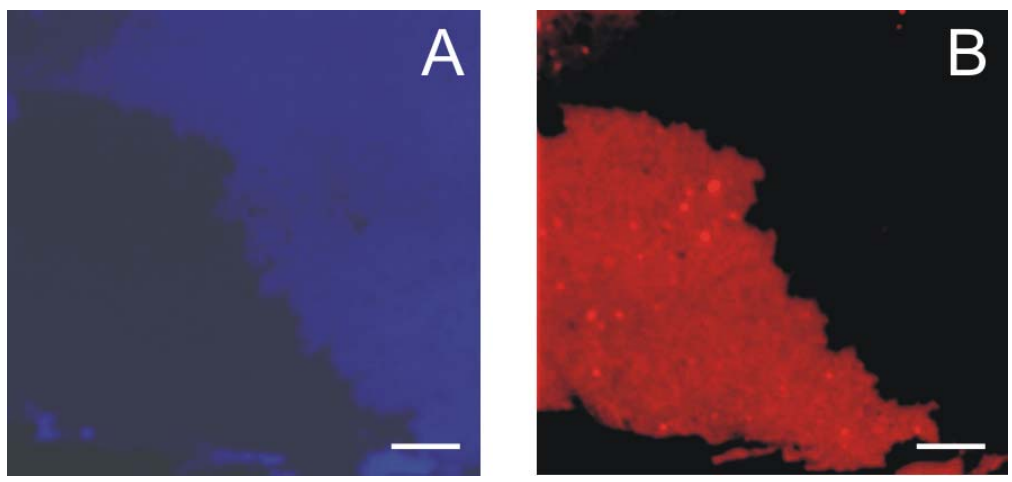

Abbildung 7.2: Konfokalmikroskopische Fluoreszenzaufnahmen von AlexaFluor633-Maleimidmarkiertem Ezrin wt, adsorbiert an einer festkörperunterstützten Membran aus POPC/PIP $/$ Perylen $(98,5: 0,5: 1)$ auf Siliziumoxid. In A ist die Perylenfluoreszenz, in B die AlexaFluor633-Maleimidfluoreszenz dargestellt. Puffer: $20 \mathrm{mM}$ TRIS/ $\mathrm{HCl}, 50 \mathrm{mM} \mathrm{KCl}, 1 \mathrm{mM}$ $\mathrm{MgCl}_{2}, 2$ mM ATP, pH 7,4. Maßstabsbalken: $5 \mu \mathrm{m}$.

Es wird deutlich, dass die blaue Membranfluoreszenz in Regionen, die mit rot fluoreszierendem Ezrin belegt sind, an Intensität verloren hat. Dieses Phänomen wurde wiederholt beobachtet und ist vermutlich auf einen FRET-Effekt zwischen den beiden verwendeten Fluorophoren zurückzuführen.

Die proteinbelegte Membranfläche wurde nun auf ihre Fähigkeit, F-Aktin spezifisch zu binden, untersucht. Die 30minütige Inkubation der Probe mit FAktinlösung und das anschließende Spülen mit F-Puffer erfolgte bei Raumtemperatur. In Abbildung 7.3 ist das Ergebnis der fluoreszenzmikroskopischen Analyse der Oberfläche zu sehen. Abbildung 7.3 A zeigt die rote Fluoreszenz des membrangebundenen Ezrinclusters. Die grüne Fluoreszenz der AlexaFluor488-Phalloidin-markierten Aktinfilamente ist in Abbildung 7.3 B gezeigt. Wie die Überlagerung beider Bilder in Abbildung 7.3 C beweist, tritt fast ausschließlich in Bereichen, wo rotes Fluoreszenzlicht zu beobachten ist, auch ein grünes Fluoreszenzsignal auf. In der Überlagerung der beiden Bilder erscheinen diese co-lokalisierten Signale in der resultierenden Mischfarbe gelb. 

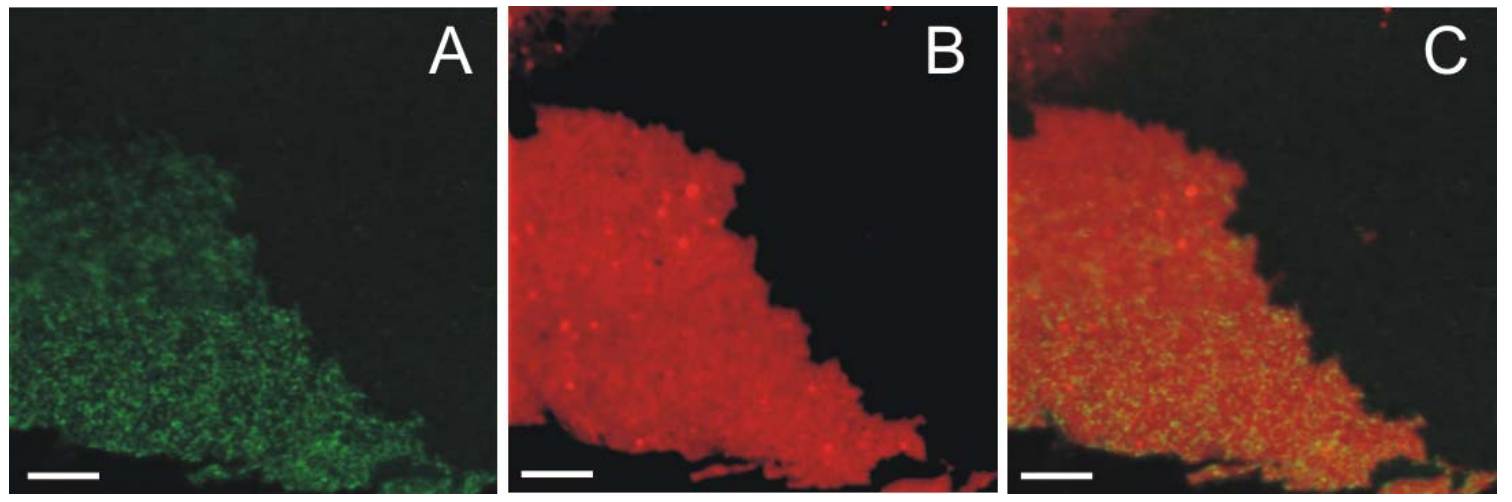

Abbildung 7.3: Konfokalmikroskopische Fluoreszenzaufnahmen von AlexaFluor633-Maleimidmarkiertem Ezrin wt, adsorbiert über eine festkörperunterstützte Membran aus POPC/PIP $/$ Perylen (89,5:10:0,5) auf Siliziumoxid, nach Zugabe von AlexaFluor488-Phalloidinmarkiertem F-Aktin. A Fluoreszenz des AlexaFluor633-Maleimid-markierten Ezrin wt. B Fluoreszenz von AlexaFluor488-Phalloidin. C Überlagerung der beiden Bilder. Puffer: 20 mM TRIS/HCl, 50 mM KCl, 1 mM MgCl, 2 mM ATP, pH 7,4. Maßstabsbalken 5 m.

Sehr wenig grünes Fluoreszenzsignal entstammt Bereichen, in denen kein rot fluoreszierendes Ezrin gebunden vorliegt. Es muss also davon ausgegangen werden, dass eine gewisse unspezifische Affinität des F-Aktins für die reine Membran auftritt. Die Oberflächenkonzentration von F-Aktin im ezrinbelegten Bereich ist allerdings signifikant erhöht, so dass eine deutliche Unterscheidung zwischen spezifischer und unspezifischer Adsorption getroffen werden kann.

\subsection{Vergleich der Affinität von Ezrin zu F-Aktin in Abhängigkeit von $\mathrm{PIP}_{2}$-Bindung und Phosphorylierungsgrad}

Zur individuellen Untersuchung der verschiedenen Parameter, die zur Aktivierung von Ezrin beitragen, wurden Membransysteme auf Silizumwafern präpariert, die entweder mit 10 mol\% DOGS-NTA-Ni oder 10 mol\% $\mathrm{PIP}_{2}$ dotiert waren, und diese in Kombination mit Ezrin wt und den beiden charakterisierten Mutanten eingesetzt. Die Membranen wurden durch Spreiten von unilamellaren Vesikeln auf hydrophilisiertem Siliziumoxid erhalten und enthielten $1 \mathrm{~mol} \%$ Perylen. So konnte sowohl vor als auch nach der Inkubation des jeweiligen Proteins die Qualität der festkörperunterstützten Membran sichergestellt werden. Die Proteininkubation erfolgte anschließend im Durchfluss und bezüglich der Dauer und Konzentration in Anlehnung an die aus Quarzmikrowaageexperimenten 
gewonnenen Daten. So konnte durch Inkubation einer mindestens $400 \mu \mathrm{M}$ konzentrierten Ezrinlösung für 30 Minuten eine maximale Oberflächenbedeckung mit Protein erreicht werden. $\mathrm{Zu}$ diesen proteinbelegten Membranen wurde anschließend mit AlexaFluor488-Phalloidin markiertes und durch unmarkiertes Phalloidin stabilisiertes F-Aktin in Lösung zugegeben, die Probe für 30 Minuten inkubiert, mit Puffer gespült und die Probenoberfläche anschließend mit Hilfe eines konfokalen Fluoreszenzmikroskops untersucht. Dabei konnte eine homogene Adsorption des fluoreszenzmarkierten F-Aktins auf der Probenoberfläche beobachtet werden, welche in Abbildung 7.4 dargestellt ist.
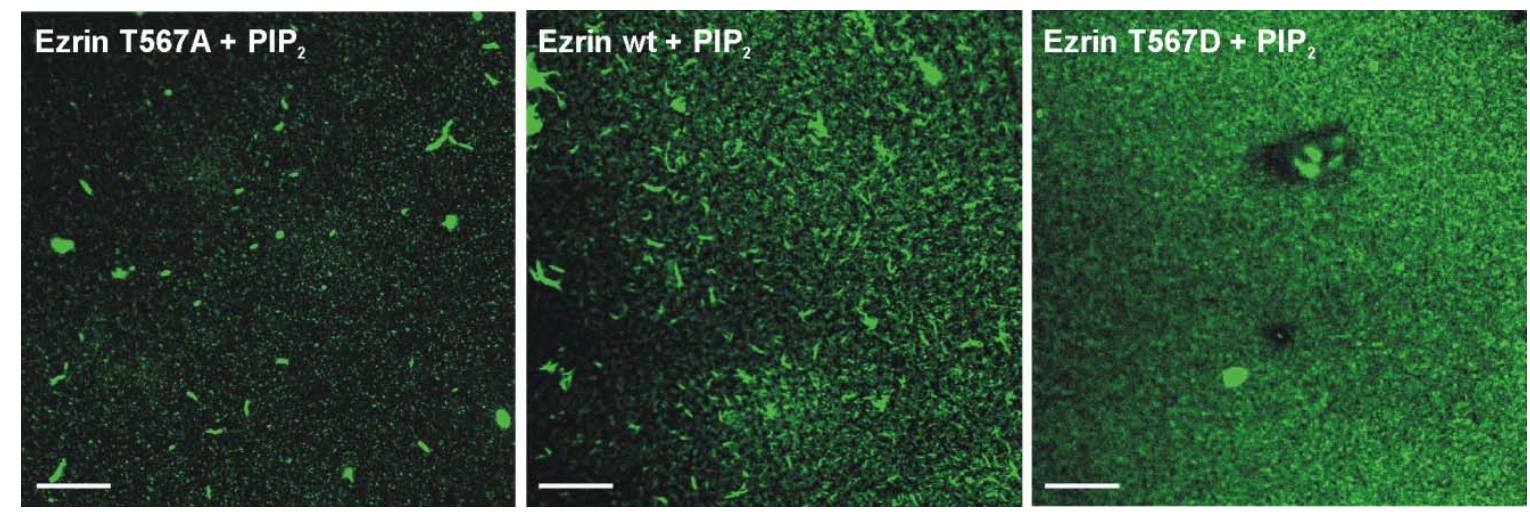

Abbildung 7.4: Konfokalmikroskopische Fluoreszenzaufnahmen von AlexaFluor488-Phalloidinmarkiertem F-Aktin, gebunden an Ezrin T567A, Ezrin wt oder Ezrin T567D auf festkörperunterstützten Membranen (POPC/PIP 2 9:1). Puffer: $20 \mathrm{~mm}$ TRIS/HCl, $50 \mathrm{~mm} \mathrm{KCl,} 1 \mathrm{~mm}$ $\mathrm{MgCl}_{2}, 2$ mM ATP, pH 7,4. Maßstabsbalken: $20 \mu \mathrm{m}$.

In Abbildung 7.4 rechts ist eine Defektstelle zu erkennen, ansonsten konnte eine sehr homogene Verteilung des F-Aktins beobachtet werden. Etwas genauer lassen sich die filamentösen Strukturen des F-Aktins in den folgenden vergrößerten Abbildungen erkennen. Diese zeigen repräsentative Fluoreszenzaufnahmen des F-Aktin-gebundenen AlexaFluor488-Phalloidin unter Verwendung aller sechs verschiedenen möglichen Protein-Lipid-Kombinationen (Abbildung 7.5). 

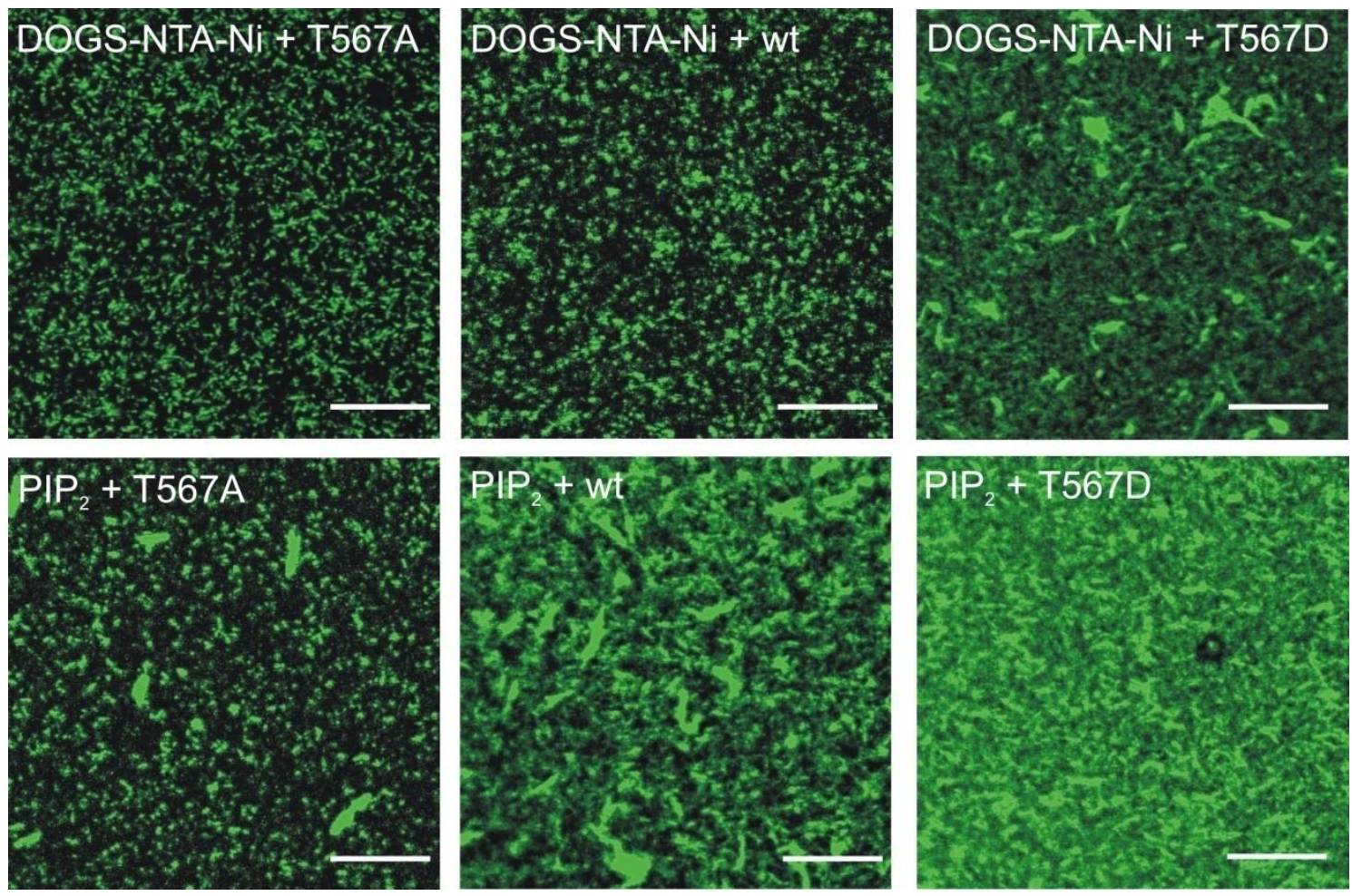

Abbildung 7.5: Konfokalmikroskopische Fluoreszenzaufnahmen des an F-Aktin gebundenen AlexaFluor488-Phalloidins nach 30minütiger Inkubation und anschließendem Spülen einer mit Ezrin belegten Membran. Die jeweils verwendeten Ezrinmutanten oder Wildtyp sowie die verwendete Immobilisierungsstrategie sind angegeben. Puffer: $20 \mathrm{mM} \mathrm{TRIS} / \mathrm{HCl}, 50 \mathrm{mM} \mathrm{KCl}, 1$ $\mathrm{mm} \mathrm{MgCl} 2,2$ mM ATP, pH 7,4. Maßstabsbalken $10 \mu \mathrm{m}$.

Im Fall der konstitutiv inaktiven Mutante Ezrin T567A werden, unabhängig vom gewählten Lipidsystem, nur wenige Filamente oberflächengebunden vorgefunden. Im Gegensatz dazu zeigt sich unter Verwendung der konstitutiv aktiven Mutante Ezrin T567D immobilisiert über DOGS-NTA-Ni eine sehr hohe Oberflächenbelegung, die durch die Verwendung von $\mathrm{PIP}_{2}$ als Bindungspartner offenbar noch gesteigert werden konnte. Für den Fall des Proteins Ezrin wt befinden sich die Ergebnisse etwa zwischen diesen Extremen, es scheint jedoch eine deutliche Steigerung der gebundenen Menge an F-Aktin aufzutreten, wenn das Lipid $\mathrm{PIP}_{2}$ anstelle von DOGS-NTA-Ni als Bindungspartner in der festkörperunterstützten Membran vorliegt.

Um die Adsorptionseigenschaften von F-Aktin auf der reinen Membran zu überprüfen, wurden Proben erstellt, auf denen nach erfolgreicher Membranpräparation F-Aktin, ergänzt durch Zugaben von AlexaFluor488Phalloidin und unmarkiertem Phalloidin, für 30 Minuten inkubiert wurde. Nach anschließendem Spülen mit F-Puffer wurden fluoreszenzmikroskopische 
Aufnahmen der Membranoberfläche erstellt. Wie in Abbildung $7.6 \mathrm{zu}$ erkennen ist, wurde an beiden Membransystemen eine gewisse Menge adsorbiertes Material gefunden.
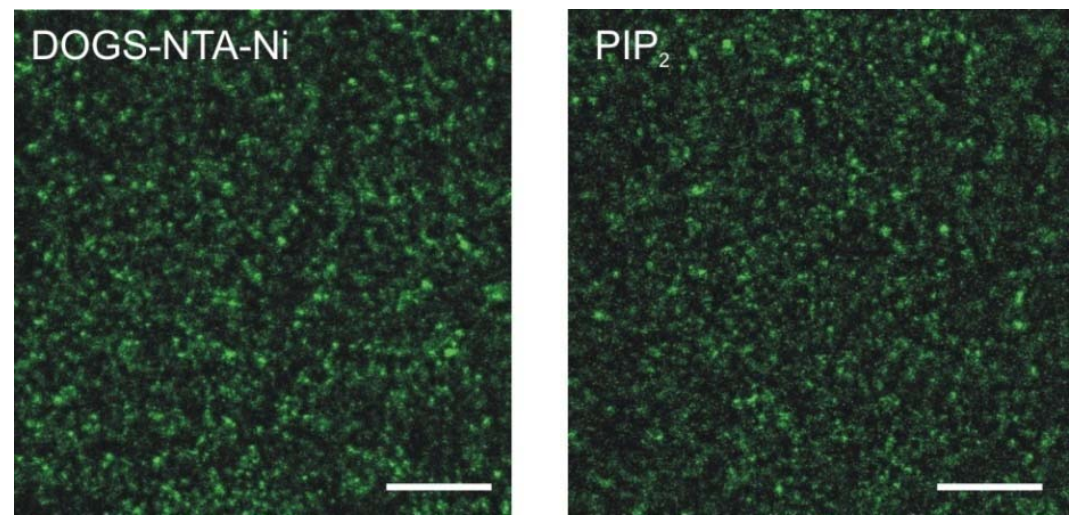

Abbildung 7.6: Repräsentative konfokalmikroskopische Aufnahmen von festkörperunterstützten Membranen aus DOPC/DOGS-NTA-Ni (9:1, links) und POPC/PIP 2 (9:1, rechts) nach 30 min Inkubation mit AlexaFluor488-Phalloidin-markiertem F-Aktin. Puffer: $20 \mathrm{mM}$ TRIS/HCl, $50 \mathrm{~mm} \mathrm{KCl}$, $1 \mathrm{~mm} \mathrm{MgCl} 2,2$ mM ATP, pH 7,4. Maßstabsbalken $10 \mu \mathrm{m}$.

Um die erhaltenen Fluoreszenzdaten zu quantifizieren und exakter vergleichen zu können, wurde eine Pixelanalyse mit Hilfe des Programms ImageJ durchgeführt. Hierbei wurde für jede einzelne Aufnahme ein Schwellenwert anhand eines nicht fluoreszierenden Bereichs der Probe bestimmt. Die Intensität in diesem Bereich wurde als Schwarz definiert. Fluoreszenzintensität, die oberhalb dieses Schwellenwerts lag, wurde als F-Aktin-belegte Fläche betrachtet und quantifiziert. Die einzelnen Schritte dieses Prozesses sind in Abbildung 7.7 dargestellt. 

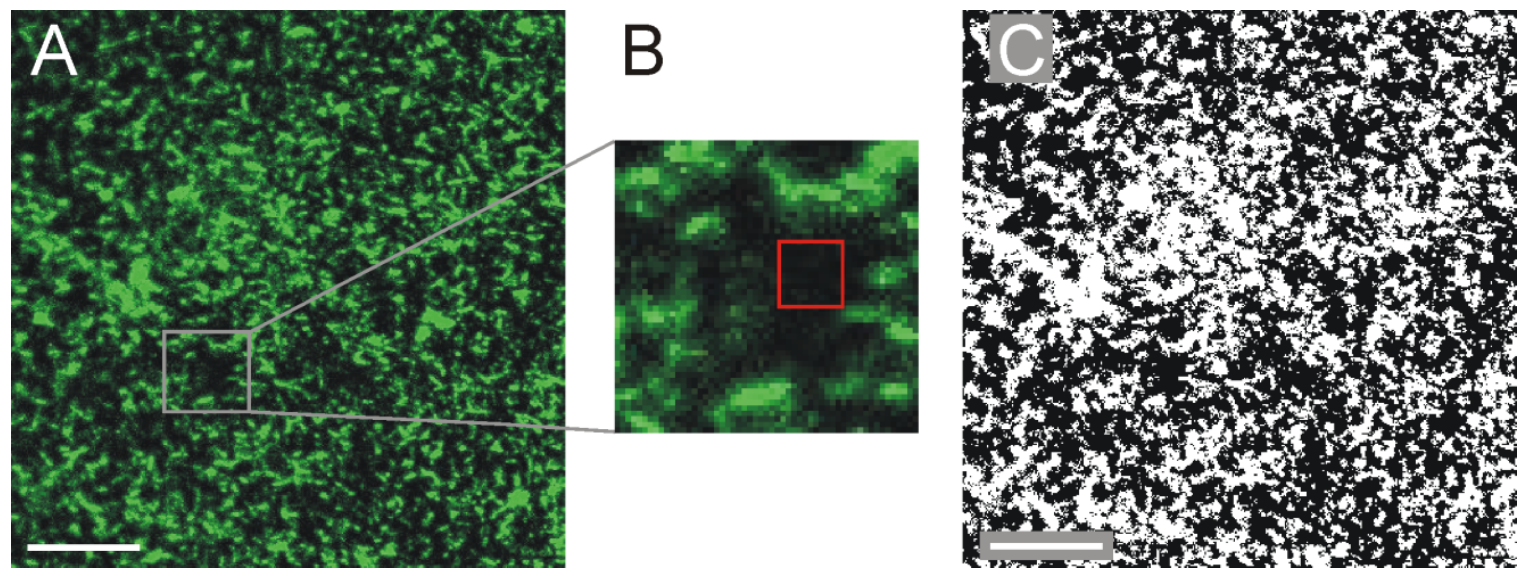

Abbildung 7.7: Illustration des Vorgehens zur Quantifizierung der F-Aktin-belegten Probenoberfläche mit ImageJ. A: Es wurde ein Bereich ausgewählt, in dem keine Fluoreszenz beobachtet werden konnte. B: Zoom in diesen Bereich; hier wurde der Schwarzwert als Schwellenwert definiert. C: Der Schwellenwert wurde anschließend auf die gesamte Aufnahme angewendet. Helle Bereiche wurden als belegte Fläche gezählt; Bereiche, deren Helligkeit unter dem definierten Schwellenwert lagen, wurden als unbelegte Fläche gezählt und sind in der Grafik in schwarz dargestellt.

Anhand der Datenanalyse lässt sich feststellen, dass auf beiden verwendeten Membransystemen unspezifische Adsorption von F-Aktin in einem ähnlichen Maß auftritt. Für die 10\% DOGS-NTA-Ni-haltige Membran wurde die Oberflächenbedeckung zu $(14 \pm 6) \%$ bestimmt. Die 10\% $\mathrm{PIP}_{2}$-haltige Membran wies mit einer Bedeckung von $(8 \pm 3) \%$ eine etwas geringere unspezifische Adsorption von F-Aktin auf. Diese tendenziell niedrigere Adsorptionsneigung scheint plausibel unter Betrachtung der elektrostatischen Gegebenheiten der einzelnen Oberflächen: Die Ladung des Lipids $\mathrm{PIP}_{2}$ liegt bei dem gegebenen $\mathrm{pH}-$ Wert von 7,4 bei -3 bis -5 (12), die von DOGS-NTA-Ni bei -1 (135). Die Aktinfilamente selbst besitzen ebenfalls eine negative Nettoladung (5). Das leicht unterschiedliche Adsorptionsverhalten von F-Aktin auf diesen Membranflächen ist daher auf unterschiedlich hohe elektrostatische Abstoßung zurückzuführen. $\mathrm{Da}$ die Oberflächeneigenschaften der Membran durch eine vollständige Bedeckung mit Protein sehr stark verändert werden, wurden diese Werte jedoch nicht direkt von den für die verschiedenen Ezrinderivate erhaltenen Resultaten abgezogen. Vielmehr dienten diese „Negativ“-Proben dem Beweis, dass keines der verwendeten Membransysteme allein einen signifikant hohen Einfluss auf das Adsorptionsverhalten des F-Aktins ausübt.

Für die proteinbelegten Membranen wurden auf Basis der Pixelanalyse folgende mittlere F-Aktin-Bedeckungsgrade auf DOGS-NTA-Ni-haltigen Membranen 
beobachtet: Der Wert für Ezrin T567A, (15 \pm 9)\%, liegt im Bereich dessen, was als unspezifische Adsorption von F-Aktin auf proteinfreien Ni-haltigen Membranen beobachtet wurde. Insofern kann die Adsorption an Ezrin T567A nicht eindeutig als spezifische Adsorption gedeutet werden. Auch für Ezrin wt liegt mit $(21 \pm 10) \%$ lediglich eine geringfügig gesteigerte Menge oberflächengebundenen F-Aktins vor. Ezrin T567D sollte durch den Austausch von Threonin gegen Aspartat in einer aktivierten Konformation vorliegen, und es zeigte sich tatsächlich eine deutliche Steigerung der adsorbierten Menge von FAktin an dieser Grenzfläche auf (58 \pm 23$) \%$.

Es wurden anschließend Messungen an $\mathrm{PIP}_{2}$-haltigen Membranen durchgeführt. Hier ergab sich sowohl im Falle von Ezrin Wildtyp als auch Ezrin T567D eine signifikante Steigerung der oberflächengebundenen F-Aktinmenge im Vergleich zu den entsprechenden Experimenten mit DOGS-NTA-Ni. Diese Steigerung wurde offensichtlich durch die Immobilisierung der Proteine Ezrin wt und T567D über $\mathrm{PIP}_{2}$ induziert. So fand sich auf Ezrin Wildtyp eine F-Aktin-Bedeckung von (49 \pm 27$) \%$, und unter Verwendung von Ezrin T567D konnte eine fast vollständige Oberflächenbedeckung von (93 \pm 11$) \%$ verzeichnet werden. Interessanterweise konnte für die konstitutiv inaktive Mutante kein solcher Einfluss der $\mathrm{PIP}_{2}$-Immobilisierung festgestellt werden. Die Oberflächenbedeckung durch F-Aktin blieb verglichen mit den Ergebnissen der Experimente mit DOGSNTA-Ni-Membranen mit (15 \pm 13$) \%$ fast gleich.

Eine Zusammenfassung dieser Ergebnisse mit der jeweiligen Probenanzahl findet sich in Tabelle 7.1 . 
Tabelle 7.1: Ergebnisse der Quantifizierung von F-Aktin, gebunden an Ezrin wt und Mutanten, auf festkörperunterstützten Membranen.

\begin{tabular}{c|c|c|c|c} 
Membran & Ezrin T567A & Ezrin wt & Ezrin T567D & ohne Protein \\
\hline \multirow{3}{*}{ DOGS-NTA-Ni } & $\begin{array}{c}(15 \pm 9) \% \\
(n=8)\end{array}$ & $\begin{array}{c}(21 \pm 10) \% \\
(n=13)\end{array}$ & $\begin{array}{c}(58 \pm 23) \% \\
(n=10)\end{array}$ & $\begin{array}{c}(14 \pm 6) \% \\
(n=4)\end{array}$ \\
\hline & & & & $(93 \pm 11) \%$ \\
PIP $_{2}$ & $(15 \pm 13) \%$ & $(49 \pm 27) \%$ & $(8 \pm 3) \%$ \\
& $(n=20)$ & $(n=14)$ & $(n=13)$ & $(n=5)$
\end{tabular}

Um die statistische Signifikanz der Ergebnisse sicherzustellen, wurde eine Varianzanalyse der Daten durchgeführt. Hierbei ergab sich ein Signifikanzlevel von $P=0,0007$ für die Bindung von Ezrin wt an DOGS-NTA-Ni beziehungsweise $\mathrm{PIP}_{2}$. Die Resultate der Bindung von Ezrin T567D an DOGS-NTA-Ni sowie $\mathrm{PIP}_{2}$ ergaben einen Wert $P=0,007$. Da ein Wert kleiner als $P=0,05$ einen signifikanten Unterschied zwischen den Gruppen beweist, spiegeln die experimentellen Ergebnisse somit zweifelsfrei einen eindeutigen Trend wider.

\subsection{Cosedimentationsexperimente mit F-Aktin und Ezrin}

Es wurden Experimente zur in vitro-Cosedimentation von Ezrin und F-Aktin durchgeführt. Hierbei sollte untersucht werden, ob Ezrin wt oder eine der Mutanten auch in Lösung eine erhöhte Affinität zu F-Aktin zeigen. Das Prinzip dieser Untersuchung beruht darauf, dass nach Inkubation des filamentösen Aktins mit löslichem Ezrin wt oder Mutanten und anschließender Ultrazentrifugation die unlöslichen Bestandteile sedimentiert werden. F-Aktin sollte in diesem Fall als unlöslicher Bestandteil ein Pellet formen, und aufgrund einer eventuellen spezifischen Affinität zu F-Aktin war die Erwartung, dass Ezrin wt, Ezrin T567A und Ezrin T567D ebenfalls cosedimentiert werden und im Pellet aufzufinden sind. Die anschließende Analyse der Proben per SDS-PAGE diente der semiquantitativen Erfassung der sedimentierten sowie der in Lösung verbliebenen Proteine. 
In Abbildung 7.8 ist ein Gel eines solchen Cosedimentationsexperiments gezeigt. Die verwendeten Proteine sind in diesen Gelen anhand ihrer unterschiedlichen Massen identifizierbar: Das Aktinmonomer weist in der SDS-PAGE eine Masse von ca. $42 \mathrm{kDa}$ auf, das Protein Ezrin wt und Mutanten erscheint typischerweise bei $81 \mathrm{kDa}$.

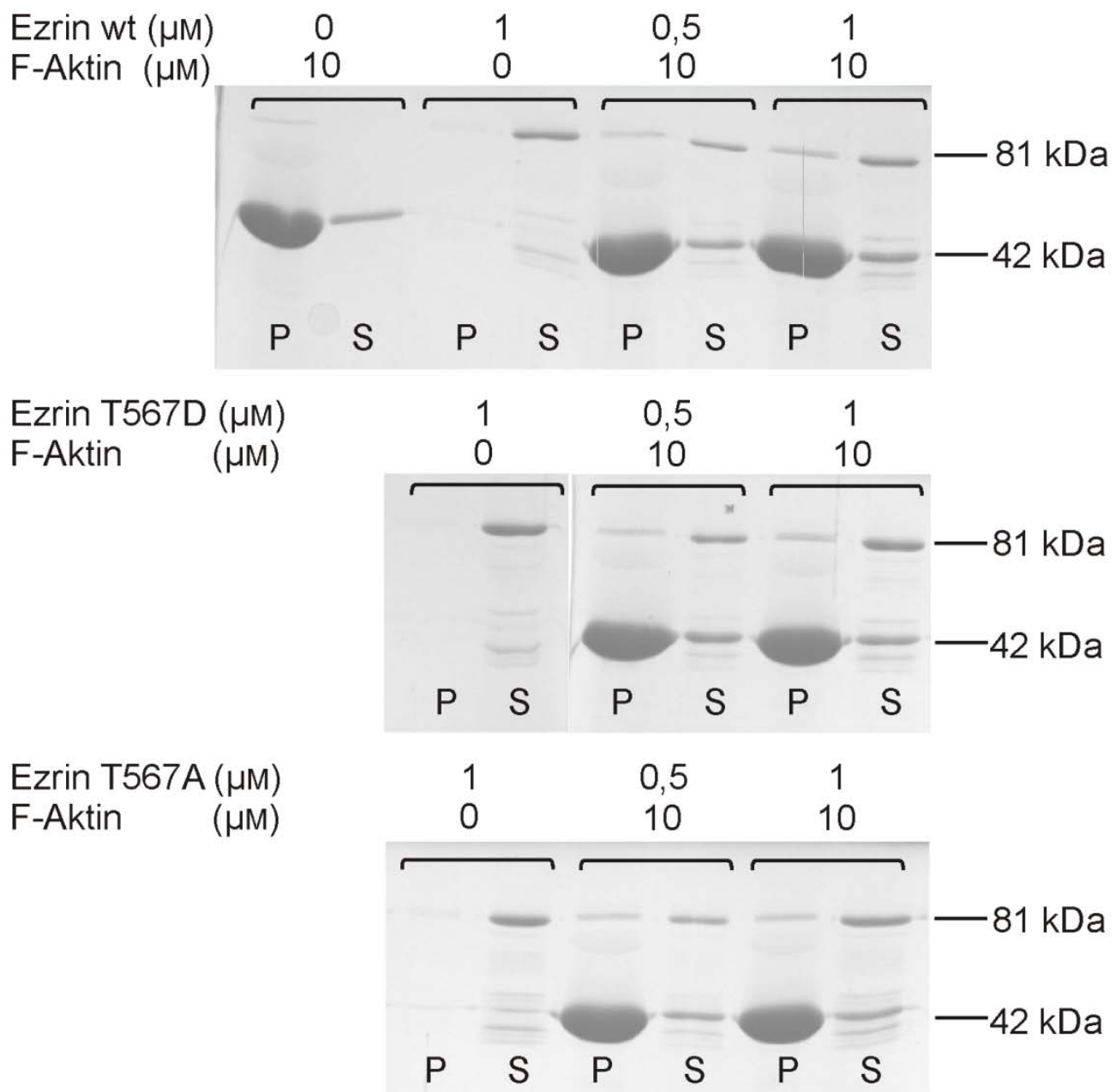

Abbildung 7.8: SDS-PAGE zur Analyse von Überstand (supernatant, $S$ ) und Pellet $(P)$ aus Cosedimentationsexperimenten mit F-Aktin und Ezrin wt, Ezrin T567D und Ezrin T567A. Die jeweils eingesetzten Konzentrationen sind in $\mu \mathrm{M}$ angegeben. Puffer: $20 \mathrm{mM} T R I S / H C l, 50 \mathrm{mM}$ $\mathrm{KCl}, 1 \mathrm{~mm} \mathrm{MgCl}$, 0,5 mM ATP, pH 7,4.

Die erste gezeigte Probe, die analysiert wurde, beinhaltete ausschließlich F-Aktin in einer Konzentration von $10 \mu \mathrm{M}$ und diente als Vergleich. Hier konnte gezeigt werden, dass F-Aktin der Erwartung gemäß polymerisiert war und daher fast 
vollständig pelletiert wurde. Daran anschließend sind in allen drei Gelen Proben gezeigt, die ausschließlich $1 \mu \mathrm{m}$ Ezrin wt, Ezrin T567D oder Ezrin T567A enthielten. Die Behandlung dieser Proben erfolgte analog der Prozedur, der auch die Gemische aus F-Aktin und Ezrin in den Verhältnissen 0,5:10 und 1:10 unterzogen wurden. So konnte bewiesen werden, dass sich die Proteine noch in Lösung befanden und im Überstand nachweisbar waren, d.h. dass das wiederholte Zentrifugieren keinen Ausfall des Proteins bewirkte.

Die Analyse der jeweiligen F-Aktin-Ezrin-Gemische beweist, dass in allen Kombinationen ein gewisser Anteil Ezrin mit F-Aktin sedimentiert wurde und im Pellet nachweisbar ist. Allerdings konnten keine deutlichen Unterschiede zwischen Ezrin wt, T567D und T567A festgestellt werden. In dieser Experimentreihe wiesen alle verwendeten Ezrinversionen scheinbar eine ähnliche, eventuell unspezifische Affinität zu F-Aktin auf. Es wurden zusätzliche Versuchsreihen durchgeführt, bei denen die Inkubationszeit und die Konzentrationsverhältnisse variiert wurden. Diese führten zu den gleichen Ergebnissen und werden an dieser Stelle daher nicht einzeln aufgeführt.

Des Weiteren wurden Cosedimentationsexperimente in Gegenwart von $\mathrm{PIP}_{2}$ durchgeführt. Da $\mathrm{PIP}_{2}$ als spezifischer Bindungspartner und potentieller Aktivator von Ezrin bekannt ist, sollten diese Experimente Aufschluss darüber erbringen, ob in Gegenwart von $\mathrm{PIP}_{2}$ eine gesteigerte Affinität von Ezrin wt und Mutanten zu F-Aktin zu beobachten ist. $\mathrm{PIP}_{2}$ wurde hierzu in F-Puffer gelöst und den Proben zugesetzt. Dabei wurde eine maximale Endkonzentration an $\mathrm{PIP}_{2}$ von $10 \mu \mathrm{M}$ eingehalten, welche die kritische Mizellarkonzentration des Lipids in wässriger Umgebung ist (136).

In Abbildung 7.9 ist das SDS-Gel eines Cosedimentationsexperiments unter Zusatz von $\mathrm{PIP}_{2}$ gezeigt. Zunächst ist eine Analyse von Proben aufgeführt, in denen $1 \mathrm{~mm}$ Ezrin in Gegenwart sowie in Abwesenheit von $\mathrm{PIP}_{2}$ vorlag. So sollte gezeigt werden, dass die Anwesenheit von $\mathrm{PIP}_{2}$ im Puffer keinen Einfluss auf die Sedimentationseigenschaften des Proteins ausübt. In der Tat befand sich auch nach zwei Zentrifugationsläufen der Hauptanteil des Proteins in Lösung und konnte im Überstand nachgewiesen werden. Jedoch scheint die Anwesenheit von $\mathrm{PIP}_{2}$ in der Lösung keinerlei Steigerung der Affinität von Ezrin wt oder Mutanten für F-Aktin zu bewirken. In den jeweiligen Pelletspuren des Gels 
zeigten sich dünne Banden bei $81 \mathrm{kDa}$, die Ezrin zuzuordnen waren, neben einer dicken Bande von 42 kDa, welche beweist, dass der Hauptanteil an F-Aktin pelletiert wurde. Wie schon in den zuvor gezeigten Gelen konnte keine unterschiedliche Affinität von Ezrin wt oder Mutanten für F-Aktin festgestellt werden. Auch die Gegenwart von $\mathrm{PIP}_{2}$ führte in dieser Versuchsanordnung zu keiner signifikant erhöhten F-Aktin-Affinität.

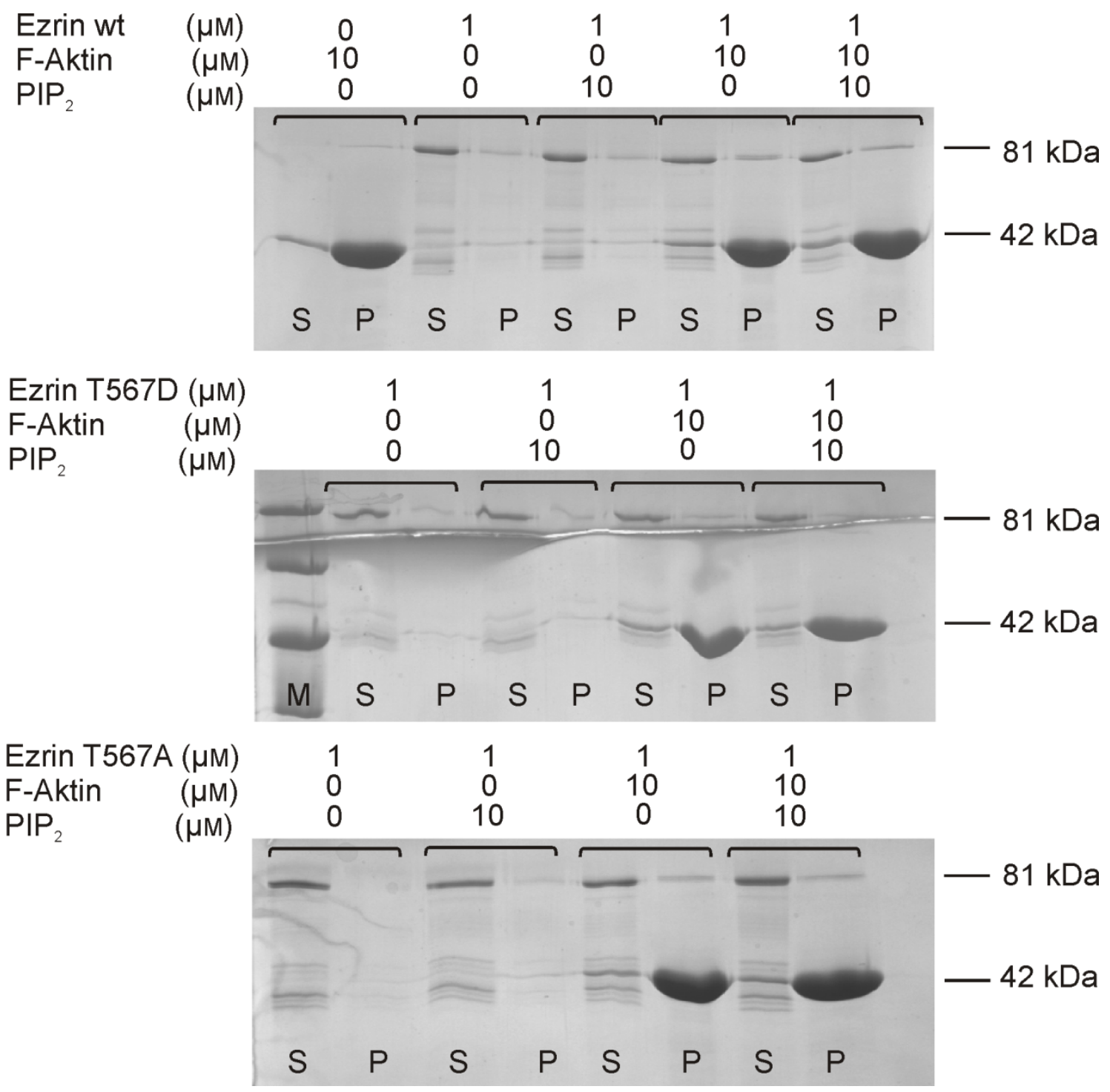

Abbildung 7.9: SDS-PAGE zur Analyse von Überstand (supernatant, $S$ ) und Pellet $(P)$ aus Cosedimentationsexperimenten mit F-Aktin und Ezrin wt, Ezrin T567D und Ezrin T567A in Gegenwart von $\mathrm{PIP}_{2}$. Zur Erleichterung der Zuordnung der Proteinmassen wurde ein Marker (M) zugesetzt. Die jeweils eingesetzten Konzentrationen sind in $\mu \mathrm{m}$ angegeben. Puffer: $20 \mathrm{~mm}$ TRIS/HCl, $50 \mathrm{~mm} \mathrm{KCl,} 1$ mM MgCl $2,0,5 \mathrm{~mm}$ ATP, pH 7,4. 


\subsection{Diskussion}

Im Rahmen dieser Arbeit wurden zwei unterschiedliche experimentelle Ansätze verfolgt, die Parameter der Aktivierung von Ezrin individuell zu adressieren und inre Einzelbeiträge zum resultierenden F-Aktin-Bindungsvermögen zu analysieren. Einerseits wurde die Bindung von Ezrin an F-Aktin an planaren Oberflächen und andererseits in Lösung beobachtet. Hierbei wurde das F-AktinBindungsvermögen als direktes Maß für den Aktivierungsgrad des Ezrins betrachtet. Die Verwendung von Ezrin wt im Vergleich mit zwei Mutanten, die jeweils die unphosphorylierbare beziehungsweise eine pseudophosphorylierte Version des Proteins darstellten, ermöglichte hierbei die separate Betrachtung des Einflusses der Phosphorylierung auf das F-Aktin-Bindungsvermögen. Der Einfluss des zweiten Aktivierungsparameters, die Bindung an $\mathrm{PIP}_{2}$, wurde für die Studien in Lösung durch Beimischung beziehungsweise Verzicht auf Zugabe von $\mathrm{PIP}_{2}$ zur Reaktionsmischung beobachtet. Im Fall der Oberflächenstudien wurde Entsprechendes durch zwei alternative Immobilisierungsstrategien erreicht. Membranen, die über einen bestimmten Anteil an $\mathrm{PIP}_{2}$ verfügten, dienten als Modellsysteme zur Untersuchung des Einflusses des natürlichen Bindungspartners auf den Aktivierungszustand der verwendeten Proteine. Über die Komplexierung des N-terminalen His-tags an DOGS-NTA-Ni konnte hingegen eine Immobilisierung der Proteine an der Oberfläche erreicht werden, die einerseits eine wohlgeordnete, einheitliche Orientierung des Proteins auf der Oberfläche ermöglichte, andererseits aber nicht den Aktivierungszustand beeinflussen sollte.

Die Interaktionsstudien an Oberflächen und in Lösung kamen zu unterschiedlichen Ergebnissen. Zunächst soll hier auf die Studien an festkörperunterstützten Membranen eingegangen werden.

Um die Spezifität der F-Aktinbindung an oberflächengebundenes Ezrin zu beweisen, wurden Studien durchgeführt, bei denen ein sehr niedriger $\mathrm{PIP}_{2}$-Gehalt der festkörperunterstützten Membran von 0,5 mol\% nach Inkubation von Ezrin wt zu einzelnen proteinbelegten neben proteinfreien Flächenanteilen führte. Die Unterscheidung des Belegungszustandes ermöglichte die Verwendung von fluoreszenzmarkiertem Ezrin wt. Es konnte eindeutig gezeigt werden, dass ausschließlich auf ezrinbelegten Flächen eine signifikante Adsorption von 
F-Aktinfilamenten stattfand, während auf ezrinfreien Flächen annähernd kein adsorbiertes F-Aktin detektierbar war. Darüber hinaus konnte auf gänzlich proteinfreien festkörperunterstützten Membranen, die jeweils $10 \mathrm{~mol} \%$ des Rezeptorlipids enthielten, eine unspezifische Adsorption von lediglich $14 \%$ für DOGS-NTA-Ni beziehungsweise $8 \%$ für $\mathrm{PIP}_{2}$ quantifiziert werden. Diese Ergebnisse dienten als Grundlage für die Interpretation der Experimente, die auf vollständig mit Ezrin belegten Membranen durchgeführt wurden. Adsorption von F-Aktin, die auf diesen Flächen beobachtet wurde, konnte damit zweifelsfrei als spezifische Adsorption an membrangebundenes Ezrin gedeutet werden. Insofern konnte in diesen Experimenten auch auf die Fluoreszenzmarkierung des Ezrins verzichtet werden, was einerseits eine potentielle Strukturbeeinflussung des Proteins durch den Fluorophor ausschließt, andererseits die spektrale Trennung des von phalloidinmarkiertem F-Aktin ausgesendeten Fluoreszenzlichts von anderen Lichtquellen erleichtert und cross talk zwischen verschiedenen Fluorophoren verhindert. Solche häufig auftretenden Effekte sollten ausgeschlossen werden, um eine möglichst quantitativ exakte Erfassung der FAktinfluoreszenz zu gewährleisten.

In der Tat wurde in der Kombination der Perylenmarkierung der festkörperunterstützten Membran mit dem AlexaFluor633-markierten Ezrin wt eine Fluoreszenzlöschung der Perylenfluoreszenz beobachtet, die vermutlich auf einen FRET-Effekt (Förster-Resonanzenergietransfer) zurückzuführen ist. Voraussetzung für einen FRET ist eine Überlappung der Absorptions- und Emissionsbanden der beiden FRET-Partner sowie eine räumliche Nähe der beiden Moleküle (137). Die Emissionsbande von Perylen mit einem Maximum bei ca. $\lambda=440 \mathrm{~nm}$ scheint zunächst nicht mit dem Absorptionsbereich des AlexaFluor633 (Anregung bei $\lambda=633 \mathrm{~nm}$ ) zu überlappen. Jedoch ist literaturbekannt, dass zwei Perylenmoleküle dimerisieren können und dann eine zweite, sehr breite Emissionsbande aufweisen (138), welche sich genau über den Absorptionsbereich des verwendeten roten Alexa-Farbstoffs erstreckt. Die stark verringerte Perylenfluoreszenz, welche in Abbildung 7.2 dargestellt ist, muss daher auf einen solchen FRET-Effekt zurückgeführt werden und stellt keinen Membrandefekt dar. 
Anhand der fluoreszenzmikroskopischen Experimente an 10\% Rezeptorlipid enthaltenden Modellmembranen in Kombination mit den verschiedenen Ezrinmutanten konnten die Einzelbeiträge zur F-Aktin-Bindefähigkeit und damit zum Gesamtaktivierungszustand des Linkerproteins Ezrin unterschieden werden. Die erhaltenen Ergebnisse sind in Abbildung 7.10 als Säulendiagramme zusammengefasst.

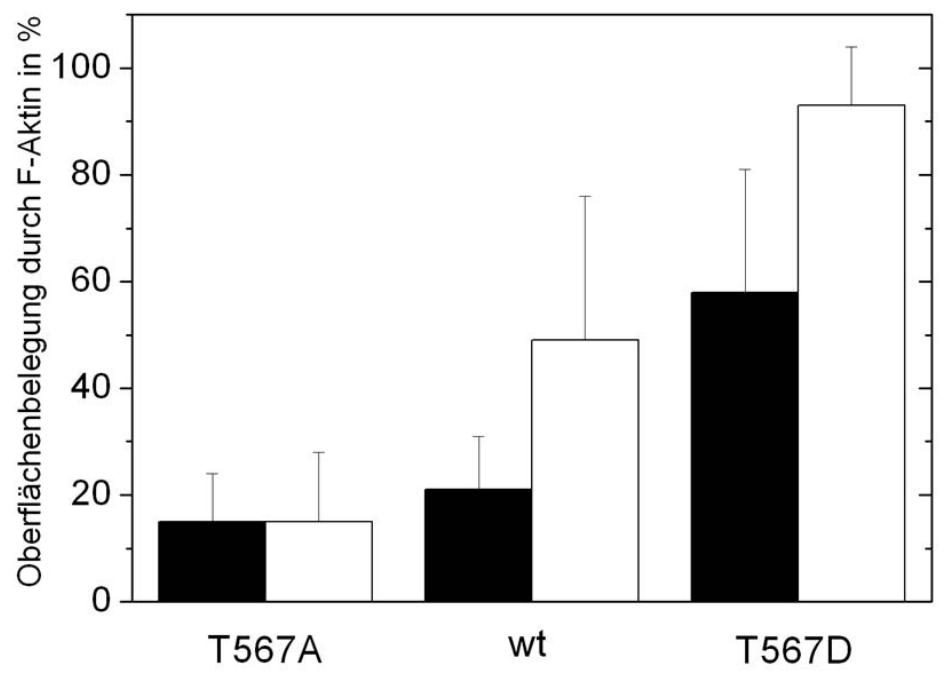

Abbildung 7.10: Darstellung der Oberflächenbelegung durch F-Aktin auf Ezrin-belegten festkörperunterstützten Membranen. Die Membranen enthielten entweder 10\% DOGS-NTA-Ni (schwarz) oder $10 \% \mathrm{PIP}_{2}$ (weiß). Die jeweils verwendeten Proteine sind angegeben.

Dabei konnte festgestellt werden, dass die Bindung an $\mathrm{PIP}_{2}$ das F-AktinBindungsvermögen um ca. 30\% steigerte, während die Pseudophosphorylierung eine Steigerung um weitere $40 \%$ bewirkte. Beide untersuchten Aktivierungsparameter liefern damit signifikante Einzelbeiträge zur Gesamtaktivierung und bewirken in einem offenbar synergistischen Zusammenspiel eine vollständige Aktivierung des Proteins Ezrin, was sich in der nahezu vollständigen Bedeckung der Probenoberfläche $(>90 \%)$ mit F-Aktin nachweisen ließ. Keiner der Aktivierungsparameter allein bewirkt eine derartig hohe F-Aktin-Bindefähigkeit von Ezrin, sondern es konnte hierbei eine zwar signifikante, in der Summe jedoch nur mittlere Bedeckung (50-60\%) der Oberfläche mit F-Aktin beobachtet werden. 
Die experimenten Ergebnisse der vorliegenden Arbeit können erstmals beweisen, dass eine Synergie von $\mathrm{PIP}_{2}$-Bindung und Phosphorylierung zur vollständigen Aktivierung von Ezrin führt. Die Fachliteratur konnte bis dato lediglich einzelne Hinweise auf diesen Befund liefern. Eine Publikation von Janke et al. aus dem Jahr 2008 kommt zu dem Schluss, dass die Bindung von Ezrin wt an $\mathrm{PIP}_{2}$ nicht nur der Membranverknüpfung dient, sondern dass hierdurch eine (partielle) Aktivierung des Ezrins induziert wird und daraus eine signifikant gesteigerte Affinität zu F-Aktin resultiert (98). Sie konnten dies sowohl anhand von Fluoreszenzstudien als auch colloidal probe-Affinitätsstudien feststellen. Von Hirao et al. konnte anhand von in vitro-Studien gezeigt werden, dass ausschließlich in Gegenwart von $\mathrm{PIP}_{2}$ eine Interaktion von ERM-Proteinen mit dem Transmembran-Glycoprotein CD44 stattfand (43). Kürzlich wurde von Carvalho et al. anhand von Fluoreszenzstudien in Lösung beobachtet, dass die Bindung von $\mathrm{PIP}_{2}$ an Ezrin eine Konformationsänderung des Proteins bewirkt (139). Sie prüften allerdings nicht, ob diese Konformationsänderung den Aktivierungszustand im Sinne einer erhöhten F-Aktin-Affinität beeinflusst.

Auch anhand von in vivo-Studien ließ sich bisher mehrfach ein entscheidender Einfluss von $\mathrm{PIP}_{2}$ auf die Ezrinaktivität feststellen. So konnte in HeLa-Zellen gezeigt werden, dass die Hochregulation einer PIP-Kinase zu einer Anreicherung von aktiviertem Ezrin an der Plasmamembran und einer Colokalisierung mit FAktin führte (140). Zu einem ähnlichen Ergebnis kam eine Studie von Matsui et al. (141), in der beobachtet wurde, dass die Überexpression von Phosphatidylinositol-4-Phosphat-5-Kinase (PI4P5K) eine Rekrutierung von ERMProteinen an die Plasmamembran bewirkte und dort die Bildung von Mikrovilli induzierte.

Auch für die entscheidende Rolle der Phosphorylierung existieren in der Literatur zahlreiche Nachweise: Anhand der Überexpression von Rho-Kinasen in Fibroblasten konnte gezeigt werden, dass eine vermehrte Phosphorylierung von Moesin mit einer Translokation des Proteins in die Mikrovilli der Zellen einherging. Auch wurde hierdurch eine stärkere Neigung der Zelle zur Ausbildung von Mikrovilli induziert (142). Eine Gelfiltrationsstudie von Chambers und Bretscher lieferte weiterhin die Erkenntnis, dass auch in der dauerhaft aktivierten Form Ezrin T567D eine schwache, doch signifikante restliche Affinität des C- für 
den N-Terminus vorlag (115). Dies bedeutet, was im Einklang mit den Ergebnissen der vorliegenden Arbeit steht, dass die Phosphorylierung von Ezrin allein keine vollständig geöffnete Konformation des Proteins zu induzieren vermag.

Von Fievet et al. konnte unter Verwendung einer N-terminal mutierten Variante von Ezrin gezeigt werden, dass beide Prozesse, sowohl $\mathrm{PIP}_{2}$-Bindung als auch Phosphorylierung, für eine effektive Aktivierung von Ezrin notwendig sind. Die eingeführte Mutation im N-Terminus des Proteins bewirkte, dass Ezrin ausschließlich im Cytoplasma vorgefunden wurde und nicht durch Kinasen phosphorylierbar war. Daraus schlossen sie, dass die Bindung an $\mathrm{PIP}_{2}$ als erster Schritt im Aktivierungsmechanismus von Ezrin essentiell ist (58).

Die konstitutiv inaktive Mutante Ezrin T567A hingegen konnte durch $\mathrm{PIP}_{2}$ nicht aktiviert werden. Damit bestand ein deutlicher Unterschied zwischen der konstitutiv inaktiven Mutante Ezrin T567A und dem Wildtyp des Proteins im Hinblick auf ihre Aktivierbarkeit durch $\mathrm{PIP}_{2}$. Eine naheliegende Erklärung für diesen Befund ist, dass die Einführung der Punktmutation die Funktionalität des Proteins beeinflusst. In der Literatur finden sich zahlreiche Beispiele für den Funktionsverlust von Proteinen bei Vorliegen einer einzelnen Punktmutation. So konnten Saleh et al. in einer umfangreichen Mutationsstudie an Ezrin beweisen, dass die Punktmutation der Aminosäure Arginin 579 zu Alanin zu einer Desaktivierung vieler Funktionen des Proteins führte (33). So fanden sie unter anderem eine veränderte Zellmorphologie und eine verringerte Zellmigration der Epithelzellen, die diese mutierte Version des Proteins exprimierten. Auch bei Connexin26 beeinträchtigen jeweils die Substitutionen V84L und M34T die $\mathrm{Ca}^{2+}$ Kanalaktivität des entsprechenden hexameren Connexons. Diese Mutationen liegen bei manchen Menschen vor und führen zu einer angeborenen Taubheit (143-144).

Durch die vorgestellten CD-spektroskopischen Strukturberechnungen wird deutlich, dass die Sekundärstrukturanteile der konstitutiv inaktiven Mutante von denen des Wildtyps vor allem bezüglich des a-helikalen Anteils (T567A: 60\%, wt: $71 \%$ ) sowie des ungeordneten Anteils (T567A: 25\%, wt: 18\%) starke Abweichungen zeigen. Da die Integrität der Struktur bei Protein-Interaktionen die Grundlage der molekularen Erkennung bildet, könnten die strukturellen 
Veränderungen den Verlust der Aktivierbarkeit von Ezrin T567A durch $\mathrm{PIP}_{2}$ oder eine Störung der F-Aktin-Bindung bewirkt haben. Bei der vorliegenden Punktmutation wurde ein Austausch einer polaren gegen eine unpolare Aminosäure vorgenommen, insofern ist eine solche Strukturbeeinflussung nicht unwahrscheinlich. Der Austausch von potentiell phosphorylierbaren Aminosäuren gegen Alanin ist im Zusammenhang mit in vivo-Experimenten eine sehr gebräuchliche Strategie. Der Leser soll daher an dieser Stelle auf die Schwierigkeiten und Grenzen der Interpretierbarkeit von experimentellen Ergebnissen unter Verwendung dieser speziellen Mutante hingewiesen werden. Diese Einschränkung gilt prinzipiell für jede Mutationsstudie und damit auch für das verwendete Ezrin T567D. Jedoch konnte hierfür anhand der vorliegenden Ergebnisse kein Funktionsverlust im Sinne eines verringerten F-AktinBindungsvermögens festgestellt werden. Die erzielten Ergebnisse sind darüber hinaus sehr gut mit den Ergebnissen für den Wildtyp korrelierbar: Für beide Proteine konnte eine Steigerung der gebundenen F-Aktinmenge um ca. 30\% gefunden werden, wenn die Immobilisierung über $\mathrm{PIP}_{2}$ erfolgte. Schließlich ist auch die Aminosäure Aspartat sowohl in ihrer Ladung, Polarität als auch Struktur dem phosphorylierten Threonin ähnlich. Um letzte Zweifel an der physiologischen Relevanz dieser Mutante auszuräumen, wäre es in Zukunft hochinteressant, eine selektive in vitro-Phosphorylierung des Wildtyps am Threonin 567 vorzunehmen und die resultierende Steigerung des F-Aktinbindevermögens im hier verwendeten experimentellen Aufbau zu überprüfen.

In der Vergangenheit wurden bezüglich der Verwendung der Ezrinmutanten T567D und T567A einige experimentelle Ergebnisse publiziert, die widersprüchlich sind. So konnten Gautreau et al. nachweisen, dass die Expression von Ezrin T567D in Epithelzellen die Morphologie dieser Zellen stark verändert. Sie konnten hier mehr Mikrovilli, längere Lamellipodien und eine starke Membrankräuselung finden, und auch die Zell-Zell-Adhäsion in den beobachteten Kolonien schien gestört. Hingegen zeigten Zellen, die die konstitutiv inaktive Mutante Ezrin T567A oder den Wildtyp exprimierten, eine glatte Zelloberfläche und regelmäßig geformte Zellkolonien. Im Gegensatz zu Ezrin T567D und Ezrin wt konnte darüber hinaus keine stabile Assoziation von Ezrin T567A mit dem Cytoskelett nachgewiesen werden (130). Diese 
Beobachtung spricht dafür, dass in diesem Fall ein vollständiger Verlust der FAktin-Bindefähigkeit von Ezrin T567A vorlag. Ein weiteres Experiment, durchgeführt von Speck et al. an transgenen Taufliegen (Drosophila melanogaster), zeigte, dass infolge der Expression der dauerhaft aktivierten Mutante T559D cortikales F-Aktin gehäuft zu finden war (145). Bei Organismen, die die dauerhaft inaktivierte Form T559A exprimierten, konnte dies nicht beobachtet werden. Einen solchen Befund berichteten Poleseollo et al. in einem sehr ähnlichen Versuch an transgenen Taufliegen ebenfalls: Ihre Arbeiten zeigten, dass sich beide der in diesem Fall GFP-markierten Mutanten deutlich in der Lokalisation und Funktion von Moesin wt unterschieden (146). Während die phosphomimetische Mutante T559D verstärkt an der apikalen Plasmamembran colokalisiert mit F-Aktin vorlag, wurde für Organismen, die die unphosphorylierbare Mutante exprimierten, eine gehäufte ektopische Lokalisation von T559A an der äußeren Oocytenmembran gefunden. Beide Proteine konnten in rescue assays die Aufgaben des Wildtyps nicht effektiv übernehmen. Was bei der letzten zitierten in vivo-Studie als zusätzlicher unbekannter Faktor absolute Aussagen erschwert, ist die Tatsache, dass hier ein Fluoreszenzfarbstoff am C-Terminus mit dem Protein verknüpft war und unbekannt ist, inwiefern diese immerhin 238 AS aufweisende Struktur die Assoziation von Aktinfilamenten mit der C-terminalen Bindungsstelle beeinflusst. Eine vielzitierte Studie von Chambers und Bretscher beweist, dass schon die Verkürzung des nativen Proteins Ezrin um zwei C-terminale Aminosäuren die Selbstassoziation des Proteins sowie auch das Bindungsvermögen von F-Aktin empfindlich stört (115). Sie empfehlen daraufhin, in Studien zur Aktivierbarkeit von ERM-Proteinen auf große, insbesondere C-terminale Markierungssubstanzen zu verzichten.

Die Cosedimentationsstudien von F-Aktin mit Ezrin wt, T567A und T567D lieferten das Ergebnis, dass nur sehr geringe Anteile der verwendeten Ezrinversionen an F-Aktin gebunden und somit im Pellet nachzuweisen waren. Der weitaus größte Anteil von Ezrin blieb in Lösung und war entsprechend im Überstand $\mathrm{zu}$ finden. Es konnte keine Abhängigkeit der geringen cosedimentierten Menge vom Verhältnis der Konzentrationen von F-Aktin und Ezrin festgestellt werden. Auch zeigte sich keine unterschiedlichen Ergebnisse für Ezrin wt oder die beiden Mutanten. Insgesamt scheint es sich hierbei nur um 
eine sehr schwache spezifische Bindung des gelösten Ezrin an F-Aktin zu handeln. Für diese schwache Interaktion spricht die Tatsache, dass ohne die Anwesenheit von F-Aktin überhaupt kein Protein pelletiert wurde.

Der Zusatz von $10 \mu \mathrm{M} \mathrm{PIP}_{2}$ zu der Reaktionsmischung aus Ezrin und F-Aktin führte zu keiner Steigerung oder Verringerung der cosedimentierten Menge an Ezrin. Abgesehen davon, dass eine einfache Beimischung des Lipids in die wässrige Lösung eventuell nicht zu einer effektiven Bindung an Ezrin geführt haben könnte, waren die Resultate zunächst überraschend. Zumindest für die Mutante Ezrin T567D wäre denkbar, dass sich gegenüber Ezrin wt und Ezrin T567A erhöhte Affinität für F-Aktin zeigt. Ein Blick in die Literatur beweist jedoch, dass auch in der Vergangenheit Cosedimentationsstudien durchgeführt wurden, die uneindeutige Ergebnisse lieferten. Zum Beispiel beschreiben Simons et al. eine Cosedimentation von Ezrin, welches zu ca. 10\% phosphoryliert war und ebenfalls zu weitaus größten Anteilen im Überstand des Reaktionsansatzes nachzuweisen war. Ein von der F-Aktinkonzentration abhängiges Bindungsverhalten von Ezrin wurde hier nicht nachgewiesen (52). Auch Shuster et al. kamen zu dem Ergebnis, dass eine sehr geringe Menge des aus lysierten Zellen stammenden - und damit vermutlich teilweise phosphorylierten - Ezrin wt mit $\beta$-Aktin cosedimentierte, während der weitaus größte Anteil der Proteinmenge in Lösung verblieb. Auch sie konnten keine konzentrationsabhängige Bindung feststellen (147). Zhu et al. schließlich berichteten von einer erfolgreichen, allerdings auch nicht vollständigen Cosedimentation einer T567D-Mutante von Ezrin mit F-Aktin, während der entsprechende Wildtyp sowie T567A zu einem etwas größeren Anteil in Lösung verblieben (148). Der Nachweis dieser Sedimentation wurde jedoch im Gegensatz zur vorliegenden Arbeit über einen Western blot geführt, was impliziert, dass eine erhöhte Sensitivität für die Unterscheidung der experimentellen Ergebnisse benötigt wurde. In dieser Studie wurden allerdings doppelt fluoreszenzmarkierte Konstrukte (YFP-Ezrin-CFP) eingesetzt, auf deren Problematik in dieser Arbeit bereits eingegangen wurde.

Es kann auf Grundlage der Daten und nach dem Kenntnisstand der zugehörigen Literatur festgestellt werden, dass in Lösung keine ausgeprägte und vor allem keine spezifische Affinität von Ezrin zu F-Aktin besteht. Auch die T567D-Mutante 
als Modell des phosphorylierten Ezrins besitzt keine gesteigerte Affinität zu FAktin.

Dies steht im Einklang mit einem in vitro-Experiment, das Nakamura et al. 1999 vorstellten. Sie konnten nachweisen, dass eine stabile Assoziation von F-Aktin mit Moesin T558D nur in Gegenwart von Phosphatidylinositol auftrat (149). In vivo konnte dagegen von Fievet et al. gezeigt werden, dass eine $\mathrm{N}$-terminal mutierte T567D-Version von Ezrin, welche nicht an $\mathrm{PIP}_{2}$ binden konnte, dennoch an Cytoskelettelementen von Epithelzellen lokalisiert war. Anhand von Extraktionsexperimenten mit dem Detergens Triton-X erreichten sie eine Trennung der membrangebundenen und cytoskelettgebundenen Proteine und wiesen so eine hohe Affinität der Ezrinmutante T567D für F-Aktin nach. Jedoch muss an dieser Stelle darauf hingewiesen werden, dass grundsätzlich zwischen in vivo und in vitro-Studien unterschieden werden muss. Ein in vitro-Assay erlaubt das gezielte Studium einiger weniger Interaktionspartner. Organismen wie Zellen hingegen können oft durch eine größere Vielzahl an Regulationsmechanismen äußere Manipulationen kompensieren. Im konkreten Fall bedeutet dies, dass die von Fievet et al. gefundene Assoziation der Ezrin T567D-Mutante ohne $\mathrm{PIP}_{2}$-Bindungsstelle zum Beispiel auch über die eingangs zitierte alternative Aktivierung über das Protein S100P erklärbar ist.

Eine denkbare Erklärung für die geringe Neigung zur Assoziation von F-Aktin und Ezrin in Lösung ist, dass die individuelle Bindung zwischen den Bindungspartnern eher schwach ist, so dass für eine dauerhafte Bindung in einer Art kooperativem Prozess mehrere Ezrinmoleküle an ein Filament binden müssen. Die Voraussetzung einer Plattform, die aus mehreren Ezrinmolekülen aufgebaut ist, um anschließend die Bindung zu einem Aktinfilament auszubilden, ist in Lösung nicht gegeben, jedoch an planaren Oberflächen. Diese Erklärung scheint plausibel, wenn man die natürliche Bindungssituation der Interaktionspartner betrachtet: An aktinreichen Strukturen wie Membrankräuselungen oder Mikrovilli wird stets eine lokal stark erhöhte Oberflächenkonzentration an Ezrin gefunden. Es konnten sogar bereits kovalent verbundene Ezrinoligomere in Mikrovilli von Plazentaepithelien nachgewiesen werden, die eine besonders stabile Bindung zum Cytoskelett aufwiesen. Die Verknüpfung erfolgt vermutlich durch eine endogene querverknüpfende Aktivität, 
z.B. durch eine Transglutaminase (128-129). Dies unterstreicht die physiologische Relevanz der Oligomerbildung von Ezrin. 



\section{BINDUNGS- UND AKTIVIERUNGSMODELL VON EZRIN}

Die vorliegende Arbeit liefert neue Erkenntnisse über die molekularen Prozesse, die zur Aktivierung von Ezrin und somit zu einer stabilen Verknüpfung von Plasmamembran und Cytoskelett führen. Anhand von Quarzmikrowaage- und FLuoreszenzexperimenten konnte das Protein-clustering von $\mathrm{PIP}_{2}$-gebundenem Ezrin nachgewiesen werden, was im gleichen Zuge zu einer Akkumulation von $\mathrm{PIP}_{2}$ unter der proteinbelegten Fläche führt. Die Bindung an $\mathrm{PIP}_{2}$ kann das Protein partiell aktivieren, eine volle Aktivierung kann jedoch nur durch die zusätzliche Phosphorylierung von T567 erreicht werden. Schließlich wurde gezeigt, dass Ezrinoligomere in einer kooperativen Weise an Aktinfilamente binden, was die physiologische Relevanz der beobachteten EzrinOligomerbildung unterstreicht.

Auf Basis der erhaltenen Daten wird an dieser Stelle ein Aktivierungsmodell postuliert, welches den Einfluss aller untersuchten Aktivierungsparameter berücksichtigt (Abbildung 8.1). Im vorgeschlagenen Modell wird durch die Bindung an $\mathrm{PIP}_{2}$ eine Konformationsänderung von Ezrin induziert, welche in einer partiellen Freilegung der C-terminalen Bindungsstelle für F-Aktin resultiert. Eine stabile Bindung von Aktinfilamenten kann jedoch erst erfolgen, wenn mehrere Ezrinmoleküle ein Oligomer bilden und kooperativ sowohl an die Plasmamembran als auch an das Filament binden. Eine weitere Stabilisierung der aktiven Konformation kann durch die Phosphorylierung des im C-Terminus befindlichen Threonin 567 erfolgen. So wird im gleichen Zuge die F-AktinBindefähigkeit erhöht. Dieses Modell steht im Einklang mit dem gegenwärtigen Verständnis einer zwei Schritte umfassenden Aktivierung des Proteins Ezrin (60). Über mögliche Desaktivierungswege kann an dieser Stelle noch keine fundierte Aussage getroffen werden. Es ist jedoch literaturbekannt, dass es neben der Desaktivierung durch Phosphatasen (150) auch durch die Aktivität von Phospholipasen zu einer Ablösung von Ezrin sowohl von der Plasmamembran als auch von Cytoskelettelementen kommt und diese beiden Möglichkeiten damit 
vermutlich einen komplexen und fein regulierbaren Mechanismus zur Desaktivierung des Proteins bilden (151).
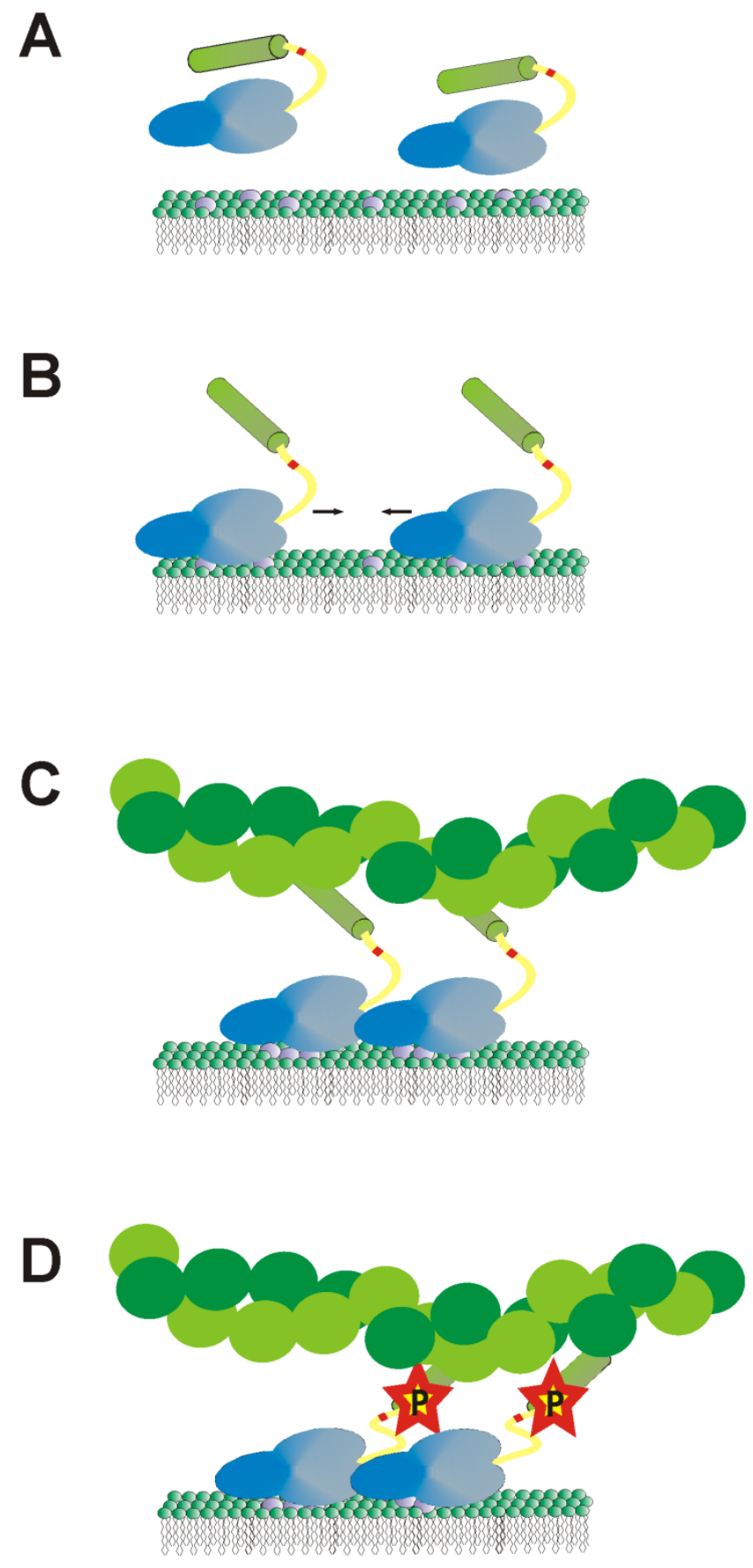

Abbildung 8.1: Postuliertes Aktivierungsmodell von Ezrin. A Ezrin liegt im Cytosol gelöst vor und befindet sich in der inaktiven Form. B Ezrin wird über die Bindung an $\mathrm{PIP}_{2}$ an die Lipidmembran rekrutiert. Intermolekulare attraktive Wechselwirkungen zwischen benachbarten membrangebundenen Ezrinmolekülen führen zur Bildung eines Proteinclusters. $\mathrm{PIP}_{2}$ wird dabei unter der proteinbelegten Fläche akkumuliert. Im gleichen Zuge resultiert aus der Bindung an $\mathrm{PIP}_{2}$ eine partielle Freilegung der F-Aktin-Bindungsstelle. C Das Ezrinoligomer bindet in einer kooperativen Weise an ein Aktinfilament. D Eine anschließende Phosphorylierung des Threonin 567 sorgt für die vollständige Konformationsöffnung und stabilisiert den aktivierten Zustand. 


\section{ZUSAMMENFASSUNG}

Im Rahmen dieser Arbeit wurde der Aktivierungsprozess von Ezrin, welches in vivo die Plasmamembran mit dem Cytoskelett verknüpft, anhand von wohldefinierten Modellmembransystemen detailliert untersucht. Dabei war von besonderem Interesse, den Einfluss der Bindung des Lipids Phosphytidylinositol4,5-bisphosphat $\left(\mathrm{PIP}_{2}\right)$ sowie der Phosphorylierung auf die Aktivierung des Proteins sowie mögliche Synergien zu analysieren und zu quantifizieren. Die verwendeten planaren Modellmembranen enthielten entweder Ni-1,2-dioleoyl-snglycero-3-([N(5-amino-1-carboxypentyl)iminodiessigsäure]succinyl) (DOGS-NTA$\mathrm{Ni)}$ zur gerichteten Immobilisierung der Proteine über einen $\mathrm{N}$-terminalen Hexahistidin-tag oder $\mathrm{PIP}_{2}$ als natürlichen Bindungspartner von Ezrin. Die Charakterisierung der Bindung von Ezrin wt sowie zweier Mutanten - die unphosphorylierbare sowie die pseudophosphorylierte Form des Proteins - an festkörperunterstützte Membranen erfolgte mittels Quarzmikrowaagetechnik. So konnten für alle drei Proteine eine hohe Affinität mit Bindungskonstanten im Bereich von $10 \mathrm{nM}$ und eine hohe Belegungsdichte auf beiden Membransystemen bewiesen werden. Anhand einer Variation der Lipidzusammensetzung der festkörperunterstützten Membran konnte geschlussfolgert werden, dass Ezrin über mehrere $\mathrm{PIP}_{2}$-Lipide an die Membran gebunden wird. Fluoreszenzmikroskopische Studien sowie eine detaillierte Analyse des Bindungsverhaltens von Ezrin konnten zeigen, dass attraktive Protein-Protein-Wechselwirkungen zur Bildung von Proteinclustern auf der Oberfläche führen. Messungen mit einer C-terminal verkürzten Version von Ezrin konnten die beobachtete intermolekulare attraktive Wechselwirkung auf den CTerminus des Proteins lokalisieren.

Mittels eines fluoreszenzmikroskopischen Assays konnte die Bindefähigkeit von Ezrin für filamentöses Aktin (F-Aktin) in Abhängigkeit von $\mathrm{PIP}_{2}$-Bindung und Phosphorylierung quantifiziert werden. Hierbei wurde das Ausmaß der FAktinbindefähigkeit als direktes Maß für den Aktivierungszustand von Ezrin betrachtet. Es konnte gezeigt werden, dass sowohl durch die Bindung an das 
Lipid $\mathrm{PIP}_{2}$ als auch durch die Phosphorylierung eine signifikante Erhöhung der ezringebundenen Menge an F-Aktin erfolgte. Erstmals konnte so bewiesen werden, dass beide Komponenten, $\mathrm{PIP}_{2}$-Bindung sowie Phosphorylierung, in einem synergistischen Prozess zu einer vollen Aktivierung des Proteins Ezrin führen. Die Bindung von Ezrin an F-Aktin konnte nur an membrangebundenem, nicht an löslichem Ezrin gefunden werden. Daraus wird geschlossen, dass die stabile Bindung von F-Aktin kooperativ über Ezrincluster erfolgt. Es konnte auf Basis der aufgenommenen Daten ein detailliertes Aktivierungsmodell erstellt werden, welches neue Einblicke in die Regulation der Verbindung von Plasmamembran und Cytoskelett bietet. 


\section{LITERATURVERZEICHNIS}

1. Alberts, B. 2008. Molecular biology of the cell. Garland Science, Taylor\&Francis Group, LLC, New York.

2. TRAFFIC- CYTOSKELETON Virtual issue. The international journal of intracellular transport.

3. Chang, L., and R. D. Goldman. 2004. Intermediate filaments mediate cytoskeletal crosstalk. Nat Rev Mol Cell Biol 5:601-613.

4. Mullins, R. D., W. F. Stafford, and T. D. Pollard. 1997. Structure, subunit topology, and actin-binding activity of the Arp2/3 complex from Acanthamoeba. J Cell Biol 136:331-343.

5. Holmes, K. C., D. Popp, W. Gebhard, and W. Kabsch. 1990. Atomic model of the actin filament. Nature 347:44-49.

6. Pantaloni, D., C. Le Clainche, and M. F. Carlier. 2001. Mechanism of actin-based motility. Science 292:1502-1506.

7. Herman, I. M. 1993. Actin isoforms. Curr Opin Cell Biol 5:48-55.

8. Korn, E. D., M. F. Carlier, and D. Pantaloni. 1987. Actin polymerization and ATP hydrolysis. Science 238:638-644.

9. Carlier, M. F., V. Laurent, J. Santolini, R. Melki, D. Didry, G. X. Xia, Y. Hong, N. H. Chua, and D. Pantaloni. 1997. Actin depolymerizing factor (ADF/cofilin) enhances the rate of filament turnover: implication in actinbased motility. J Cell Biol 136:1307-1322.

10. Sun, H. Q., M. Yamamoto, M. Mejillano, and H. L. Yin. 1999. Gelsolin, a multifunctional actin regulatory protein. J Biol Chem 274:33179-33182.

11. Bugyi, B., and M. F. Carlier. 2010. Control of actin filament treadmilling in cell motility. Annu Rev Biophys 39:449-470.

12. McLaughlin, S., J. Wang, A. Gambhir, and D. Murray. 2002. PIP(2) and proteins: interactions, organization, and information flow. Annu Rev Biophys Biomol Struct 31:151-175.

13. Berridge, M. J., and R. F. Irvine. 1984. Inositol trisphosphate, a novel second messenger in cellular signal transduction. Nature 312:315-321. 
14. Lomasney, J. W., H. F. Cheng, L. P. Wang, Y. Kuan, S. Liu, S. W. Fesik, and K. King. 1996. Phosphatidylinositol 4,5-bisphosphate binding to the pleckstrin homology domain of phospholipase C-delta1 enhances enzyme activity. J Biol Chem 271:25316-25326.

15. Raucher, D., T. Stauffer, W. Chen, K. Shen, S. Guo, J. D. York, M. P. Sheetz, and T. Meyer. 2000. Phosphatidylinositol 4,5-bisphosphate functions as a second messenger that regulates cytoskeleton-plasma membrane adhesion. Cell 100:221-228.

16. Fukami, K., K. Furuhashi, M. Inagaki, T. Endo, S. Hatano, and T. Takenawa. 1992. Requirement of phosphatidylinositol 4,5-bisphosphate for alpha-actinin function. Nature 359:150-152.

17. Heiss, S. G., and J. A. Cooper. 1991. Regulation of CapZ, an actin capping protein of chicken muscle, by anionic phospholipids. Biochemistry 30:8753-8758.

18. Haus, U., H. Hartmann, P. Trommler, A. A. Noegel, and M. Schleicher. 1991. F-actin capping by cap32/34 requires heterodimeric conformation and can be inhibited with PIP2. Biochem Biophys Res Commun 181:833839.

19. Hofmann, A., L. Eichinger, E. Andre, D. Rieger, and M. Schleicher. 1992. Cap100, a novel phosphatidylinositol 4,5-bisphosphate-regulated protein that caps actin filaments but does not nucleate actin assembly. Cell Motil Cytoskeleton 23:133-144.

20. Bretscher, A., K. Edwards, and R. G. Fehon. 2002. ERM proteins and merlin: integrators at the cell cortex. Nat Rev Mol Cell Biol 3:586-599.

21. Zachowski, A. 1993. Phospholipids in animal eukaryotic membranes: transverse asymmetry and movement. Biochem J 294 ( Pt 1):1-14.

22. Tall, E. G., I. Spector, S. N. Pentyala, I. Bitter, and M. J. Rebecchi. 2000. Dynamics of phosphatidylinositol 4,5-bisphosphate in actin-rich structures. Curr Biol 10:743-746.

23. Donaldson, J. G. 2005. Arfs, phosphoinositides and membrane traffic. Biochem Soc Trans 33:1276-1278. 
24. Tong, J., L. Nguyen, A. Vidal, S. A. Simon, J. H. Skene, and T. J. Mclntosh. 2008. Role of GAP-43 in sequestering phosphatidylinositol 4,5bisphosphate to Raft bilayers. Biophys J 94:125-133.

25. Laux, T., K. Fukami, M. Thelen, T. Golub, D. Frey, and P. Caroni. 2000. GAP43, MARCKS, and CAP23 modulate $\mathrm{PI}(4,5) \mathrm{P}(2)$ at plasmalemmal rafts, and regulate cell cortex actin dynamics through a common mechanism. J Cell Biol 149:1455-1472.

26. Menke, M., V. Gerke, and C. Steinem. 2005. Phosphatidylserine membrane domain clustering induced by annexin A2/S100A10 heterotetramer. Biochemistry 44:15296-15303.

27. Gambhir, A., G. Hangyas-Mihalyne, I. Zaitseva, D. S. Cafiso, J. Wang, D. Murray, S. N. Pentyala, S. O. Smith, and S. McLaughlin. 2004. Electrostatic sequestration of PIP2 on phospholipid membranes by basic/aromatic regions of proteins. Biophys J 86:2188-2207.

28. Epand, R. M., P. Vuong, C. M. Yip, S. Maekawa, and R. F. Epand. 2004. Cholesterol-dependent partitioning of Ptdlns(4,5)P2 into membrane domains by the N-terminal fragment of NAP-22 (neuronal axonal myristoylated membrane protein of $22 \mathrm{kDa}$ ). Biochem J 379:527-532.

29. Bretscher, A. 1983. Purification of an 80,000-dalton protein that is a component of the isolated microvillus cytoskeleton, and its localization in nonmuscle cells. J Cell Biol 97:425-432.

30. Tsukita, S., Y. Hieda, and S. Tsukita. 1989. A new 82-kD barbed endcapping protein (radixin) localized in the cell-to-cell adherens junction: purification and characterization. J Cell Biol 108:2369-2382.

31. Lankes, W., A. Griesmacher, J. Grunwald, R. Schwartz-Albiez, and R. Keller. 1988. A heparin-binding protein involved in inhibition of smoothmuscle cell proliferation. Biochem J 251:831-842.

32. Chishti, A. H., A. C. Kim, S. M. Marfatia, M. Lutchman, M. Hanspal, H. Jindal, S. C. Liu, P. S. Low, G. A. Rouleau, N. Mohandas, J. A. Chasis, J. G. Conboy, P. Gascard, Y. Takakuwa, S. C. Huang, E. J. Benz, Jr., A. Bretscher, R. G. Fehon, J. F. Gusella, V. Ramesh, F. Solomon, V. T. Marchesi, S. Tsukita, S. Tsukita, K. B. Hoover, et al. 1998. The FERM 
domain: a unique module involved in the linkage of cytoplasmic proteins to the membrane. Trends Biochem Sci 23:281-282.

33. Saleh, H. S., U. Merkel, K. J. Geissler, T. Sperka, A. Sechi, C. Breithaupt, and $\mathrm{H}$. Morrison. 2009. Properties of an ezrin mutant defective in $\mathrm{F}$-actin binding. J Mol Biol 385:1015-1031.

34. Doi, Y., M. Itoh, S. Yonemura, S. Ishihara, H. Takano, T. Noda, and S. Tsukita. 1999. Normal development of mice and unimpaired cell adhesion/cell motility/actin-based cytoskeleton without compensatory upregulation of ezrin or radixin in moesin gene knockout. J Biol Chem 274:2315-2321.

35. Saotome, I., M. Curto, and A. I. McClatchey. 2004. Ezrin is essential for epithelial organization and villus morphogenesis in the developing intestine. Dev Cell 6:855-864.

36. Tamura, A., S. Kikuchi, M. Hata, T. Katsuno, T. Matsui, H. Hayashi, Y. Suzuki, T. Noda, S. Tsukita, and S. Tsukita. 2005. Achlorhydria by ezrin knockdown: defects in the formation/expansion of apical canaliculi in gastric parietal cells. J Cell Biol 169:21-28.

37. Kikuchi, S., M. Hata, K. Fukumoto, Y. Yamane, T. Matsui, A. Tamura, S. Yonemura, H. Yamagishi, D. Keppler, S. Tsukita, and S. Tsukita. 2002. Radixin deficiency causes conjugated hyperbilirubinemia with loss of Mrp2 from bile canalicular membranes. Nat Genet 31:320-325.

38. Kitajiri, S., K. Fukumoto, M. Hata, H. Sasaki, T. Katsuno, T. Nakagawa, J. Ito, S. Tsukita, and S. Tsukita. 2004. Radixin deficiency causes deafness associated with progressive degeneration of cochlear stereocilia. J Cell Biol 166:559-570.

39. Turunen, O., T. Wahlstrom, and A. Vaheri. 1994. Ezrin has a $\mathrm{COOH}-$ terminal actin-binding site that is conserved in the ezrin protein family. $\mathrm{J}$ Cell Biol 126:1445-1453.

40. Algrain, M., O. Turunen, A. Vaheri, D. Louvard, and M. Arpin. 1993. Ezrin contains cytoskeleton and membrane binding domains accounting for its proposed role as a membrane-cytoskeletal linker. J Cell Biol 120:129-139. 
41. Henry, M. D., C. Gonzalez Agosti, and F. Solomon. 1995. Molecular dissection of radixin: distinct and interdependent functions of the aminoand carboxy-terminal domains. J Cell Biol 129:1007-1022.

42. Martin, M., C. Andreoli, A. Sahuquet, P. Montcourrier, M. Algrain, and P. Mangeat. 1995. Ezrin NH2-terminal domain inhibits the cell extension activity of the $\mathrm{COOH}$-terminal domain. J Cell Biol 128:1081-1093.

43. Hirao, M., N. Sato, T. Kondo, S. Yonemura, M. Monden, T. Sasaki, Y. Takai, S. Tsukita, and S. Tsukita. 1996. Regulation mechanism of ERM (ezrin/radixin/moesin) protein/plasma membrane association: possible involvement of phosphatidylinositol turnover and Rho-dependent signaling pathway. J Cell Biol 135:37-51.

44. Heiska, L., K. Alfthan, M. Gronholm, P. Vilja, A. Vaheri, and O. Carpen. 1998. Association of ezrin with intercellular adhesion molecule-1 and -2 (ICAM-1 and ICAM-2). Regulation by phosphatidylinositol 4, 5bisphosphate. J Biol Chem 273:21893-21900.

45. Yonemura, S., M. Hirao, Y. Doi, N. Takahashi, T. Kondo, S. Tsukita, and S. Tsukita. 1998. Ezrin/radixin/moesin (ERM) proteins bind to a positively charged amino acid cluster in the juxta-membrane cytoplasmic domain of CD44, CD43, and ICAM-2. J Cell Biol 140:885-895.

46. Smith, W. J., N. Nassar, A. Bretscher, R. A. Cerione, and P. A. Karplus. 2003. Structure of the active $\mathrm{N}$-terminal domain of Ezrin. Conformational and mobility changes identify keystone interactions. J Biol Chem 278:4949-4956.

47. Barret, C., C. Roy, P. Montcourrier, P. Mangeat, and V. Niggli. 2000. Mutagenesis of the phosphatidylinositol 4,5-bisphosphate (PIP(2)) binding site in the $\mathrm{NH}(2)$-terminal domain of ezrin correlates with its altered cellular distribution. J Cell Biol 151:1067-1080.

48. Bretscher, A., D. Reczek, and M. Berryman. 1997. Ezrin: a protein requiring conformational activation to link microfilaments to the plasma membrane in the assembly of cell surface structures. J Cell Sci $110(\mathrm{Pt}$ 24):3011-3018.

49. Li, Q., M. R. Nance, R. Kulikauskas, K. Nyberg, R. Fehon, P. A. Karplus, A. Bretscher, and J. J. Tesmer. 2007. Self-masking in an intact ERM- 
merlin protein: an active role for the central alpha-helical domain. J Mol Biol 365:1446-1459.

50. Hamada, K., T. Shimizu, T. Matsui, S. Tsukita, and T. Hakoshima. 2000. Structural basis of the membrane-targeting and unmasking mechanisms of the radixin FERM domain. Embo J 19:4449-4462.

51. Koltzscher, M., C. Neumann, S. Konig, and V. Gerke. 2003. Ca2+dependent binding and activation of dormant ezrin by dimeric S100P. Mol Biol Cell 14:2372-2384.

52. Simons, P. C., S. F. Pietromonaco, D. Reczek, A. Bretscher, and L. Elias. 1998. C-terminal threonine phosphorylation activates ERM proteins to link the cell's cortical lipid bilayer to the cytoskeleton. Biochem Biophys Res Commun 253:561-565.

53. Matsui, T., M. Maeda, Y. Doi, S. Yonemura, M. Amano, K. Kaibuchi, S. Tsukita, and S. Tsukita. 1998. Rho-kinase phosphorylates $\mathrm{COOH}$-terminal threonines of ezrin/radixin/moesin (ERM) proteins and regulates their head-to-tail association. J Cell Biol 140:647-657.

54. Belkina, N. V., Y. Liu, J. J. Hao, H. Karasuyama, and S. Shaw. 2009. LOK is a major ERM kinase in resting lymphocytes and regulates cytoskeletal rearrangement through ERM phosphorylation. Proc Natl Acad Sci U S A 106:4707-4712.

55. Ng, T., M. Parsons, W. E. Hughes, J. Monypenny, D. Zicha, A. Gautreau, M. Arpin, S. Gschmeissner, P. J. Verveer, P. I. Bastiaens, and P. J. Parker. 2001. Ezrin is a downstream effector of trafficking PKC-integrin complexes involved in the control of cell motility. Embo J 20:2723-2741.

56. ten Klooster, J. P., M. Jansen, J. Yuan, V. Oorschot, H. Begthel, V. Di Giacomo, F. Colland, J. de Koning, M. M. Maurice, P. Hornbeck, and H. Clevers. 2009. Mst4 and Ezrin induce brush borders downstream of the Lkb1/Strad/Mo25 polarization complex. Dev Cell 16:551-562.

57. Pearson, M. A., D. Reczek, A. Bretscher, and P. A. Karplus. 2000. Structure of the ERM protein moesin reveals the FERM domain fold masked by an extended actin binding tail domain. Cell 101:259-270.

58. Fievet, B. T., A. Gautreau, C. Roy, L. Del Maestro, P. Mangeat, D. Louvard, and M. Arpin. 2004. Phosphoinositide binding and 
phosphorylation act sequentially in the activation mechanism of ezrin. $\mathrm{J}$ Cell Biol 164:653-659.

59. Yonemura, S., T. Matsui, S. Tsukita, and S. Tsukita. 2002. Rho-dependent and -independent activation mechanisms of ezrin/radixin/moesin proteins: an essential role for polyphosphoinositides in vivo. J Cell Sci 115:25692580.

60. Roch, F., C. Polesello, C. Roubinet, M. Martin, C. Roy, P. Valenti, S. Carreno, P. Mangeat, and F. Payre. 2010. Differential roles of Ptdlns(4,5)P2 and phosphorylation in moesin activation during Drosophila development. J Cell Sci 123:2058-2067.

61. Laemmli, U. K. 1970. Cleavage of structural proteins during the assembly of the head of bacteriophage T4. Nature 227:680-685.

62. http://www.expasy.ch/.

63. www.probes.invitrogen.com.

64. Whitmore, L., and B. A. Wallace. 2008. Protein secondary structure analyses from circular dichroism spectroscopy: methods and reference databases. Biopolymers 89:392-400.

65. Kelly, S. M., T. J. Jess, and N. C. Price. 2005. How to study proteins by circular dichroism. Biochim Biophys Acta 1751:119-139.

66. Galla, H.-J. 1988. Spektroskopische Methoden in der Biochemie. Georg Thieme Verlag, Stuttgart.

67. http://mach7.bluehill.com/proteinc/cd/cdspec.html.

68. Whitmore, L., and B. A. Wallace. 2004. DICHROWEB, an online server for protein secondary structure analyses from circular dichroism spectroscopic data. Nucleic Acids Res 32:W668-673.

69. Ende, D. M., K.-M. . 1993. Impedanzspektroskopie. Chemie in unserer Zeit 27:134-140.

70. Coster, H. G., and J. R. Smith. 1974. The molecular organisation of bimolecular lipid membranes. A study of the low frequency MaxwellWagner impedance dispersion. Biochim Biophys Acta 373:151-164.

71. Steinem, C. 1997. Ionentransport in festkörperunterstützten Lipiddoppelschichten. Eine Untersuchung der Aktivität von Melittin, Gramicidin, Valinomycin und Bakteriorhodopsin. Universität Münster. 
72. Steinem, C., and A. Janshoff. 2007. Piezoelectric sensors. Springer Verlag.

73. Janshoff, A., H. J. Galla, and C. Steinem. 2000. Piezoelectric MassSensing Devices as Biosensors-An Alternative to Optical Biosensors? Angew Chem Int Ed Engl 39:4004-4032.

74. Sauerbrey, G. 1959. Verwendung von Schwingquarzen zur Wägung dünner Schichten und zur Mikrowägung. Zeitschrift für Physik 155:206222.

75. Nomura, T. O., M. 1982. Frequency shifts of piezoelectric quartz crystal microbalances: 1. General considerations. Anal. Chem. 142:281-284.

76. Buttry, D. A. W., M. D. 1990. In-situ interfacial mass measurements with piezoelectric transducers: fundamentals and applications. Science 249:1000-1007.

77. Kastl, K., A. Herrig, E. Luthgens, A. Janshoff, and C. Steinem. 2004. Scrutiny of annexin A1 mediated membrane-membrane interaction by means of a thickness shear mode resonator and computer simulations. Langmuir 20:7246-7253.

78. Kaspar, M., H. Stadler, T. Weiss, and C. Ziegler. 2000. Thickness shear mode resonators ("mass-sensitive devices") in bioanalysis. Fresenius $\mathrm{J}$ Anal Chem 366:602-610.

79. Dickert, F. L., O. Hayden, R. Bindeus, K. J. Mann, D. Blaas, and E. Waigmann. 2004. Bioimprinted QCM sensors for virus detection-screening of plant sap. Anal Bioanal Chem 378:1929-1934.

80. Janshoff, A. 1997. Präparation, Charakterisierung und Anwendung biofunktionalisierter Goldoberflächen - eine impedanzspektroskopische und mikrogravimetrische Studie. Universität Münster.

81. Tsien, R. Y. 1998. The green fluorescent protein. Annu Rev Biochem 67:509-544.

82. Chalfie, M., Y. Tu, G. Euskirchen, W. W. Ward, and D. C. Prasher. 1994. Green fluorescent protein as a marker for gene expression. Science 263:802-805. 
83. Shimomura, O., F. H. Johnson, and Y. Saiga. 1962. Extraction, purification and properties of aequorin, a bioluminescent protein from the luminous hydromedusan, Aequorea. J Cell Comp Physiol 59:223-239.

84. Atkins, P. W. 2002. Physikalische Chemie. 3. korrigierte Auflage.

85. Esa, A., P. Edelmann, G. Kreth, L. Trakhtenbrot, N. Amariglio, G. Rechavi, M. Hausmann, and C. Cremer. 2000. Three-dimensional spectral precision distance microscopy of chromatin nanostructures after triple-colour DNA labelling: a study of the BCR region on chromosome 22 and the Philadelphia chromosome. J Microsc 199:96-105.

86. Binnig, G., C. F. Quate, and C. Gerber. 1986. Atomic force microscope. Phys Rev Lett 56:930-933.

87. www.pdb.org. Protein Data Bank.

88. Gould, K. L., A. Bretscher, F. S. Esch, and T. Hunter. 1989. cDNA cloning and sequencing of the protein-tyrosine kinase substrate, ezrin, reveals homology to band 4.1. Embo J 8:4133-4142.

89. Turunen, O., R. Winqvist, R. Pakkanen, K. H. Grzeschik, T. Wahlstrom, and A. Vaheri. 1989. Cytovillin, a microvillar Mr 75,000 protein. cDNA sequence, prokaryotic expression, and chromosomal localization. J Biol Chem 264:16727-16732.

90. Herrig, W. A. 2007. Wechselwirkung von Ezrin mit PIP2-haltigen artifiziellen Membransystemen und mit F-Aktin. In Naturwissenschaftliche Fakultät IV Chemie und Pharmazie. Universität Regensburg, Regensburg.

91. Braunger, J. A. 2010.

92. Mao, D., E. Wachter, and B. A. Wallace. 1982. Folding of the mitochondrial proton adenosinetriphosphatase proteolipid channel in phospholipid vesicles. Biochemistry 21:4960-4968.

93. Provencher, S. W., and J. Glockner. 1981. Estimation of globular protein secondary structure from circular dichroism. Biochemistry 20:33-37.

94. Johnson, W. C. 1999. Analyzing protein circular dichroism spectra for accurate secondary structures. Proteins 35:307-312.

95. Sreerama, N., and R. W. Woody. 2000. Estimation of protein secondary structure from circular dichroism spectra: comparison of CONTIN, 
SELCON, and CDSSTR methods with an expanded reference set. Anal Biochem 287:252-260.

96. Ishikawa, H., A. Tamura, T. Matsui, H. Sasaki, T. Hakoshima, and S. Tsukita. 2001. Structural conversion between open and closed forms of radixin: low-angle shadowing electron microscopy. J Mol Biol 310:973-978.

97. Liu, D., L. Ge, F. Wang, H. Takahashi, D. Wang, Z. Guo, S. H. Yoshimura, T. Ward, X. Ding, K. Takeyasu, and X. Yao. 2007. Single-molecule detection of phosphorylation-induced plasticity changes during ezrin activation. FEBS Lett 581:3563-3571.

98. Janke, M., A. Herrig, J. Austermann, V. Gerke, C. Steinem, and A. Janshoff. 2008. Actin binding of ezrin is activated by specific recognition of PIP2-functionalized lipid bilayers. Biochemistry 47:3762-3769.

99. Janshoff, A., and C. Steinem. 2005. Label-free detection of protein-ligand interactions by the quartz crystal microbalance. Methods Mol Biol 305:4764.

100. Steinem, C., A. Janshoff, J. Wegener, W. P. Ulrich, W. Willenbrink, M. Sieber, and H. J. Galla. 1997. Impedance and shear wave resonance analysis of ligand-receptor interactions at functionalized surfaces and of cell monolayers. Biosens Bioelectron 12:787-808.

101. Liu, Y. C., C. M. Wang, and K. P. Hsiung. 2001. Comparison of different protein immobilization methods on quartz crystal microbalance surface in flow injection immunoassay. Anal Biochem 299:130-135.

102. Duevel, R. V. C., R. M. . 1992. Amide and ester surface attachment reactions for alkanethiol monolayers at gold surfaces as studied by polarization modulation fourier transform infrared spectroscopy. Anal. Chem. 64:337-342.

103. Mirsky, V. M., M. Riepl, and O. S. Wolfbeis. 1997. Capacitive monitoring of protein immobilization and antigen-antibody reactions on monomolecular alkylthiol films on gold electrodes. Biosens Bioelectron 12:977-989.

104. Dorn, I. T., Neumaier, K. R. , Tampé, R. 1998. Molecular recognition of histidine-tagged molecules by metal-chelating lipids monitored by fluorescence energy transfer and correlation spectroscopy. J. Am. Chem. Soc. 120:2753-2763. 
105. Porath, J., J. Carlsson, I. Olsson, and G. Belfrage. 1975. Metal chelate affinity chromatography, a new approach to protein fractionation. Nature 258:598-599.

106. Dorn, I. T., K. R. Neumaier, and R. Tampé. 1998. Molecular recognition of histidine-tagged molecules by metal-chelating lipids monitored by fluorescence energy transfer and correlation spectroscopy. J Am Chem Soc 120:2753-2763.

107. Herrig, A., M. Janke, J. Austermann, V. Gerke, A. Janshoff, and C. Steinem. 2006. Cooperative adsorption of ezrin on PIP2-containing membranes. Biochemistry 45:13025-13034.

108. Blin, G., E. Margeat, K. Carvalho, C. A. Royer, C. Roy, and C. Picart. 2008. Quantitative analysis of the binding of ezrin to large unilamellar vesicles containing phosphatidylinositol 4,5 bisphosphate. Biophys $\mathrm{J}$ 94:1021-1033.

109. Gershon, P. D., and S. Khilko. 1995. Stable chelating linkage for reversible immobilization of oligohistidine tagged proteins in the BIAcore surface plasmon resonance detector. J Immunol Methods 183:65-76.

110. Lata, S., A. Reichel, R. Brock, R. Tampe, and J. Piehler. 2005. Highaffinity adaptors for switchable recognition of histidine-tagged proteins. $J$ Am Chem Soc 127:10205-10215.

111. Niggli, V., C. Andreoli, C. Roy, and P. Mangeat. 1995. Identification of a phosphatidylinositol-4,5-bisphosphate-binding domain in the N-terminal region of ezrin. FEBS Lett 376:172-176.

112. Reimhult, E., C. Larsson, B. Kasemo, and F. Hook. 2004. Simultaneous surface plasmon resonance and quartz crystal microbalance with dissipation monitoring measurements of biomolecular adsorption events involving structural transformations and variations in coupled water. Anal Chem 76:7211-7220.

113. Janmey, P. A., and U. Lindberg. 2004. Cytoskeletal regulation: rich in lipids. Nat Rev Mol Cell Biol 5:658-666.

114. Fehon, R. G., A. I. McClatchey, and A. Bretscher. 2010. Organizing the cell cortex: the role of ERM proteins. Nat Rev Mol Cell Biol 11:276-287. 
115. Chambers, D. N., and A. Bretscher. 2005. Ezrin mutants affecting dimerization and activation. Biochemistry 44:3926-3932.

116. Niggli, V. 2001. Structural properties of lipid-binding sites in cytoskeletal proteins. Trends Biochem Sci 26:604-611.

117. Nagle, J. F., and S. Tristram-Nagle. 2000. Structure of lipid bilayers. Biochim Biophys Acta 1469:159-195.

118. Carvalho, K., L. Ramos, C. Roy, and C. Picart. 2008. Giant unilamellar vesicles containing phosphatidylinositol(4,5)bisphosphate: characterization and functionality. Biophys J 95:4348-4360.

119. Reiss, H., H. L. Frisch, and J. L. Leibowitz. 1959. Statistical Mechanics of rigid Spheres. The Journal of Chemical Physics 31:369-380.

120. Ceyrolles, W. J., P. Viot, and J. Talbot. 2002. Kinetics of Heterogeneous Adsorption: Mean-Field Theory and Simulations. Langmuir 18:1112-1118.

121. Jonsson, P., M. P. Jonsson, J. O. Tegenfeldt, and F. Hook. 2008. A method improving the accuracy of fluorescence recovery after photobleaching analysis. Biophys J 95:5334-5348.

122. Kahya, N., and P. Schwille. 2006. How phospholipid-cholesterol interactions modulate lipid lateral diffusion, as revealed by fluorescence correlation spectroscopy. J Fluoresc 16:671-678.

123. Yeagle, P. L. 1985. Cholesterol and the cell membrane. Biochim Biophys Acta 822:267-287.

124. Reviakine, I., W. Bergsma-Schutter, C. Mazeres-Dubut, N. Govorukhina, and A. Brisson. 2000. Surface topography of the p3 and p6 annexin $V$ crystal forms determined by atomic force microscopy. J Struct Biol 131:234-239.

125. Darst, S. A., M. Ahlers, P. H. Meller, E. W. Kubalek, R. Blankenburg, H. O. Ribi, H. Ringsdorf, and R. D. Kornberg. 1991. Two-dimensional crystals of streptavidin on biotinylated lipid layers and their interactions with biotinylated macromolecules. Biophys J 59:387-396.

126. Gary, R., and A. Bretscher. 1995. Ezrin self-association involves binding of an $\mathrm{N}$-terminal domain to a normally masked C-terminal domain that includes the F-actin binding site. Mol Biol Cell 6:1061-1075. 
127. Turunen, O., M. Sainio, J. Jaaskelainen, O. Carpen, and A. Vaheri. 1998. Structure-function relationships in the ezrin family and the effect of tumorassociated point mutations in neurofibromatosis 2 protein. Biochim Biophys Acta 1387:1-16.

128. Berryman, M., R. Gary, and A. Bretscher. 1995. Ezrin oligomers are major cytoskeletal components of placental microvilli: a proposal for their involvement in cortical morphogenesis. J Cell Biol 131:1231-1242.

129. Zhu, L., Y. Liu, and J. G. Forte. 2005. Ezrin oligomers are the membranebound dormant form in gastric parietal cells. Am J Physiol Cell Physiol 288:C1242-1254.

130. Gautreau, A., D. Louvard, and M. Arpin. 2000. Morphogenic effects of ezrin require a phosphorylation-induced transition from oligomers to monomers at the plasma membrane. J Cell Biol 150:193-203.

131. Reichl, D. 2000. Aufbau, Charakterisierung und Optimierung eines optischen Sensorsystems zur reflektometrischen Interferenzspektroskopie mit mehrfarbigen Leuchtdioden. In Universität Tübingen.

132. Podolski, J. L., and T. L. Steck. 1990. Length distribution of F-actin in Dictyostelium discoideum. J Biol Chem 265:1312-1318.

133. Cooper, J. A. 1987. Effects of cytochalasin and phalloidin on actin. J Cell Biol 105:1473-1478.

134. Estes, J. E., L. A. Selden, and L. C. Gershman. 1981. Mechanism of action of phalloidin on the polymerization of muscle actin. Biochemistry 20:708-712.

135. Kremser, L., G. Bilek, D. Blaas, and E. Kenndler. 2007. Capillary electrophoresis of viruses, subviral particles and virus complexes. J Sep Sci 30:1704-1713.

136. Huang, F. L., and K. P. Huang. 1991. Interaction of protein kinase C isozymes with phosphatidylinositol 4,5-bisphosphate. J Biol Chem 266:8727-8733.

137. Förster, T. 1948. Zwischenmolekulare Energiewanderung und Fluoreszenz. Annalen der Physik 437:55-75.

138. Ferguson, J. 1966. Absorption and Emission Spectra of the Perylene Dimer. The Journal of Chemical Physics 44:2677-2683. 
139. Carvalho, K., N. Khalifat, O. Maniti, C. Nicolas, S. Arold, C. Picart, and L. Ramos. 2010. Phosphatidylinositol 4,5-bisphosphate-induced conformational change of ezrin and formation of ezrin oligomers. Biochemistry 49:9318-9327.

140. Auvinen, E., N. Kivi, and A. Vaheri. 2007. Regulation of ezrin localization by Rac1 and PIPK in human epithelial cells. Exp Cell Res 313:824-833.

141. Matsui, T., S. Yonemura, S. Tsukita, and S. Tsukita. 1999. Activation of ERM proteins in vivo by Rho involves phosphatidyl-inositol 4-phosphate 5kinase and not ROCK kinases. Curr Biol 9:1259-1262.

142. Oshiro, N., Y. Fukata, and K. Kaibuchi. 1998. Phosphorylation of moesin by rho-associated kinase (Rho-kinase) plays a crucial role in the formation of microvilli-like structures. J Biol Chem 273:34663-34666.

143. Bicego, M., M. Beltramello, S. Melchionda, M. Carella, V. Piazza, L. Zelante, F. F. Bukauskas, E. Arslan, E. Cama, S. Pantano, R. Bruzzone, P. D'Andrea, and F. Mammano. 2006. Pathogenetic role of the deafnessrelated M34T mutation of Cx26. Hum Mol Genet 15:2569-2587.

144. Wang, H. L., W. T. Chang, A. H. Li, T. H. Yeh, C. Y. Wu, M. S. Chen, and P. C. Huang. 2003. Functional analysis of connexin-26 mutants associated with hereditary recessive deafness. J Neurochem 84:735-742.

145. Speck, O., S. C. Hughes, N. K. Noren, R. M. Kulikauskas, and R. G. Fehon. 2003. Moesin functions antagonistically to the Rho pathway to maintain epithelial integrity. Nature 421:83-87.

146. Polesello, C., I. Delon, P. Valenti, P. Ferrer, and F. Payre. 2002. Dmoesin controls actin-based cell shape and polarity during Drosophila melanogaster oogenesis. Nat Cell Biol 4:782-789.

147. Shuster, C. B., and I. M. Herman. 1995. Indirect association of ezrin with F-actin: isoform specificity and calcium sensitivity. J Cell Biol 128:837-848.

148. Zhu, L., R. Zhou, S. Mettler, T. Wu, A. Abbas, J. Delaney, and J. G. Forte. 2007. High turnover of ezrin T567 phosphorylation: conformation, activity, and cellular function. Am J Physiol Cell Physiol 293:C874-884.

149. Nakamura, F., L. Huang, K. Pestonjamasp, E. J. Luna, and H. Furthmayr. 1999. Regulation of F-actin binding to platelet moesin in vitro by both 
phosphorylation of threonine 558 and polyphosphatidylinositides. Mol Biol Cell 10:2669-2685.

150. Fukata, Y., K. Kimura, N. Oshiro, H. Saya, Y. Matsuura, and K. Kaibuchi. 1998. Association of the myosin-binding subunit of myosin phosphatase and moesin: dual regulation of moesin phosphorylation by Rho-associated kinase and myosin phosphatase. J Cell Biol 141:409-418.

151. Hao, J. J., Y. Liu, M. Kruhlak, K. E. Debell, B. L. Rellahan, and S. Shaw. 2009. Phospholipase C-mediated hydrolysis of PIP2 releases ERM proteins from lymphocyte membrane. J Cell Biol 184:451-462. 



\section{ANHANG}

\subsection{Chemikalien}

Acrylamid-Bisacrylamid (30 \%)

Agar

Aktin

Alexa Fluor ${ }^{\circledR} 488$ Phalloidin

APS

Argon

ATP

Bromphenolblau

Calciumchlorid, $\mathrm{CaCl}_{2} \cdot 6 \mathrm{H}_{2} \mathrm{O}$

Chloroform

Cholesterin

Chrom

Coomassie Brillant Blue G250

Complete-mini, EDTA-free

DOPC

DTT

EDTA (Na-Salz)

Essigsäure

Ethanol

Glycerin

Glycin

Gold

Hefeextrakt

HEPES

HMDS
Carl-Roth $\mathrm{GmbH}$, Karlsruhe

Merck, Darmstadt

Cytoskeleton (über tebu-bio, Offenbach)

Invitrogen, Eugene, USA

Sigma-Aldrich, Taufkirchen

Air Liquide, Düsseldorf

Sigma-Aldrich, Taufkirchen

Carl-Roth $\mathrm{GmbH}$, Karlsruhe

Merck, Darmstadt

Merck, Darmstadt

Sigma-Aldrich, Taufkirchen

Bal-Tec, Pfäffikon, $\mathrm{CH}$

Carl-Roth $\mathrm{GmbH}$, Karlsruhe

Roche, Mannheim

Avanti Polar Lipids, Alabaster, USA

Sigma-Aldrich, Taufkirchen

Sigma-Aldrich, Taufkirchen

Merck, Darmstadt

Merck, Darmstadt

Merck, Darmstadt

Merck, Darmstadt

Cressington (über: Elektronen-Optik-

Service $\mathrm{GmbH}$, Dortmund)

Carl-Roth $\mathrm{GmbH}$, Karlsruhe

Carl-Roth GmbH, Karlsruhe

Carl-Roth $\mathrm{GmbH}$, Karlsruhe 
Imidazol

lod

IPTG

Kaliumchlorid

Kaliumhexacyanoferrat (III), $\mathrm{K}_{3}\left[\mathrm{Fe}(\mathrm{CN})_{6}\right]$

Kaliumiodid

Kanamycin

Magnesiumchlorid, $\mathrm{MgCl}_{2} \cdot 6 \mathrm{H}_{2} \mathrm{O}$

$\beta$-Mercaptoethanol

Methanol, reinst

Mucasol $\circledast$

Natriumazid

Natriumchlorid

Natriumdihydrogenphosphat

Natriumhydrogenphosphat

Natriumhydroxid

Ni-NTA-Agarose

DOGS-NTA-Ni

1-Oktanthiol

$\mathrm{PIP}_{2}$

$\mathrm{PIP}_{2}$-TopFluor

$\mathrm{PIP}_{2}$-BodipyTMR

$\mathrm{PIP}_{2}$-BodipyFL

POPC

Salzsäure

Schwefelsäure

SDS

TEMED

TRIS
Sigma-Aldrich, Taufkirchen

Carl-Roth GmbH, Karlsruhe

Sigma-Aldrich, Taufkirchen

Merck, Darmstadt

Merck, Darmstadt

Carl-Roth GmbH, Karlsruhe

Sigma-Aldrich, Taufkirchen

Merck, Darmstadt

Carl-Roth GmbH, Karlsruhe

Merck, Darmstadt

Merck, Darmstadt

Merck, Darmstadt

Merck, Darmstadt

Merck, Darmstadt

Merck, Darmstadt

Merck, Darmstadt

Qiagen, Hilden

Avanti Polar Lipids, Alabaster, USA

Sigma-Aldrich, Taufkirchen

Avanti Polar Lipids, Alabaster, USA

Avanti Polar Lipids, Alabaster, USA

Echelon Biosciences, Salt Lake City,

USA (über Mobi-Tec, Göttingen)

Echelon Biosciences, Salt Lake City, USA (über Mobi-Tec, Göttingen)

Avanti Polar Lipids, Alabaster, USA

Merck, Darmstadt

Merck, Darmstadt

Merck, Darmstadt

Sigma-Aldrich, Taufkirchen

Sigma-Aldrich, Taufkirchen 
Trypton

Wasserstoffperoxid (30\%)
Carl-Roth GmbH, Karlsruhe

Carl-Roth GmbH, Karlsruhe

\subsection{Materialien}

Cellophan

Dialyseschläuche VISKING

Kalrez ${ }^{\circledR}$ Dichtringe

5-MHz-AT-cut Quarze

Mikroliterspritze

Deckgläser

Platindraht

Polycarbonatmembran

Pumpschläuche, Tygon

Quarzküvette

Silberleitkleber

Siliziumträger

Teflonschläuche

Trocknungsrahmen für Gele
Carl-Roth GmbH, Karlsruhe

Carl-Roth GmbH, Karlsruhe

DuPont (über: Fahrenholz, Hattingen)

KVG, Neckarbischofsheim

Hamilton, Bonaduz, $\mathrm{CH}$

Plano GmbH, Wetzlar

Good Fellow, Cambridge (UK)

Avestin, Ottawa, Canada

Ismatec, Wertheim-Mondfeld

Hellma GmbH, Mühlheim

Conrad Elektronik, Wernberg

CrysTec GmbH, Berlin

VWR International, Darmstadt

Carl-Roth GmbH, Karlsruhe

\subsection{Geräte}

Reinstwasseranlage

Millipore Elix

Millipore, Eschborn

MilliQ A10

Millipore, Eschborn

\section{Impedanzspektrometer}

Impedance/ Gain-Phase Analyzer SI Solartron Instruments, Farnborough, 1260 UK

QCM

QCM 200

Stanford Research Systems Inc., 
Peristaltikpumpe

\section{Konfokales Laserrastermikroskop}

LSM 710 Examiner

\section{Rasterkraftmikroskop}

Nano Wizard II

\section{Plasmacleaner}

Plasma Cleaner PDC 32 G-2

\section{CD-Spektrometer}

Jasco-810 spectrometer

\section{Sonstiges}

Gelelektrophoreseapparatur PerfectBlue Peqlab, Erlangen

Twin S

Miniextruder (Liposofast@)

$\mathrm{pH}-$ Meter

Schüttelinkubator SM 30

Thermomixer

Tip-Sonifier Sonoplus HD2070

Ultraschallbad Sonorex

UV-VIS-Spektrometer Cary50

Vakuumtrockenschrank

Vortexer
Sunnyvale, USA

RegloDigital Ismatec, WertheimMondfeld

Carl Zeiss AG (Jena)

JPK Instruments AG, Berlin

Harrick Plasma, Ithaca, USA

Gross-Umstadt, Germany
Avestin, Ottawa, Canada
Calimatic 766 Knick, Berlin
Edmund Bühler $\mathrm{GmbH}$, Tübingen
Eppendorf, Hamburg
Bandelin, Berlin
Bandelin, Berlin
Varian, Palo Alto, USA
Binder, Tuttlingen
Heidolph, Schwabach 


\subsection{Abkürzungsverzeichnis}

AFM

APS

ATP

BVD

C-ERMAD

DAG

DOGS-NTA-Ni

DOPC

DTT

EDTA

ERM

F-Aktin

FERM

ICAM

$\mathrm{IP}_{3}$

IPTG

His-tag

$\mathrm{kDa}$

LUV

LB

MARCKS

$\min$

N-ERMAD
Rasterkraftmikroskop (atomic force microscope)

Ammoniumperoxodisulfat

Adenosintriphosphat

Butterworth van Dyke

C-terminal ERM association domain

Diacylglycerol

Ni-1,2-Dioleoyl-sn-glycero-3-([N(5-

Amino-1-

Carboxypentyl)iminodiessigsäure]

succinyl)

Dioleoyl-sn-glycero-3-phosphocholin

1,4-Dithiotreitol

Ethylendiamintetraacetat

Ezrin-Radixin-Moesin

Filamentöses Aktin

Four-point one protein ERM

Intercellular adhesion molecule

Inositoltriphosphat

Isopropyl- $\beta-D-T h i o g a l a c t o p y r a n o s i d$

Hexahistidin-tag

Kilodalton

große unilamellare Vesikel (large

unilamellar vesicles)

Lysogeny broth

myristoylated alanine-rich C kinase substrate

Minute

$N$-terminal ERM association domain 
OD

OT

PAGE

$\mathrm{PIP}_{2}$

POPC

QCM

rpm

SDS

TEMED

Tris

TSM

UV

Vis

\subsection{Symbolverzeichnis}

A

C

C

d

E

f

h

Im

I

k

K

L
Optische Dichte

1-Oktanthiol

Polyacrylamidgelektrophorese

Phosphatidylinositol-4,5-bisphosphat

1-Palmitoyl-2-Oleyl-sn-glycero-3-

phosphocholin

Quarzmikrowaage (Quartz Crystal

Microbalance)

revolutions per minute (Umdrehungen

pro Minute

Natriumdodecylsulfat

$\mathrm{N}, \mathrm{N}, \mathrm{N}^{\prime}, \mathrm{N}^{\prime}$-Tetramethylethylendiamin

Tris(hydroxymethyl)-aminoethan

Dickenscherschwinger

(thickness

shear mode)

Ultraviolett

sichtbares Licht

Fläche

Konzentration

Kapazität

Dicke

Extinktion

Frequenz

Höhe

Imaginärteil einer komplexen Zahl

Strom

Ratenkonstante

Gleichgewichtskonstante

Induktivität 
$m$

M

$n$

$r$

$R$

$R e$

$S_{f}$

$t$

$T$

$U$

Z

Z

$\Delta$

$\varepsilon$

$\varepsilon_{0}$

$\varepsilon_{r}$

$\lambda$

$\mu$

$\Theta$

$\varphi$

$\rho$

$\omega$
Masse

molare Masse

Laufzahl, Stoffmenge

Radius

Widerstand

Realteil einer komplexen Zahl

Sauerbreykonstante

Zeit

Temperatur

Spannung

Koordinate

Impedanz

Differenz, Phasendifferenz

Extinktionskoeffizient

elektrische Feldkonstante

Dielektrizitätskonstante

Wellenlänge

Schermodul

Belegungsgrad

Einfallswinkel,

Brechungswinkel,

Phasenverschiebung

(Oberflächen)dichte

Kreisfrequenz 



\section{LEBENSLAUF}

Sabine Bosk

geboren am 7. November 1981 in Nordhorn

Staatsangehörigkeit: deutsch

\section{Schulbildung}

$08 / 1988-07 / 1992$

$08 / 1992-07 / 1994$

$08 / 1994-07 / 2001$

$07 / 2001$

\section{Studium}

$10 / 2001-09 / 2002$

$10 / 2002$

$10 / 2004$

$05 / 2006-07 / 2006$

$11 / 2006-05 / 2007$

$07 / 2007$

seit $10 / 2007$
Altendorfer Grundschule, Nordhorn

Orientierungsstufe Deegfeld, Nordhorn

Gymnasium am Stadtring, Nordhorn

Allgemeine Hochschulreife

Studium der Instrumentalpädagogik (Hauptfach Violine) an der Hochschule für Musik und Theater Rostock Beginn des Diplomstudiengangs Chemie an der GeorgAugust-Universität Göttingen

\section{Diplomvorprüfungen}

Forschungsprojekt in Organischer Chemie im Arbeitskreis von Prof. Dr. M. Malacria an der Université Pierre et Marie Curie (Paris, Frankreich)

Diplomarbeit im Arbeitskreis von Prof. Dr. C. Steinem am Institut für Organische und Biomolekulare Chemie, GeorgAugust-Universität Göttingen;

Titel: Quantifizierung der Wechselwirkung von Polycystin2 mit seinen spezifischen Interaktionspartnern mittels Quarzmikrowaagetechnik

\section{Diplomprüfungen}

Promotion im Arbeitskreis von Prof. Dr. C. Steinem am Institut für Organische und Biomolekulare Chemie, GeorgAugust-Universität Göttingen;

Titel der Doktorarbeit: Aktivierbarkeit und Akkumulation von Ezrin in Abhängigkeit von $\mathrm{PIP}_{2}$ 
Veröffentlichungen und Tagungsbeiträge

$11 / 2010$

$10 / 2010$

$01 / 2010$

$07 / 2009$

$03 / 2008$
„Activation of F-actin binding capacity of ezrin: synergism of $\mathrm{PIP}_{2}$ interaction and phosphorylation", Sabine Bosk, Julia A. Braunger, Volker Gerke, Claudia Steinem, Biophysical Journal, zur Veröffentlichung angenommen. "Investigation into the activation process of ezrin" (Poster); Jahrestagung der Deutschen Gesellschaft für Bophysik, Bochum, Teilnahme unterstützt durch ein Stipendium der GDCh "Quantifying the interaction of the C-terminal regions of polycystin-2 and polycystin-1 attached to a lipid bilayer by means of QCM“, Daniela Behn, Sabine Bosk, Helen Hoffmeister, Ralph Witzgall, Andreas Janshoff, Claudia Steinem, Biophysical Chemistry 2010, 150, 47-53. "Influence of Ezrin on $\mathrm{PIP}_{2}$ distribution in artificial membrane systems” (Poster); Internationaler Workshop „Scanning Probe Microscopies and Organic Materials", Bremen "Influence of Ezrin on $\mathrm{PIP}_{2}$ distribution in artificial membrane systems" (Poster); Internationaler Workshop der Deutschen Gesellschaft für Biophysik „Mechanical and Electrical Properties of Artificial and Cellular Membranes", Gomadingen 


\section{DANKSAGUNG}

Prof. Dr. Claudia Steinem hat diese Arbeit stets unterstützt, war zu jeder Zeit zu intensiven Fachdiskussionen bereit und hat mit vielen wertvollen Anregungen zum Erfolg dieser Arbeit beigetragen. Ich danke ihr sehr für eine lehrreiche und fördernde Promotionszeit.

Herrn Prof. Dr. Abel danke ich für die Bereitschaft, das Korreferat dieser Arbeit zu übernehmen, sowie für die interessanten thesis committee-Treffen.

Herrn Prof. Dr. Tittmann, Herrn Prof. Dr. Diederichsen, Herrn Prof. Dr. Brockmöller und Herrn Juniorprofessor Dr. Ducho danke ich für die bereitwillige Zusage, als Mitglieder der Prüfungskommission aufzutreten.

Unserem Kooperationspartner Herrn Prof. Dr. Gerke vom ZMBE in Münster danke ich für die gute Zusammenarbeit und hilfreiche Anregungen. Auch der lehrreiche Besuch in Münster, verbunden mit einer Proteinisolierung aus Primärgewebe im Schlachthof Coesfeld, wird mir in guter Erinnerung bleiben.

Unsere technischen Assistentinnen, Michaela Klingebiel und Jutta Gerber-Nolte, haben meine Arbeit mit Rat und Tat unterstützt, dafür danke ich ihnen sehr. Auch Hans-Jörg Langer hat mir mit seiner langjährigen Erfahrung den Einstieg in die Doktorarbeit erleichtert, vor allem in Verbindung mit der Ezrinisolierung.

Unseren Sekretärinnen Marianne Wagener und Frau Gastrock danke ich für die vielen organisatorischen Handgriffe, die oft im Verborgenen bleiben.

Meinen erstklassigen Diplomanden bzw. Bachelorstudenten Dany, Conrad, Julia, Corinna und Lothar danke ich für ihre engagierte, gewissenhafte Arbeit, die mich in vielerlei Hinsicht sehr unterstützt hat.

Für das Korrekturlesen dieser Arbeit danke ich Christoph, Ines, Julia und Dany sowie allen, die es angeboten, aber nichts mehr abbekommen haben.

Während der manchmal harten Promotionszeit war die Arbeitsgruppe eine meiner wichtigsten Stützen. Das freundschaftliche Arbeitsklima, die Hilfsbereitschaft und der tolle Zusammenhalt zeichnen jeden einzelnen von euch aus. Ihr werdet mir unheimlich fehlen. 
Der Volkstrauertag wird in meinem Kopf für immer mit einem bestimmten musikalischen Thema unterlegt sein. Danke für dieses Trauma, Maggiore Quartett! Aber auch danke für die wunderschöne Musik.

Dany, Julia, Ines und Gretel: Mit Wein und Käse und guten Gesprächen konntet ihr immer wieder zu meinem seelischen Wohlbefinden beitragen. Danke für eure tolle Freundschaft.

Meinen Schulfreundinnen Teresa, Ines und Gina schicke ich einen herzlichen Dank für ihre Aufmunterungen, ihr Interesse und ihre treue Freundschaft.

Einen großen Bruder wie meinen zu haben ist unbezahlbar. Du bist mir in vielen Dingen ein Vorbild, Peter.

Tausend Dank gilt meinen einzigartigen Eltern. Was sie leisten, um mich stets zu unterstützen und bestmöglich zu fördern, kann ihnen niemand nachmachen. Darum widme ich ihnen diese Arbeit und noch mehr, wenn ich könnte.

Schließlich danke ich von Herzen Pascal dafür, dass er während der Höhen und Tiefen meiner Promotionszeit immer für mich da war. Dank dir waren diese arbeitsreichen Jahre vor allem glückliche Jahre. Ich freue mich auf unsere gemeinsame Zukunft. 